\title{
UNIVERSIDAD POLITÉCNICA DE
}

ESCUELA TÉCNICA SUPERIOR DE INGENIERÍA AGRONÓMICA, ALIMENTARIA Y DE BIOSISTEMAS

Development of new applications in industrial backgrounds based on Middle Infrared spectroscopy (MID IR) using low cost and uncooled sensors

María del Sagrario Maldonado Gil Msc. Eng. Chemical

Madrid 2019 

DEPARTAMENTO DE INGENIERÍA AGROFORESTAL

ESCUELA TÉCNICA SUPERIOR DE INGENIEROS AGRÓNOMOS

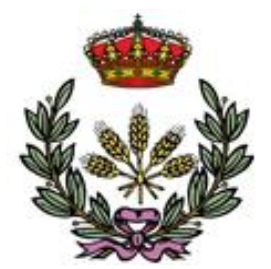

Development of new applications in industrial backgrounds based on Middle Infrared spectroscopy (MID IR) using low cost and uncooled sensors

Maria del Sagrario Maldonado Gil

Chemical engineer

Doctoral Thesis Supervisors:

Pilar Barreiro Elorza, Proffesor in Agroforestry Engineering Germán Vergara Ogando, PhD Physics

Madrid 2019 


\section{POLITÉCNICA}

\section{(D-15)}

Tribunal nombrado por el Magfco. y Excmo. Sr. Rector de la Universidad Politécnica de Madrid, el día de de 2016.

Presidente:

Secretario:

Vocal:

Vocal:

Vocal:

Suplente:

Suplente:

Realizado el acto de defensa y lectura de Tesis el día de del 2016.

En la E.T.S.I. A.A.B

EL PRESIDENTE

LOS VOCALES

EL SECRETARIO 


\section{AUTORIZACIÓN PARA LA DEFENSA}

Pilar Barreiro Elorza, catedrática de universidad en el Departamento de Ingeniería Agroforestal de la Universidad Politécnica de Madrid, y Germán Vergara Ogando, Director Técnico Ejecutivo de New Infrarred Technologies, como directores de la Tesis Doctoral "Development of new applications for low cost Lead Selenide Middle Infrared sensors in the Fuel and Oil Industry", realizada por Maria del Sagrario Maldonado Gil, alumna del programa de doctorado en Agroingeniería del departamento Ingeniería Rural 240C, para aspirar al grado de Doctor Internacional por la Universidad Politécnica de Madrid.

\section{AUTORIZO}

La presentación de esta memoria para que se proceda al trámite de su lectura y defensa ante el tribunal correspondiente.

$Y$ para que conste a los efectos oportunos, firmo el presente certificado en Madrid, a de del 2019. 
A mi madre 


\section{AGRADECIMIENTOS - ACKNOWLEDGEMENTS}

I want to acknowledge to the research group from Polytechnic University of Madrid LPF TAGRALIA for giving me the opportunity of doing my PhD. Thank you for all your patience to me, special thanks to my advisor, Prof. Pilar Barreiro Elorza, for all your help and dedication, and all the great things you have taught me. It has been a long way that we have walked together, and I will never forget it.

Thank you so much to Prof. Belen Diezma Iglesias, because she has always tried to find the way for me to keep on. And a special thanks to Prof. Margarita Ruiz-Altisent, who first gave me my great opportunity in Madrid, she barely knew me and trusted me, givig me those which would be the two best years of my life. Thanks to all the professors from the LPF research team.

Thanks to the Project Manager of this research group, D. Blanca Muñoz Moreno, for being so helpful not only with bureaucratic stuff, but with many other issues along this time. Thank you to all my work mates from LPF TAGRALIA, especially to Miguel, Ángela, Teresa, Satyabrata, Wilson and Tatiana, who very well helped me at every moment.

Also I want to thank to PhD. Germán Vergara Ogando from New Infrared Technologies, S.L., who has been always supporting me during these years. He is not just a co-director and advisor, but has also become a good friend to me.

And thank you to my work mates at New Infrared Technologies, who taught me how to deal with MATLAB and electronics.

A special acknowledgement to the Texas A\&M University research group Perception, Sensing and Instrumentation Lab, firstly to Prof. Ricardo Gutiérrez-Osuna, and of course my work mates and also friends too, who made my scholarship much easier and happier: Zelun, Guanlong, Chris, Adam, ShaoJin, Akhill, Gena, and a special mention to my "latin" friends Roger and Dennis.

Another special thanks to Dad. I know how hard it has been for you, struggling with all this, and I feel so grateful you have being supporting me, and a huge special dedication to my Mom, who always wanted me to become higher and happier. 


\section{Table of contents}

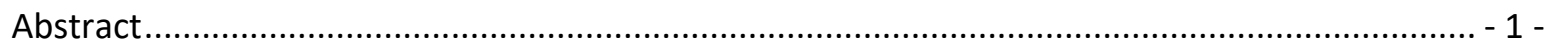

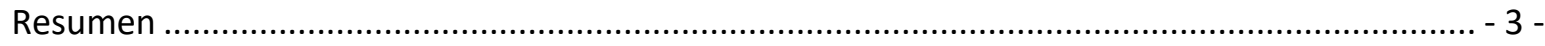

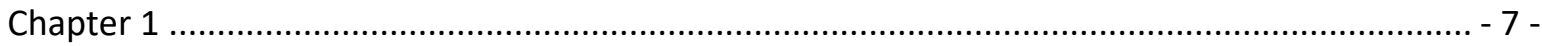

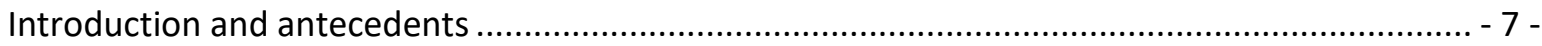

1.1 Fossil fuels as source of energy and their consumption historically ............................. - 7 -

1.2 Additives and octane boosters as main blending components ................................ - 11 -

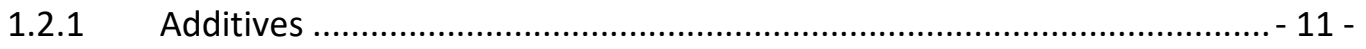

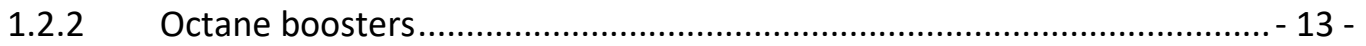

1.3 Ethanol as multi-functional blending component ................................................. - 14 -

$1.4 \mathrm{~N}$-butanol as a potential blending component in comparison to ethanol ................... - 16 -

1.5 Methanol as potential adulterant or additive ....................................................... - 18 -

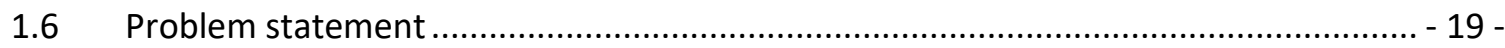

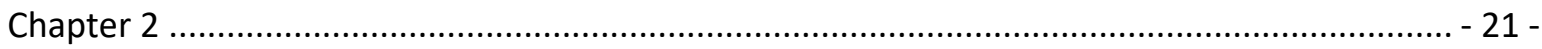

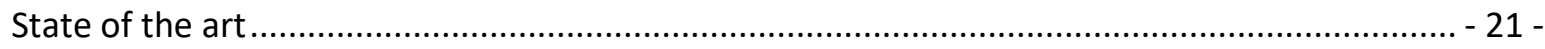

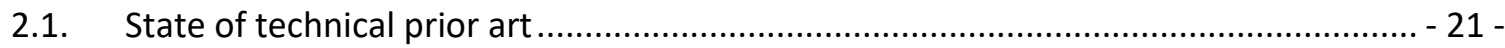

2.1.1. The first patented inventions related to optical devices applied to fuel quality control - $21-$

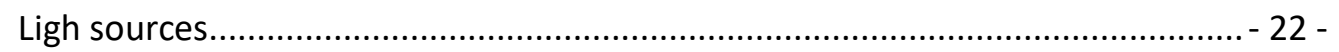

Spectral ranges (detectors) ..................................................................... - 23 -

Inventors and assignees from the disclosed patents....................................... 26 -

2.1.2. Specific experimental set-up........................................................ 28 -

Liquid measurements ........................................................................... 28 -

Gas measurements ….............................................................................. 30 -

2.1.3. Detector principle ...................................................................... 34 -

2.1.4. Spectral curves ........................................................................... 35 - 
2.1.5. Mathematical methods used at data analysis ........................................ 41 -

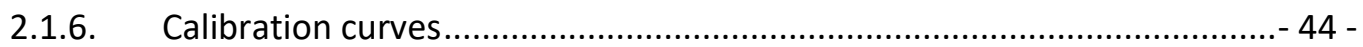

2.1.7. Summary of remarkable points about the technical state of the art ........- 46 -

2.2. State of scientific prior art.

2.2.1. Effect of alcohol blend on engine performance..................................... 47 -

2.2.2. Main analytical techniques for fuel quality assessment .......................... 47 -

2.2.3. Infrared spectroscopy for fuel quality control ......................................... 48 -

Effect of ethanol in the infrared spectra ............................................................. 48 -

Near and Middle Infrared Spectroscopy ............................................................ 48 -

2.2.4. What has been done till now and how it contributes to solve the problem of fuel quality assessment ................................................................................ 53 -

2.2.5. Exposing the gap in scientific current knowledge .................................. 54 -

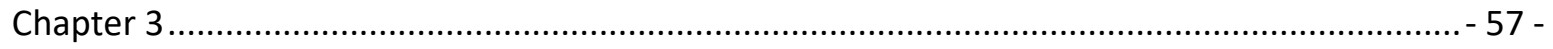

Antecedents, Hypothesis and Objectives....................................................................... 57 -

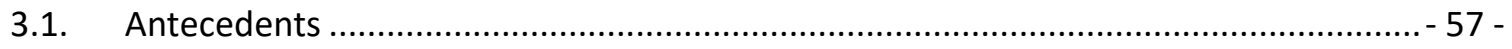

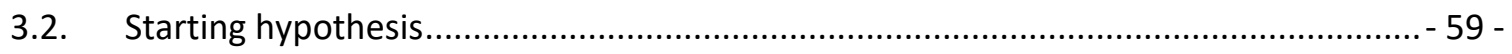

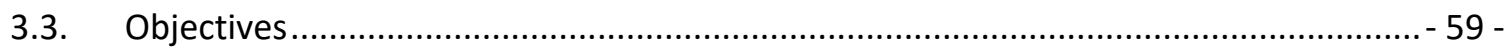

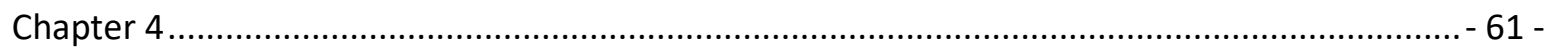

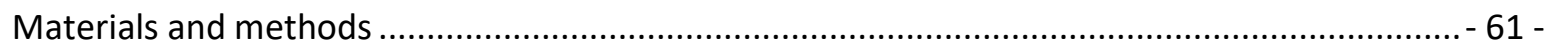

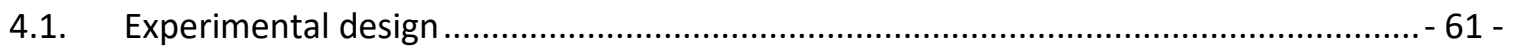

4.1.1. The Middle Infrared Spectrometer and its components .......................... 62 -

4.1.1.1. The Mid Infrared sensor ........................................................... 62 -

4.1.1.2. The light source …................................................................. 64 -

4.1.1.3. The sample holder ...................................................................... 66 -

4.1.2. Establishment of a fixed experimental set up........................................ 67 -

4.1.2.1. Fixing the light intensity and focusing the optical lens to obtain an

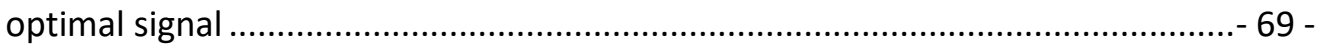


4.1.2.2. Determining the optimal sample presentation .............................. 70 -

4.1.2.3. Establishing a specific layout for the spectrometer components ..... - 70 -

4.1.2.4. Choosing an acquisition time .................................................. 71 -

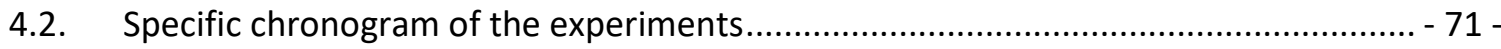

4.2.1. The work developed inside the CEI Moncloa framework (years 2013-2015)... $73-$

4.2.2. The experimental set up with a new device and the analysis performed at the manufacturing company New Infrared Technologies ...................................... 73 -

4.2.3. The work developed inside the LPF laboratory and the Computer Science and Engineering Department PSI Lab, from Texas A\&M University................................ - 73 -

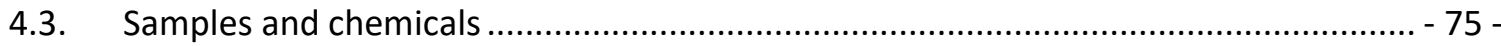

4.3.1. Experiment 1: Identification of pure fuel, additives and adulterants in gasoline - 75 -

4.3.2. Experiment 2: Characterization of gasoline and alcohol blends............... - 78 -

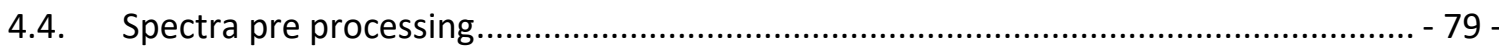

4.4.1. The Savitzsky-Golay algorithm ........................................................ 80 -

4.4.2. The Baseline Correction ................................................................... 82 -

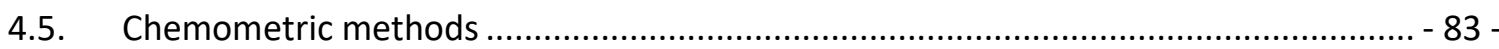

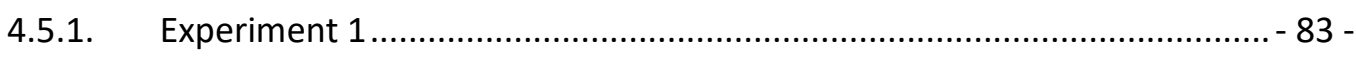

4.5.1.1. Principal Components Analysis .................................................. 83 -

4.5.1.2. Discriminant Analysis (MANOVA) ............................................... 83 -

4.5.1.3. Classification procedure ......................................................... 84 -

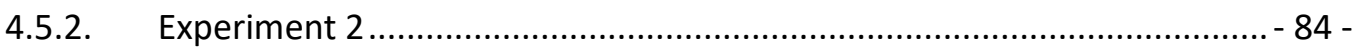

4.5.2.1. Quantitative PLS...................................................................... 84 -

4.5.2.2. MANOVA analysis for each percentage and chemical simultaneously- 85

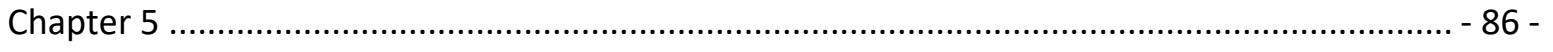

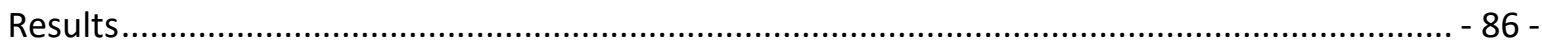


5.1. Preliminary results from setting up the device and method $86-$

5.2. Apparatus and method development for fuel analysis

5.2.1. Fixing the light intensity and focusing the optical lens to obtain a stable signal - $87-$

5.2.2. First spectra acquisition and data storage ........................................... 88 -

5.2.3. Triggering the spectra recording to homogenize the data ........................ 91 -

5.2.4. Development of a MATLAB script for automatic reading of the acquisition files $\quad-94$ -

5.3. Establishing an experimental set up for gas measurements (volatile compounds in headspace) $96-$

5.3.1. Acquisition from headspace in gasoline and alcohols $96-$

5.4. The bandwidth calculation and its utility $100-$

5.5. Establishing a fixed layout and protocol for new liquid measurement at the NIT laboratory $102-$

5.6. Experiment 1: Identification of pure fuel, adulterants and additives in gasoline. $-103-$

5.6.1. Preliminary Analysis $-103-$

5.6.2. Principal Component Analysis .................................................................... 106 -

5.6.3. Multivariate Analysis of Variance (MANOVA) ......................................... 109 -

5.6.4. Characteristic values $-111-$

5.7. Experiment 2: Characterization of alcohol and gasoline blends $-113-$

5.7.1. Visualization of spectra $113-$

5.7.2. Quantitative prediction of overall blend concentration $113-$

5.7.2.1. Supervised analysis of the blends by MANOVA ............................. 115 -

5.7.2.2. Wavelength contribution to quantitative and qualitative models ..- 118 -

5.8. The use of FTIR for determination of acetone and ethanol $120-$ Chapter 6 $123-$

Discussion. $123-$ 
6.1. The use of the MID IR spectral range for measuring chemicals in fuels. Comparison with the previous state of the art

6.2. The most relevant aspects regarding to the results ............................................... - 126 -

6.2.1. The infrared spectra of mixtures and how it influenced the simultaneous quantification and identification of gasoline and alcohol blends from a chemical point of view - $128-$

6.3. Discussion on spectra pre-processing and data analysis

6.4. The infrared spectral range used by the PbSe sensor and what to expect about it... - 130 -

6.5. Possible prospective applications of the developed device in field $-132-$

Chapter 7 $135-$

Conclusions $135-$

7.1. The identification of the key absorption wavelengths for each chemical compound

$-135-$

7.2. The discriminant analysis performed on the spectra according to the key wavelengths: A tool to differentiate between chemical substances

$-136-$

7.3. The issue of high volatile compounds such as methanol and gasoline: A prospect of future improving.....

7.4. The algorithm for quantitatively determine concentrations: An useful tool to implement in fuel industry

7.5. A qualitative approach by MANOVA to reinforce and validate the quantitative results obtained by PLS

$-136-$

7.6. Main goals achieved

$-137$

Chapter 8

$-138-$

Proposal for future research

$138-$

Chapter 9

139

References

139

Annexes 145

Annex I: Conferences $146-$ 
1 International Conference of Agricultural Engineering (CIGR) Aarhus, Denmark. June 2016.

PROSPECTIVE OF THE USE OF MID IR FOR FOOD-TO-FUEL CHARACTERIZATION $146-$

3.4. Abstract $-146-$

3.5. Introduction. $147-$

3.6. Materials and methods $149-$

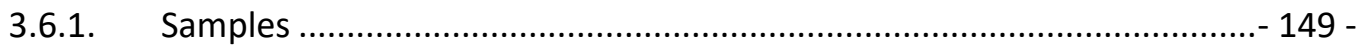

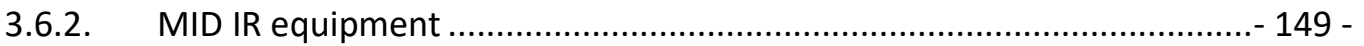

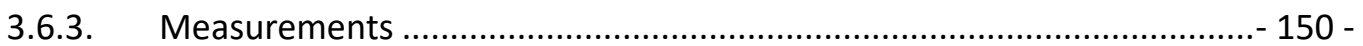

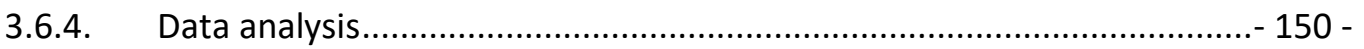

3.6.5. Principal Component Analysis .......................................................... 151 -

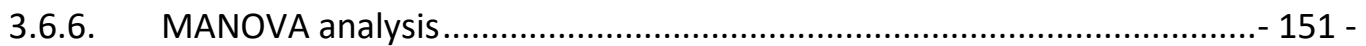

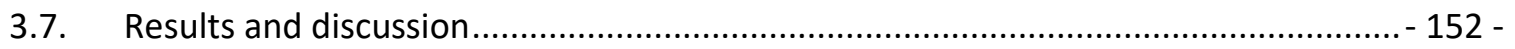

3.7.1. Principal Component Analysis ......................................................... 152 -

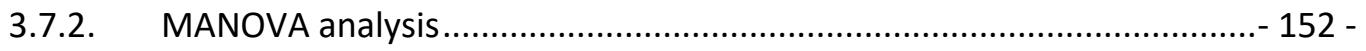

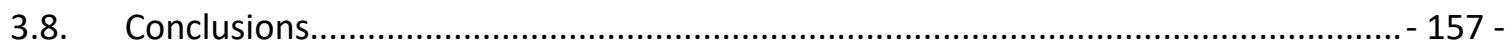

4. IX Congresso Ibérico de Agroengenharia. Bragança, Portugal. September, 2017 .............. - 158 -

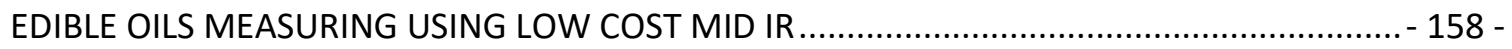

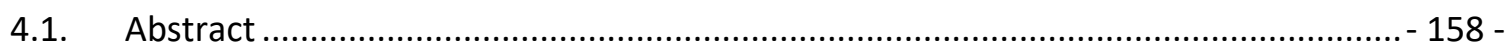

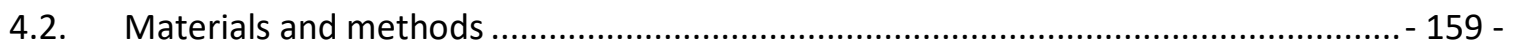

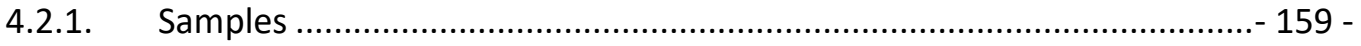

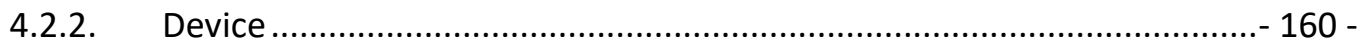

4.2.3. Measuring procedure ...................................................................... 161 -

4.2.4. Spectra acquisition ........................................................................ 162 -

4.2.5. Spectra pre-treatment ………………............................................ 162 -

4.2.6. Principal Component Analysis ............................................................ 162 -

4.2.7. MANOVA analysis ......................................................................... 162 - 
4.3. Results

4.3.1. Data analysis $-163-$

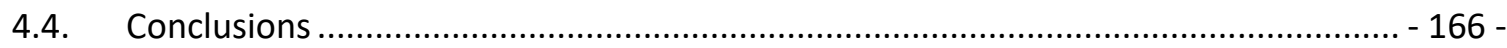

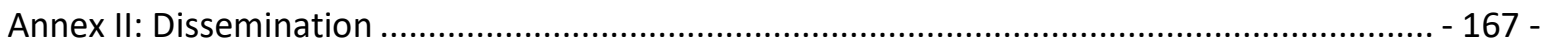

5. Research paper published in Q1 journal (Fuel Processing technology......................... - 167 MID-INFRARED UNCOOLED SENSOR FOR THE IDENTIFICATION OF PURE FUEL, ADDITIVES

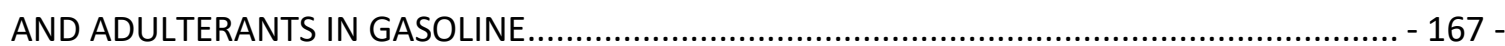

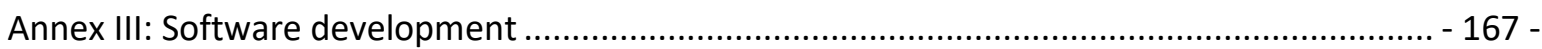

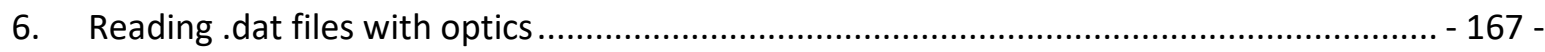

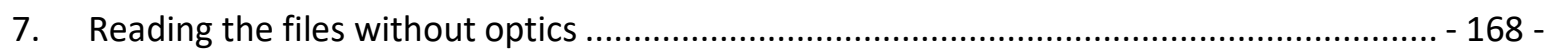




\section{Tables Index}

Table 1.Summary of the ethanol fuel production a year all over the world during the period between 2014 and 2016 (Balat 2011) . $15-$

Table 2. Ethanol, gasoline and n-butanol properties. Sources: Brekke (K., 2007); Davis and Diegel (Davis S.C., 2006); Gallagher et al. (Gallagher PW, 2003 (25)), Graboski (M.S., 2009); Reynolds (R.E.); Sheehan et al. (Sheehan J., 1998); Wu et al. (Wu M., 2007). ...................- 17 Table 3.Differences between IR and Raman methods..................................................... 25 Table 4.Inventors, institutions and assignees for each of the disclosed patents ...............-27 Table 5.Screening of some patented devices from the 90's to 2008 for liquid fuel applications $-29-$

Table 6.Screening of some patented devices from 2002 to 2016 for applications in volatile compounds and exhaust gases from fuels. -31 -

Table 7.Compilation of the mathematical methods used by each of the inventors applied to the patented inventions... $43-$

Table 8.NIR and MID IR strengths and weaknesses comparison..... $51-$

Table 9. Some recommended operating parameters of SiC infrared lamps manufactured by Hawkeye Technolgies, Inc. according to the experimental conditions required...... $65-$ Table 10. Work stages of this thesis in order to obtain the specific application on fuel quality control $-72-$

Table 11.Gasoline fuel precedence and dates of sampling..... $-76-$ Table 12.Days, number of individuals, replicates and repetitions for the experiment 1 ..- 77 Table 13.Total of individuals used for the experiment 1 -77 Table 14.Screening of the days and blend rates used for methanol and gasoline blends, considering $0 \%$ the pure gasoline and $100 \%$ the pure alcohol. The percentages used for each day of measurement are marked with a cross $(x)$ $-78-$ Table 15.Screening of the days and blend rates used for ethanol and gasoline blends, considering $0 \%$ the pure gasoline and $100 \%$ the pure alcohol. The percentages used for each day of measurement are marked with a cross $(x)$ - 79 Table 16.Screening of the days and blend rates used for butanol and gasoline blends, considering $0 \%$ the pure gasoline and $100 \%$ the pure alcohol. The percentages used for each day of measurement are marked with a cross $(x)$. - 79 Table 17. Liquid substances used for the preliminary experiments to set up the device and the method.. - 91 - 
Table 18. Short-chain alcohols (ethanol and methanol) boiling points compared to pure gasoline. $-98$

Table 19.Theoretical absorption wavelengths for hydrocarbons and alcohol bonds ..... - 105 Table 20.Percentage of variance retained by the first five principal components and F-test values obtained from the ANOVA analysis performed on the scores of each principal component. $-106-$

Table 21. Eigenvalues and segregation power of each canonical variable obtained from MANOVA applied on the calibration set $-110-$

Table 22.Characteristic values from MANOVA. The Average values of each canonical variable from the calibration and validation set are displayed. $-111-$ Table 23.Centroids 112

Table 24.Confusion matrix comparing the observed and predicted classes for both the calibration and validation sets. $-112$

Table 25.Root mean square errors of calibration and validation in the quantitative prediction analysis by Partial Least Squares in the train and test sets and the applied spectral pre processing, that is baseline correction in this case. $115-$

Table 26. Percentage of variance retained by each of the ten principal components used for the discriminant analysis in this experiment. $115-$

Table 27.Distances from each concentration in percentage group centroid to the center of the triangle formed by plotting canonical variables 1 and 2 117 Table 28. Percentages ratio of acetone and ethanol injected to the FTIR device through dynamic mass flow. $-120$

Table 29.Example given as an approach to the prospective future application of the results obtained in quantitative terms. 133

Table 30.Summary of segregation functions used in the MANOVA analysis at each stage of the mathematical procedure. Canonical variables are represented by $\mathrm{C} 1, \mathrm{C} 2, \mathrm{C} 3$ and $\mathrm{C} 4$......$156-$

Table 32. Samples numbers and type of edible oils and their procedence $-160-$

Table 33. Spectral wavelengths of interest given in microns 161 -

Table 34.Main parameters of the measuring procedures carried out at each department. ...$161-$

Table 35. Weight ranges tested in the new analytical procedure. $-162$ 
Table 36. Comparison between the segregation power of the canonical variables obtained from the MANOVA analysis performed in both devices 1 and 2 ..................................... 165 - 


\section{Figures Index}

Figure 1.Global fossil fuel consumption in terms of coal, natural gas and crude oil from 1800 to nowadays. - 9 -

Figure 2.Index of average fossil fuel prices for coal, oil and natural gas over the last 30 years (Santos 2000) $-10-$

Figure 3.Diagram showing the indication of the approximate dates of introduction of major fuel additive types (Smil 2017). $-12-$

Figure 4.Schematic drawing of the experimental device corresponding to the patented invention for measuring hydrocarbon fuel properties, which was released in 1993 for liquid fuels applications. -30 -

Figure 5. Detailed drawing of the invention patented by Yu-Min Chen et al., 2006 ......... 32 Figure 6. Plant view drawing of the invention patented by Yu-Min Chen et al., 2006...... 33 Figure 7. Schematic drawing of the invention patented by Zelepouga et al., 2016.......... 33 Figure 8. Schematic diagram of the remote sensor for exhaust emission monitoring patented by Lord et al., 2002 - 34 -

Figure 9.Plot of the second derivative of absorbance versus wavelengths for olefins superimposed on other PIANO constituents from 2050 to $2250 \mathrm{~nm}(4878-4445 \mathrm{~cm}-1)$. . - 35 Figure 10.Second derivative of NIR spectra plot showing aromatics superimposed on other PIANO constituents from 800 to $900 \mathrm{~nm}$. $-36-$

Figure 11.Graphical comparison of absorbance (in arbitrary units) exhibited by fuel enhancers in two gasolines, one at 92.8 octane (dotted line trace) having aromatic octane enhancers, and one at 87.1 octane (solid line trace) without aromatics (Clarke 1993) ... - 36 Figure 12.Graphical comparison of absorbance (in arbitrary units) exhibited by fuel enhancers in two gasolines, one at 94 octane (solid line trace) having MTBE and aromatic octane enhancers, and one at 86 octane (dotted line trace) without MTBE (Clarke 1993)..... 37 -

Figure 13.Comparison of absorbance exhibited by the components of two gasolines, one at 91.2 octane (curve 1 ) and one at 87.3 octane (curve 2 ) $-37-$

Figure 14.Graphical representation of absorbance exhibited by a gasoline formulated with a blend of MTBE, aromatic, alcohol (including ethanol) octane enhancers, detected according to the invention. $-38-$

Figure 15.MID IR spectrum of ambient air, the number 100 encodes the $\mathrm{CO} 2$ absorption peak at about $2550 \mathrm{~cm}^{-1}$ (3.9-4.0 microns approximately) in this region. $-39-$ 
Figure 16.UV VIS spectrum of ambient air. The number 102 encodes the deuterium emission peak of the lamp used. - 39 -

Figure 17. MID IR spectrum of the pollutants from the vehicle exhaust emissions measured by the apparatus in the invention described above (Lord 2002) ...................................... 40 Figure 18.UV Vis absorption bands of pollutants in vehicle exhaust emissions................- 41 Figure 19.Plot of the "lab reported" results obtained for the NOx measurement in a winter gasoline (that is one of the EPA parameters to determine in quality control of reformulated gasoline) against the NIR predicted values using the patented prediction model $-44-$ Figure 20.Linear fit correlation of NIR (top left), RAMAN (top right), and FTIR (bottom) benzene content measured in a gasoline versus conventional laboratory methods......... 45 Figure 21.(left). Volume percent aromatics as measured by gas chromatography (GCPIANO) versus the volume percent predicted according to the present invention. (right) Plot of reformate research octane predicted by NIR versus a knock engine. $-46-$ Figure 22. Graphical scheme of the experimental set up used to the spectra acquisition for liquid samples. - 62 Figure 23.Graphical scheme of the experimental set up used to the spectra acquisition in gaseous samples. - 63 -

Figure 24. Image of the sensor embodiment. $64-$

Figure 25. Emissivity of the SiC versus wavelengths before and after heating and compared to the heated and polished one (Dengfeng, et al. 2016). $66-$ Figure 26. Sapphire optical transmission versus wavelength in microns curves, for the UVgrade and Commercial types...... $-67-$ Figure 27. Experimental design which covers tests on pure substances (patron chemicals) as well as these chemical produced from yeast cell cultures (Rivas, et al. 2015) .................... 68 Figure 28. Dynamic acquisition of gaseous or volatile compounds ..................................... 69 Figure 29. Line up of the steps given to establish a fixed experimental set up to obtain reproducible and repetitive measurements $69-$ Figure 30. Layout of the main components of the spectrometers. The source, the sample cell and the camera are fixed by screws to the ground in an optimal distance obtained by

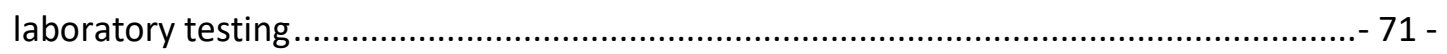

Figure 31. Texas A\&M Engineering Experimental Station (Bryan, TX, USA) .....................- 74 Figure 32. Experimental set up and spectra acquisition of the FTIR device for acetone and ethanol measuring $-75-$ 
Figure 33.Illustration of least-squares smoothing by locally fitting a second-degree polynomial (solid line) to five input samples.

$-81-$

Figure 34. (Left) Raw middle infrared spectra from the validation set without any preprocessing. (Right) Pre-processed smoothed spectra using Savitzky-Golay algorithm..... - 82 Figure 35. Comparison of the smoothed spectra versus the smoothed and baseline corrected spectra, with the highest and lowest parts of the curves taken to zero. This method is useful to eliminate the drift caused by the temperature in the sensor. $-82-$ Figure 36. Shape of the spectra corresponding to the radiation from the infrared source, after being focused and optical lens removed in the acquisition sofware........................ 88 Figure 37. PbSe MID IR detector scheme in terms of wavelengths $-89-$

Figure 38. Spectra pre processing by Excel of an analyte in solution at different concentrations $-90-$

Figure 39. First derivative of the spectra from liquid substances. Numerals refer to each type of compound, being 1 the potassium sorbate, 2 the olive oil, 3 the glucose, 4 the ethanol and 5 the 1,3-pentadiene $-92-$ Figure 40. First derivative of the spectra acquired during a experiment (named as "ep3" in the legend) at different times of exposure (t1, t2 and $t 3$ ). As it can be observed, the variation on the concentration of the gas is higher during the first instants. $-93-$ Figure 41. Loadings for the PC1 obtained from the PCA applied over the experiments performed on headspace volatile compounds $-94-$

Figure 42. Raw (top) and smoothed spectra (bottom) obtained directly through the designed script. - 95 -

Figure 43. Experimental set up designed for volatile compounds in headspace $-96-$ Figure 44. Raw spectra of volatile from pure commercial gasoline at different storage conditions $-98-$

Figure 45. Raw spectra scattering of pure volatilized methanol and ethanol. The

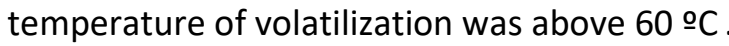
- $99-$ Figure 46. Smoothed and normalized spectra of volatilized pure alcohols (MetOH and EtOH) at the beggining and the end of the acquisition ( $\mathrm{t} 1$ and $\mathrm{t} 2$ respectively) 100 Figure 47. Bandwidth calculation on the raw spectra of a gaseous patron compound (1,3pentadiene) $-101$

Figure 48. Bandwidth calculation of two absorption peaks in a set of measured spectra from headspace of yeasts cultures. The smaller ones correspond to the gas 1,3-pentadiene whilst 
the bigger ones are typical absorption peaks of CO2 at channel 100 (which corresponds to 4.2 microns). $102-$

Figure 49.Spectral curves pre processing: (Left) Average blc-corrected-spectra from each sort of pure substance. (Right) Average normalized spectra from each of the pure substances. $-103-$

Figure 50. (Left) raw spectra of fuels (gasoline and diesel). Raw spectra of alcohols (Right)...$105-$

Figure 51. Loadings from principal components 1, 2, 3 and 5 of the calibration dataset.- 107

Figure 52. Graphical 2D scattering of the scores of PC1 versus the scores of PC2 of the same calibration dataset. $107-$

Figure 53. (Left and right) Graphical scattering of the scores of PC1 versus the scores of PC3 and $\mathrm{PC5}$ respectively. $108-$ Figure 54.Projection of the validation set canonical variables (Cval1 and Cval2) on the calibration set canonical variables (CV1 and CV2, retaining the 75 and $15 \%$ of the segregation power respectively) $109-$ Figure 55. Weights of the contributions of wavelengths from the canonical variables. .- 110 Figure 56. (Left) Mean raw spectra obtained from all the samples belonging to the pure substances from the train set. (Right) Pre-processed spectral curves from all the samples of the train set (baseline corrected). $-113-$ Figure 57.Root mean square error of Calibration and Cross Validation curves and indicating that the optimal number of Latent Variables is in the span between 4 and 5 in order to minimize these two errors. -114 Figure 58. Plot of the percentage of variance explained in the dependent variable $Y$ captured by each PLS component or latent variable at the quantitative analysis. ..........- 114 Figure 59. Projection of the validation set on the MANOVA plane .................................- 116 Figure 60.Centroids of latent variables in MANOVA................................................... 116 Figure 61. Radial distances and average angles from each alcohol blend cluster centroid to the origin according to MANOVA canonical variables.................................................. 118 Figure 62.Contribution of the wavelengths to the quantitative PLS model ..................... 119 Figure 63.Weights of each wavelength from canonical variables CV1 and CV2 .............. 119 Figure 64. Spectra collected from de dynamic measurements of acetone and ethanol using an FTIR. $-121-$ 
Figure 65.Generic Middle infrared spectrum.

$-131-$

Figure 66.User interface approach of the proposal for a future prospected device

$-133-$

Figure 67.Graphical scheme of the steps followed in the mathematical analysis carried out. $150-$

Figure 68.Scattering representation of the 1-way-MANOVA analysis performed on the whole data set (up), and Weight of each principal component contribution to their MANOVA eigenvectors regarding the information given by the canonical variables. .... - 153 Figure 69.Graphical scattering representation of the 1-way-MANOVA analysis made to the oils data set, using the canonical variables $\mathrm{C} 1, \mathrm{C} 2, \mathrm{C} 3$ and $\mathrm{C} 4$. The legend displays the different types of oils classified in the analysis. $-154-$ Figure 70.Graphical scattering of the 1-way-MANOVA analysis made to the alcohols data set using the canonical variables: $\mathrm{C} 1$ agaist $\mathrm{C} 2$ and $\mathrm{C} 1$ against $\mathrm{C} 3$. $-154-$

Figure 71.Mathematical hierarchical segregation procedure carried out from the row spectra to the end classification which predicts potential sources of adulteration between oils, and distinguishes between different chain lengths of alcohols $-155-$ Figure 75.(Left) Picture of the sensor used to the experiment, consisting in an array of 128 detectors. (right) Experimental set up of the measure device: (1) infrared source with a parabolic reflector (Hawkeye technologies, Inc.) (2) sapphire wafers containing the sample, (3) middle infrared detector (New Infrared Technologies, S.L.). -160 -

Figure 76. Spectra acquisition during 6 seconds, taking 3 replicates and 3 repetitions per sample. $-163-$

Figure 77. Mathematical procedure carried out to perform the data analysis, starting by the spectral curves pre-treatment, followed by the PCA and the MANOVA analysis to discriminate between samples. $-163$

Figure 78. Cartesian diagram plot of the main clusters segregated by the MANOVA analysis performed on the oil samples (top and bottom left). Contribution of CV1 and CV3 in terms of wavelenght weights to the analysis (Top and bottom right) $164-$

Figure 79. Projection of the MANOVA space obtained from the results with optics on the MANOVA space obtained from the results without optics. $-165-$ 



\begin{abstract}
Air pollution due to the greenhouse emissions of pollutants by vehicles, is an issue whose gravity is increasing, and it gains more significance for big cities such as Madrid. Controlling the composition of vehicle fuel can reduce pollutant emissions from combustion and it can also improve the performance of the vehicle engine. The intentional addition of offspecification fuel or contaminants can occur during the distribution of fuels and it is difficult to detect, unless the fuel is analyzed at every stage or the fuel quality is carefully monitored.
\end{abstract}

Establishing a fuel effective compliance program regarding specifications is important to ensure that fuels sold at gas stations meet all the requirements, and at the same time it is challenging because fuel is manipulated by many different agents along the distribution chain. It may also result costly, as the equipments used to measure the fuel composition are based on laboratory chromatographs and spectrometers. These techniques need of highly qualified staff, and large amount of samples, time and laboratory reagents consumption.

Consequently, it becomes necessary the use of simple, fast, and accurate techniques to carry out this quality control process. Although optical methods (non destructive) such as Infrared and RAMAN Spectroscopy have been widely applied and studied, they still pose drawbacks such as the lack of in-field applicability and the high cost of the equipment currently employed for it. 
In this PhD thesis a new device is proposed and developed for the quality control of pure fuel and its blends with alcohols (additives and adulterants). It consists on complementing or replacing current laboratory techniques by an innovative compact MID IR sensor based on a combination of a linear-array of detectors made of Vapour-phase-deposited Lead Selenide (PbSe) coupled to a linear variable filter of wavelengths selection between 2.9 and 4.5 microns (3450-2222 $\left.\mathrm{cm}^{-1}\right)$. This device provides a clear and quick analysis of fuel, either pure or blended with alcohols, using the specified wavelength range. A simple, fast and accurate method has been developed to determine fuel composition in three single steps: the development of the device set-up; the recording of the spectra with optimized parameters; and a fast processing of the data based on chemometrics as to being able to easily get implemented at any stage of the fuel distribution chain.

The results obtained in the first part of this thesis demonstrated the prospective of this device as a tool to differentiate pure chemical substances such as diesel oils, gasoline, and alcohols with increasing hydrocarbon chain length from $1 \mathrm{C}$ (Methanol) to 6C ( $\mathrm{n}$-Hexanol) by applying an appropriate pre-processing method in order to remove the noise and the drift from the spectra. A Principal Components Analysis provided a reduction in the dimensionality of the data and a preliminary differentiation between diesel oils, gasoline and alcohols when plotting PC1 (retaining $95.35 \%$ of variance) against PC2 (4 \%), PC3 (0.21 \%) and PC5 (0.07\%). The most remarkable fact regarding these results was the relevancy of the information gathered by the PC2, PC3 and PC5; whilst the higher amount of information was retained by PC1 (95\% of variance). Afterwards, a MANOVA analysis was applied on the scores from PC1 to PC5, and the two first canonical variables gave a neat segregation among pure substances when graphically represented in a Cartesian diagram. A total of 75 spectra were used for doing this calibration of the method. These results were validated using the projection of new data sets (420 spectra) achieving a $100 \%$ of successfully classified individuals. The key wavelengths used for this analysis were 3035, 3101 and 3145 $\mathrm{cm}^{-1}$ (3.3-3.2 microns) by the variable canonical 1, and 3035 and $3145 \mathrm{~cm}^{-1}$ by the canonical 2.

The second part of this thesis was based on the experiments conducted to assess the capacity of the device and method, set up for simultaneously quantifying and identifying the type of alcohol in gasoline and the corresponding alcohol mixtures in a 10, 20, $30 \%$ $(\mathrm{v} / \mathrm{v})$. After the spectra pre-processing by a smoothing and baseline correction, two different approaches were followed in order to quantify and determine the type of alcohol 
contained in the blend. Quantitative analysis was done by applying a PLS regression using 253 and 134 spectra for the train and test sets respectively. The results obtained for the training and validation data sets gave a goodness of fitting of 0.95 in both of them, with a Root Mean Square Error of Calibration and Cross Validation of 7.4 and $8.5 \%$ respectively, using 5 latent variables to build the model. These results demonstrated the ability of the sensor for quantitatively predicting concentrations of alcohol up to $10 \%$. In parallel, a PCA was performed on the pre processed spectra followed by a MANOVA analysis that gave a segregation triangular pattern, where each vertex of the triangle corresponded to a type of alcohol and it was qualitatively determined by the angles values $\left(173^{\circ}\right.$ for methanol, $57.1^{\circ}$ for ethanol and $304^{\circ}$ for $n$-butanol in the calibration data set, and $177.4^{\circ}, 55.05^{\circ}$ and 306.3

- respectively for the validation data set) and the radial distance measurement of each cluster centroid to the centre of the triangle gave a parallel way to determine the concentrations of each alcohol. This method was validated with the projection of a new data set (97 spectra) on the loadings obtained from the calibration set (181 spectra). For this analysis, the spectra of pure gasoline were not taken into account, and neither the 40 $\%$ methanol and ethanol mixtures, as they did not result of practical interest for the analysis.

The experimental set up implemented in this thesis together with the search of the most appropriate data analysis methods provided a new fast and accurate optical method to determine and quantify pure chemical substances and their blends with a prospect of being applied in the near future, at the fuel distribution chain.

\section{Resumen}

La contaminación del aire debido a las emisiones de contaminantes de efecto invernadero por los vehículos, es un problema cuya gravedad está aumentando y adquiere más importancia para las grandes ciudades como Madrid. Controlar la composición del combustible del vehículo puede reducir las emisiones contaminantes de la combustión y también puede mejorar el rendimiento del motor del vehículo. La adición intencional de combustible fuera de especificación o contaminantes puede ocurrir durante la distribución de combustibles y es difícil de detectar, a menos que el combustible se analice en cada etapa o la calidad del combustible se controle cuidadosamente. 
Establecer un programa de cumplimiento efectivo de combustible con respecto a las especificaciones es importante para garantizar que los combustibles vendidos en las estaciones de servicio cumplan con todos los requisitos, y al mismo tiempo es un desafío porque el combustible es manipulado por muchos agentes diferentes a lo largo de la cadena de distribución. También puede resultar costoso, ya que los equipos utilizados para medir la composición del combustible se basan en cromatógrafos y espectrómetros de laboratorio. Estas técnicas requieren personal altamente calificado y una gran cantidad de muestras, tiempo y consumo de reactivos de laboratorio.

En consecuencia, se hace necesario el uso de técnicas simples, rápidas, precisas y exactas para llevar a cabo este proceso de control de calidad. Aunque los métodos ópticos (no destructivos) como la espectroscopía infrarroja y RAMAN se han aplicado y estudiado ampliamente, todavía presentan inconvenientes como la falta de aplicabilidad in-situ y el alto coste de los equipos actualmente empleados para ello.

En esta tesis doctoral se propone y desarrolla un nuevo dispositivo para el control de calidad del combustible puro y sus mezclas con alcoholes (aditivos y adulterantes). Consiste en complementar o reemplazar las técnicas de laboratorio actuales por un innovador sensor compacto MID IR basado en una combinación de un conjunto lineal de detectores hechos de seleniuro de plomo depositado en fase de vapor ( $\mathrm{PbSe}$ ) acoplado a un filtro variable lineal de selección de longitudes de onda entre 2.9 y 4,5 micras $\left(3450-2222 \mathrm{~cm}^{-1}\right)$. Este dispositivo proporciona un análisis claro y rápido del combustible, ya sea puro o mezclado con alcoholes, utilizando el rango de longitud de onda especificado. Se ha desarrollado un método simple, rápido y preciso para determinar la composición del combustible en tres pasos simples: el desarrollo de la configuración del dispositivo; la grabación de los espectros con parámetros optimizados; y un procesamiento rápido de análisis de los datos basado en quimiometría para poder implementarlos fácilmente en cualquier etapa de la cadena de distribución de combustible.

Los resultados obtenidos en la primera parte de esta tesis demostraron la posibilidad de que este dispositivo sea una herramienta para diferenciar sustancias químicas puras como gasoleo, gasolina y alcoholes con una longitud de cadena de hidrocarburos creciente de $1 \mathrm{C}$ (metanol) a 6C (n-hexanol) aplicando un método de pre-procesamiento apropiado para eliminar el ruido y la deriva de los espectros. Un análisis de componentes principales proporcionó una reducción en la dimensionalidad de los datos y una diferenciación 
preliminar entre gasóleo, gasolina y los alcoholes visualizando el PC1 (que retiene el 95.35\% de varianza) frente a PC2 (4\%), al PC3 (0.21\%) y al PC5 (0.07\%). El hecho más notable con respecto a estos resultados fue la relevancia de la información recogida por los PC2, PC3 y PC5; aunque la mayor cantidad de información está retenida por el PC1 (95\% de variación). Posteriormente, se aplicó un análisis MANOVA a las muestras proyectadas en los componentes principales PC1 a PC5. Las dos primeras variables canónicas dieron una clara segregación entre sustancias puras cuando se representan gráficamente en un diagrama cartesiano. Se utilizó un total de 75 espectros para realizar esta calibración del método. Estos resultados fueron validados utilizando la proyección de nuevos conjuntos de datos (420 espectros) logrando un 100\% de individuos clasificados con éxito. Las longitudes de onda clave utilizadas para este análisis fueron 3035, 3101 y $3145 \mathrm{~cm}^{-1}$ (3.3-3.2 micras) por la variable canónica 1, y 3035 y $3145 \mathrm{~cm}^{-1}$ por la canónica 2 .

La segunda parte de esta tesis se basó en los experimentos realizados para evaluar la capacidad del dispositivo y el método, configurado para cuantificar e identificar simultáneamente el tipo de alcohol en la gasolina y las mezclas de alcohol correspondientes en un 10, 20,30\% (v/ v). Después del procesamiento previo de los espectros mediante un suavizado y una corrección de referencia, se siguieron dos enfoques diferentes para cuantificar y determinar el tipo de alcohol contenido en la mezcla. El análisis cuantitativo se realizó mediante la aplicación de una regresión PLS utilizando 253 y 134 espectros para el set de datos de entrenamiento y prueba del modelo, respectivamente. Dichos resultados devolvieron un coeficiente de ajuste de mínimos cuadrados con un valor de 0.95 en ambos, con un error cuadrático medio de calibración y validación cruzada de 7.4 y 8.5\% respectivamente, utilizando 5 variables latentes para construir el modelo. Estos resultados demostraron la capacidad del sensor para predecir cuantitativamente las concentraciones de alcohol de hasta el $10 \%$. Paralelamente, se realizó un análisis de componentes principales (PCA) en los espectros pre-procesados seguido de un análisis multivariante de la varianza (MANOVA) que dio un patrón triangular de segregación, donde cada vértice del triángulo correspondía a un tipo de alcohol y se determinó cualitativamente por los valores de los ángulos (173 ${ }^{\circ}$ para metanol , $57.1^{\circ}$ para etanol y $304^{\circ}$ para $n$-butanol en el conjunto de datos de calibración, y $177.4^{\circ}, 55.05^{\circ}$ y $306.3^{\circ}$ respectivamente para el conjunto de datos de validación) y la medición de la distancia radial de cada centroide del grupo al centro del triángulo dio Una forma paralela para determinar las concentraciones de cada alcohol. Este método fue validado con la proyección de un nuevo conjunto de datos (97 
espectros) en las variables canónicas obtenidas del conjunto de calibración (181 espectros).

Para este análisis, no se tuvieron en cuenta los espectros de la gasolina pura, ni tampoco las mezclas de metanol y etanol al $40 \%$, ya que no resultaron de interés práctico para el análisis.

La configuración experimental implementada en esta tesis junto con la búsqueda de los métodos de análisis de datos más apropiados proporcionó un nuevo método óptico rápido y preciso para determinar y cuantificar sustancias químicas puras y sus mezclas con la posibilidad de aplicarse en un futuro próximo, en la cadena de distribución de combustible. 


\section{Chapter 1}

\section{Introduction and antecedents}

There exist some original causes at the time of vindicating the use of gasoline and alcohol blends. These reasons are mainly related to the non-renewability of fossil fuels and the environmental pollution caused by them. That is why new renewable sources of energy are being investigated. Nevertheless, when it comes to implement new chemicals in the fuel composition, it is also necessary an adequate quality control regarding to the vehicles engine performance and the emissions generated from the exhaust gases.

This background leads to an exhaustive preliminary analysis of the fossil fuels and their historical evolution, the introduction of additives and/or blending components in the gasoline or diesel formulation, and the potential adulterations that it may suffer.

\subsection{Fossil fuels as source of energy and their consumption historically}

Fossil fuels are the most used source of energy all over the world. This fact is due to they constitute a high-power energy source because of their great heating power, given by their carbon-carbon and hydrogen-carbon bonds, which are highly energetic. This feature has been making them useful for the industry. Fossil fuels usage has allowed the great economic and demographic growing up since the Industrial Revolution in XIX century. In 
2007, coal, petroleum and hydrogen gas combustion represented $86.4 \%$ from the world primary energy (U.S. Energy Information Administration 2015) ${ }^{1}$.

They came from a decomposition and transformation of organic matter process that takes thousands of years due to the temperature and pressure under several layers of sediments deposited over the organic matter accumulated underneath them. This process was carried out in oxygen absence and its million-years lasting made the fossil fuels a non-renewable source of energy, due to they are consumed more quickly than they are generated.

Concerns surrounding this risk of depletion have persisted for decades not only at regional, but also at global levels (Smil 2017). But the fossil fuels dependence is not only a matter of running out these resources, but also an environmental issue as disclosed below.

The transport sector relies heavily on fossil fuels, for example in the form of gasoline or diesel oils. The excessive usage of fossil fuels however, is not only leading to a depletion of these resources but also it is presumed to contribute to the greenhouse effect, air pollution, acid rain, ozone wearing and climate change. Pollutants generated via combustion of fossil fuels, e.g. carbon monoxide or dioxide, unburned hydrocarbons (UHC), nitrous oxides (NOx), hydrofluorocarbons (HFC) and others, pose a serious problem not only for environment but also for human health (Corsetti, Zehentbauer, et al. 2015). Hence, there is a strong need of new alternative fuels and a more demanding quality control of fuels and vehicle exhaust emissions too.

Regarding the fossil fuel consumption historically, although fossil fuel production and consumption began with coal, whose first use was reported as far back as $4000 \mathrm{BC}$ in China (Smil 2017); large-scale combustion of coal is typically correlated with the period around the beginning of the Industrial Revolution (year 1800). It can be seen that the global consumption of fossil energy has increased more than 1300 -fold since then to the year 2017. As shown, coal was the first and only fossil source until the 1860 s when crude oil consumption began. Natural gas production began a couple of decades later, in the 188090s.

The 20th century saw a large diversification of fossil energy consumption, with coal declining from 96 percent of total production in 1900 to less than 30 percent in 2000.

\footnotetext{
${ }^{1}$ https://www.eia.gov/todayinenergy/detail.php?id=26912
} 
Today, crude oil is the largest energy source, accounting for around 39 percent of fossil energy, followed by natural gas and coal at 33 and 28 percent, respectively.

Figure 1 below displays the global fossil fuel consumption from the year 1800 onwards to the year 2017, in terms of global use of these sources, regarding to coal, natural gas and crude oil in terawatt-hours (TW/h) (Smil 2017).

On the other hand Figure 2 shows the index of average fossil fuel prices for coal, oil and natural gas over the 30 last years. This index is measured relative to the year 2000 , where prices in 2000 are equal to 100 (Smil 2017), (Dudley 2015), (Jamrozik 2017). It can be seen that natural gas prices have been the least variable over this period (remaining relatively close to 100 across the last 30 years). Coal has shown the greatest volatility (rising to four times the 2000 price in 2008, and nearly 3.5 times in 2011 . Oil has similarly shown volatility, varying by two to three-folds over this period.

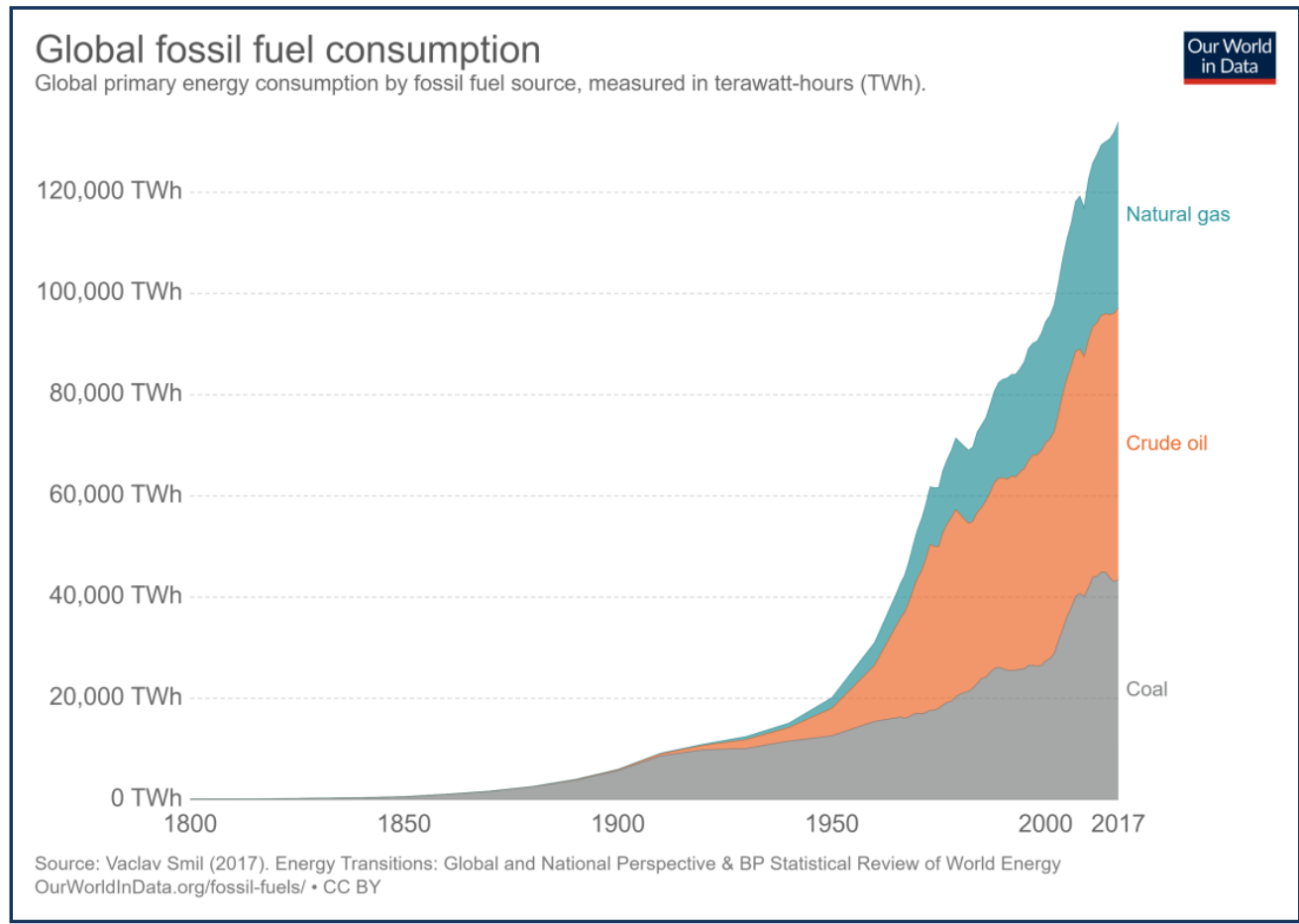

Figure 1.Global fossil fuel consumption in terms of coal, natural gas and crude oil from 1800 to nowadays

A significant increase on natural gas and crude oil is observed since the 90 's due to a peak in petrochemical industry. 


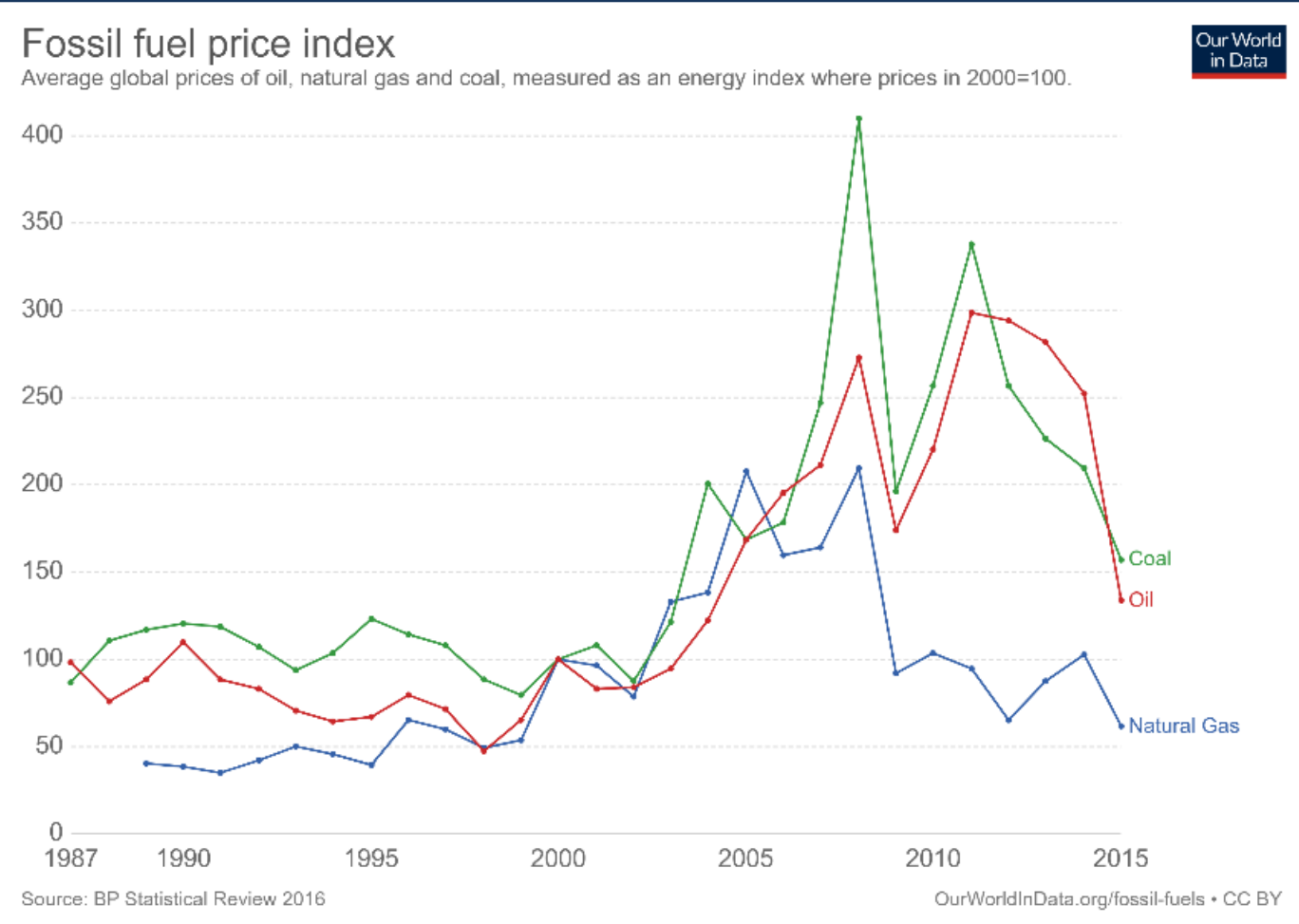

Figure 2.Index of average fossil fuel prices for coal, oil and natural gas over the last $\mathbf{3 0}$ years (Santos 2000)

The question often asked with regards to fuel reserves is: when are they going to run out? Because they are finite resources and will eventually run out if consumed indefinitely.

This background pointed out for the need of renewable sources that have been gradually implemented in the new vehicle engines. Some of these alternative fuels are based on which are known as bio-fuels. These are transportation fuels that are produced from biomass materials and are usually blended with petroleum fuels (gasoline or diesel fuels) but can also be used on their own. This means less gasoline or diesel fuel is burned and also the combustion process is cleaner than when gasoline or pure diesel fuel is used.

In a joint research work in 1917, Charles Kettering (inventor of electric self-starter) and Midgley blended ethyl alcohol (grain alcohol) with gasoline and concluded that alcohols mixed with gasoline could produce a suitable motor fuel (Nadim and Hoag 2001). It was discovered that alcohol had many advantages over other additives, because it burned clean and free from any deposits, it produced higher compression ratios inside the engines without knocking and generated more horsepower due to an increase in the octane number. 
Ethanol has been frequently and widely used as an automotive vehicle fuel due to the variety of renewable resources available for its industrial scale production especially in some countries such as Brazil or the US (Adenilton 2012). Additionally, the fact of containing oxygen in its structure provides the potential to reduce particulate emission in compression-ignition engines. Methyl-Tertbutyl Ether (MTBE) used to be the oxygenated chemical added to gasoline instead of the ethanol, but it has been demonstrated to be toxic and environmentally harmful and also it is not renewable as alcohols (Hansen 2005).

The knocking or detonation in Internal Combustion Engines (ICE) occurs when the peak of the combustion process takes place at a moment that is not the optimal on the combustion cycle. To avoid this phenomenon that causes damage to the spark ignition engine, some additives have been studied and proposed for the gasoline fuel. So on, in the early 20th century, Thomas Midgely, a research scientist working for the Dayton Research Laboratories of Dayton (Ohio) discovered that the addition of iodine to gasoline substantially reduced the engine knocks and so on preventing damages to the vehicle. He related engine knocks to low quality of fuel combustion (later known as octane rating). lodine raised octane rating and eliminated the knocks. lodine had two major drawbacks; it was corrosive and prohibitively expensive (Nadim, et al. 2001).

\subsection{Additives and octane boosters as main blending components}

Gasoline is a petroleum-derived liquid that is used primarily as a fuel in internal combustion engines (ICE), particularly Spark ignition Otto Engine (SI). Gasoline is a blend of hydrocarbons with some contaminants, including sulfur, nitrogen, oxygen, and certain metals. The four major constituent groups of gasoline are olefins, aromatics, paraffins, and napthenes. (Demirbas 2015).

\subsubsection{Additives}

The Additives Manufacturers association from Europe (ATC) defines a fuel additive as: $A$ chemical substance or preparation, added to fuel, in concentrations typically of less than $1 \%$, to impart or enhance desirable properties or to suppress undesirable properties. Additive treat levels do not approach those of blending components such as ethanol for use in gasoline, where the use levels are typically for $3 \%$ to $20 \%$ of the hydrocarbon base fuel volume. 
An additive may be used as a single stand-alone product to resolve a specific issue, for example at the refinery or, frequently, may be combined with other products to create a multi-functional package for use in finished fuels for the automotive industry. Typical single additives are dosed at $50-500 \mathrm{mg} / \mathrm{kg}$ range, while a multifunctional package may be used at treat levels in the range $350-3500 \mathrm{mg} / \mathrm{kg}(0.035-0.35 \%)$ depending on the extent and the range of benefits desired.

A very wide range of additives has been developed to meet the needs of the fuel industry as indicated in Figure 3 below. These may be encountered at the refinery, in distribution systems and storage tanks or in use, for example in numerous different transport applications.

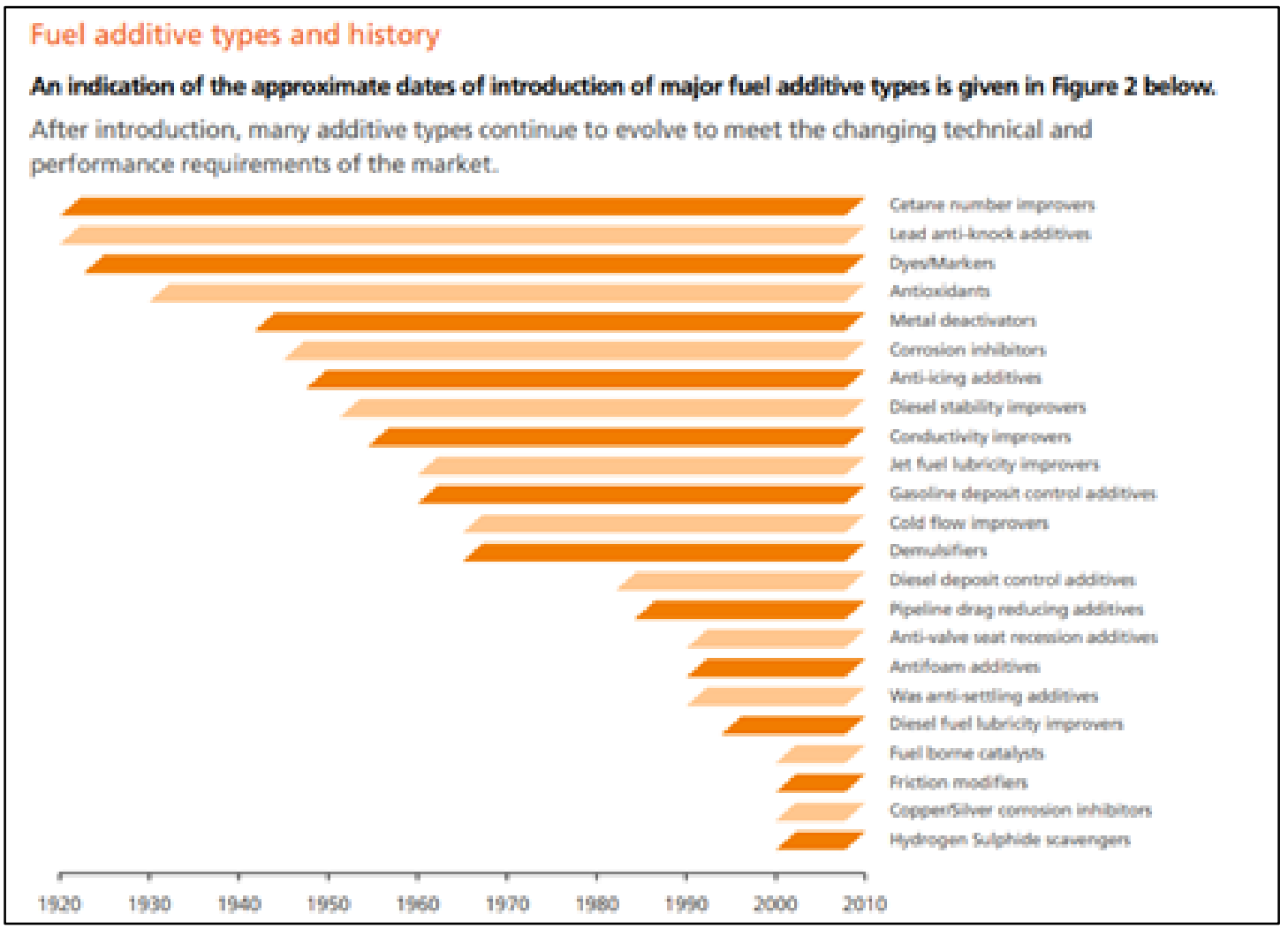

Figure 3.Diagram showing the indication of the approximate dates of introduction of major fuel additive types (Smil 2017).

As it can be observed, the first type of additives that were introduced into the additive market were the Cetane Number improvers for diesel oils and lead anti-knock additives for gasoline in parallel, followed by the dyes and/or markers, antioxidants, metal deactivators, corrosion inhibitors, and anti-icing additives. The rest of types of additives were being implemented from the 60's on. New additives are still being developed and implemented in 
gasoline and diesel fuel in order to improve their properties with regards to their transport and the correct working of the vehicle engine.

According to the ATC the petroleum additive industry is a significant operating sector of the world economy, with a world-wide turnover of about $€ 7,000$ million, ( $€ 1,900$ million in Europe) and research and development (R\&D) spending in 2005 of $€ 400$ million ( $€ 115$ million in Europe). The industry has 8,400 direct employees world-wide (2,800 in Europe), maintaining some 75 R\&D and manufacturing sites globally (25 in Europe).

Additives need to comply with European REACH (Registration, Evaluation, Authorization and Restriction of Chemicals) regulations linked to health and safety legislation which poses a significant challenge.

\subsubsection{Octane boosters}

On the other hand, octane number or octane rating is a measure of the level of temperature and pressure needed to ignite the fuel/air mixture, high-octane fuels prevent premature ignition. Such premature ignition can create a knocking on the engine, causing stress and potential damage on it, as it was described in previous sections.

Octane number is defined nowadays as a measure of the knock resistance of gasoline. It can take a numerical value from 0 to 100 , and describes the behavior of a fuel during combustion. It comes necessary differentiating between the Research Octane Number (RON) and the Motor Octane Number (MON). While the RON is a measure or description of the fuel behavior at low temperatures and speeds $\left(65^{\circ} \mathrm{C}\right.$ in the inlet, $600 \mathrm{rpm}$ ) (Demirbas 2015), in an attempt to simulate the acceleration behavior, the MON is a measure of the fuel behavior at high temperature and speed (i.e. such as when driving fast on a highway). According to the specific regulations, a gasoline RON should be at least 95.0 if it is Super and at least 98.0 if this is a Super Plus gasoline. Nevertheless, the MON should be at least 85.0 for Super and 88.0 for Super Plus gasoline. The difference is that RON is usually specified at service stations, whilst MON is not known to the public as it is not specified at service stations. Other difference is that usually RON is higher that the specifications, whilst MON is generally at the limit of the specification². 
Modern spark ignition engines have a typical octane requirement in the range 90-98 research octane number (RON). Operation on fuel of inadequate octane quality produces unwanted noise from detonation and may result in engine damage. ${ }^{2}$

Octane boosters, also called antiknock compounds, comprise principally organometallic chemistries including Tetraethyl Lead (TEL), Ferrocene and Methyl cyclopentadienyl manganese tricarbonyl (MMT). Tetraethyl lead (formula, $\left(\mathrm{CH}_{3} \mathrm{CH}_{2}\right)_{4} \mathrm{~Pb}$ ) was first mixed with gasoline in the 1920 s as a patented octane booster. Burning of TEL generates lead oxide, which poisons catalytic converters. The use of compounds containing lead causes environment pollution.

On the other hand, the use of organic compounds as octane boosters, such as N-methyl aniline, ethanol, methyl tertiary butyl ether (MTBE), etc. is less effective than when using organometallic additives.

\subsection{Ethanol as multi-functional blending component}

As disclosed above, alcohols have been chosen as the candidates to replace MTBE and other additives because of their renewability and eco-friendly character (Szulczyk 2010).

Preceding research has been oriented to investigate the impact of fuel-alcohol blends in the spark ignition (SI) engine performance and its emissions produced, by comparison of the results obtained from the gasoline-alcohol fuel blends (concretely at E5 and E10 blending rates) to those of pure gasoline fuel (Balat 2011). These results indicated that alcoholgasoline blends provided better properties to the gasoline (Abu-Zaid, Badran and Yamin 2004) since they improve oxygen content, and enhance octane number; more oxygen in the fuel allows more complete combustion and reduction of carbon monoxide emissions.

In 2003, the Environmental Protection Agency (EPA) issued a waiver that authorizes the incorporation of up to $15 \%$ ethanol into gasoline for cars and light pickup trucks made from 2001 onwards.

The world's top ethanol fuel producers in 2011 were the US with 52.6 billion liters, followed by Brazil with 21.1 billion liters. Together they account for the $87.1 \%$ of the world production ( 84.6 billion liters). Strong incentives, coupled with other industry development initiatives, are giving rise to fledgling ethanol industries in countries such as Germany,

\footnotetext{
${ }^{2}$ www.mabanaft.com s.f.
} 
Spain, France, Sweden, China, Thailand, Canada, Colombia, India, Australia, and some Central American countries.

Table 1 below summarizes the annual ethanol fuel production by the main producer countries among 2014 and 2016. It also shows the evolution in the amount of ethanol fuel produced along these three years that follows an increasing tendency from 2014 to 2016. This means that the use of ethanol blended with gasoline is technically working on and moving forward.

Table 1.Summary of the ethanol fuel production a year all over the world during the period between 2014 and 2016 (Balat 2011)

\begin{tabular}{|c|c|c|c|c|}
\hline \multicolumn{5}{|c|}{ Annual fuel production by country (2014-2016) (Millions of US liquid gallons per year) } \\
\hline World rank (2017) & Country & 2016 & 2015 & 2014 \\
\hline 1 & United States & 15.330 & 14.806 & 14.300 \\
\hline 2 & Brazil & 7.295 & 7.093 & 6.190 \\
\hline 3 & European Union & 1.377 & 1.387 & 1.445 \\
\hline 4 & China & 845 & 813 & 635 \\
\hline 5 & Canada & 436 & 436 & 510 \\
\hline 6 & Thailand & 322 & 334 & 310 \\
\hline 7 & Argentina & 264 & 211 & 160 \\
\hline 8 & India & 225 & 211 & 155 \\
\hline$*$ & Rest of the world & 490 & 391 & 865 \\
\hline & World total & 26.094 & 25.682 & 24.570 \\
\hline
\end{tabular}

In the past, ethanol was not given expectancy due to its insufficient production and high price (Eyidogau, et al. 2010). That moved on research and development of new sources for biologically obtained ethanol, better known as bio ethanol (of relatively low cost and environmentally friendly), which is mainly produced by the alcoholic fermentation of 
agriculture feedstocks (e.g. sugar cane and corn). These raw materials are classified into three categories of agricultural raw materials: simple sugars, starch and lignocelluloses.

\section{$1.4 \mathrm{~N}$-butanol as a potential blending component in comparison to ethanol}

To cope up with increased demand for ethanol, alcohols with increased carbon numbers such as butanol can be utilized as heightened substitutes because the implement of ethanol as fuel in gasoline engines is mainly limited by its low heating value (LHV).

Butanol has four isomers: n-butanol, isobutanol, sec-Butanol, and tert-butanol. Among them, only $n$-butanol is produced from fermentation through the Acetone-Butanol-Ethanol $(A B E)$ process. The remaining isomers are not discussed in this section, because they are not produced by the ABE process, so they do not pose the same sustainability as the nbutanol. Both $\mathrm{n}$-butanol and ethanol can be fermented from the same feedstocks, which include the sugar and starch crops and lignocellulosic fermentation from wood and crop residues, and fast-growing energy crops like hybrid poplar, switchgrass, and willow. Furthermore, the capital and facilities used to produce ethanol can be switched to butanol fermentation with minimal costs. These facts pose an advantage to replace ethanol by butanol in fuel blends.

When n-butanol is added to gasoline, their blends are denominated in the same way than when using ethanol, following the code of the letter " $N$ " (as the initial letter of the $n$ butanol), followed by a number that indicates the percentage of alcohol in the blend. For instance, N20 is a blend which contains exactly a $20 \%$ of n-butanol.

$\mathrm{N}$-butanol offers some advantages with respect to ethanol. More specifically, it overcomes three lacks or deficiencies of ethanol: 1) n-butanol owes higher energy content than ethanol; 2) butanol-gasoline blends are more hydrophobic than the ones made with ethanol, and more affined to the gasoline too; and 3) n-butanol can be blended with gasoline in any percentage, all the way up to $100 \%$. Since $n$-butanol is a longer chain hydrocarbon, and thus resembles gasoline more closely.

Referring to Table 2, pure n-butanol has an octane rating of 87 , which is comparable to gasoline fuels. However, ethanol has a higher octane rating. This higher octane rating gives 
ethanol an advantage. Petroleum distributors could buy a cheaper, low-octane fuel and blend it with ethanol to increase its octane. However, octane rating is not the only important fuel property (Szulczyk 2010).

Table 2. Ethanol, gasoline and $\mathbf{n}$-butanol properties. Sources: Brekke (K., 2007); Davis and Diegel (Davis S.C., 2006); Gallagher et al. (Gallagher PW, 2003 (25)), Graboski (M.S., 2009); Reynolds (R.E.); Sheehan et al. (Sheehan J., 1998); Wu et al. (Wu M., 2007).

\begin{tabular}{|ccccc|}
\hline & Units & Gasoline & Pure ethanol & Pure butanol \\
\hline Oxygen content & $100 \%$ & Close to 0 & 36 & 22 \\
\hline $\begin{array}{c}\text { Octane number } \\
\text { Reid vapor } \\
\text { pressure }\end{array}$ & $100 \%$ & 85 to 94 & 112.5 to 114 & 87 \\
\hline $\begin{array}{c}\text { Higher heating } \\
\text { value }\end{array}$ & MJ/liter & 0.480 to 1.034 & 0.159 & 0.023 \\
\hline $\begin{array}{c}\text { Lowe heating } \\
\text { value }\end{array}$ & 34.8 & 23.6 & - \\
\hline
\end{tabular}

Table 2 demonstrates that gasoline has almost zero oxygen, ethanol contains $36 \%$ oxygen, and butanol contains $22 \%$ oxygen.

According to the Reid Vapor Pressure, a fuel needs a minimum vapor pressure to start a cold engine. $\mathrm{N}$-utanol has a lower Reid vapor pressure than ethanol. Thus, $\mathrm{n}$-butanol does not easily vaporize which may make it more difficult to start a cold engine. However, the Environmental Protection Agency regulates a gasoline's maximum vapor pressure. Easy vaporization of fuel leads to higher pollution levels, especially during hot summers. The sun's ultraviolet radiation converts these volatile organic compounds along with $\mathrm{NO}_{\mathrm{x}}$ gases into ground ozone pollution (Environmental Protection Agency of US, 2008 ${ }^{3}$ ). So on, butanol's low vapor pressure is both a benefit and a disadvantage.

\footnotetext{
${ }^{3}$ https://cfpub.epa.gov/ncea/risk/recordisplay.cfm?deid=190806
} 
Another important fuel property is its energy content. Referring to Table 2, butanol contains approximately $86 \%$ of the energy of gasoline, while ethanol contains approximately $65 \%$. The lower energy content reduces the acceleration and mileage from a gallon of fuel. Thus, butanol fares much better in energy content and is closer to gasoline in energy content. The differences in energy content would lead to different market prices for the fuels.

Butanol has one property that may hinder the public's adoption of this fuel. Butanol is toxic to humans when excessive or prolonged exposure to butanol vapors (The Dow Chemical Company, $\left.2009^{4}\right)$. However, gasoline is formed of hundreds of compounds and some of these compounds are just as toxic.

What makes butanol a better alternative? Butanol has high energy content, butanolgasoline blends do not separate in the presence of water, and butanol can be blended with gasoline at any percentage without modifying the gasoline engine. Furthermore, butanol has a comparable octane level to gasoline and a lower vapor pressure. Gasoline distributors could buy a cheaper gasoline and blend in butanol to meet the EPA's minimum fuel requirements.

\subsection{Methanol as potential adulterant or additive}

Methanol and ethanol, both anhydrous, are added to the gasoline in many countries around the world, generally in the ratio of $10 \%$ (v/v) (Fernandes, et al. 2008).

During the ethanol crisis of 1989 in Brazil, alternative additives were investigated to be incorporated into the gasoline, such as, the oxygenated compounds from petroleum like MTBE, (ethyl-tert-butyl-ether) and TAME, (tert-amyl-methyl-ether). At that time, in addition to a reduction of the amount of anhydrous ethanol added to the gasoline, a new fuel called MEG (which means $33 \%$, $v / v$ of methanol $+60 \%$, v/v of ethanol $+7 \%$, $v / v$ of gasoline) was proposed. Although its production had been authorized, its commercialization was considered dangerous due to methanol manipulation, finally being abandoned (Santos 2000). The addition of methanol to gasoline is currently forbidden in Brazil. However in some countries, such as USA, it is still used (Abu-Zaid, Badran and Yamin 2004).

Previous studies carried out in 2015 by Abreu et al. (Romário, Abreu and Paz 2015) in Brazil, dealt with the adulteration of fuel mixing it with methanol. This practice is more usual and

\footnotetext{
${ }^{4}$ http://www.annualreports.com/Company/the-dow-chemical-company
} 
important in a sort of biodiesel called hydrated ethyl alcohol fuel (HEAF) that is mainly used in countries like Brazil, where sugar cane agricultural waste and other biological feedstocks are found in high amounts. This fuel is constituted by anhydrous ethanol blended with gasoline. The production and consumption of this fuel are increasingly larger, making it more susceptible to adulterations with methanol, due to the similarity in the chemistry of both alcohols and the much lower price of methanol. Specifically, a common nonconformity refers to the addition of methanol to HEAF (Lemos, Romário and Abreu 2015).

In recent studies developed in 2017 by Jamrozik, it was discovered that the addition of methanol to diesel fuel blends in up to $30 \%(\mathrm{v} / \mathrm{v})$ could have some positive effects regarding the engine performance and the emissions. More specifically, it was observed that the addition and the increase in the methanol content of up to $30 \%$ in diesel methanol blends had a positive effect on thermal efficiency. Moreover this increase led to a substantial reduction in carbon monoxide emissions and did show a significant effect on emissions of hydrocarbons and carbon dioxide. Nevertheless, a further increase in volume on methanol of over $30 \%$ caused disturbances in the combustion process, a substantial decline in incylinder pressure and unsteady engine work (Jamrozik 2017).

\subsection{Problem statement}

Taking all the information provided above into account, regarding to fuel additives, blending components and adulterations, it must be remarked that not only qualitative determination but also quantification is also important when it comes to know the type of additive or alcohol added to the gasoline, because it is also considered adulteration when the alcohol is blended with the gasoline in higher than the amount legally established.

The procedures for quality tests and norms for fuels commercialization are based on recognized standard methods that usually involve multiple laboratory techniques such as gas and liquid chromatography, ion absorption, and atomic spectrometry. These techniques usually result in high costs regarding to personnel and reagents consumption, and take longer at the stage of sample preparation, so they result in higher time consumption too, which makes them disadvantageous for the petrochemical companies.

Sampling is expensive and the fuel might result spoiled during the process, therefore real time and in situ measuring techniques are required in order to guarantee the accuracy and 
reliability of the analysis. Also, the longer a fuel is onboard in a vessel, in a tank or in a distribution network, the more opportunity there is for it to change and deviate from its specification or to be contaminated. So on, some companies who dedicate to fuel quality testing are trying to include in field support by infrared portable spectrometer among their analysis in addition to the traditional laboratory methods ${ }^{5}$.

On the other hand, considering the increasing use of additives in the fuel industry, there is a need of accurate and robust analytical techniques in order to determine exactly the alcohol-fuel proportions, as well as the identification of the type of alcohol molecule in use.

Furthermore, there is an increasing interest in non-invasive, non-destructive and rapid assessment techniques since the number of analysis per year can exceed 1.5 million, depending on the type of fuel studied and the legislations from each country. In this framework it the optical methods will most probably gradually replace the chemical ones.

\footnotetext{
${ }^{5}$ www.astm.org
} 


\section{Chapter 2}

\section{State of the art}

This chapter has been structured into technical and scientific prior art. The former refers mainly to patented optical devices (apparatus and methods). Most of them work in the Infrared and are applied to solve issues that are similar to the one in this thesis (fuel quality control), some of them are applied for liquid measurements and the others are for gas. The latter section focuses on scientific publications from the research that has been developed about spectroscopic techniques and the mathematical methods used to analyze fuel and fuel-alcohol blends.

\subsection{State of technical prior art}

As indicated in the problem statement optical methods are expected to gradually replace the chemical ones, and thus are specifically considered for the technical state of prior art.

\subsubsection{The first patented inventions related to optical devices applied to fuel quality control}

The first relevant number of optical inventions goes back to the first 90's and the early XXI Century to measure fuels or other kind of organic liquid or gaseous matters in real time and in situ. The results demonstrated that optical devices constituted an effective and accurate tool comparable to traditional chemical methods due to their quick response, better accuracy and non-invasive way of sample measuring and data acquisition. However, these optical methods needed to be supported by complex chemometric approaches. 
The optical devices reviewed here were designed not only to identify and determine the ethanol, methanol or another constituents in the blend content, but also for the study and characterization of some raw diesel or gasoline parameters such as octane index, hydrocarbon content profile (PIANO), etc. as will be discussed towards the released patents since 1993.

As subsequently disclosed, most of these optical devices referred above are based on infrared spectroscopy. The infrared radiation can be divided in three regions known as Near $\left(12500-4000 \mathrm{~cm}^{-1}\right)$, Middle $\left(4000-400 \mathrm{~cm}^{-1}\right)$ and Far infrared $\left(400-10 \mathrm{~cm}^{-1}\right)$. Some of the patents are focused in apparatus and methods that work in a determined wavelength span, whilst some others combine two or more different regions. The following parts make a disclosure about the instrumentation that is associated with these invetions, starting by a exposure about the light sources and afterwards the type of detectors depending on the spectral range used. Afterwards, a brief screening of the inventors or assignees is given, before going to describe the specific experimental set up used for each invention regarding to their applications.

\section{Ligh sources}

As the spectroscopy is a technique based on the study of the absorption and emission of light and other radiations by matter, the instruments for measuring infrared absorption all require a source of continuous infrared radiation of different frequencies. (Graybeal and Hurst 2018). These all processes depend on the wavelength of the radiation. The decomposition of electromagnetic radiation into its component wavelengths is fundamental to spectroscopy. Evolving from the first crude prism spectrographs that separated sunlight into its constituent colors, modern spectrometers have provided increasing wavelength resolution.

The main types of electromagnetic sources include the broadband-light sources, which are based on the generation of light separately from the sample. A typical broadband light source that can be used for either emission or absorption spectroscopy is a metal filament heated to high temperature (Graybeal and Hurst 2018).

Infrared sources usually consist of an inert solid that is electrically heated to a temperature between 1.500 and $2.200 \mathrm{~K}$. The heated material will then emit infrared radiation. 
Other kinds of sources are the line and the laser sources. The first ones are capable of primarily emitting radiation with discrete, well-defined frequencies are also widely used in spectroscopy. The second ones are also line sources that emit radiation over a very narrow frequency range.

Different kinds of sources are eligible depending mainly on the spectral range in study and the type of sample and detector used. For instance, normally the FTIR spectrometers use type of broadband lamp that is the Globar or Nernst lamp source for the MID IR region. The Nernst or Globar filament is made of rare earth oxides in the form of a hollow cylinder.

If the Far IR region is to be examined, then a high pressure Mercury lamp can be used. This one is a lamp that produces light as a result of an electrical discharge generated by two electrodes in a high-pressure mercury vapor that is contained in a transparent bulb (Van Bommel 2012).

For the Near Infrared, Tungsten-halogen lamps are usually employed as sources. These are a specific type of Globar source which consists of a Tugnsten filament that is sealed into a compact transparent envelope filled with a mixture of an inert gas and a small amount of an halogen such as iodine or bromine. The combination of the halogen gas and the tungsten filament produces an halogen cycle chemical reaction that re-deposits the evaporated tungsten on the filament. These kinds of sources work at temperatures of around $250^{\circ} \mathrm{C}$.

The light sources employed on the inventions discussed in this section can be different types such as broadband sources which supply a continuous spectrum in a wide range of wavelengths from the NIR and/or the MID IR, or tunable frequency sources such as the ultra-short pulsed lasers. Some of the inventions patented and discussed here combine two different types of sources, such as UV Vis and IR beams (Lord 2002) for whom two different kinds of sources are used, i.e. a Silicon Carbide lamp heated to $1000{ }^{\circ} \mathrm{C}$ for the $I R$ and a Deuterium or high pressure Xenon lamp for the UV Vis spectral range in the case of the invention that combines this type of sensor with the Infrared ones (Lord 2002).

\section{Spectral ranges (detectors)}

Most of the devices or inventions patented are based on an appropriate wavelength selection in order to pick the target compounds and avoid interferences or cross sensitivities to other analytes that absorb or transmit radiation at the same wavelengths. 
The first patented invention to disclose at this section was in 1993, when the company Boston Advanced Technologies, Inc. patented a method and apparatus based in the MID IR (4000 to $500 \mathrm{~cm}^{-1}$, or $20.0-2.5$ microns) (Clarke 1993) to analyze components in fuel solution. This method was useful to measure octane index and Reid Vapor Pressure of the fuel. These properties to determine had nothing to do with the alcohol or other additives content, but it meant the starting point for the application of the infrared spectroscopy to measure the fuel quality.

Following this line, (Maggard 1994) patented an apparatus based on a combination of NIR selected wavelengths (wavelength ranges of 2.05 to 2.25 microns for olefins identification: 0.88-0.974, 1.152-1.230, 1.320-1.380, 1.470-1578, 1.614-1.644, 1.746-1.810, 1.94-2.00, and 2.058-2.130 microns for paraffin and isoparaffin identification) to measure and analyze percentage of various hydrocarbons (PIANO), research octane index and motor octane index of gasoline, and cetane index of diesel fuels through these hydrocarbons profiling.

The gasoline adulteration issue was addressed much later by an invention patented in 2006. (Chen and Asher 2006) used a very narrow section from the MID range (2800 to 3200 $\mathrm{cm}^{-1}$ which is equivalent to 3.6-3.12 microns). The patented invention comprised a fuel reservoir as sample cell, and a heating mechanism to determine the fuel dilution in a sample. This parameter is an indicative of a possible engine disfunction. The concentration of fuel in crankcase lubrication oil provides an important indication of engine condition and can signal the need for engine maintenance. Most engines collect some fuel in the crankcase oil under normal operation, however excessive fuel dilution usually indicates engine malfunction, improper operation, or overly extended periods between oil changes. Usually this fuel dilution was determined by means of gas chromatography analysis or other techniques.

Many patents released later than 2000 combine two or more different optical methods that work in different spectral wavelength ranges (such as combining NIR with MIR, RAMAN or UV VIS).

The reasons why RAMAN is a complimentary technique to IR spectroscopy may be explained from the information gathered in Table 3 below (Peeran 2005). 
Table 3.Differences between IR and Raman methods

\begin{tabular}{|c|c|}
\hline RAMAN & FTIR \\
\hline $\begin{array}{l}\text { It is due to the scattering of light by the } \\
\text { vibrating molecules. }\end{array}$ & $\begin{array}{l}\text { It is the result of absorption of light by } \\
\text { vibrating molecules. }\end{array}$ \\
\hline $\begin{array}{c}\text { The vibration is Raman active if it causes a } \\
\text { change in molecules polarization. }\end{array}$ & $\begin{array}{l}\text { Vibration is IR active if there is change in } \\
\text { dipole moment. }\end{array}$ \\
\hline $\begin{array}{l}\text { The molecule need not possess a } \\
\text { permanent dipole moment. }\end{array}$ & $\begin{array}{c}\text { The vibration concerned should have a } \\
\text { change in dipole moment due to that } \\
\text { vibration. }\end{array}$ \\
\hline Water can be used as a solvent. & $\begin{array}{l}\text { Water cannot be used due to its intense } \\
\text { absorption in IR.87 }\end{array}$ \\
\hline $\begin{array}{c}\text { Sample preparation is not very } \\
\text { complicated, as it can be in any state. }\end{array}$ & $\begin{array}{c}\text { Sample preparation is elaborate } \\
\text { Gaseous samples can rarely be used. }\end{array}$ \\
\hline Cost of instrumentation is higher than IR & Comparatively inexpensive \\
\hline
\end{tabular}

As derived from Table 3, both techniques (RAMAN and FTIR) are useful depending on the substance, and sample presentation. In an ideal situation, the best results would be obtained by combining both devices simultaneously. For an instance, (Wellch and Bledsoe 2000) patented a method and device in the year 2000 to analyze several properties in a reformulated gasoline (RFG) such as Reid Vapor Pressure (RVP), sulfur, olefin and aromatic contents, distillation properties, volatile carbon (VOCs) and nitrogen oxides (NOx) by combining NIR and RAMAN techniques.

Regarding UV Vis spectroscopy (Lord 2002) patented a device which combined a nondispersive IR and UV Vis to quantify pollutants in exhaust emissions. The choice between IR or UV or both combined, comes from the need to measure some compounds that absorb better in one wavelength range or another. For example, some pollutants such as NO absorb in the UV wavelength range. 
A recent embodiment (Zelepouga 2016) for in situ measurement of the fuel gas composition and heat values combines three types of sensors in an attempt to overcome the inaccuracies associated with the cross-sensitivity of known sensors. A specific target is set for each sensor: NIR (0.9-1.7 microns/11111-5882 $\left.\mathrm{cm}^{-1}\right)$ for measuring concentrations of hydrocarbons and carbon dioxide, a MID IR sensor (up to 5-8 microns/2000-1250 $\mathrm{cm}^{-1}$ ) for measuring concentrations of carbon monoxide, and a semiconductor-based sensor for measuring the hydrogen concentration and to reduce the cross sensitivity of previous ones. The apparatus of this invention may be integrated with turbines, engines or any combustion system for efficient exhaust gases control.

As it can be extracted from the points disclosed above, many approaches have been done before in order to improve the accuracy and versatility of the patented devices along the last decades.

One of the main aims of the inventions disclosed above is gathering the widest wavelengths range using the simplest instrumentation possible. And that is the contribution provided by this thesis, as it found out the applications for a rugged and compact device with no moving parts that works in a wavelength range that gathers the near and the middle infrared regions simultaneously, in a spectral range spanned between 2 and 5 microns, that is where most of the organic molecules absorb radiation, as it shows strong vibration modes of the carbon-hydrogen, carbonyl and hydroxyl functional groups.

\section{Inventors and assignees from the disclosed patents}

In order to get a better knowledge of the inventions origin and understanding the motivations and applications for each development, a brief screening of the inventors, institutions and assignees who released each of the studied patents is shown below in Table 4. 


\begin{tabular}{|c|c|c|c|c|}
\hline Patent ID & Year & Inventor/s & Country & Assignee/s \\
\hline US5225679 & 1993 & $\begin{array}{l}\text { Richard H. Clarke } \\
\text { Deming Tang }\end{array}$ & $\begin{array}{l}\text { United } \\
\text { States }\end{array}$ & $\begin{array}{l}\text { Boston Advanced } \\
\text { Technologies, Inc. }\end{array}$ \\
\hline US5349189 & 1994 & Steven M. Maggard & $\begin{array}{l}\text { United } \\
\text { States }\end{array}$ & Ashland Oil, Inc. \\
\hline US6140647 & 2000 & $\begin{array}{l}\text { William T. Welch, Roy R. } \\
\text { Bledsoe, Brian K. Wilt, } \\
\text { Michael B. Sumner }\end{array}$ & $\begin{array}{l}\text { United } \\
\text { States }\end{array}$ & $\begin{array}{l}\text { Marathon Ashland } \\
\text { Petroleum }\end{array}$ \\
\hline US6455851 & 2002 & $\begin{array}{l}\text { Harry C. Lord, Marc M. } \\
\text { Baum }\end{array}$ & $\begin{array}{l}\text { United } \\
\text { States }\end{array}$ & $\begin{array}{l}\text { Air Instruments and } \\
\text { Measurement, Inc }\end{array}$ \\
\hline $\begin{array}{l}\text { US200601921 } \\
\text { 22A1 }\end{array}$ & 2006 & $\begin{array}{l}\text { Yu-Min Chen } \\
\text { William Asher }\end{array}$ & $\begin{array}{l}\text { United } \\
\text { States }\end{array}$ & On-Site Analysis, Inc. \\
\hline US7420170 & 2008 & $\begin{array}{l}\text { Luis Ramirez-Arizmendi } \\
\text { Heather D. Hamje }\end{array}$ & $\begin{array}{l}\text { United } \\
\text { States }\end{array}$ & $\begin{array}{l}\text { Exxonmobil Research } \\
\text { and Engineering } \\
\text { company }\end{array}$ \\
\hline EP2944944A1 & 2015 & Chayan Mitra et al & Europe & $\begin{array}{l}\text { General Electric } \\
\text { Company }\end{array}$ \\
\hline US9291610 & 2016 & $\begin{array}{l}\text { Serguei Zelepouga, John } \\
\text { M. Pratapas, Alexei V. } \\
\text { Saveliev, Villas V. Jangale }\end{array}$ & $\begin{array}{l}\text { United } \\
\text { States }\end{array}$ & $\begin{array}{l}\text { Gas Technology } \\
\text { Institute (IL) and } \\
\text { North Carolina State } \\
\text { University (NC) }\end{array}$ \\
\hline
\end{tabular}

As it can be extracted from Table 4, most of the patented inventions were released in the United States. Only one of the patents is European, but its applicants came from different nationalities such as India and the United States. Regarding the institutions who applied for the patents, they can be classified in two main groups: those who belong to technical companies (engineering, manufacturing, etc.) who designed and manufactured the patented devices as a part of their products; and those who belong mainly to oil and petrochemical sectors, which apply the designed, implemented technology or method to the fuel or gaseous emissions quality control. 
And finally, it is remarkable the fact that only one patent is applied by a company together with a university. This is the case of the latest patent from 2016, which was released by the Gas Technology Institute of Illinois together with the North Carolina State University. This could mean that applied research and development carried out by the universities together with the companies has been growing up during the last few years in an attempt to develop new technologies that are applicable to the fuel industry.

\subsubsection{Specific experimental set-up}

From the patents mentioned above, some devices have been patented for liquid fuels while others refer to gaseous chemicals. This fact affects the sample presentation and position inside the measuring chamber, and so more detailed information are included in this paragraph.

\section{Liquid measurements}

Sample presentation, volume adjustment and concentration are less complicated for liquid than for gaseous samples. Nevertheless, in the case of gasoline errors may occur due to certain volatile compounds that are susceptible to evaporate while measuring; in such cases the temperature is a parameter that must be monitored along the acquisition process, because it affects directly to the presence of volatile compounds in a headspace and their concentrations.

Table 5 below summarizes patents from the 90 's to 2008 for liquid fuel applications with varying IR spectral ranges (NIR or MID IR), and target compounds. The earliest devices were designed for industrial environment: tank (1993) or continuous flow (1994). The most recent patents (2000 and 2008) since they refer only to the method and do not include an apparatus. 
Table 5.Screening of some patented devices from the 90 's to 2008 for liquid fuel applications

\begin{tabular}{|c|c|c|c|c|c|c|}
\hline & & & LIQ & & & \\
\hline Year & Patent ID & Title & Calibration & $\begin{array}{l}\text { Measuring } \\
\text { site }\end{array}$ & $\begin{array}{l}\text { Spectrum and } \\
\text { wavelength } \\
\text { span }\end{array}$ & $\begin{array}{c}\text { Target } \\
\text { analytes }\end{array}$ \\
\hline 1993 & US5225679 & $\begin{array}{l}\text { Method and } \\
\text { apparatus for } \\
\text { determining } \\
\text { hydrocarbon fuel } \\
\text { properties }\end{array}$ & Yes & $\begin{array}{l}\text { Liquid fuel } \\
\text { tank }\end{array}$ & $\begin{array}{c}\text { MID } \\
4000 \text { to } 500 \mathrm{~cm}^{-1}\end{array}$ & $\begin{array}{l}\text { MTBE } \\
\text { Aromatic } \\
\text { Alcohols } \\
\text { Octane }\end{array}$ \\
\hline 1994 & US5349189 & $\begin{array}{c}\text { Process and } \\
\text { apparatus for } \\
\text { analysis of } \\
\text { hydrocarbons by } \\
\text { near IR spectroscopy }\end{array}$ & Yes & $\begin{array}{l}\text { Batch or } \\
\text { continuous } \\
\text { sample } \\
\text { feeding } \\
\text { arrangement } \\
\text { (Non } \\
\text { specified) }\end{array}$ & NIR & $\begin{array}{l}\text { Hydrocarbons } \\
\text { (PIANO) } \\
\text { components( } \\
\text { paraffin, } \\
\text { isoparaffin, } \\
\text { aromatics, } \\
\text { naphtenes } \\
\text { and olephins) }\end{array}$ \\
\hline 2000 & US6140647 & $\begin{array}{l}\text { Gasoline RFG } \\
\text { analysis by a } \\
\text { spectrometer }\end{array}$ & Yes & $\begin{array}{c}\text { Batches of } \\
\text { gasoline RFG } \\
\text { in different } \\
\text { blends }\end{array}$ & $\begin{array}{l}\text { NIR and RAMAN } \\
\text { (wavenumbers } \\
\text { span non } \\
\text { specified) }\end{array}$ & $\begin{array}{l}\mathrm{HC} \text { in liquid } \\
\text { gasoline and } \\
\text { exhaust } \\
\text { emissions }\end{array}$ \\
\hline 2008 & US7420170 & $\begin{array}{l}\text { FTIR Chemometric } \\
\text { method to } \\
\text { determine cetane } \\
\text { number of diesel } \\
\text { fuels containing }{ }^{(*)} \mathrm{FA} \\
\text { alkyl ester additives }\end{array}$ & Yes & $\begin{array}{l}\text { Batch set-up } \\
\text { for the diesel } \\
\text { sample in } \\
\text { study }\end{array}$ & $\begin{array}{c}\text { MID } \\
4900-3500 \mathrm{~cm}^{-1} \\
2200-1800 \mathrm{~cm}^{-1} \\
1700-1624 \mathrm{~cm}^{-1}\end{array}$ & $\begin{array}{c}\text { Cetane } \\
\text { number of } \\
{ }^{(* *)} \text { RMES } \\
\text { diesel fuel oil }\end{array}$ \\
\hline
\end{tabular}

$(*)$ Fatty acid, $(* *)$ Rapeseed methyl ester

Limited details of sample presentation are provided in the most recent patent documents, in which only block diagrams are shown, while patent in 1993 (Figure 4) specifies that the sample should flow through a sample cell immersed in the storage tank, and the signal transmitted by an optical fiber to the processor. 


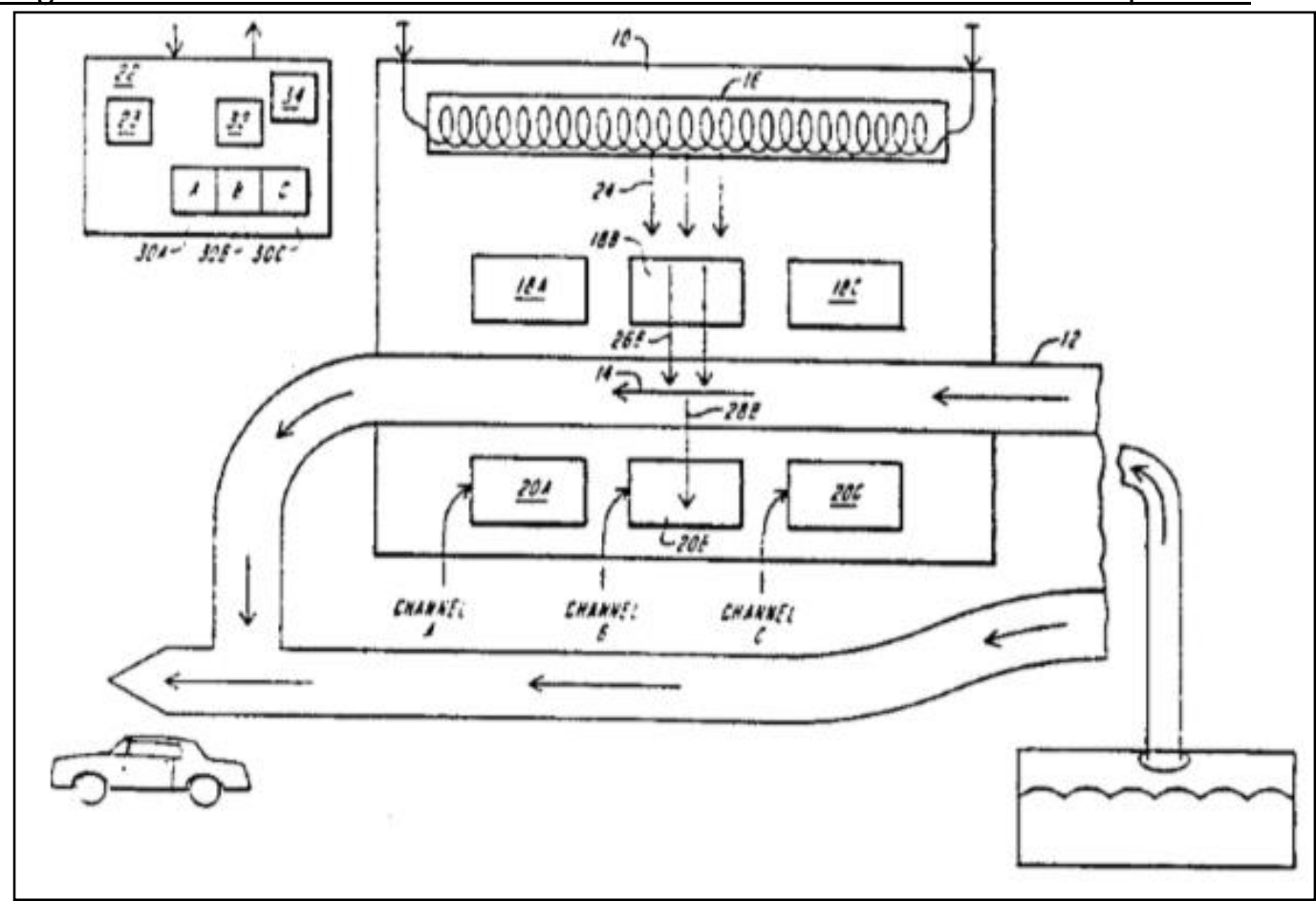

Figure 4.Schematic drawing of the experimental device corresponding to the patented invention for measuring hydrocarbon fuel properties, which was released in 1993 for liquid fuels applications.

Details such as the vehicle and the fuel tank are specified. Same occurs with the piping and heating that are clearly specified as their way to the final processor.

\section{Gas measurements}

The sample flow cell features constitutes the specificity of patents related to gaseous sample determination (inventions patented from 2002 to 2016), in either of the cases, samples are fully gaseous: exhaust gas plumes or heated sample. As a consequence, the need of controlling temperature and pressure is mandatory in these cases as it affects the volatile compounds concentration. Table 6 below summarizes for gaseous fuel applications which in all cases includes MID range, in two of the cases in combination with other spectral ranges (NIR or UV). FTIR-based devices (spectra scanned by moving mirrors) are not used for gaseous samples since notorious fluctuations are shown on the spectral peaks at measuring volatile or gas flows. 
Table 6.Screening of some patented devices from 2002 to 2016 for applications in volatile compounds and exhaust gases from fuels.

\begin{tabular}{|c|c|c|c|c|c|c|}
\hline & \multicolumn{6}{|c|}{ GAS } \\
\hline Year & Patent ID & Title & $\begin{array}{c}\text { Calibrati } \\
\text { on }\end{array}$ & $\begin{array}{l}\text { Measuring } \\
\text { site }\end{array}$ & $\begin{array}{c}\text { Spectrum and } \\
\text { wavelength } \\
\text { span }\end{array}$ & Target analytes \\
\hline 2002 & US6455851 & $\begin{array}{l}\text { Spectroscopic } \\
\text { remote sensing } \\
\text { exhaust } \\
\text { emission } \\
\text { monitoring } \\
\text { system }\end{array}$ & $\begin{array}{c}\text { Non } \\
\text { specified }\end{array}$ & $\begin{array}{l}\text { Exhaust } \\
\text { emissions } \\
\text { from plume } \\
\text { of in-use } \\
\text { vehicles }\end{array}$ & $\begin{array}{l}\text { MID IR and UV } \\
\text { Vis } \\
\text { (wavenumbers } \\
\text { span non } \\
\text { specified) }\end{array}$ & $\begin{array}{l}\mathrm{CO}, \mathrm{CO}_{2}, \mathrm{HC}, \mathrm{NO} \text {, } \\
\mathrm{N}_{2} \mathrm{O}, \mathrm{C}_{2} \mathrm{H}_{2}, \mathrm{NH}_{3} \text { and } \\
\mathrm{SO}_{2}, \text { aromatic } \\
\text { hydrocarbons, } \\
\text { aldehydes and some } \\
\text { others }\end{array}$ \\
\hline 2006 & $\begin{array}{c}\text { US2006019 } \\
2122\end{array}$ & $\begin{array}{l}\text { Apparatus and } \\
\text { method for } \\
\text { measuring fuel } \\
\text { dilution of } \\
\text { lubricant }\end{array}$ & $\begin{array}{c}\text { Non } \\
\text { specified }\end{array}$ & $\begin{array}{l}\text { Fuel } \\
\text { dilution in } \\
\text { petroleum } \\
\text { product }\end{array}$ & $\begin{array}{c}\text { MID IR } \\
2800-3200 \mathrm{~cm}_{1}^{-}\end{array}$ & $\begin{array}{l}\text { Volatile } \\
\text { hydrocarbons in } \\
\text { diesel oil to detect } \\
\text { adulteration with } \\
\text { gasoline }\end{array}$ \\
\hline 2016 & US9291610 & $\begin{array}{l}\text { Method and } \\
\text { apparatus for } \\
\text { real-time } \\
\text { measurement of } \\
\text { fuel gas } \\
\text { compositions } \\
\text { and heating } \\
\text { values }\end{array}$ & Yes & $\begin{array}{l}\text { Fuel gas } \\
\text { mixtures }\end{array}$ & $\begin{array}{l}\text { 11111-5882 } \\
\mathrm{cm}^{-1} \text { (NIR) } \\
\text { Up to } 667 \mathrm{~cm}^{-1} \\
\text { (MID IR) }\end{array}$ & $\begin{array}{l}\text { Hydrocarbons and } \\
\text { carbon dioxide }\end{array}$ \\
\hline
\end{tabular}




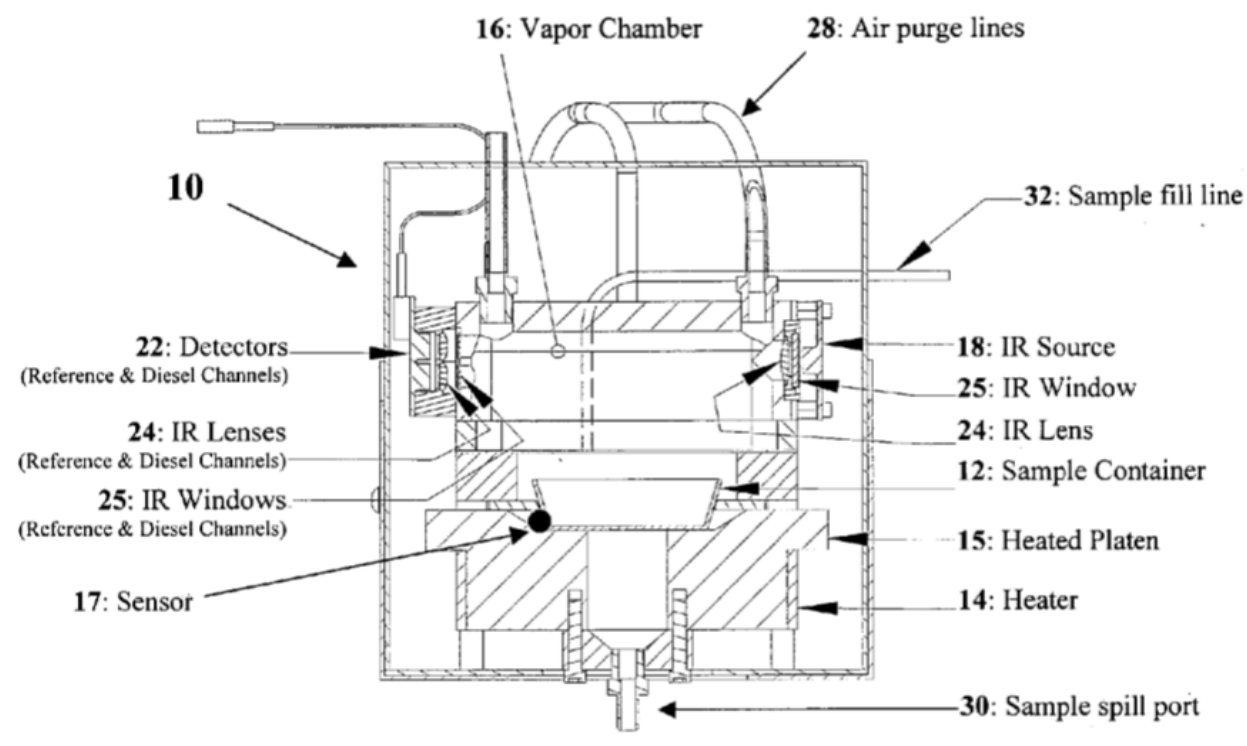

Figure 5. Detailed drawing of the invention patented by Yu-Min Chen et al., 2006

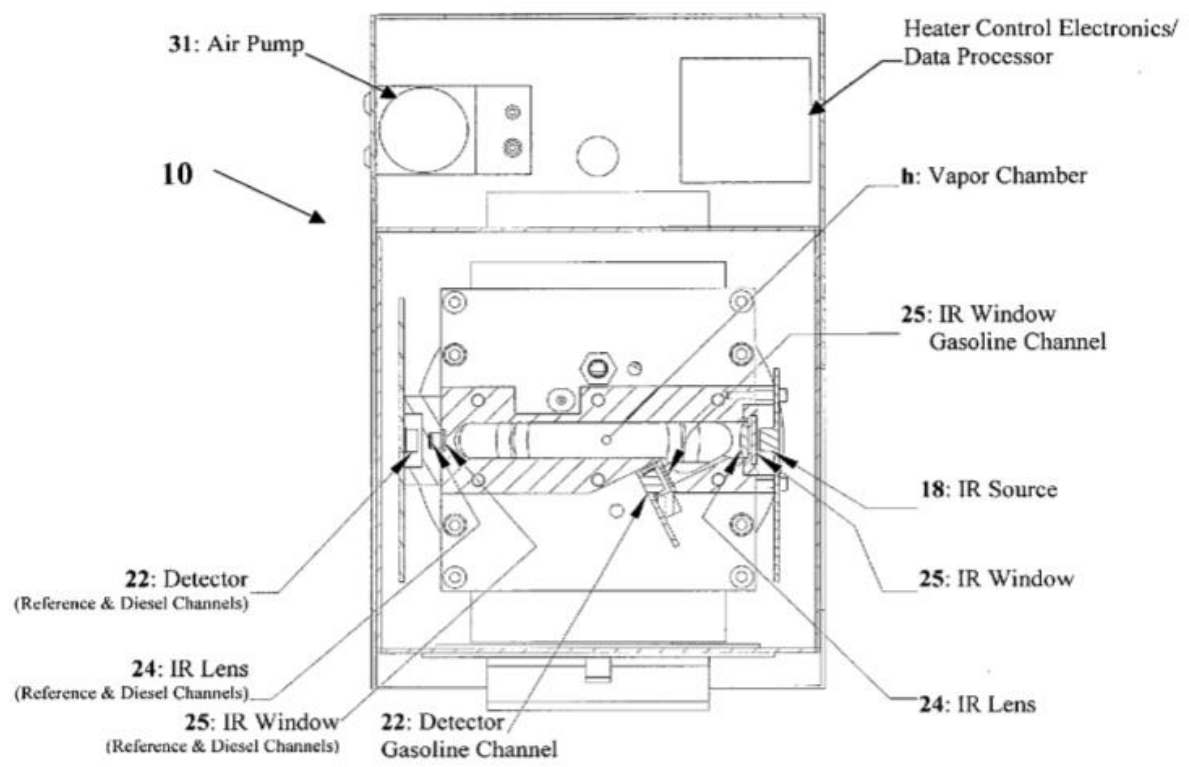

Figure 6. Plant view drawing of the invention patented by Yu-Min Chen et al., 2006

Numerals correspond to each component of the apparatus described by the drawing of its front and plant section sights. 


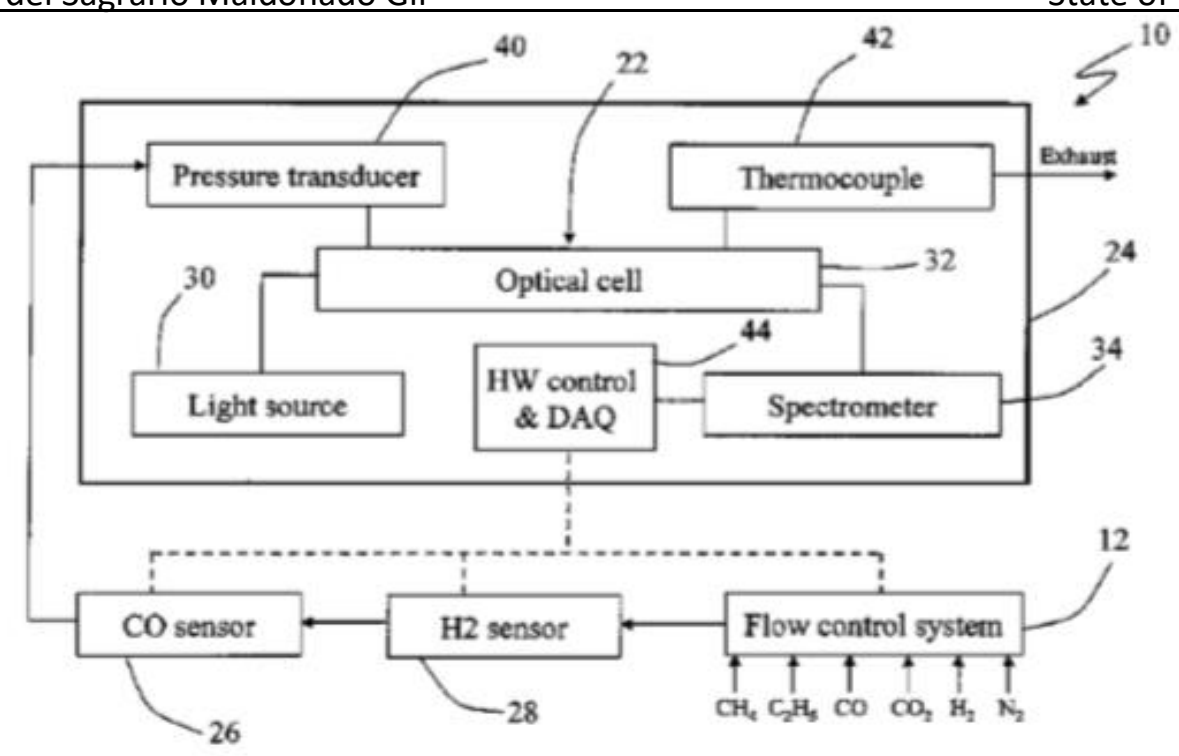

Figure 7. Schematic drawing of the invention patented by Zelepouga et al., 2016

In this case a block diagram was used to describe the structure and layout of the apparatus, pointing out each of the types of sensors and control systems.

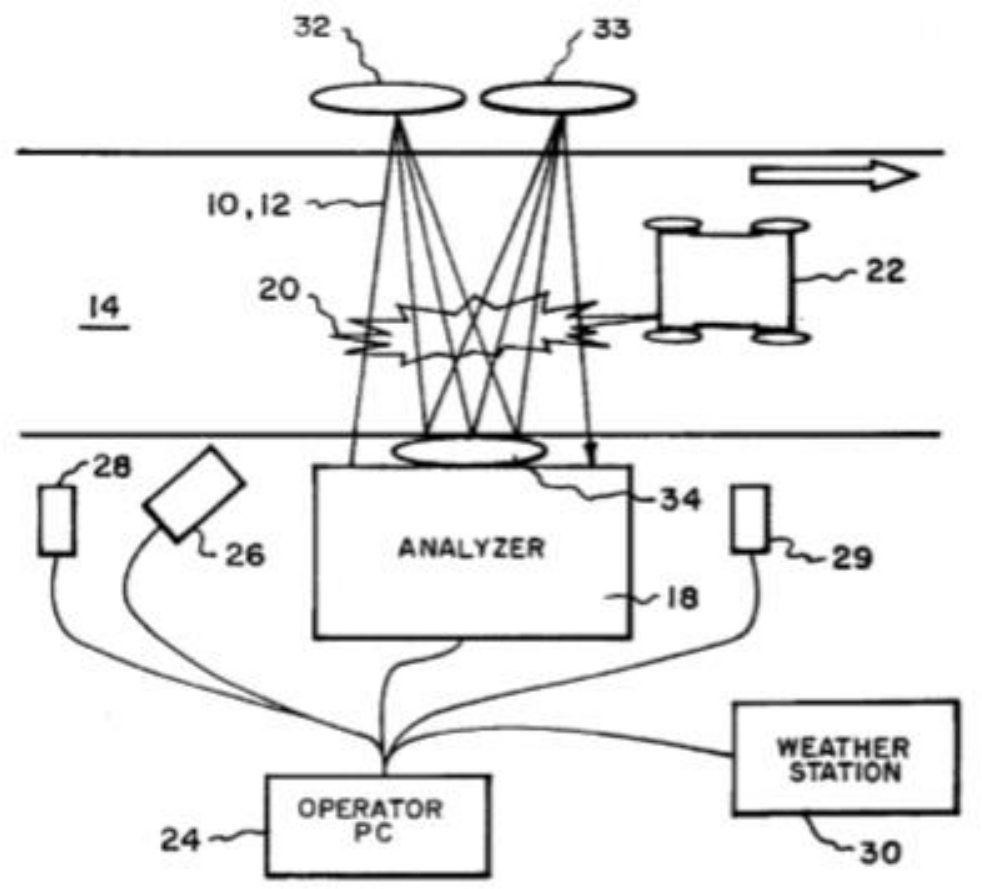

Figure 8. Schematic diagram of the remote sensor for exhaust emission monitoring patented by Lord et al., 2002

Figure 5 and Figure 6 describe the invention patented by (Chen and Asher 2006) for measuring fuel dilution in petroleum product by spectroscopic analysis. It consists on an 
apparatus and method for spectral analysis, more specifically for detecting and quantifying the fuel dilution, a parameter that is an indicator of possible adulterations in the product. For such purpose, the apparatus consists on a sample reservoir for receiving a liquid sample, a heather to vaporize it, a vapor collector and a spectrometer for analyzing the collected vapors. The numerals from 1 to 30 refer to each part from the device. It is the case of a quite specific design, as the authors explain in deep detail how each component works by means of drawings of each section sight from the front, or transversal. Also a contrast is appreciated with regards to the schematic block diagram from the patent by (Zelepouga 2016) showed in the Figure 7 to measure the gas composition by using three different sensors, a NIR sensor, a MID Infrared and a semiconductor sensor is shown. The invention provides an apparatus and method for in situ and real time measurement of the composition and heating value of fuel gas mixtures, reducing the cross sensitivities to other gases than the target ones. It consists on a NIR sensor for measuring hydrocarbons and $\mathrm{CO}_{2}$, a MID IR sensor to measure $\mathrm{CO}$ and a semiconductor sensor to measure $\mathrm{H}_{2}$.

Figure 8 is extracted from the invention patented in 2002 by Lord et al. to measure the exhaust plume gases emitted by vehicles. This invention consists in a remote gas sensor based in IR and UV absorption spectroscopy to construct a remote exhaust emission monitoring system for multiple components such as $\mathrm{CO}, \mathrm{CO}_{2}, \mathrm{HC}, \mathrm{NO}, \mathrm{N}_{2} \mathrm{O}, \mathrm{C}_{2} \mathrm{H}_{2}, \mathrm{SO}_{2}$, dust and others. These chemicals can be measured either in real time or by post-processing of the acquired spectra. Reflecting mirrors are used in this instance in order to make the sources beams traverse the flow cell a plurality of times. These beams are not coaxial, so they do not require any optical device to split them. The detectors used may either be dispersive linear arrays or Fourier Transform type. In this case also numerals are used to describe each part of the device in a schematic drawing showing the main components of the device. 


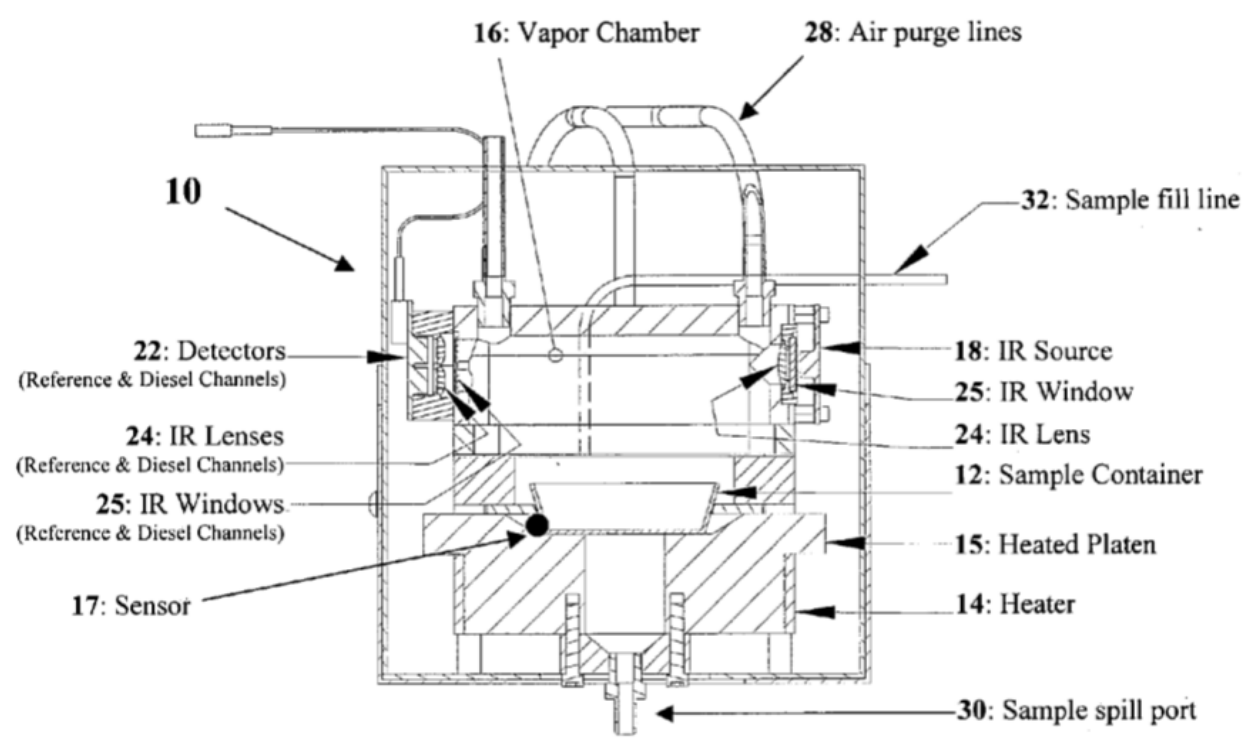

Figure 5. Detailed drawing of the invention patented by Yu-Min Chen et al., 2006

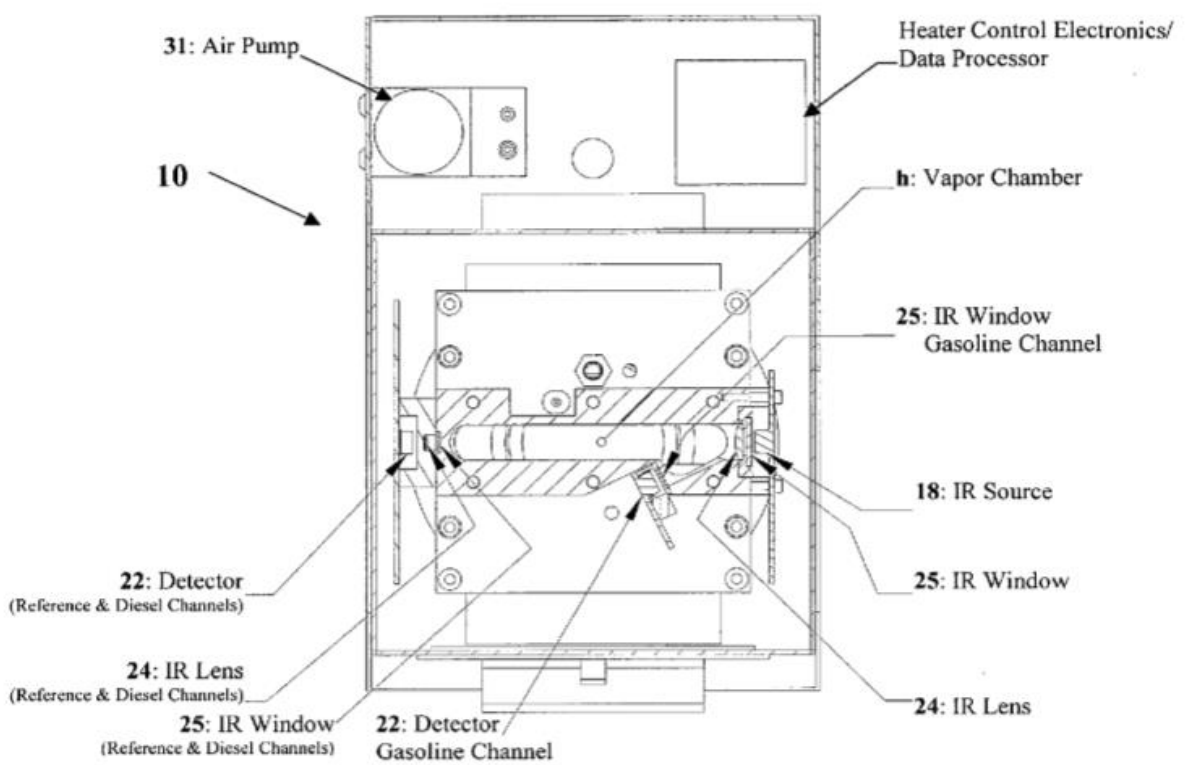

Figure 6. Plant view drawing of the invention patented by Yu-Min Chen et al., 2006

Numerals correspond to each component of the apparatus described by the drawing of its front and plant section sights. 


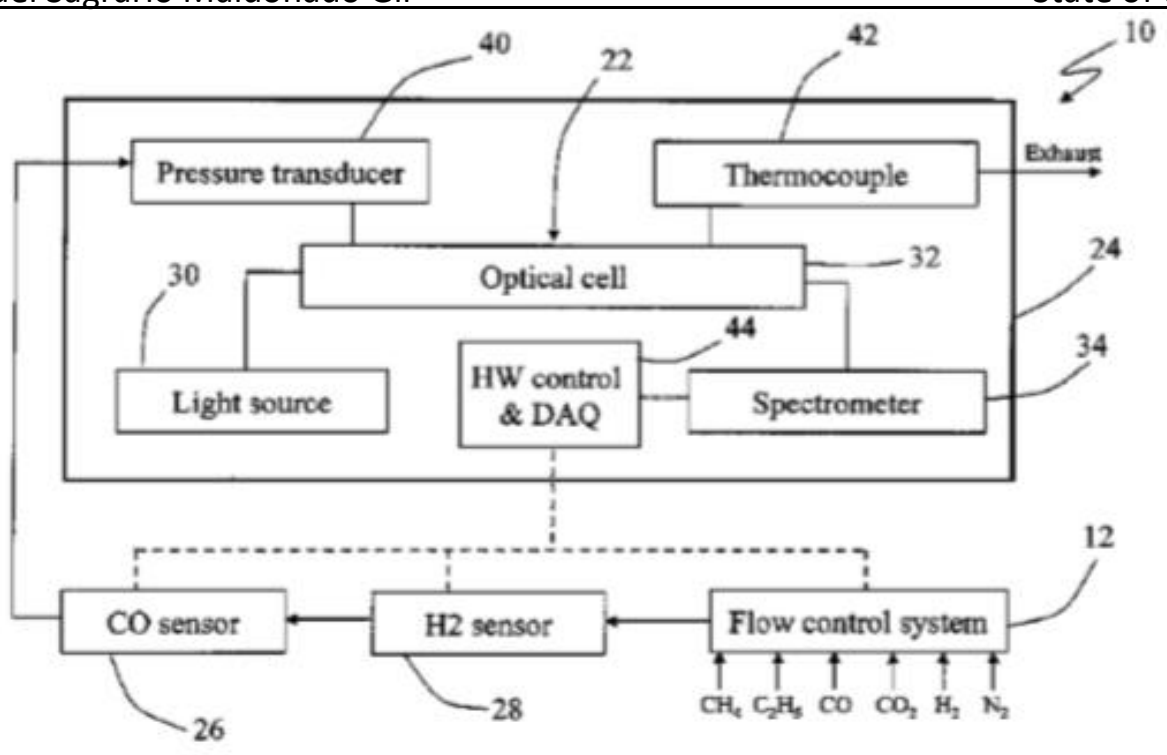

Figure 7. Schematic drawing of the invention patented by Zelepouga et al., 2016

In this case a block diagram was used to describe the structure and layout of the apparatus, pointing out each of the types of sensors and control systems.

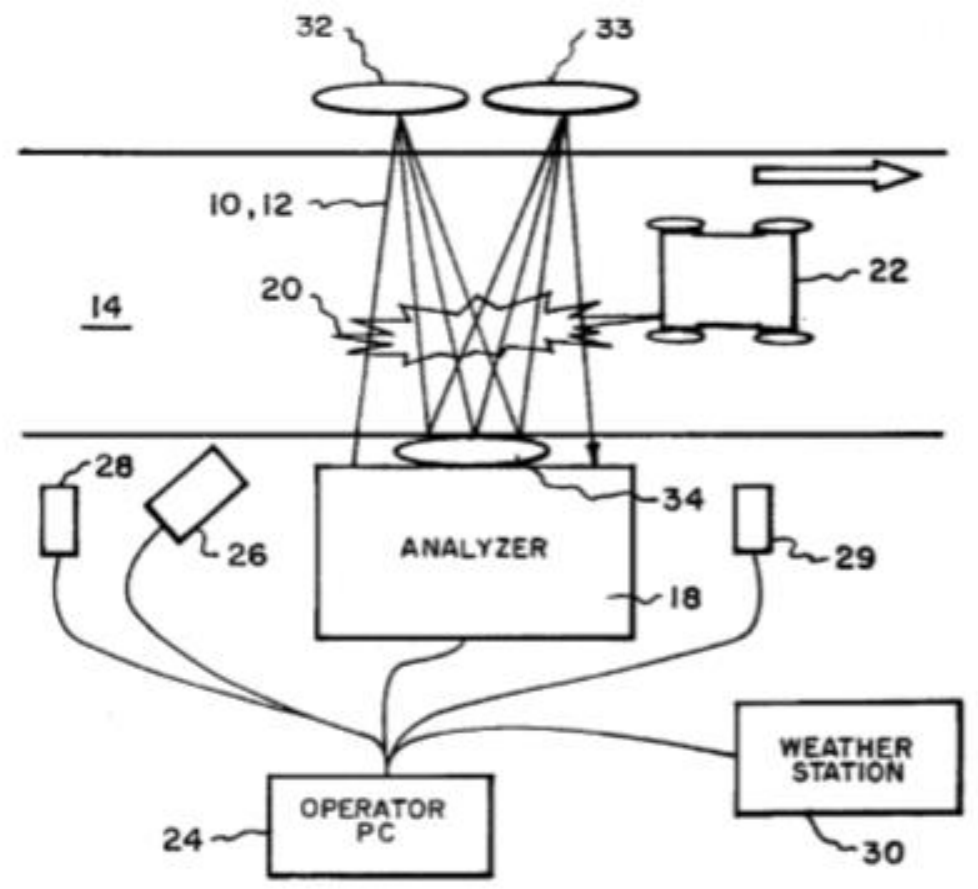

Figure 8. Schematic diagram of the remote sensor for exhaust emission monitoring patented by Lord et al., 2002

All these drawings showed in the figure 4 above have in common that they focus on the sources, lens and detectors, as on their role and position in the global set up design. 


\subsubsection{Detector principle}

The spectrometers to be used at the inventions mentioned and discussed above are either be rapid scanning dispersive or non dispersive devices.

They can employ linear or two dimensional detector arrays or Fourier transform IR or RAMAN spectrometers, (Wellch and Bledsoe 2000).

In several inventions from the ones discussed in this section, the spectrometer is not only formed by the source light and the detector, it also uses optical devices to collimate light beams, reflecting mirrors or interferometers being able to detect a plurality of chemical compounds either in liquid or gas phase. In some patented inventions, the different IR and UV Vis beams are combined to be made coaxial using beam splitters and reflecting mirrors (Lord 2002).

The method and apparatus patented by (Zelepouga 2016) also comprises a semiconductorbased sensor, in addition to the NIR and MID IR sensors used to measure the gas composition in the fuel.

As it can be deduced from the patents discussed above, all these inventions are described and claimed in a way that it is understood that the sensor nature is flexible as long as it can be implemented in the experimental set up and the measures can be taken in the specified way (either continuous or batch, liquid or gas state, and so on).

\subsubsection{Spectral curves}

The invention patented in 1994 (Maggard 1994), provides the qualitative content of some hydrocarbons such as paraffin, isoparaffin, aromatic, naphtenes and olefins (which is called PIANO) and octane applied to quality control of fuel. This method is based on a selection of key wavelengths from the NIR spectrum in where these hydrocarbons absorb. Figure 9 and Figure 10 show two examples from this invention of spectral curves in their second derivative, corresponding to different hydrocarbons spectra superimposed on the rest of the PIANO components spectra at different wavelengths ranges from the NIR. 


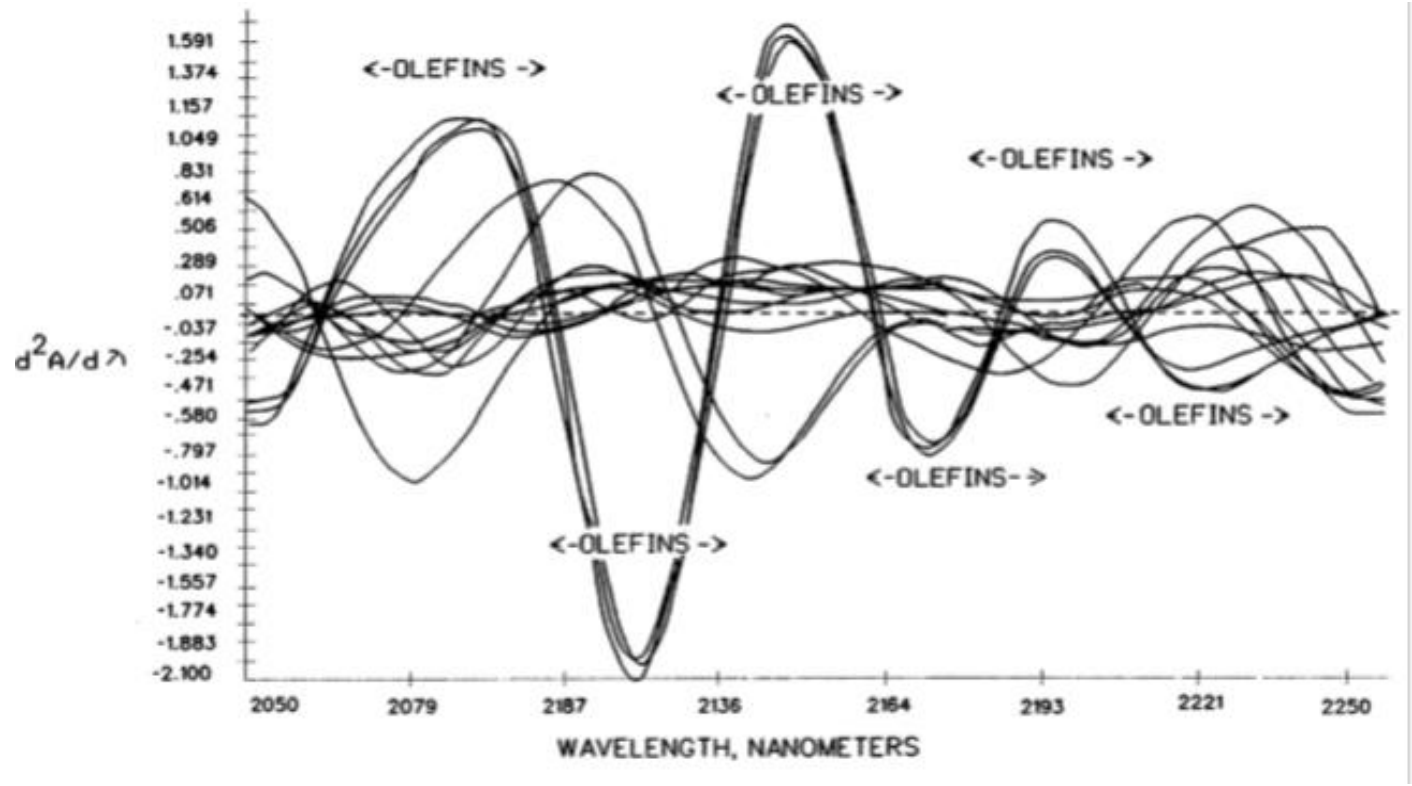

Figure 9.Plot of the second derivative of absorbance versus wavelengths for olefins superimposed on other PIANO constituents from 2050 to 2250 nm (4878-4445 cm-1).

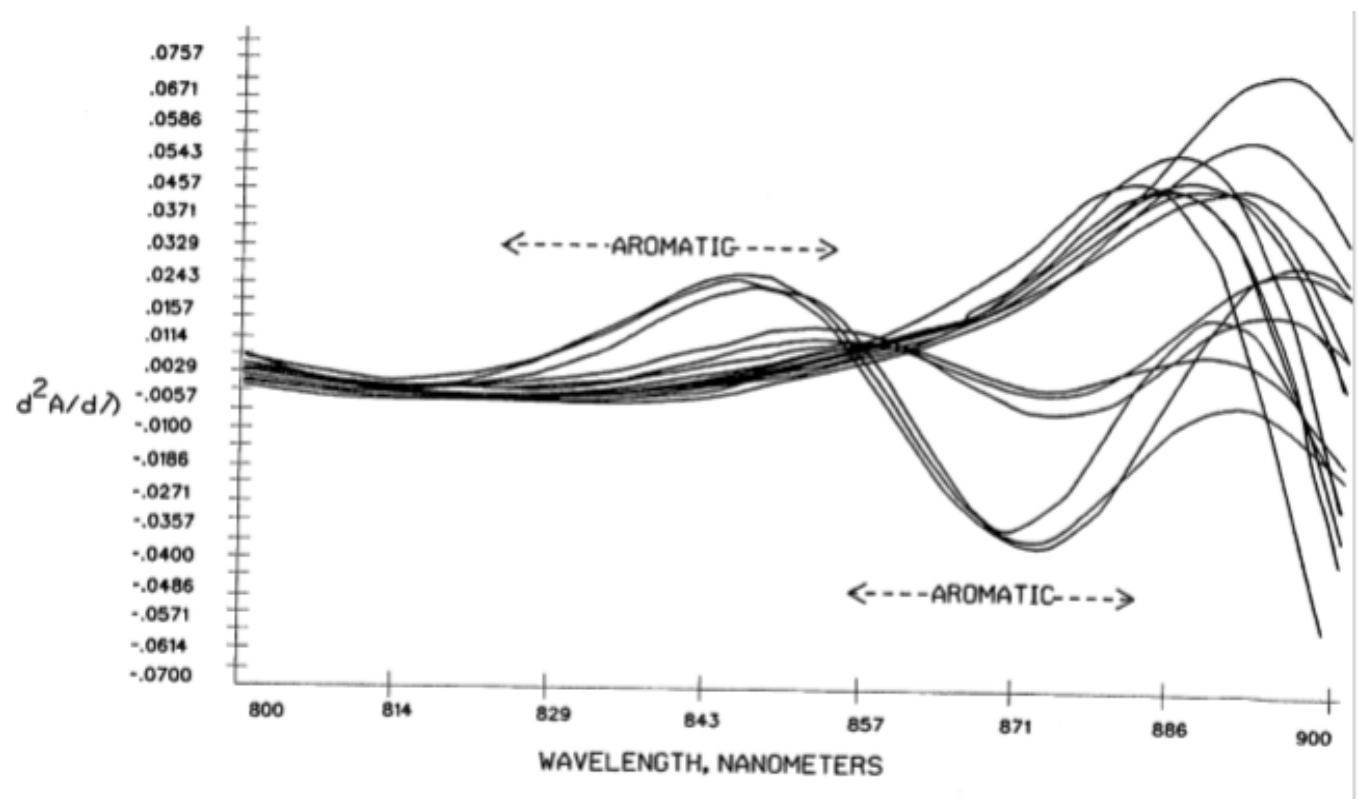

Figure 10.Second derivative of NIR spectra plot showing aromatics superimposed on other PIANO constituents from 800 to $900 \mathrm{~nm}$.

The MID IR applied to fuel quality control in liquid phase (patent ID US5225679, 1993) working in the wavelength range between 4000 and $500 \mathrm{~cm}^{-1}$ (20-2.5 microns) provides the absorption spectra from two different octane rate gasolines (Figure 11), focusing on the effects of different octane enhancers additives such as aromatics, MTBE and alcohols. 


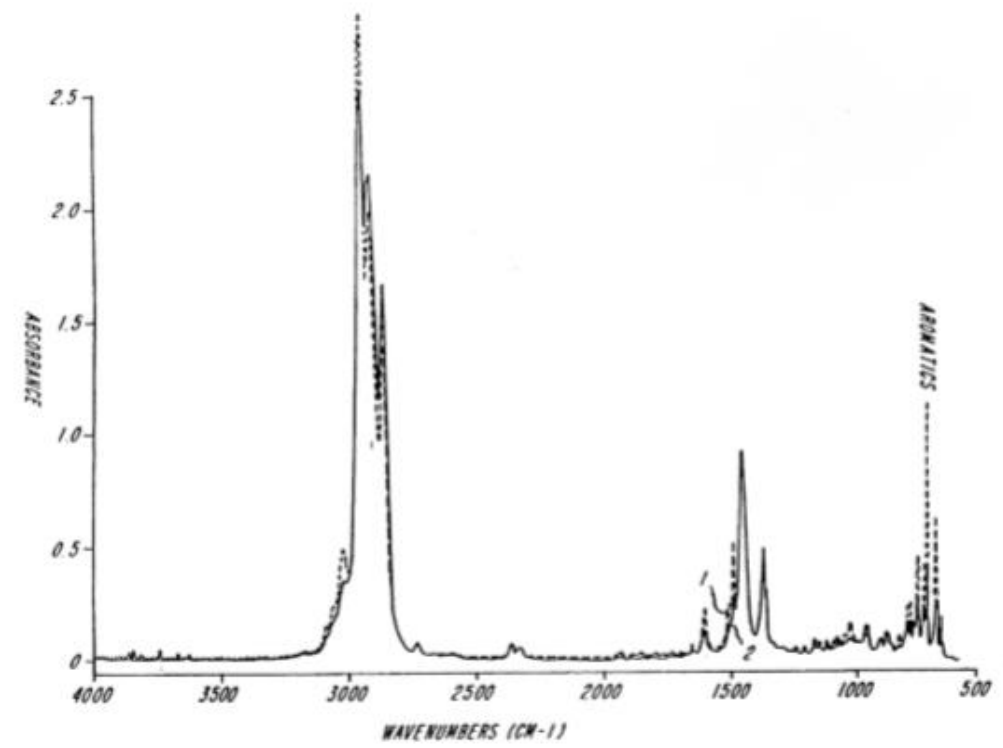

Figure 11.Graphical comparison of absorbance (in arbitrary units) exhibited by fuel enhancers in two gasolines, one at 92.8 octane (dotted line trace) having aromatic octane enhancers, and one at 87.1 octane (solid line trace) without aromatics (Clarke 1993)

Both Figure 11 and Figure 12 are illuminated in the MID IR range of about 4000 to $500 \mathrm{~cm}^{-1}$, in the practice of the invention.

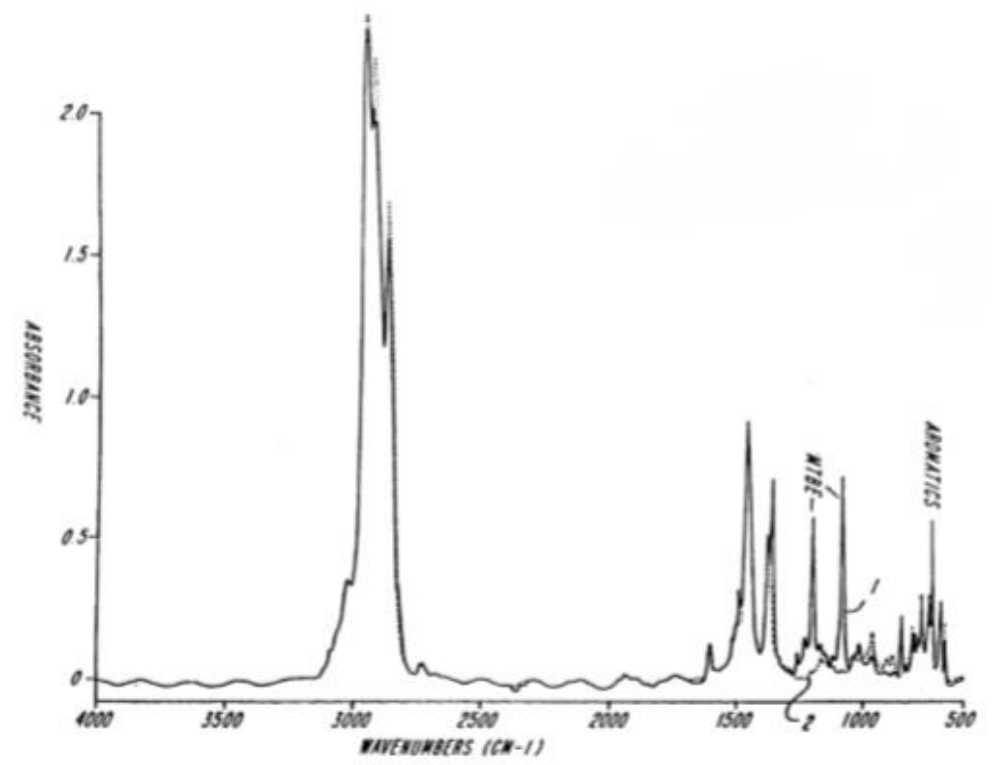

Figure 12.Graphical comparison of absorbance (in arbitrary units) exhibited by fuel enhancers in two gasolines, one at 94 octane (solid line trace) having MTBE and aromatic octane enhancers, and one at 86 octane (dotted line trace) without MTBE (Clarke 1993). 


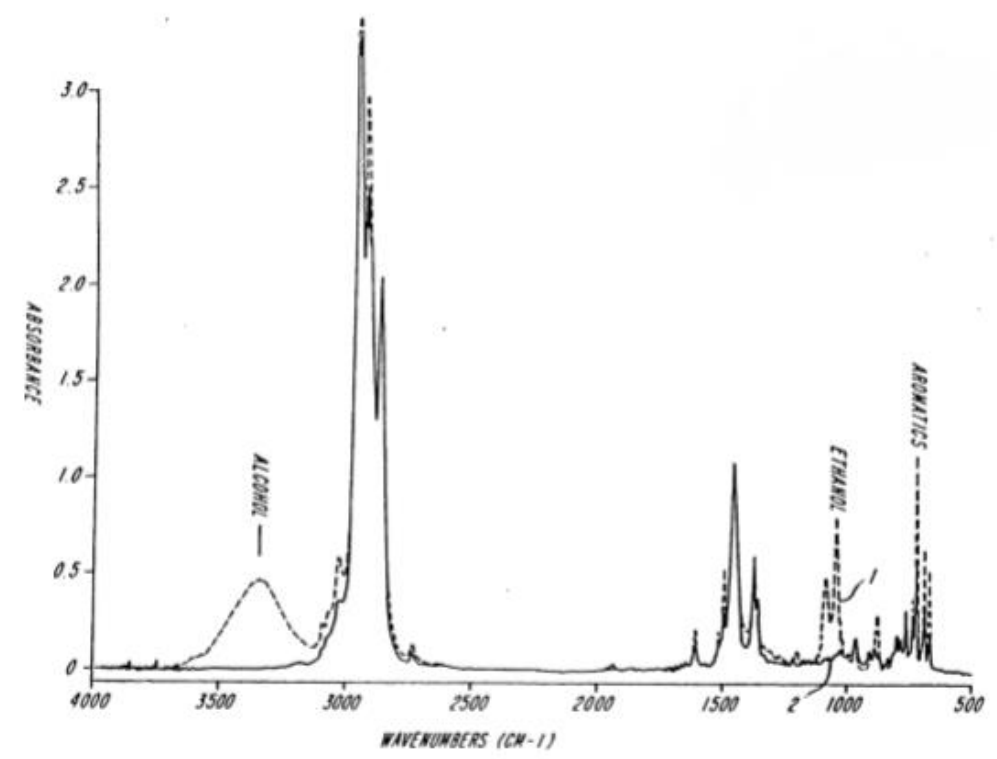

Figure 13.Comparison of absorbance exhibited by the components of two gasolines, one at $\mathbf{9 1 . 2}$ octane (curve 1) and one at 87.3 octane (curve 2).

The 91.2 octane fuel uses alcohol (including ethanol) and aromatics as octane enhancers. The 87.3 octane fuel lacks the alcohol fuel enhancers. As shown, a vibrational mode signature for alcohols is at about $3300 \mathrm{~cm}^{-1}$ (3.0 microns), and therefore a detector limited to a narrow spectrum at about $3300 \mathrm{~cm}^{-1}$ can detect variations in light intensity attributed to absorption caused by the vibrations associated with MID-IR excited alcohols. As well, ethanol has a unique signature at $1100 \mathrm{~cm}^{-1}$ (9.1 microns). 


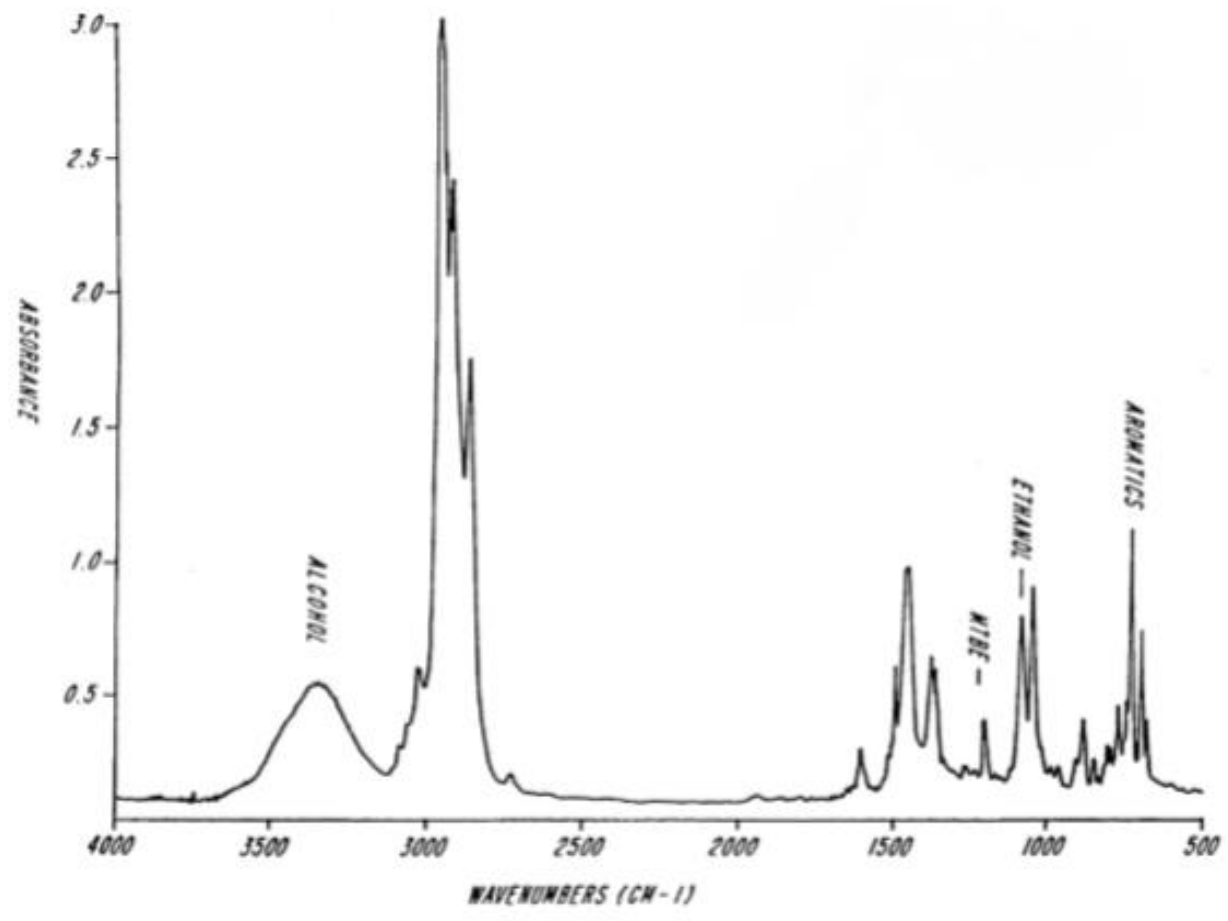

Figure 14.Graphical representation of absorbance exhibited by a gasoline formulated with a blend of MTBE, aromatic, alcohol (including ethanol) octane enhancers, detected according to the invention.

The peak at $1200 \mathrm{~cm}^{-1}$ (8.33 microns) indicates MTBE quantity, the peaks at $500-800 \mathrm{~cm}^{-1}$ indicate aromatic quantity, the peak at $3300 \mathrm{~cm}^{-1}$ indicates alcohol quantity, and the peak at $1100 \mathrm{~cm}^{-1}$ indicates ethanol. In practice of the invention, the fuel in this figure was accurately predicted to have an octane rating of 93.6.

Figure 15, Figure 16, Figure 17 and Figure 18 below were extracted from the patented invention in 2002 (Lord 2002), where two spectrometers based on MID IR and UV Vis respectively, are combined to measure air pollutants from the vehicle exhaust plumes. These figures show the MID IR and UV spectra from ambient air and from vehicle exhaust emissions respectively, with the aim of doing a comparison of both spectra and so identifying the main pollutants that are present in the exhaust gases. The spectra measured by this device are showed and explained in the figures below: 


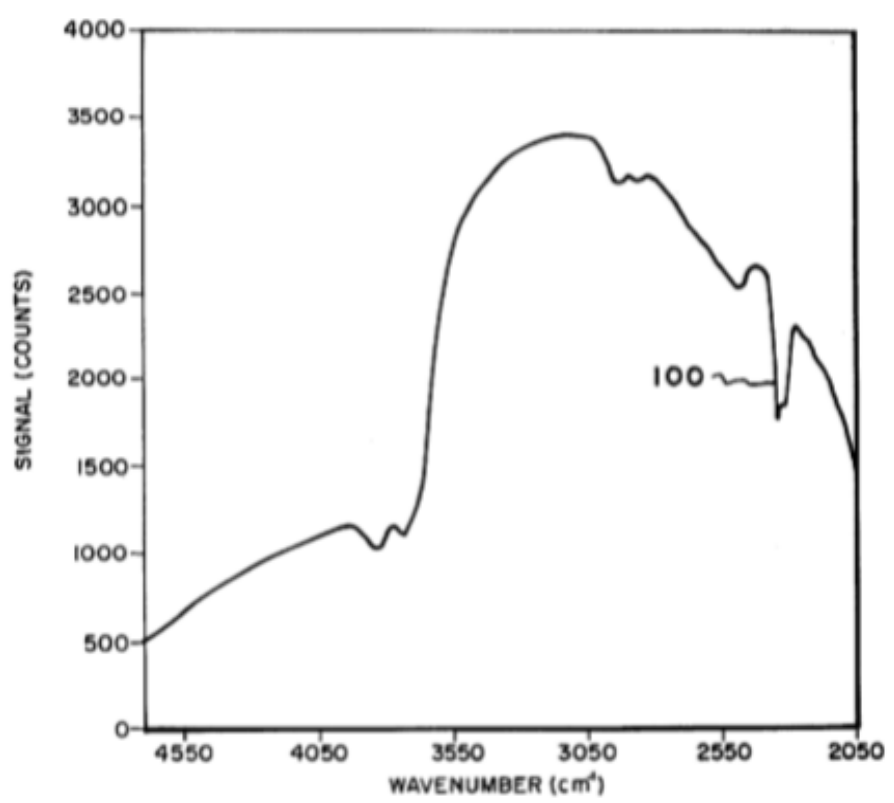

Figure 15.MID IR spectrum of ambient air, the number 100 encodes the $\mathrm{CO} 2$ absorption peak at about $2550 \mathrm{~cm}^{-1}$ (3.9-4.0 microns approximately) in this region.

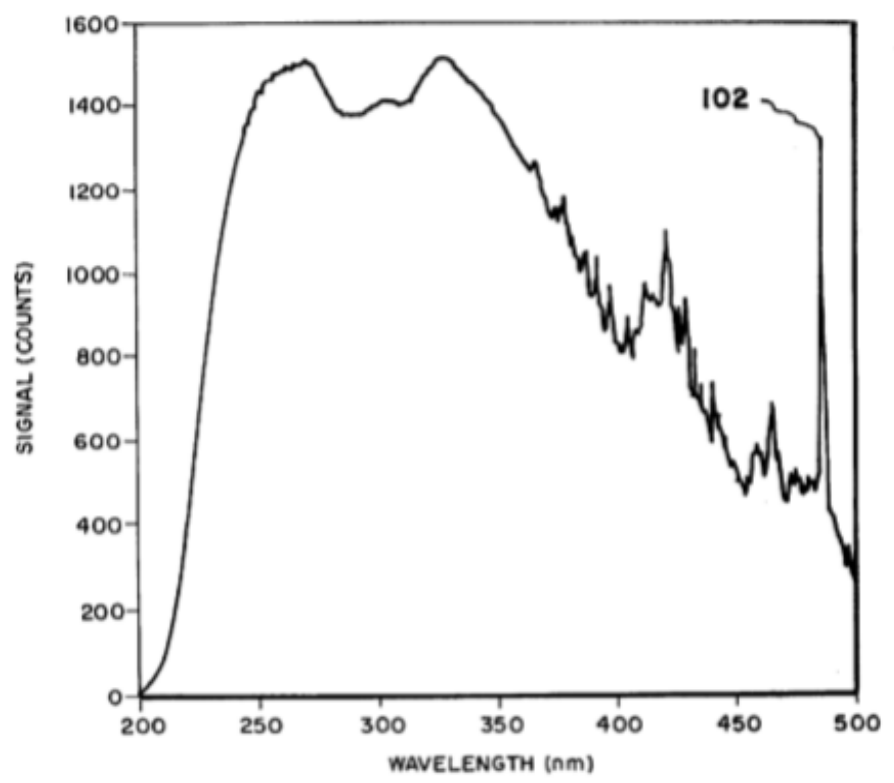

Figure 16.UV VIS spectrum of ambient air. The number 102 encodes the deuterium emission peak of the lamp used. 


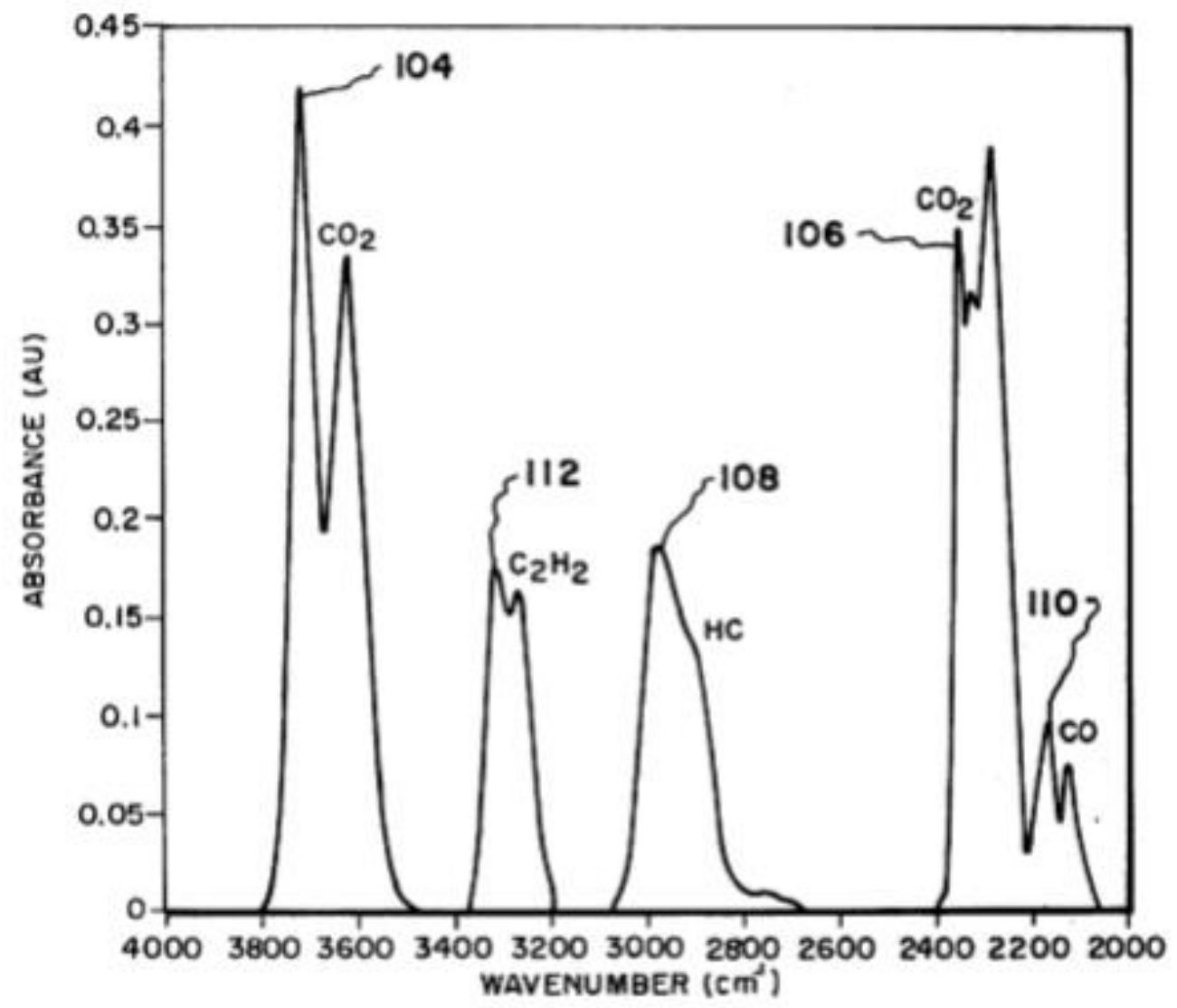

Figure 17. MID IR spectrum of the pollutants from the vehicle exhaust emissions measured by the apparatus in the invention described above (Lord 2002).

104 and 106 numbers encode the two spectral bands corresponding to $\mathrm{CO}_{2}$ absorption peaks around $3800-3500 \mathrm{~cm}^{-1}$ (2.6-2.8 microns) and $2400-2200 \mathrm{~cm}^{-1}$ (4.2-4.5 microns), whilst 108 encodes HC such as propane absorption peaks around 3100-2700 cm-1(3.2-3.7 microns), 110 corresponds to the peak from CO at around 2200 and $2100 \mathrm{~cm}^{-1}$ (4.5-4.7 microns) and 112 , by last, 112 corresponds to the acetylene $\left(\mathrm{C}_{2} \mathrm{H}_{2}\right)$ absorption peak at 3400 $3200 \mathrm{~cm}^{-1}(2.9-3.1$ microns). 


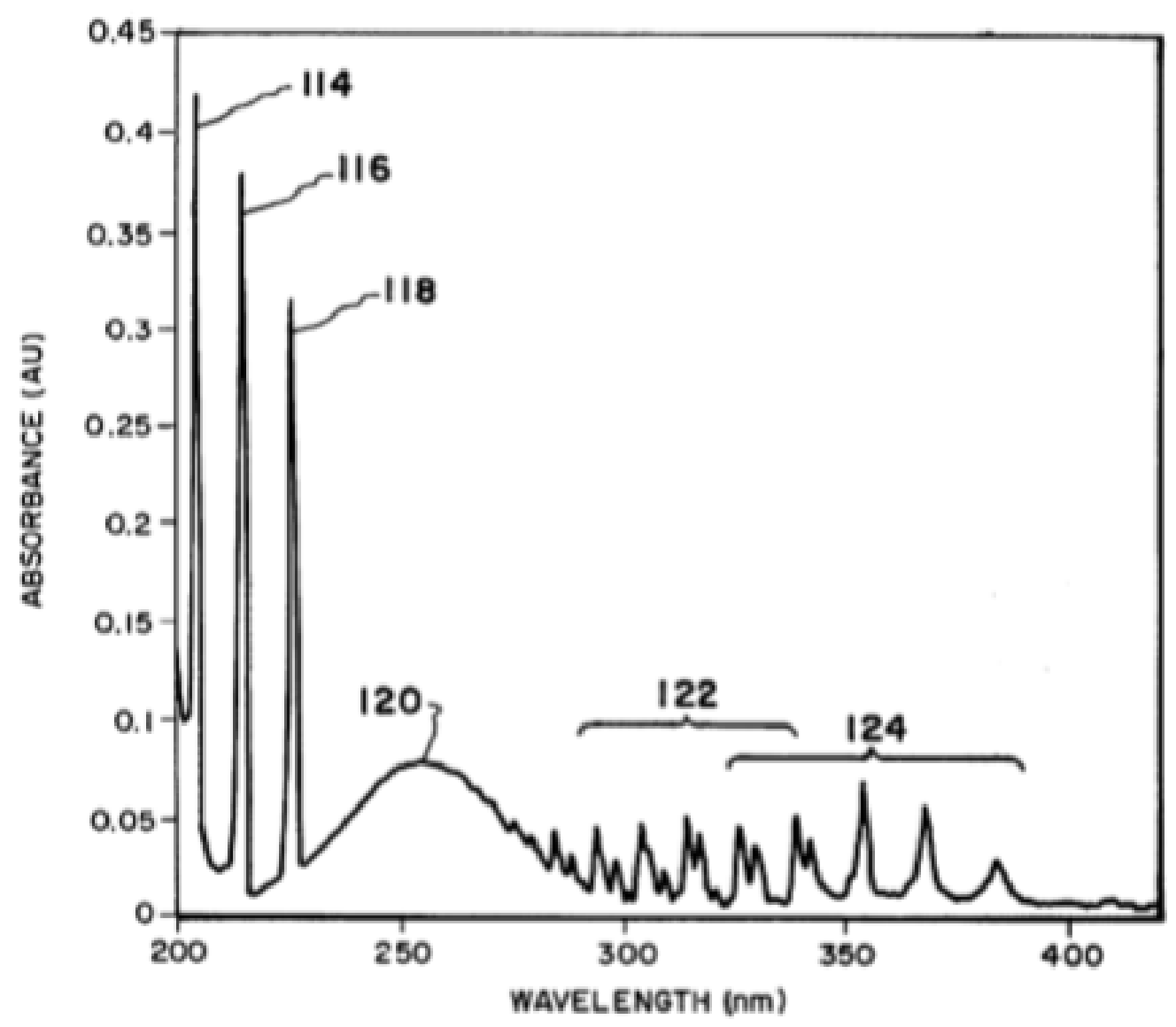

Figure 18.UV Vis absorption bands of pollutants in vehicle exhaust emissions.

Bands 114, 116 and 118 correspond to NO three absorption peaks around approximately 200-240 nanometers $\left(50000-42000 \mathrm{~cm}^{-1}\right)$, the broadened peak at $250 \mathrm{~nm}\left(40000 \mathrm{~cm}^{-1}\right)$ whose encoding number is 120 corresponds to the ozone $\left(\mathrm{O}_{3}\right)$ that is not directly emitted by the vehicle but later formed by photochemistry, and the bands 122 and 124 correspond to formaldehyde ( $\mathrm{HCHO}$ ) and nitrous acid ( $\mathrm{HONO}$ ) absorbing in a wavelength span of around $300-350 \mathrm{~nm}\left(33300-28570 \mathrm{~cm}^{-1}\right)$ and $235-400 \mathrm{~nm}\left(42550-25000 \mathrm{~cm}^{-1}\right)$ respectively.

\subsubsection{Mathematical methods used at data analysis}

When working with IR absorption spectroscopic devices, the absorbance signal from the measurement of each chemical compound, used either solely or in conjunction with other bands, will preferably be mathematically processed to mostly provide derived signals which are indicative of the concentrations (or properties) being measured (Oliveri, et al. 2019).

Preferred techniques for mathematical signal pre-processing are absorbance base-line offset corrected absorbance data; first, second, third, fourth or higher derivative of the 
absorbance spectrum; rating the absorbance at one wavelength by another; spectral subtraction; and various combinations of these mathematical techniques.

Also valuable are the well known curve-fitting techniques of Savitzky-Golay and KubelkaMunk, and N-point smoothing (signal averaging).

For the statistical data treatment (once pre-processed) are also possible such as partial least squares (PLS), Gauss-Jordan Row reduction, etc. (Alasadi and Baya 2017).

Here below is shown a table (Table 7) that compiles each patented invention and its corresponding processing mathematical method applied on the acquired signal. As it can be inferred from the Table 7 above, the pre processing methods have a great importance in all these techniques as a complimentary tool, removing the noise and extracting the most information from the spectra. The same happens with the optimal selection of wavelengths and the database availability in order to identify the analytes of interest. 
Table 7.Compilation of the mathematical methods used by each of the inventors applied to the patented inventions.

\begin{tabular}{|c|c|c|}
\hline Patent ID & $\begin{array}{c}\text { Fuel } \\
\text { phase }\end{array}$ & Mathematical method \\
\hline $\begin{array}{l}\text { US005225679A } \\
1993\end{array}$ & Liquid & $\begin{array}{l}\text { Linear correlation of absorption data with volume percent of fuel } \\
\text { component in solution and octane rating }\end{array}$ \\
\hline $\begin{array}{l}\text { US00534.9189A } \\
1994\end{array}$ & Liquid & $\begin{array}{l}\text { Key wavelengths selection for chemicals identification } \\
\text {-Second derivative at different absorption wavelengths } \\
\text {-Multiple linear regression to model the individual component } \\
\text { concentrations } \\
\text {-Weighting constants (from Gauss-Jordan algorithm) }\end{array}$ \\
\hline $\begin{array}{l}\text { USOO6140647A } \\
2000\end{array}$ & Liquid & $\begin{array}{l}\text {-First, second or higher derivatives as pre processing method } \\
\text {-Partial Least Squares (PLS), Multivariate Linear Regression (MLR) } \\
\text { and Principal Components Regression (PCR) } \\
\text {-Neural Networks } \\
\text {-Prediction models that correlate the observed spectral data with the } \\
\text { predicted emissions }\end{array}$ \\
\hline $\begin{array}{l}\text { USOO7420170B2 } \\
2008\end{array}$ & Liquid & $\begin{array}{l}\text {-Training set with } 241 \text { samples } \\
\text {-Two spectral regions used for the Multivariate-based MID IR FTIR } \\
\text { model }\left(4900-3500 \mathrm{~cm}^{-1} \text { and } 2200-1624 \mathrm{~cm}^{-1}\right)\end{array}$ \\
\hline $\begin{array}{l}\text { USOO6455.851B1 } \\
2002\end{array}$ & Gas & $\begin{array}{l}\text {-Fourier Transform into absorbance spectra } \\
\text {-Pattern recognition algorithms and spectral reference database to } \\
\text { identify chemicals } \\
\text {-Lambert Beer law for linear correlation between absorbance and } \\
\text { concentration } \\
\text {-Absorbance spectrum linearly or higher order polynomials fitting } \\
\text { baselined over the absorption band of the analyte being measured. } \\
\text {-Pattern recognition algorithm applied to spectral data using a } \\
\text { reference analyte spectrum as a blank }\end{array}$ \\
\hline $\begin{array}{l}\text { US20060192122A1 } \\
2006\end{array}$ & Gas & $\begin{array}{l}\text { Linear correlation of intensity with analyte concentration } \\
\text { (Lambert Beer law) }\end{array}$ \\
\hline $\begin{array}{l}\text { EP2944944A1 } \\
2015\end{array}$ & Gas & Wavelength modulation spectroscopy \\
\hline $\begin{array}{l}\text { US009291610B2 } \\
2016\end{array}$ & Gas & $\begin{array}{l}\text {-Mean centering and statistical scaling or normalization as pre } \\
\text { processing methods } \\
\text {-Principal Components Regression and Partial least Squares } \\
\text { Regression algorithms as statistical analysis of spectral data }\end{array}$ \\
\hline
\end{tabular}




\subsubsection{Calibration curves}

Regarding to the calibration curves, it can be observed that all of the patents for applications in liquid fuels include calibration curves in their documents. In the most recent one (2016) concerning gaseous applications only a cross sensitivity analysis is included with no quantitative reference values. This is an important thing to take into account which points to the difficulty of providing validation measurements in gas phase.

Figure 19 shows the calibration curves to validate the liquid measurements of EPA parameters in a winter gasoline, in contrast to other methods reported by a certified laboratory. More specifically, the graph displays the NIR-predicted NOx concentration in the gasoline plotted against the corresponding NOX values obtained by inserting the conventional "lab reported" oxygenates, sulfur, RVP, PIANO results for aromatics, olefins and benzene, and distillation by ASTM D-3710 into the EPA complex formula. This validation should be made by the inventors to test the robustness of the patented model.

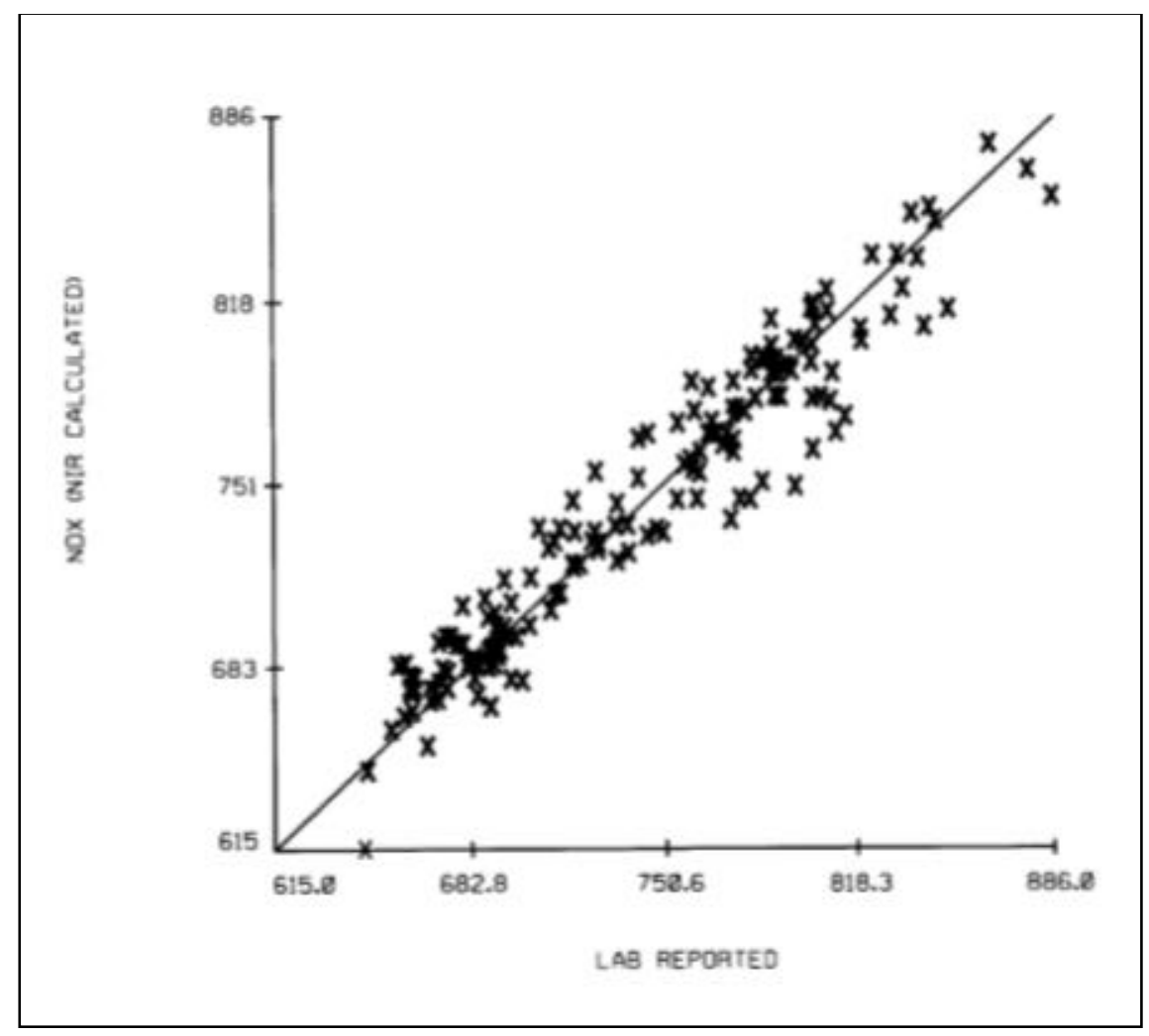

Figure 19.Plot of the "lab reported" results obtained for the NOx measurement in a winter gasoline (that is one of the EPA parameters to determine in quality control of reformulated gasoline) against the NIR predicted values using the patented prediction model

The patented prediction model for these NIR measurements of this same target compound corresponds to the patent ID. US614064). 
Figure 20 shows the estimation of benzene content in a winter gasoline from liquid samples by means of NIR, FTIR and RAMAN sensors against conventional methods (US6140647, 2000). A good fit can be observed between the data acquired by optical methods and conventional laboratory techniques, which confirms the reliability and robustness of these kinds of devices to determine fuel quality.
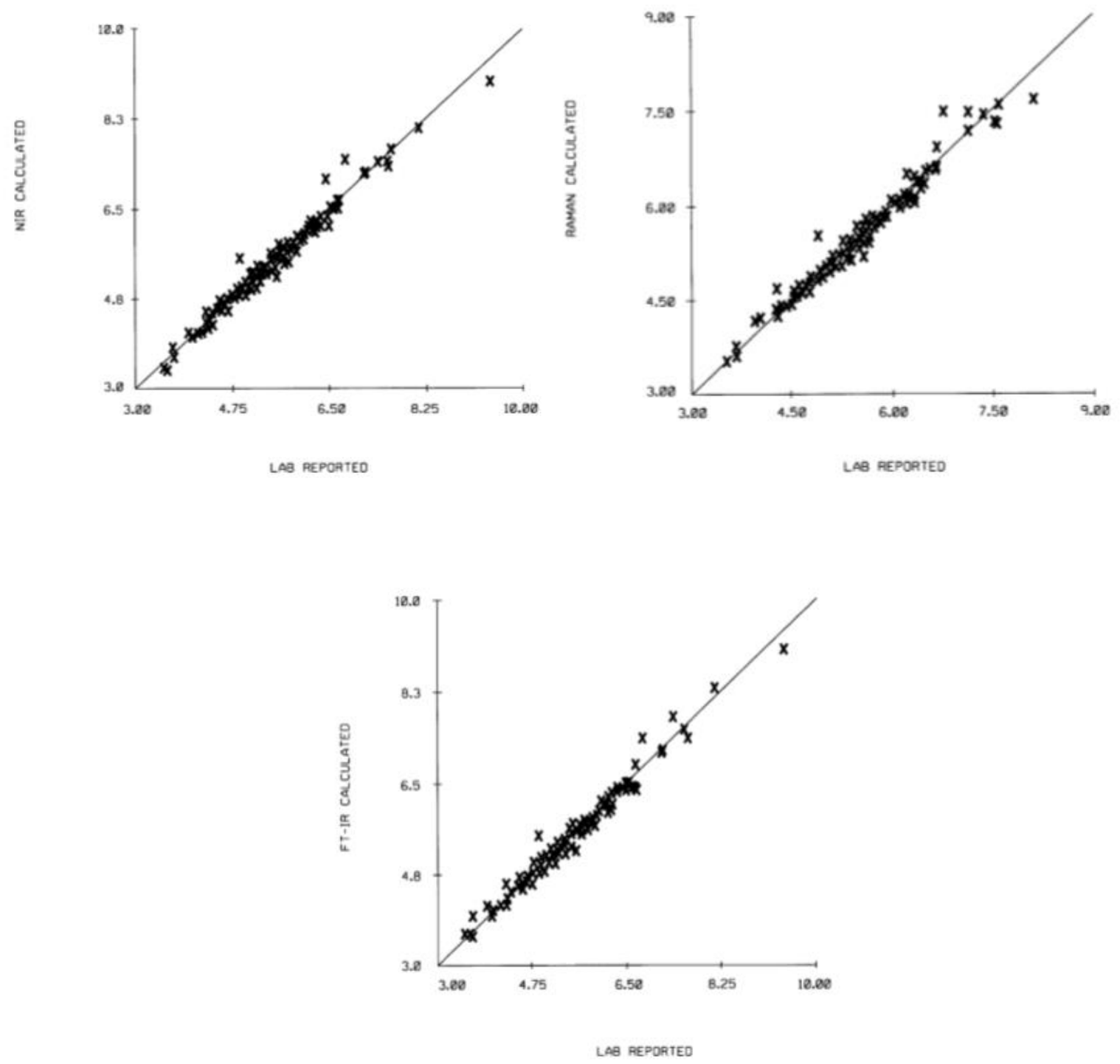

Figure 20.Linear fit correlation of NIR (top left), RAMAN (top right), and FTIR (bottom) benzene content measured in a gasoline versus conventional laboratory methods. 
The acquired MID IR spectra from each type of gasoline are shown in the Figure 21 below:
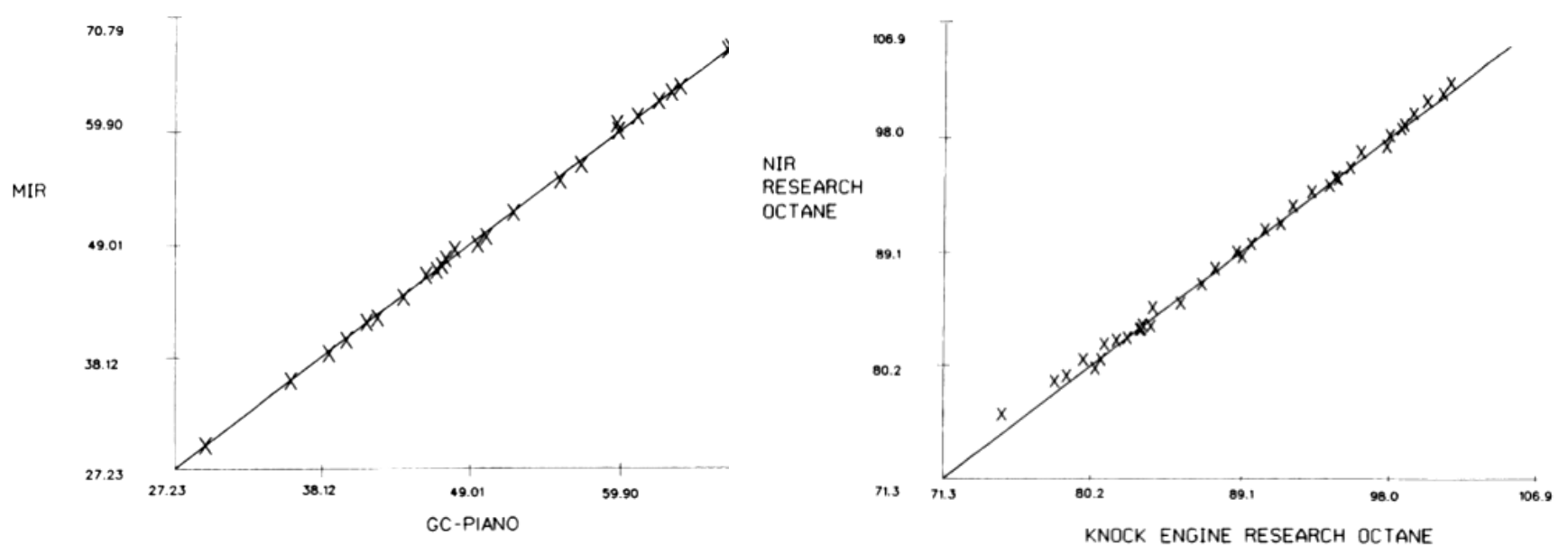

Figure 21.(left). Volume percent aromatics as measured by gas chromatography (GC-PIANO) versus the volume percent predicted according to the present invention. (right) Plot of reformate research octane predicted by NIR versus a knock engine.

\subsubsection{Summary of remarkable points about the technical state of the art}

The patented inventions disclosed above are a proof of the increasing interest in optical and/or spectroscopic methods for fuel quality control same as applied on liquid or gas phase along the last decades. Different types of approaches have been developed regarding to the sample presentation, type of detector, and the ways of improving the signal to noise ratio and the mathematical algorithms to extract the maximum information from the spectral data acquire by each of the devices.

Different wavelengths ranges and techniques have been used combined, such as IR with RAMAN and UV Vis, and they have been patented in different embodiments that used diverse sorts of acquisition, pre processing and analyzing methods for liquid and gaseous fuel and exhaust samples.

\subsection{State of scientific prior art}

The scientific state of the prior art regarding to publications in papers about the research of new analytical methods to measure fuel quality by means of optical devices based in infrared and RAMAN spectroscopy and the effect of alcohols as additives in the engine performance is disclosed along the points below. 


\subsubsection{Effect of alcohol blend on engine performance}

Some authors (Eyidogau, et al. 2010) assessed the performance of a SI engine using ethanol-gasoline or methanol-gasoline blends instead of the pure gasoline fuel. The results obtained from the use of alcohol-gasoline fuel blends were compared to those of gasoline fuel indicating that when alcohol-gasoline fuel blends were used, the brake specific fuel consumption increased. Also the cylinder gas pressure started to rise later than gasoline fuel, and almost in the all test conditions, the lowest peak heat release rate was obtained from the gasoline fuel use.

Other authors (Gopinath 2017) studied the effect of adding n-butanol to gasoline in different proportions such as N10, N20 and N30 and the blends were tested in a fourstroke, four-cylinder multi-point fuel injection (MPFI) spark ignition (SI) engine using an eddy current dynamometer to investigate the combustion and emissions behavior of these $\mathrm{n}$-butanol blends. The tests were conducted over a rotational range of $1400 \mathrm{rpm}-2800 \mathrm{rpm}$ under a constant load of $20 \mathrm{Nm}$. The results obtained indicate that use of $\mathrm{n}$-butanol blends produced lower hydrocarbon $(\mathrm{HC})$ and carbon monoxide $(\mathrm{CO})$ levels than the pure gasoline but nitrogen oxide (NOx) emissions were found to be higher. When ignition timing was retarded, NOx emissions for all n-butanol blends decreased. So on, it is advantageous to use $\mathrm{n}$-butanol as an additive to the pure fuel regarding to the exhaust emissions and to the engine performance as well.

To ensure reliable engine operation, control strategies based on a measurement of the composition need to be developed.

\subsubsection{Main analytical techniques for fuel quality assessment}

The tests for fuel quality control are internationally regulated by the American Society for Testing and Materials (ASTM) according to the specifications fixed by the Environmental Protection Agency (EPA). Gas chromatography is the major analytical technique applied due to the fuel characteristics such as volatility and matrix complexity. It is usually employed to determine various properties of fuels such as the content of oxygen and hydrocarbons such as aromatics and olefins (Ugena, et al. 2018).

Other analytical techniques have also been explored, showing the same accuracy and precision as ASTM standardized methods such as nuclear magnetic resonance (NMR) spectroscopy (Khijwania 2007). Consequently, the recent studies have been focused on improving these techniques to replace the traditional standardized ones. 


\subsubsection{Infrared spectroscopy for fuel quality control}

Infrared spectroscopy is the main optical technique studied in this dissertation; hence a specific review about this method is included in the document, starting with a comparison between NIR and MIR techniques and their applications. In general, the use of NIR and MIR techniques is carried out combining the spectral data set with chemometric multivariate methods and thus, they will also be considered in this paragraph.

\section{Effect of ethanol in the infrared spectra}

When it comes to analyze the ethanol content in a gasoline blend, hydrogen bonds among ethanol molecules cause frequency shifts and excess infrared absorbance phenomena, so adjusting the spectral window before calculating the ratio of intensities have been ways to correct and eliminate such effects (Corsetti, McGloin and Kiefer 2015). Usually ethanol causes fluctuations when measuring its mixtures in a volatile phase, like other volatile organic chemicals (Huang and Gutiérrez-Osuna 2016) so it is recommendable applying the appropriate pre-treatment and data analysis methods to process the signal and extract the maximum information from the IR spectra.

\section{Near and Middle Infrared Spectroscopy}

Fourier Transform Infrared Spectroscopy (FTIR), either in the near (NIR) or middle (MID) ranges from the Infrared region, has been one of the most common techniques chosen for measuring various constituents in a mixture, due to its high sensitivity and wavelength resolution.

The basis of FTIR equipment is a Michelson interferometer that is used to create an interference from two source beams which contains the spectral information. It makes use of the Fourier-transform of the diffractive pattern in the time domain generated by this interference to extract the spectral information.

In comparison, in a dispersive IR equipment wavelength selection can be done by tuning the source laser frequencies or by directly coupling a diffraction grating or a linear variable filter (LVF) to the sensor. Previous studies applied to food quality control were carried out in order to make a comparison between the FTIR and the dispersive instruments of Near Infrared devices according to their signal-to-noise ratio, instrument stability, light penetration depth and predictive capacity (Peirs, et al. 2002). As a conclusion, it was found that the FTIR achieved a higher signal-to-noise ratio. Also, the dispersive instrument got 
significantly lower prediction errors, which makes it more robust at the time of determining quantitative predictions.

When comparing the analytical performance of NIR and MID IR, the first one presents advantages such as its sensitivity and reproducibility, presenting a small level of interference and vibrational absorption coefficient, thus allowing an interaction more efficient between the light source and the studied material. Another advantage of NIR spectroscopy is related to the sample preparation. For the NIR analysis, water can be used as a solvent; and glass and quartz as cell windows, focus lenses and optical fiber.

The main disadvantage of NIR is related to the difficulty in assigning off the functional groups by presenting overtone-type vibrations and their combination (Martins, Da Silva Filho and Pacheco 2016), (Demirbas 2009). Also it presents other drawbacks such as giving false readings, high limits of detection for some chemicals, high scattering level and problems of selectivity for some organic compounds (Villena Gonzales and Mobasher 2019).

During the early development of infrared spectroscopy the focus was on the use of NIR, that is now firmly established in the food sector. Nevertheless, as MID IR instrumentation has developed, becoming simpler to use and more accessible in terms of cost, its applications have been increasingly reported. One of the reasons of this increase is that the fundamental vibrations of molecular bonds occur in this region more remote from the NIR (from 3 microns/ $4000 \mathrm{~cm}^{-1}$ on). Additionally, the MID IR presents a higher optical throughput, consequently more radiation interacts with the sample.

In regards of Far IR (FIR) this technique is used for applications that are very different from the applications of NIR and MID IR, and that is why a comparison of this technique is not included. The main applications of FIR are for example the observation of lattice vibrations of crystals, low frequency skeletal motions of organics and the stretching modes of heavy atoms such as Uranium (Gilbert 2017).

Previous recent works (Correia 2018)have demonstrated and developed the applicability of a portable micro-near infrared micro-spectrometer in the fuel quality control of diesel to determine the quantity of biodiesel in diesel fuel; and the ethanol and methanol content in a gasoline. 
On the other hand, water, methanol, and ethanol were able to be determined by this micro NIR spectrometer in ethanol-hydrated fuel (EHF). Results obtained from these cited authors showed that for gasoline blends, the gasoline, ethanol, and methanol contents ranged from 0.0 to $75.0 \mathrm{wt} \%, 25.0-75.0 \mathrm{wt} \%$, and $0.0-50.0 \mathrm{wt} \%$, respectively. In the Ethanol Hydrated Fuel control, the ethanol, water, and methanol contents ranged from 0.0 to 100.0 wt\%, 0.0-50.0 wt\%, and 0.0-50.0 wt\%, respectively (Niemeyer and Hagen 2016). Results like these demonstrated the prospective of an in situ fast and accurate method to develop and deploy into the standardized systems.

Nevertheless, while NIR spectroscopy has found many broad applications in industrial processes management, in some cases other procedures such as Raman and MID-IR spectroscopy could provide more useful analytical data more readily. It is the MID-IR spectral region where most of the fundamental structural information is produced and when measurements in that region can be made on a particular class of samples. It may well be the method of choice, as the spectra obtained from this region are more discriminating than the NIR ones (Zhang, Yuan and Coronado 2012).

Table 8 below shows a summarized comparison of both techniques regarding to their main strengths and weaknesses. 
Table 8.NIR and MID IR strengths and weaknesses comparison

\begin{tabular}{|c|c|c|c|}
\hline STRENGHTS & & WEAKNESSES & \\
\hline NIR & MID IR & NIR & MID IR \\
\hline \multirow[t]{3}{*}{$\begin{array}{l}\text { Higher energy levels } \\
\text { because radiation } \\
\text { levels from black body } \\
\text { emitters peak at } \\
\text { shorter wavelengths }\end{array}$} & $\begin{array}{l}\text { Organic functional } \\
\text { groups have } \\
\text { characteristic and well } \\
\text { delineated absorption } \\
\text { bands in this spectral } \\
\text { region }\end{array}$ & $\begin{array}{l}\text { The absorption bands } \\
\text { occurring there are the } \\
\text { overtones of the } \\
\text { fundamental bands } \\
\text { residing in the mid-IR } \\
\text { region. As a result, } \\
\text { they are relatively } \\
\text { weak and not clearly } \\
\text { delineated. This makes } \\
\text { quantitative } \\
\text { calculations complex } \\
\text { and calibration } \\
\text { procedures quite } \\
\text { laborious and not } \\
\text { transferable from one } \\
\text { instrument to another }\end{array}$ & $\begin{array}{l}\text { As a result of the } \\
\text { mentioned black body } \\
\text { radiation curve, } \\
\text { available energy in the } \\
\text { Mid-IR decreases } \\
\text { substantially with } \\
\text { wavelength }\end{array}$ \\
\hline & $\begin{array}{l}\text { Since molecules differ } \\
\text { from each other by } \\
\text { having different } \\
\text { combinations of } \\
\text { functional groups, } \\
\text { their MID-IR spectra } \\
\text { can be used to identify } \\
\text { them and to } \\
\text { characterize their } \\
\text { structure }\end{array}$ & & $\begin{array}{l}\text { MID-IR transmitting } \\
\text { materials are more } \\
\text { expensive and in some } \\
\text { cases less chemically } \\
\text { resistant. Mid-IR } \\
\text { optical fibers tend to } \\
\text { be very expensive and } \\
\text { quite difficult to } \\
\text { manipulate }\end{array}$ \\
\hline & $\begin{array}{l}\text { MID-IR spectra of } \\
\text { mixtures are additive. } \\
\text { Absorption bands }\end{array}$ & & $\begin{array}{l}\text { Most materials are } \\
\text { strongly absorbing in } \\
\text { the MID-IR and }\end{array}$ \\
\hline
\end{tabular}




\begin{tabular}{|c|c|c|}
\hline NIR & NIR & MID IR \\
\hline & $\begin{array}{l}\text { associated with } \\
\text { individual components } \\
\text { in a mixture are } \\
\text { frequently isolated } \\
\text { from other bands and } \\
\text { can be used to } \\
\text { quantify the individual } \\
\text { components by the } \\
\text { strength of their } \\
\text { absorption }\end{array}$ & $\begin{array}{l}\text { therefore cells with } \\
\text { extremely short } \\
\text { effective path lengths } \\
\text { - in a span of } 10 \text { - } \\
100 \mu \mathrm{m} \text { - must be used }\end{array}$ \\
\hline $\begin{array}{l}\text { Low cost materials } \\
\text { such as glass and } \\
\text { quartz transmit NIR } \\
\text { radiation and can be } \\
\text { used as cell windows, } \\
\text { focusing lenses and } \\
\text { optical fibers }\end{array}$ & $\begin{array}{l}\text { Calibration models in } \\
\text { the MID-IR are much } \\
\text { more generic than that } \\
\text { in the NIR and thus is } \\
\text { more readily } \\
\text { transferable from } \\
\text { instrument } \\
\text { instrument }\end{array}$ & \\
\hline
\end{tabular}

The fact that MID IR spectra of mixtures are additive, converts MID IR sensors in a useful tool to not only qualitatively but also quantitatively analyze fuel blends. As a conclusion from the ideas exposed above, in an ideal case the most appropriate would be combining both spectral ranges to determine as many properties as possible to achieve a better characterization of the desired substrate. Regarding to the sample preparation, the NIR may result more advantageous, mainly because of the possibility of including water as a solvent, so the media are frequently prepared in water or most of the substrates contain water in their structures. Nevertheless when it comes to the characterization of organic matters, the MID IR results more useful, as it shows more specific and selective information about the functional groups and bounds. That is why it is appropriate for mixture quantification and determination, as the calibration models obtained from this technique are more generic and transferable from one device to another. As it can be inferred from the Table 8 above, the combination of NIR and MID IR spectroscopy is the most useful way to in situ and in real time determine the fuel quality control of gasoline and their blends with the maximum information provided and accuracy.

Nevertheless, there are not many publications referring to the use of middle infrared spectroscopy applied to fuel quality control, as a direct tool in real time and in situ for gasoline blends. 
However, MID IR has been used to monitor and predict the distillation profile and cold properties of diesel fuel and gasoline, in combination with neural networks as the chemometric tool supporting the analysis (Pasadakis, Sourligas and Foteinopoulos 2006). It has been also applied to determine physical properties of diesel fuel such as dynamic and kinematic viscosities and other properties of biodiesel-diesel blends (Soares, Rocha and Teixeira 2013) , (Jamrozik 2017).

On the other hand, in 2015 other authors (Corsetti, Zehentbauer, et al. 2015) used the MID IR range by means of a FTIR spectrometer to characterize gasoline-ethanol blends from a molecular point of view, and this way being able to study the interactions between alcohol and gasoline molecules. In the same paper another method is disclosed in order to select the key absorption wavelengths corresponding to vibrational stretching and bending of certain functional groups as $\mathrm{CH}$ and $\mathrm{OH}$.

The same authors have also studied the applicability of the RAMAN technique at the analysis of gasoline-alcohol blends comparing it with the infrared spectroscopy (Corsetti and Kiefer 2016). For each method, two different approaches for data evaluation are tested and compared: Firstly, the calibration of the intensity ratio of characteristic peaks as function of composition; secondly, a principal component regression (PCR). According to these authors, both methods were found to have comparable uncertainty. For the evaluation of the Raman spectra, the PCR method yielded better accuracy than the intensity ratio approach. In addition, they made a detailed investigation of the influence of noise in the signal. When the full IR spectra were evaluated by PCR, even high noise levels did not reduce the measurement accuracy significantly.

Other authors have profited the range of MID IR wavelengths to make a characterization of pure gasoline fuels by measuring their hydrocarbons, which absorption peaks in the infrared region are found around 3.4 microns (Dupuy and Kister 2015). In this case, the MID IR spectroscopy was not applied to blends but to pure gasoline analysis in vapor phase.

The most remarkable conclusion from this disclosure above is the fact that middle infrared has been mostly applied to diesel and biodiesel quality control, and not so frequently applied in gasoline and its blends. 


\subsubsection{What has been done till now and how it contributes to solve the problem of fuel quality assessment}

All the research and development invested in the fuel quality control issue to date has led to a better knowledge of the gasoline and diesel fuels composition, by means of new tools to analyze the different types of spectra obtained by each technique. It has also allowed a better understanding of how the additive, alcohol in this case, affects to the gasoline in what refers to vapor pressure and molecular interactions. These parameters are crucial when it comes to the vehicle engine performance, and at the same time they determine the way in which the fuel should be stored and transported towards the distribution points.

Fourier Transform Infrared Spectroscopy (FTIR) has been widely used for the purpose of determining and quantifying ethanol in different fuel blends, and in addition, to study the behavior of these blends (Ye, et al. 2009). The before disclosed authors (Corsetti, McGloin and Kiefer 2015) suggested that the Hydrogen bond between molecules of ethanol in a blend is weakened upon gasoline addition, but still such bonds do not disappear completely. It seems like some ethanol clusters are formed which interact with the gasoline molecules through Van deer Waals forces. This fact may be important regarding the engine behavior when using gasoline-alcohol blends.

These all studies were usually developed at a laboratory scale and using different percentages of blending, spanning between the 5 and 50 percent of alcohol or additive in the blends, to cover a wider range of potential mixture proportions, although in practice the blends are made in an additive proportion between 10 and $20 \%$ in volume $(\mathrm{v} / \mathrm{v})$.

The results obtained from them, regarding to the sample presentation, the developed experimental set up in each case and the multivariate techniques of data analysis (supervised and unsupervised) that were used as supporting tools have contributed to evaluate which method or model became more useful and accurate at the time of acquiring and processing the data obtained from the spectra and obtaining back the highest amount of chemical information in a robust way.

\subsubsection{Exposing the gap in scientific current knowledge}

Despite of all the research and development invested on new analytical methods based fundamentally on the optical techniques and more concretely focused on the infrared spectroscopy in the near and middle regions (due to the most of chemical organic species absorb at this spectral ranges), optical methods still remain unused outside the laboratory, 
and there exists a lack of devices which can be implemented in field, this means, in the storage tanks of fuels, or in petrol stations, to give an example.

The main gap of these optical techniques described above, is the lack of a rugged, compact, and uncooled sensor to be assembled in a device that is able to be implemented in field and works in the optimal wavelength range to detect the key organic species that play the main role at the fuel quality control, as they provide the means to distinguish one pure substance from another.

On the other hand, from the review made above it can be observed that only few of the experiments were carried out using commercial gasoline, whilst most of them were done using gasoline surrogates. A gasoline surrogate is synthesized by mixing the different hydrocarbons that are part of the gasoline composition (n-heptane, n-octane, trimethylpentane, etc.) but without any other kind of additive.

When using pure commercial gasoline, it should be warned that the work is being done not only with these hydrocarbons, which build the raw composition of gasoline, but also with some additives (even though in small proportions). So the gap comes by the next question: Which results are more robust or reliable? Are those which come from the laboratory under ideal conditions (using pure surrogates of gasoline synthesized at the laboratory) or those who are performed using real gasoline samples from winter and summer collection? There is a need of validation of this gap.

Consequently, when investigating the fuel quality it is a remarkable question to pose whether using commercial gasoline or preferably use surrogates made of heptanes and octane to ensure the pureness of the analysis. 


\section{Chapter 3}

\section{Antecedents, Hypothesis and Objectives}

\subsection{Antecedents}

There exist numerous studies about the applications of the Near Infrared spectroscopy (NIR) in the food and pharmaceutical industries laboratories, and in the monitoring of synthesis chemical reactions at a laboratory scale.

Nevertheless, the prospective of MID IR Spectroscopy at an industrial level has not been exhaustively studied till the date. This type of spectroscopy is actually still in a stage of development from the point of view of the manufacturing and improvement of the detectors. Only a few scientific publications have been released to the date related to this subject (Vergara, Linares, et al. 2014).

On the other hand, the application of these uncooled devices has been performed uniquely in the field of Defense for detection through infrared emissions detection; and in the steel and automotive industries for the monitoring of welding processes or exhaust gaseous emissions in which the sample is not previously treated and is directly placed in the field of view of the measuring device (G. Vergara, R. Linares, et al. 2014).

New Infrared Technologies owns the technical capacity to optimize the detectors in size, acquisition speed and resolution to be adapted to different industrial sectors depending on each application specifications. The company has been awarded with the Innovation Radar 
Award 2018 by the European Commission and by the Real Engineering Academy in 2016, which awarded NIT with the Academiae Dilecta recognition ${ }^{6}$.

Regarding the sensor exclusively, New Infrared Technologies is the only company who manufactures and commercializes infrared detectors made of pollycristaline vapour phase deposited PbSe all over the world (Sierra, Torquemada and Vergara 2014). The methods used by NIT are protected by the international patents ID EP1876652 and EP18529, consisting respectively on a method of treating non-refrigerated, spectrally-selective Lead Selenide Infrared detectors, by selecting and preparing them, delineating and depositing multilayer interference filters.

The method proposed by NIT for the treatment of polycrystalline Lead Selenide Infrared detectors on the interference filters is based on monolithically integrating the linear variable filter and the PbSe detector (Vergara, Pérez and Montojo 2003). This innovative method for processing detectors, based on a vapor phase deposition (VPD) technique, has allowed manufacturing the first 2D array of polycrystalline PbSe with good electro optical characteristics. The perspectives opened by these sensors are numerous and very important, converting the old PbSe detector in a serious alternative to others uncooled technologies in the low cost IR detection market. The number of potential applications is huge, some of them with high commercial impact such as personal IR imagers, enhanced vision systems for automotive applications and other not less important in the security or Defense domains such as sensors for active protection systems (APS) or low cost seekers (Vergara, Torquemada and Montojo 2007) The technology described results useful in the field of low cost infrared detection. The MID IR spectral range allows detecting most of the organic compounds as fuels and their volatile, due to the bound $\mathrm{C}-\mathrm{H}$ and $\mathrm{C}-\mathrm{O}$ vibrations absorb in this region from the spectrum.

Nevertheless, no applications in the Chemistry field have been studied to date, so this opens up to the main hypotheses of this PhD research.

About eight years ago, New Infrared Technologies joined the Polytechnic and Complutense universities from Madrid, in a common project called Campus de Excelencia Moncloa in order to extend the applications and possibilities of their PbSe sensors in the agro-food

${ }^{6}$ https://www.niteurope.com/la-real-academia-ingenieria-reconoce-new-infrared-technologies-nitpremio-academiae-dilecta/ 
field. As a result of this collaboration, various research works and this thesis have been developed.

One on the most significative papers obtained from this collaboration was a published study about the capability of this PbSe sensor in the range of $2.5-4.5$ microns to detect the presence of the volatile 1,3-pentadiene, which is considered an indicator of the spoil process in packaged foods (Rivas, et al. 2015). This methodology also allowed the determination of $\mathrm{CO}_{2}$ in the same packaged foods. The results from this research publication demonstrated the potential applicability of these PbSe sensors in the Food Industry, and extensively in other industries where volatile chemicals need to be detected and/or determined.

Afterwards, the synergy between the LPF TAGRALIA group and the company NIT gave back a new application of the PbSe sensors in the automotive industry, through a method which detected the defectuous spot welding in the batteries manufactured for vehicles by means of the in-situ thermography and chemometric methods (Maldonado, et al. 2017).

\subsection{Starting hypothesis}

The starting point for this $\mathrm{PhD}$ research came by giving an answer to the question:

- Is the MID- device manufactured and patented by NIT able to qualitatively and quantitatively to measure chemicals in fuels?

- Will it have a future in the fuel industry?

\subsection{Objectives}

The main aim of this PhD dissertation is expanding the market niche of the low cost MID IR technology patented by NIT and the development of new experimental set ups and mathematical data analysis methods (Chemometrics) for the study of their applicability to more specific sectors from industry such as the fuel quality control, established as an specific objective, all of them directly involving fuel analysis

So the main goals are the design, testing and set-up of a MID-IR device at a laboratory scale based on the absorption range of hydrocarbon and alcohols, i.e. 2.5 and 4.9 microns 
(around $4000-2000 \mathrm{~cm}^{-1}$ ) using the low technology developed by NIT. These main goals were reached through following the specific objectives pointed below:

- To obtain repetitive, reproducible, and stable spectra along time, as well as a fast and simple software for acquisition and data storage.

- To optimize the measuring device with regard to main sources of variation (components distances, layout and acquisition time among others).

- To optimize the signal to noise ratio in the detector in order to achieve as best resolution as possible.

- To improve the sensor by means of the optimal wavelength range selection and a fixed bandwidth.

- To apply the most appropriate Chemometrics among the supervised and nonsupervised procedures in order to obtain neat results and visual information for a given application of the sensor. 


\section{Chapter 4}

This document has been structured according to most relevant results, gathered in two different experiments. For both of them material and methods and results are presented jointly.

Additionally, there have been several communications in a variety of congresses that are included in Annex I. The first one refers to the initial steps in the use of MID IR for both fuels and edible oils. The second congress communication presents an innovative use of MID IR for the identification of the quality of welding, while the third refers to a more detailed analysis of edible oils.

Finally, Annex II includes a JCR publication in Fuels that includes the results in experiment 1, while the second experiment remains unpublished at the time of writing this document.

\section{Materials and methods}

\subsection{Experimental design}

This section provides the details of the MID IR equipment together with the experimental design and applied statistical procedures. Regarding the MID IR equipment a specific description is provided: the PbSe sensor and its embodiment in a camera; the layout of all the elements from the spectrometer device to reduce the drift and obtain reproducible measurements; the optimal material to hold the sample, and the acquisition method. Additionally to the spectral data pre-processing used, the unsupervised and supervised

analysis carried out, to discriminate between chemicals or quantify the blending percentages in mixtures, are included. The simplicity and rapidity of the acquisition method 
together with the automated spectra classification constitute the novelty provided by this thesis.

\subsubsection{The Middle Infrared Spectrometer and its components}

The instrumentation and set-up consisted of an infrared source, a sample chamber and a detector.

\subsubsection{The Mid Infrared sensor}

The mid-infrared (MIR) spectrometer used for this study was based on a nondispersive linear sensor model CORE-HS LUXELL 128, which is manufactured by the company New Infrared Technologies (Boadilla del Monte, Madrid). The sensor comprises a line of 128 detectors of vapor phase deposited PbSe (VPD PbSe) and has coupled a linear variable filter (LVF), in the wavelength range between 2.5 and $4.5 \mu \mathrm{m}$. The PbSe detection band ranges between 1 to $5 \mu \mathrm{m}$. The peak detection wavelength is $3.7 \mu \mathrm{m}$. The integration time ranges between 4 and $20 \mu \mathrm{s}$ (selectable on the instrument). The acquisition rate is up to 300 spectra per second, so it is faster than other kinds of sensors. The experimental set up for liquids is schematized in the Figure 22 below, whilst the experimental set up for gases is shown in the Figure 23 next:

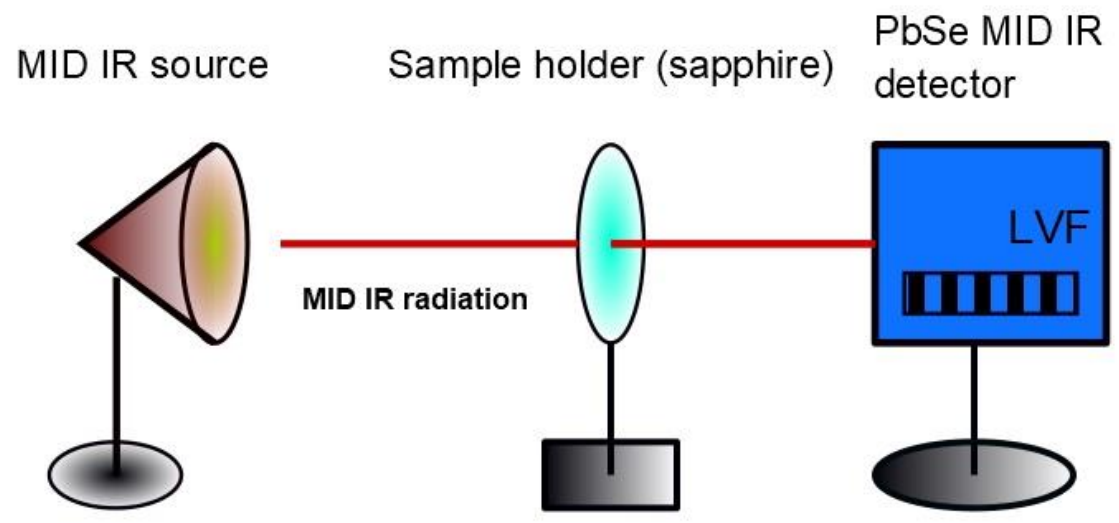

Figure 22. Graphical scheme of the experimental set up used to the spectra acquisition for liquid samples 


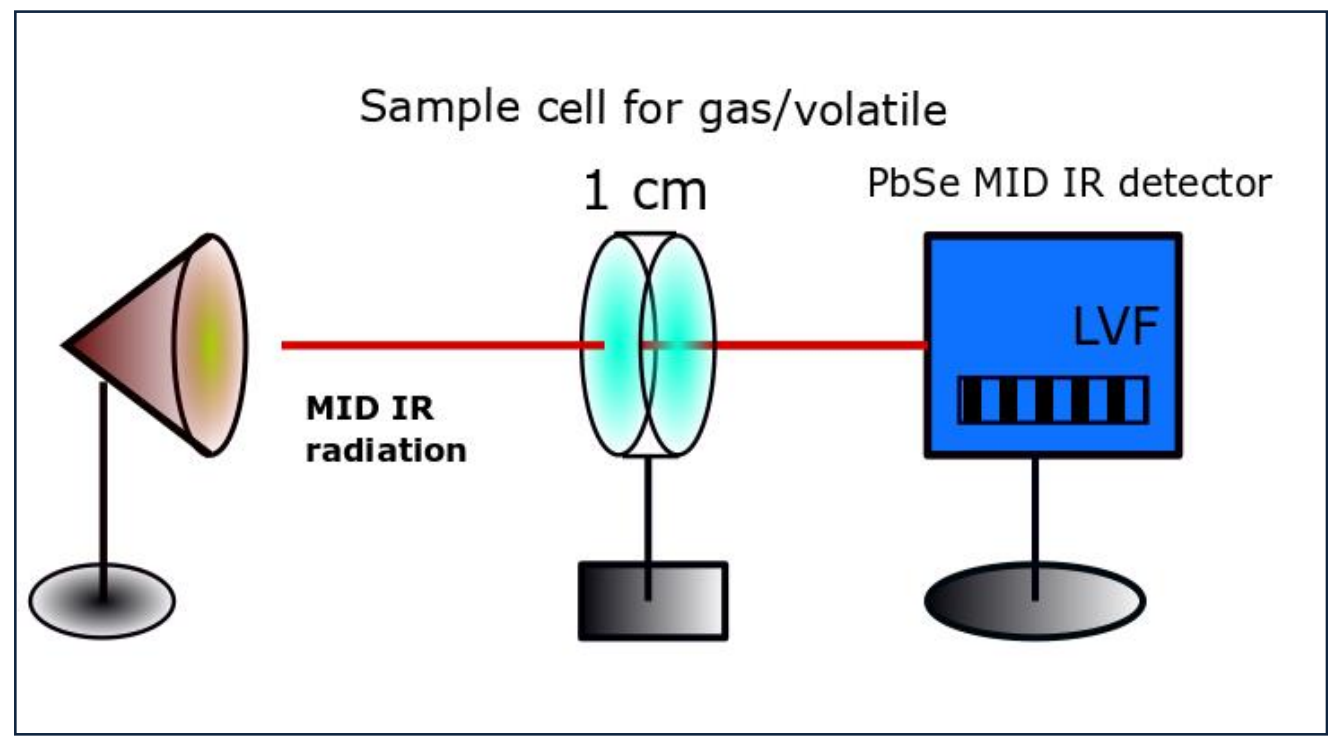

Figure 23.Graphical scheme of the experimental set up used to the spectra acquisition in gaseous samples

The MID IR radiation gets out from the source lamp and then it passes through the thin optical path created by the two sapphire windows containing the drop of sample between them. The main variables that affected each of the experiments were the Field of View (FOV) and the acquisition time. Regarding to the FOV, it was fixed for all the experiments performed according to the best way to make the detector receiving the highest amount of light. The results improved considerably when this configuration was achieved, as the absorption peaks became more intense and clearer with less noise levels.

The acquisition time played an important role too, so on it was fixed too at 11 seconds of recording, in order to obtain the most reproducible results at the signal processing stage.

This spectrometer, with no moving parts, is a rugged, compact and economically affordable device. A picture of this sensor embodiment is shown in the Figure 24 below: 


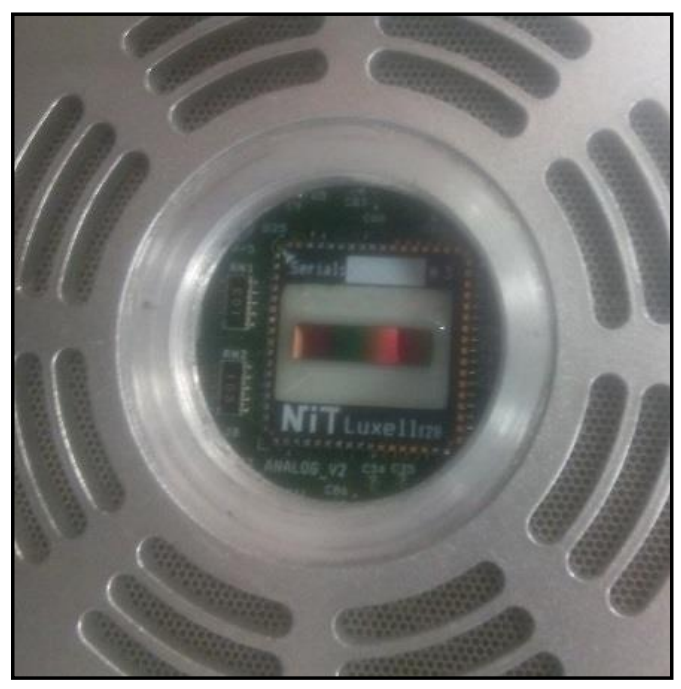

Figure 24. Image of the sensor embodiment

The sensor embodiment is formed by the linear array of PbSe and the metal housing for the camera. The experimental set-up includes the source, the sample holder and the detector, fixed on a support by means of screws.

\subsubsection{The light source}

The infrared light source consisted on a Silicon Carbide (SiC) filament and a parabolic reflector (IR-SiX, Hawkeye Technologies, Inc.).

One of the main advantages of these types of sources is that they do not need to operate in a sealed atmosphere, being able to work at room conditions in situ.

The specifications of the source lamp regarding to its intensity and radiation power depend strongly on the type material of what sample holder is made and its transparency and absorption values to the MID IR radiation. In this case, the Sapphire windows were chosen, as sample holder, because they were transparent to the radiation at this wavelength range.

The design of these lamps is oriented to experimental conditions which require high temperatures and greater output from their infrared source, a stable signal, and physical and thermal strength.

These emitters are manufactured using a patented silicon nitride and a silicon carbide material. The advanced ceramic technology ensures a very stable product ${ }^{7}$.

\footnotetext{
${ }^{7}$ www.hawkeyetechnologies.com
} 
The Table 9 below shows some of the commercial information referring to the Hawkeye Inc. lamps, according to the specifications given by the experimental conditions. In the case studied, the Silicon Carbide lamp was used.

Table 9. Some recommended operating parameters of SiC infrared lamps manufactured by Hawkeye Technolgies, Inc. according to the experimental conditions required.

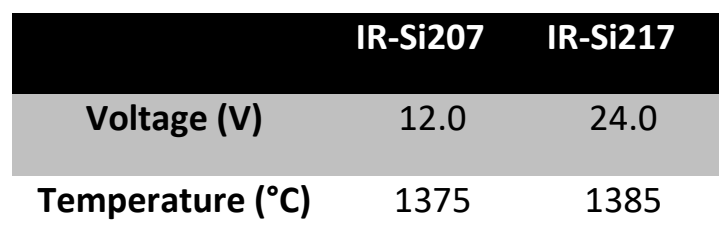

\begin{tabular}{lll} 
Current (A) & 2.0 & 1.5 \\
\hline Power (W) & 24.0 & 37.0 \\
\hline
\end{tabular}

$\begin{array}{ccc}\text { Emmisivity (\%) } & 80 & 80 \\ \text { Material } & \begin{array}{c}\text { Silicon } \\ \text { Carbide }\end{array} & \begin{array}{c}\text { Silicon } \\ \text { Carbide }\end{array}\end{array}$

In the case of concern the model IR-Si207 was used, so on the intensity was set at 4.5 A, while voltage was fixed at $6.5 \mathrm{~V}$ during the assays performance. The emittance of Sapphire versus wavelength in microns at different conditions: after heating (corresponds to the black one), after heating and polished and at its original state (the blue curve) is shown in the Figure 25 below. It can be observed that in the range of wavelength between 2 and 5 microns, after heating the $\mathrm{SiC}$ reaches a maximum emissivity of the $95 \%$, that is not significantly different from the original state (Dengfeng, et al. 2016). 


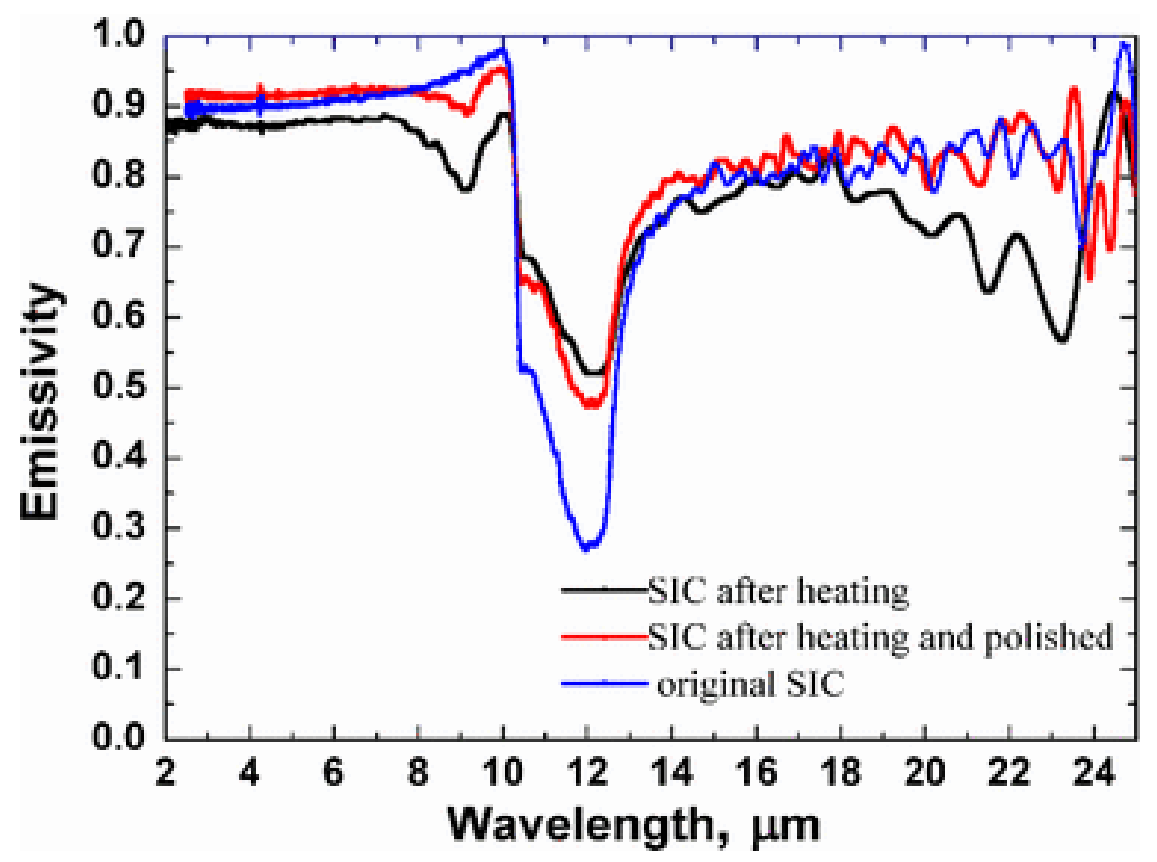

Figure 25. Emissivity of the SiC versus wavelengths before and after heating and compared to the heated and polished one (Dengfeng, et al. 2016).

\subsubsection{The sample holder}

Liquid samples were allocated between two sapphire windows without any spacer in between, thereby allowing a very thin optical path (around 200 microns).

Sapphire windows feature extreme chemical resistance and surface hardness, being thinner and stronger than standard glass windows, easily transmitting a wide range of wavelengths.

Sapphire is the second hardest crystal next to diamonds and, because of their structural strength, sapphire windows can be made much thinner than other common dielectric windows with improved transmittance. Chemically, sapphire is single crystal aluminum oxide (Al2O3) and is useful in a transmission range from $0.2-5.5 \mu \mathrm{m}$.

The optical transmission of the UV-grade and the Standard Commercial grade Sapphire used in these experiments (corresponding to the curves 1 and 2 respectively) is displayed on the Figure 26 below: 


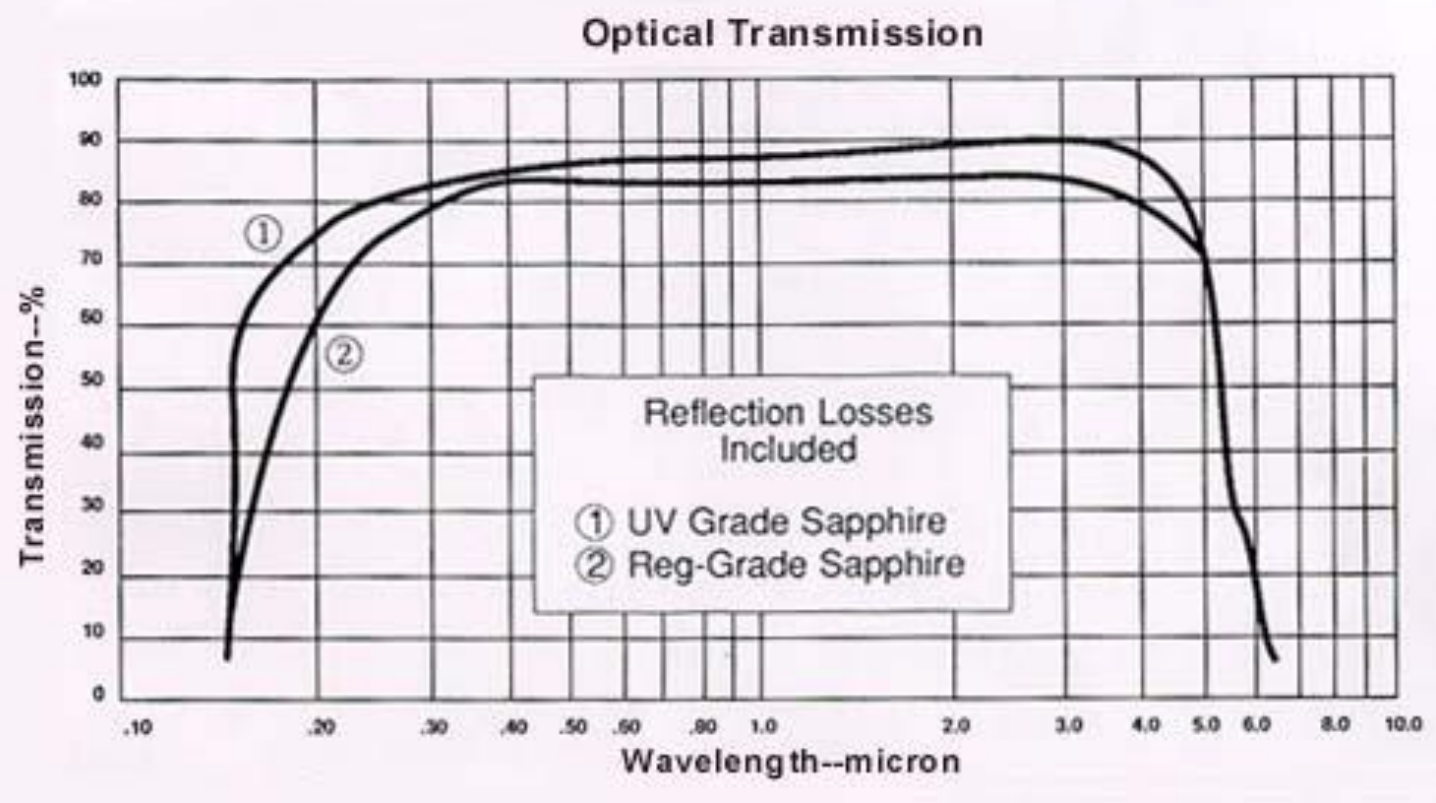

Figure 26. Sapphire optical transmission versus wavelength in microns curves, for the UV-grade and Commercial types

From the curves above it can be deduced that in a wavelength span between 2 and 5 microns the optical transmission of the type of sapphire used in this thesis reaches above the $85 \%$.

\subsubsection{Establishment of a fixed experimental set up}

The establishment of a fixed protocol for carrying out the measurements involved several stages. The first of all them, was fixing the amount of light that reached the sensor to obtain the optimal signal. This one was followed by acquiring the first liquid measurements that were done by subtracting the background (i.e. the measurements of blank, which was referred to the empty sapphire wafers and the environment).

The next step was finding out a pre treatment for these first noisy and drifty spectral curves. Different liquid chemicals were analyzed using this configuration. Smoothing and PCA were applied in a first approach to differentiate among them.

After being able to differentiate among chemicals, the next step was testing the experimental set up to measure volatile compounds in a headspace. For this aim, a specific type of flask was used. This one consisted on a glass bottle sealed with a cap and a tap to release the vapors in the headspace. Vapors were released inside a ring-shaped sample cell which was sealed with the two sapphire windows that were used for the liquid 
measurements (Rivas, et al. 2015). Figure 27 below shows the experimental set up used for the volatile compounds measurement in the case of 1,3-pentadiene and $\mathrm{CO}_{2}$ produced by yeasts as an indicator of food spoilage.

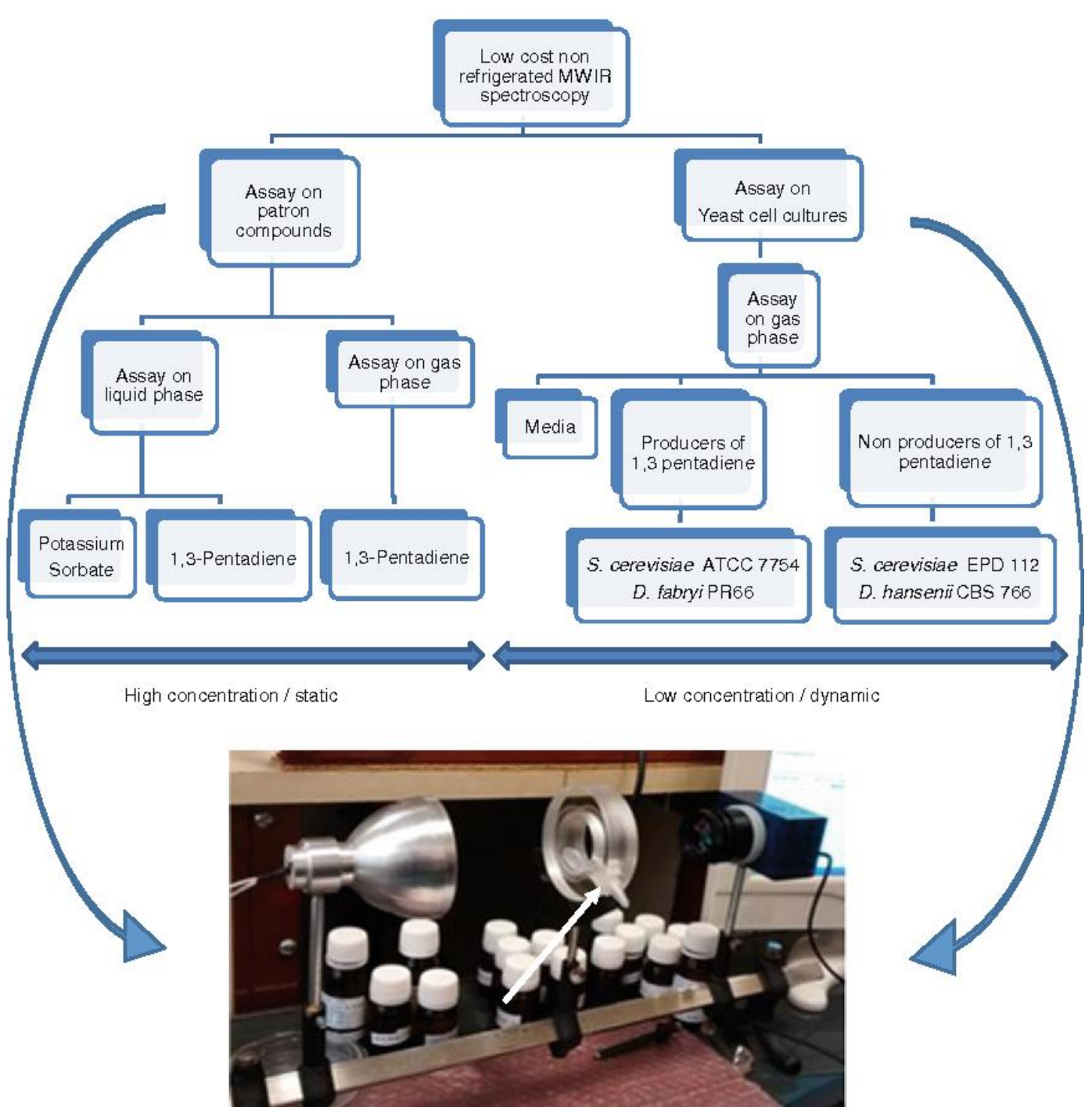

Figure 27. Experimental design which covers tests on pure substances (patron chemicals) as well as these chemical produced from yeast cell cultures (Rivas, et al. 2015)

These experiments were performed in liquid patron compounds as static measurements, and when the analytes were in the volatile released by yeasts they were performed in dynamic, as it resulted of interest observing when the target gas appeared in the spectrum.

Dynamic spectrum of volatile compounds can be observed in Figure 28 below: 

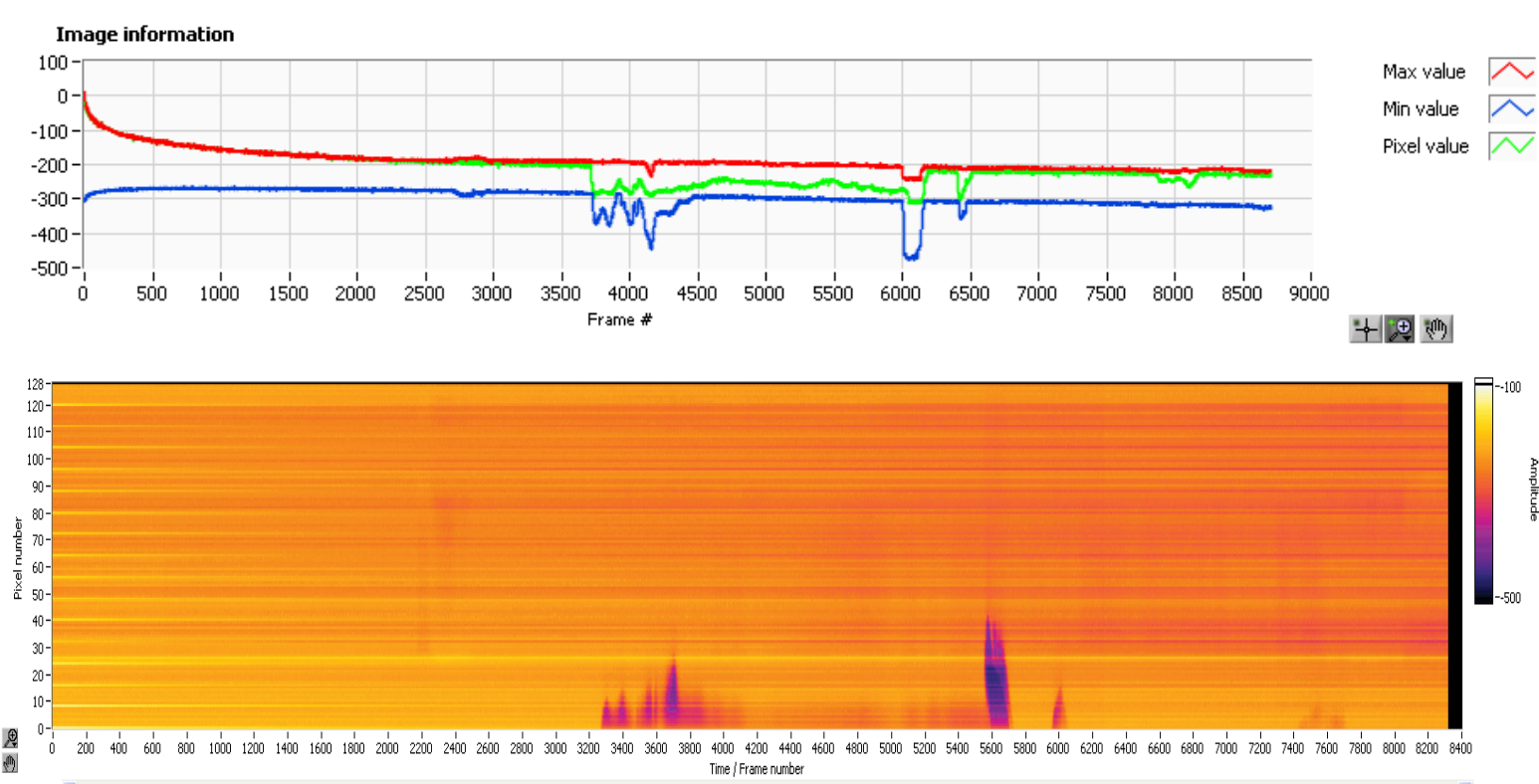

Figure 28. Dynamic acquisition of gaseous or volatile compounds

The next steps to this one were the establishment of a fixed layout and an acquisition time that were able to give repetitive and reproducible measurements. The stages of the experimental set up fixing process are schematized in the Figure 29 below:

Fixing the optimal signal to noise ratio
Determining an

addecuate sample

presentation
Establishing a specific

layout for the

spectrometer

components
Choosing an

acquisition time

Figure 29. Line up of the steps given to establish a fixed experimental set up to obtain reproducible and repetitive measurements

\subsubsection{Fixing the light intensity and focusing the optical lens to obtain an optimal signal}

The aim of this preliminary experimental step was adjusting the light emitted by the source in order to feed the optimal signal to the detector. Initially, an optical lens was assembled to the FPA to collimate the light radiation. Different values of intensity of the source were 
tested while focusing the lens in the camera with the goal of obtaining an optimal signal to noise ratio.

Afterwards it was discovered that a better signal to noise ratio was reached when removing the optics from the FPA. As a consequence, the experiments were performed without optical lens.

\subsubsection{Determining the optimal sample presentation}

When starting working with gasoline, it was checked out the ability of this device to measure the volatile organic compounds emitted by the fuel in storage conditions. For this purpose, the same experimental procedure as described above for chemicals produced by yeast in the food spoilage was applied to samples of liquid gasoline inside the glass flasks with a tap in their cap to release the vapors contained in the headspace.

For substances such as diesel oil and alcohols, this configuration was not useful, as they did not release such amount of volatile compounds to be detected by the PbSe sensor. That led to continue employing the sapphire wafers as a sample cell and dropping the liquid sample between them. For the spectra processing, the background was subtracted as it was done in previous liquid measurements.

\subsubsection{Establishing a specific layout for the spectrometer components}

The distances between the source, the sample cell and the detector, they all played a key role at the time of performing the experiments, as this parameter affected the intensity of signal and the stability in the absorption spectra. Given a fixed signal to noise ratio, this variable was fixed in order to enhance the repeatability of the measurements. The source, the sample container and the sensor were arranged as showed in the Figure 30 below: 


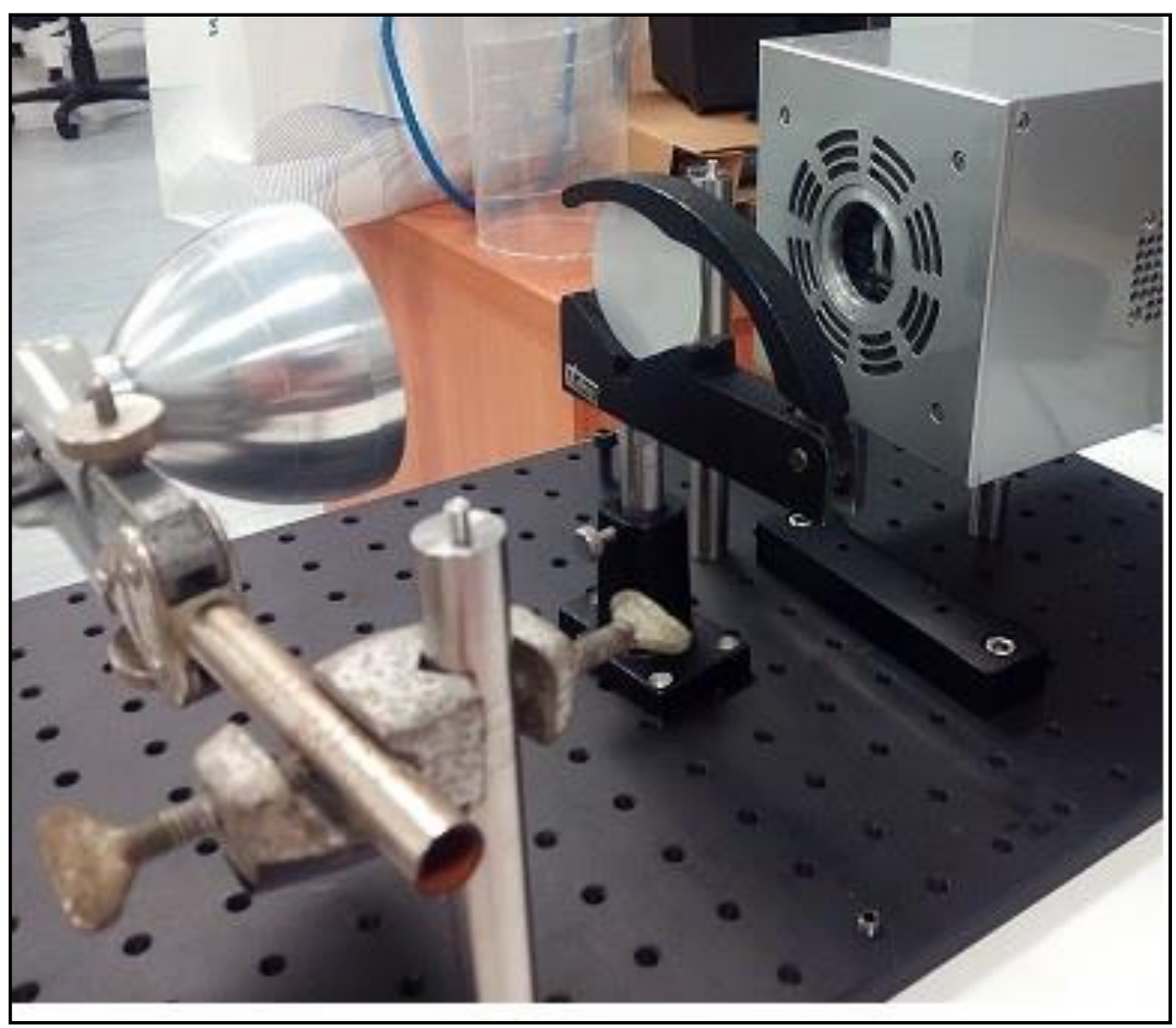

Figure 30. Layout of the main components of the spectrometers. The source, the sample cell and the camera are fixed by screws to the ground in an optimal distance obtained by laboratory testing

\subsubsection{Choosing an acquisition time}

As the variables mentioned above, the acquisition time was fixed to a unique value in seconds too. The main aim of this fact was oriented to the data processing. After several batches of trials, it was found out that the optimal duration of the acquisition or spectral recording was 11 seconds, as it allowed the data to be stored in a small size file and clearly seeing the absorption peak in a short processing time. These recorded spectra were processed by $M A T L A B^{\circ}$ by a script that read the file and simultaneously subtracted the background.

\subsection{Specific chronogram of the experiments}

The development of an optimal device to measure fuels and their blends involved several stages corresponding to different workplaces. The scheme of these stages and their corresponding workplaces and achievements is showed in the Table 10 below: 
Table 10. Work stages of this thesis in order to obtain the specific application on fuel quality control

\begin{tabular}{|c|c|c|}
\hline Years & Workplace & Experiments \\
\hline 2013-2015 & CEI MONCLOA & $\begin{array}{l}\text { Preliminary results obtained for } \\
\text { food spoilage by yeasts } \\
\text { (detection of } 1,3 \text { pentadiene and } \\
\text { CO) (Rivas, et al. } 2015 \text { ) }\end{array}$ \\
\hline Year 2016 & New Infrared Technologies (NIT) & $\begin{array}{l}\text { Establishment of a new } \\
\text { experimental set up with a new } \\
\text { device without optics with the } \\
\text { aim of measuring fuels and their } \\
\text { mixtures. } \\
\text { Implementing the PCA algorithm } \\
\text { in the software of a device and } \\
\text { method to monitor defective } \\
\text { and non defective spot welding } \\
\text { at automotive industry }\end{array}$ \\
\hline Year 2017 & $\begin{array}{l}\text {-Back to work at LPF lab and } \\
\text { calibration transfer from the } \\
\text { factory device to the laboratory } \\
\text { set up } \\
\text {-Scholarship at Texas A\&M } \\
\text { University for the Fall semester }\end{array}$ & $\begin{array}{l}\text {-Analysis on headspace for } \\
\text { volatile compounds in gasoline } \\
\text {-Analysis on edible oils mixtures } \\
\text { by MID and NIR } \\
\text {-Data processing on the raw } \\
\text { spectra acquired at the LPF } \\
\text { laboratory. } \\
\text {-FTIR measurements in gas flow } \\
\text { for volatiles such as ethanol and } \\
\text { acetone }\end{array}$ \\
\hline
\end{tabular}




\subsubsection{The work developed inside the CEI Moncloa framework (years 2013-} 2015)

During this stage, the first device manufactured from NIT was used to detect and analyze volatile chemicals such as 1,3-pentadiene and $\mathrm{CO}_{2}$ in order to detect food spoilage carried out by yeasts. The experimental set up was fixed for this purpose, using a special sample cell to gather the gas that was released from the yeast, and the spectra were collected in a dynamic way of recording, fixing the frame when the absorption peak of 1,3 pentadiene or $\mathrm{CO}_{2}$ appeared (Rivas, et al. 2015).

\subsubsection{The experimental set up with a new device and the analysis performed at the manufacturing company New Infrared Technologies}

During this period, the experimental work was developed in the manufacturing company laboratory. A new set up had to be fixed after a batch of tests. A new sensor was used with the LVF but without the optics. A layout for each of the spectrometer components was fixed and same with the time of acquisition or recording of the spectra for liquid measurements. This new set up was applied to the measurement of pure substances (Maldonado, et al. 2017) and gasoline and alcohol mixtures, following exactly the same procedure.

\subsubsection{The work developed inside the LPF laboratory and the Computer Science and Engineering Department PSI Lab, from Texas A\&M University}

While working in the LPF laboratory, several trials were carried out: the first one was regarding the improvement of an experimental set up for measuring volatile compounds in gasoline and their mixtures with alcohols. This improvement was useful for pure gasoline volatile compounds measurement, but not as useful when it came to mixtures of gasoline and alcohols.

In a parallel way, edible oils and their mixtures (made of a high quality olive oil mixed with a cheaper one) were analyzed using the NIR and the MID IR simultaneously. The aim of these experiments were testing the ability to detect possible adulterations and keep the data stored for taking them to the scholarship at Texas A\&M University where they should be processed using the specific techniques of the host research team (PSI Lab). 
When starting the mentioned scholarship at Texas A\&M University, the first aim was finding out an optimal data processing for edible oils and their mixtures in order to difference between pure oils and their adulterations with low cost ones.

Afterwards the goal was fixed on the fuel and their mixtures with alcohols. Using the same data processing, the aim was being able of simultaneously quantifying and identifying the type of alcohol added to the blend.

And finally, an FTIR equipment was used to measure the concentrations of alcohol and acetone in their volatile state in air. These chemicals were diluted in air flow at different concentrations to be measured by the FTIR device. Pre and post processing methods were applied on these spectra in order to do an accurate quantification. The FTIR measurements were performed at the Texas A\&M Engineering Experimental Station. Figure 31 below shows the Texas A\&M Engineering Experimental Station (Bryan, TX) where the experiments were carried out. Even though the small size of the sampling cell a large variability in the spectra was found concluding that this procedure had still a long way until fully design and validated. Therefore it was decided to differ its use for future research works.
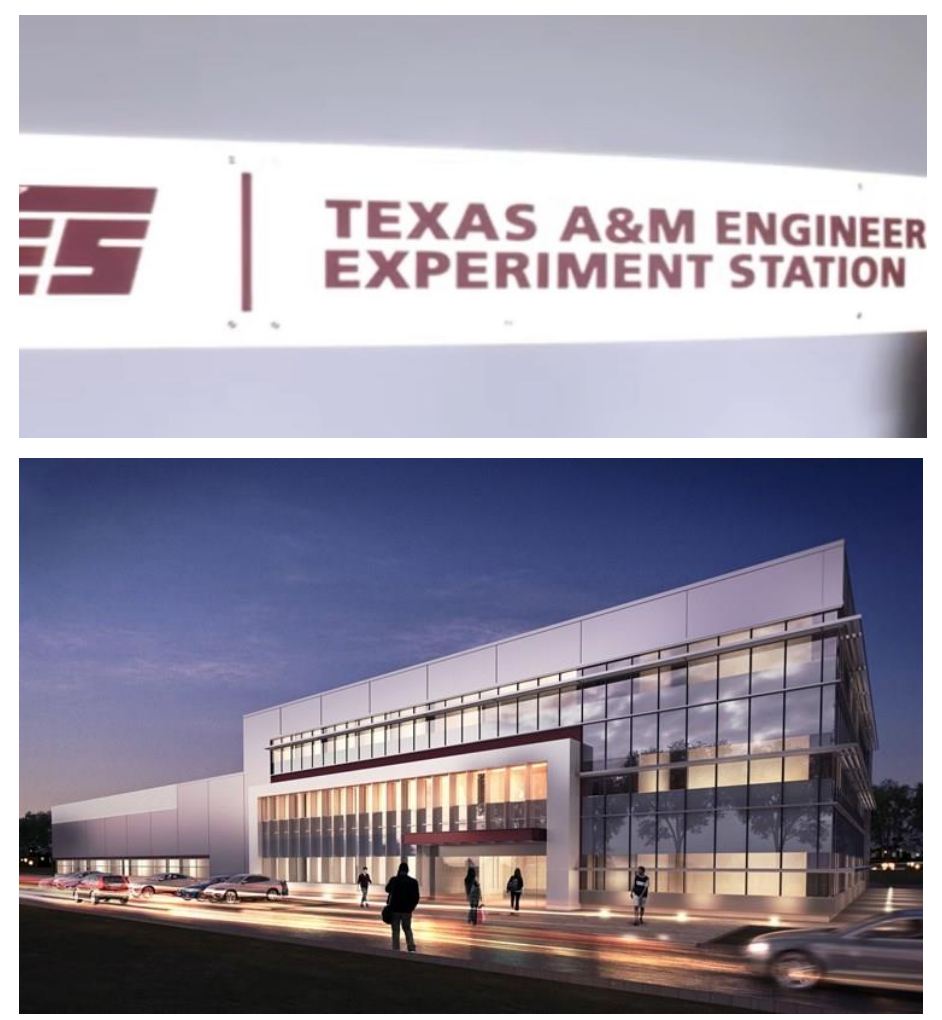

Figure 31. Texas A\&M Engineering Experimental Station (Bryan, TX, USA) 
The Figure 32 below shows the FTIR sample cell for measuring volatile chemicals such as acetone and ethanol in variable concentrations by adjusting the air mass flow.

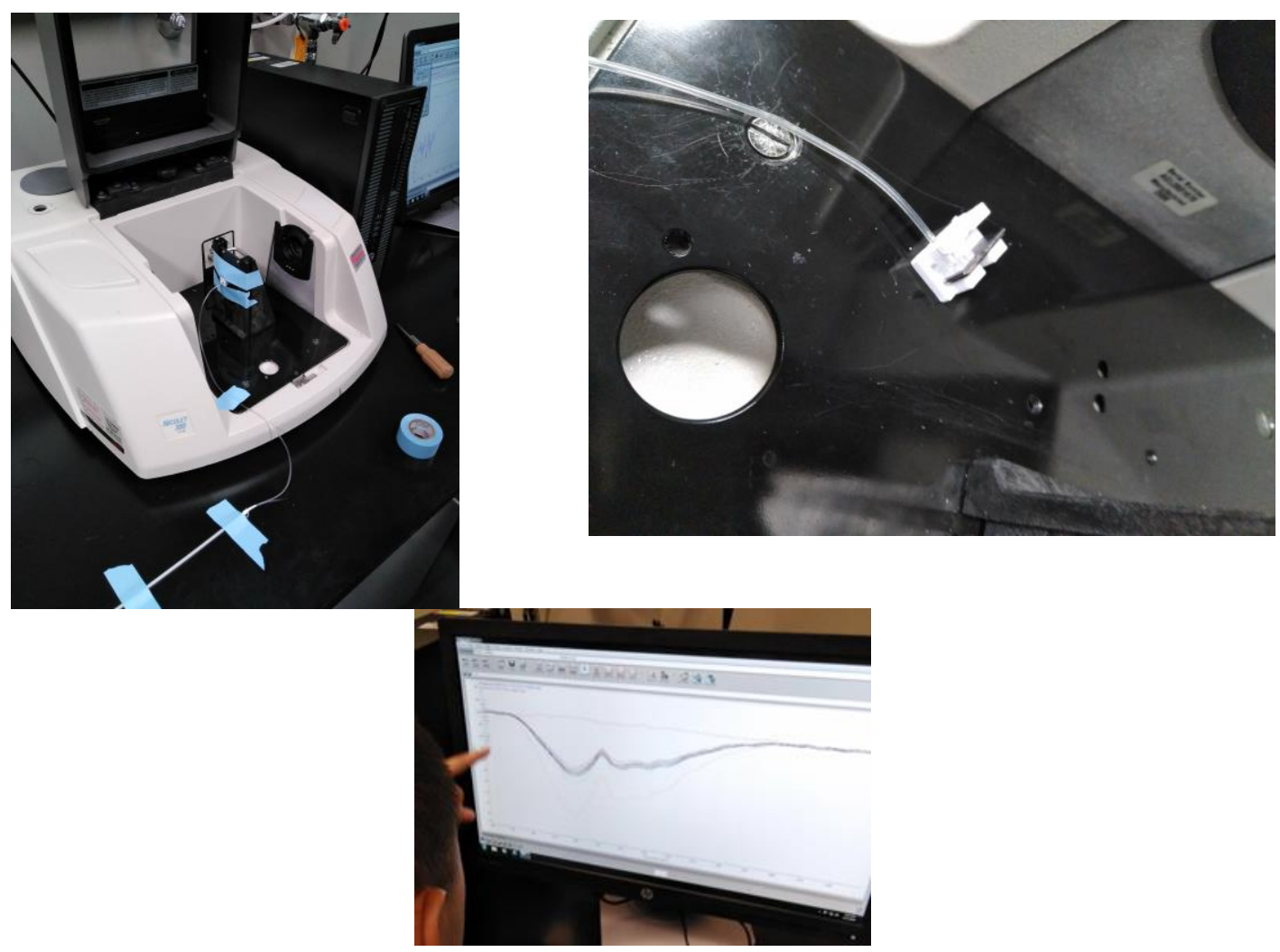

Figure 32. Experimental set up and spectra acquisition of the FTIR device for acetone and ethanol measuring

\subsection{Samples and chemicals}

\subsubsection{Experiment 1: Identification of pure fuel, additives and adulterants in gasoline}

Three gasoline samples were taken in two different seasons (winter and summer gasoline according to legislation) and from different sources, also with varying octane numbers (between 95 and 98).

Three diesel oil samples were used, also from different quality and origin (two diesel oils destined to fuel for vehicles and one diesel oil destined to heating fuel). 
The chemicals used for the test were different long chained alcohols as laboratory reagents (99.5\% analytical grade). They were all bought from Panreac ${ }^{\circledR}$. The alcohols used were methanol, ethanol, n-propanol, n-butanol and n-hexanol.

Measurements were taken on different days to ensure the repeatability and reproducibility of the results. To be more precise, the alcohols were measured on seven different dates and the fuels were measured on nine different days.

The Table 11 below screens the fuel types used for these analyses, their precedence and features.

Table 11.Gasoline fuel precedence and dates of sampling

\begin{tabular}{|c|c|c|c|c|}
\hline SAMPLE & SAMPLING DATE & BRAND & LOCATION IN MADRID & RON \\
\hline G- 1 & 11/15 (Winter) & $\dot{\imath} ?$ & ETSI Agrónomos & 95 \\
\hline G- 2 & 12/15 (Winter) & $\dot{\imath} ?$ & $\begin{array}{l}\text { New Infrared Technologies (Blind } \\
\text { sample) }\end{array}$ & 95 \\
\hline G- 3 & 09/2016 (Summer) & REPSOL & Usera (Madrid) & 95 \\
\hline G- 4 & 09/2016 (Summer) & CEPSA & Boadilla del Monte (Madrid) & 98 \\
\hline G- 5 & 09/2016 (Summer) & REPSOL & Coslada (Madrid) & 98 \\
\hline
\end{tabular}

The

Table 12 below shows the days of measuring, number of repetitions, replicates and individuals used for all the assays constituting this experiment. 
Table 12.Days, number of individuals, replicates and repetitions for the experiment 1

\begin{tabular}{|c|c|c|c|c|}
\hline Sample type & $\begin{array}{l}\text { Days of } \\
\text { measuring }\end{array}$ & $\begin{array}{l}\text { Number of } \\
\text { repetitions }\end{array}$ & $\begin{array}{l}\text { Number of } \\
\text { replicates }\end{array}$ & $\begin{array}{l}\text { Number of } \\
\text { individuals }\end{array}$ \\
\hline Gasoline (type 1) & 7 & 3 & 3 & 63 \\
\hline Gasoline (type 2) & 7 & 3 & 3 & 63 \\
\hline Gasoline (type 3) & 4 & 9 & 3 & 108 \\
\hline Gasoline (type 4) & 3 & 9 & 3 & 81 \\
\hline Gasoline (type 5) & 2 & 9 & 3 & 54 \\
\hline Diesel oil (type 1) & 7 & 3 & 3 & 63 \\
\hline Diesel oil (type 2) & 7 & 3 & 3 & 63 \\
\hline Diesel oil (type 3) & 7 & 3 & 3 & 63 \\
\hline Methanol & 5 & 3 & 3 & 45 \\
\hline Ethanol & 5 & 3 & 3 & 45 \\
\hline Propanol & 5 & 3 & 3 & 45 \\
\hline Butanol & 5 & 3 & 3 & 45 \\
\hline Hexanol & 5 & 3 & 3 & 45 \\
\hline
\end{tabular}

Table 13.Total of individuals used for the experiment 1

\section{Calibration set}

75 samples

\section{Validation set}

423 samples 
The calibration set was formed by 75 samples of different long-chained alcohols (methanol, ethanol, propanol, n-butanol and hexanol), two sorts of gasoline (winter and summer), three sorts of diesel oils (different petrol stations). 3 replicates and 3 repetitions were acquired from each fuel sample and 2 replicates and 3 repetitions were acquired from each alcohol.

The validation set was formed by 420 (after discarding 3 outliers) samples corresponding to 3 replicates and 3 repetitions acquired from measurements conducted on several days. These samples were of the same types of gasoline, diesel oils and alcohols. These data sets were concatenated and then projected onto the PC and MANOVA spaces. The projection onto the PC space was achieved by multiplying the normalized spectra by the loading matrix. The new canonical projections were obtained by first centering the PC scores of the validation set with regard to the calibration data, and subsequently projecting them onto MANOVA, via multiplication by the eigenvectors.

The days of measuring to make up the calibration and validation sets were chosen following the criteria of being as much separated as possible, i.e. choosing the first and last days of measuring for each data set.

\subsubsection{Experiment 2: Characterization of gasoline and alcohol blends}

The three commercial gasoline samples and alcohols employed in this experiment were the same as those used for experiment 1.

The mixtures of gasoline with alcohols were daily prepared using different proportions ranging from 10 to 40 percent of alcohol in gasoline $(\mathrm{v} / \mathrm{v})$. For methanol and ethanol mixtures, the proportions used were 10, 20, 30 and $40 \%$, whilst for the n-butanol blends, only two percentages were used: 20 and $30 \%$ (no blends of n-butanol are commercially used beyond 30\%). Pure chemicals (gasoline and alcohols) were also analyzed as controls every testing date.

Table 14, Table 15 and Table 16 below show the screening of the methanol, ethanol and $n$ butanol mixtures used for this experiment. The percentages used go from 0 to 100 depending on the amount of alcohol that was mixed with the gasoline to make the blend. 
Table 14.Screening of the days and blend rates used for methanol and gasoline blends, considering $0 \%$ the pure gasoline and $100 \%$ the pure alcohol. The percentages used for each day of measurement are marked with a cross $(x)$

\begin{tabular}{|c|c|c|c|c|c|c|c|}
\hline \multicolumn{2}{|c|}{ Methanol } & \multicolumn{6}{|c|}{ Percentages } \\
\hline Day & №of sp & 0 & 10 & 20 & 30 & 40 & 100 \\
\hline 1 & 24 & $X$ & & $X$ & $X$ & & $X$ \\
\hline 2 & 18 & $x$ & $X$ & $X$ & $X$ & $x$ & $x$ \\
\hline 3 & 24 & & $X$ & $X$ & $X$ & $x$ & \\
\hline 4 & 15 & $x$ & $x$ & $x$ & $x$ & $x$ & \\
\hline 5 & 24 & $X$ & & $X$ & $X$ & & $X$ \\
\hline 6 & 18 & $X$ & $X$ & $X$ & $X$ & $x$ & \\
\hline Total & 123 & & & & & & \\
\hline
\end{tabular}

Table 15.Screening of the days and blend rates used for ethanol and gasoline blends, considering 0 $\%$ the pure gasoline and $\mathbf{1 0 0} \%$ the pure alcohol. The percentages used for each day of measurement are marked with a cross $(x)$

\begin{tabular}{|cccccccc|}
\hline \multicolumn{7}{|c}{ Ethanol } & \multicolumn{7}{c|}{ Percentages } \\
\hline Day & №f sp & 0 & 10 & 20 & 30 & 40 & 100 \\
\hline $\mathbf{1}$ & 18 & $\mathrm{X}$ & $\mathrm{X}$ & $\mathrm{X}$ & $\mathrm{X}$ & $\mathrm{X}$ & $\mathrm{X}$ \\
\hline $\mathbf{2}$ & 24 & $\mathrm{X}$ & & $\mathrm{X}$ & $\mathrm{X}$ & & $\mathrm{X}$ \\
\hline $\mathbf{3}$ & 15 & $\mathrm{X}$ & $\mathrm{X}$ & $\mathrm{X}$ & $\mathrm{X}$ & $\mathrm{X}$ & \\
\hline $\mathbf{4}$ & 24 & $\mathrm{X}$ & & $\mathrm{X}$ & $\mathrm{X}$ & & $\mathrm{X}$ \\
\hline $\mathbf{5}$ & 16 & $\mathrm{X}$ & $\mathrm{X}$ & $\mathrm{X}$ & $\mathrm{X}$ & $\mathrm{X}$ & \\
\hline $\mathbf{6}$ & 21 & & $\mathrm{X}$ & $\mathrm{X}$ & $\mathrm{X}$ & $\mathrm{X}$ & \\
\hline Total & 118 & & & & & \\
\hline
\end{tabular}

Table 16.Screening of the days and blend rates used for butanol and gasoline blends, considering 0 $\%$ the pure gasoline and $\mathbf{1 0 0} \%$ the pure alcohol. The percentages used for each day of measurement are marked with a cross $(x)$.

\begin{tabular}{|cccccccc|}
\hline Butanol & \multicolumn{7}{c|}{ Percentages } \\
\hline Day & №f sp & 0 & 10 & 20 & 30 & 40 & 100 \\
\hline $\mathbf{1}$ & 50 & $\mathrm{X}$ & & $\mathrm{X}$ & $\mathrm{X}$ & $\mathrm{X}$ \\
\hline $\mathbf{2}$ & 48 & $\mathrm{X}$ & & $\mathrm{X}$ & $\mathrm{X}$ & $\mathrm{X}$ \\
\hline
\end{tabular}




\begin{tabular}{|c|c|c|c|c|c|}
\hline 3 & 49 & $\bar{x}$ & $x$ & $x$ & $x$ \\
\hline Total & & & & & \\
\hline
\end{tabular}

There were only three days of measurement for $n$-butanol and two percentages of blending used (20 and 30), due to then- butanol was introduced later in the experiments.

\subsection{Spectra pre processing}

MATLAB $^{\circledR}$ computing environment (Mathworks ${ }^{\circledR}$, Inc.) was used for the mathematical analysis on pre-processed spectra. The following pre-processing methods have the aim of removing the noise and drift from the spectral curves acquired and this way getting an increase in the resolution of the device and extracting the maximum information from the signal. All of them are common to the experiments 1 and 2 .

\subsubsection{The Savitzsky-Golay algorithm}

The raw spectral curves acquired by the spectrometer were first smoothed in order to remove the noise, using the Savitzsky-Golay filter (Savitzsky and Golay 1964). This algorithm is widely used in signal processing and it was proposed as a method of data smoothing based on local least-squares polynomial approximation. It was showed that fitting a polynomial to a set of and input samples and then evaluating the resulting polynomial at a single point within the approximation interval is equivalent to discrete convolution with a fixed impulse response. The lowpass filters obtained by this method are widely known (in some sectors) as Savitzsky-Golay filters. These authors were interested in smoothing noisy data obtained from chemical spectrum analyzers, and they demonstrated that least squares smoothing reduces noise while maintaining the shape and height of waveform peaks (in their case, Gaussian-shaped spectral peaks) (Schafer 2011).

The basic idea behind least-squares polynomial smoothing is depicted in Figure 33, which shows a sequence of samples $x[n]$ of a signal as solid dots. Considering for the moment the group of $2 M+1$ samples centered at $n=0$, we obtain (by a process to be described) the coefficients of a polynomial that minimize the mean-squared approximation error for the group of input samples centered on $n=0$, as showed in the equations below:

$$
p(n)=\sum_{k=0}^{N} a_{k} n^{k}
$$




$$
\varepsilon_{N}=\sum_{n=-M}^{M}(p(n)-x[n])^{2}
$$

The analysis is the same for any other group of $2 M+1$ input samples. We shall refer to $M$ as the "half width" of the approximation interval. In Figure 13, where $N=2$ and $M=2$, the solid curve on the left in this same figure is the polynomial $p(n)$ evaluated on a fine grid between -2 and +2 , and the smoothed output value is obtained by evaluating $p(n)$ at the central point $n=0$. That is, $y[0]$, the output at $n=0$, is

$$
y[0]=p(0)=a_{0}
$$

i.e., the output value is just equal to the 0th polynomial coefficient. In general, the approximation interval need not be symmetric about the evaluation point. This leads to nonlinear phase filters, which can be useful for smoothing at the ends of finite-length input sequences. The output at the next sample is obtained by shifting the analysis interval to the right by one sample, redefining the origin to be the position of the middle sample of the new block of $2 M+1$ samples, and repeating the polynomial fitting and evaluation the central location. This can be repeated at each sample of the input, each time producing a new polynomial and a new value of the output sequence $y[n]$.

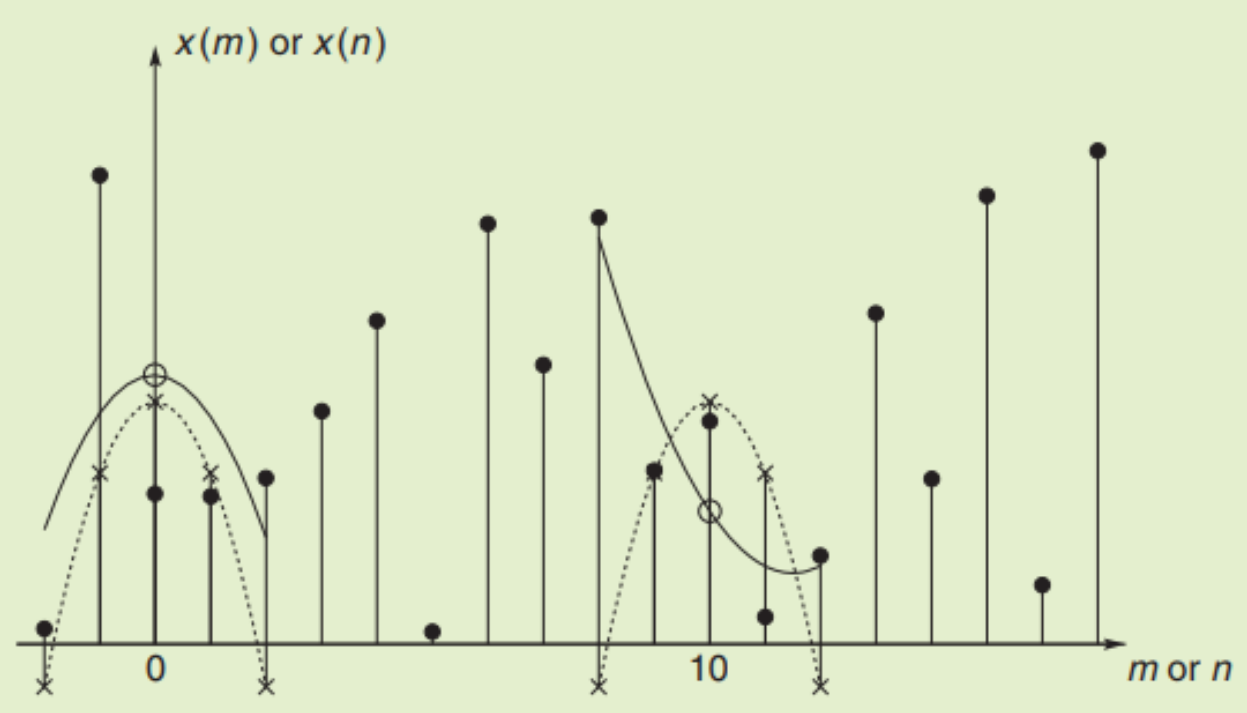

Figure 33.Illustration of least-squares smoothing by locally fitting a second-degree polynomial (solid line) to five input samples. 
Filled dots $(\bullet)$ denote the input samples, and empty dots $\left({ }^{\circ}\right)$ denote the least-squares output sample, and $x$ denotes the effective impulse response samples (weighting constants). (The dotted line denotes the polynomial approximation to centered unit impulse.)

The Figure 34 below shows spectral curves raw and pre-processed by the S-G. smoothing method. It is notorious how the noise is completely removed from the curves.
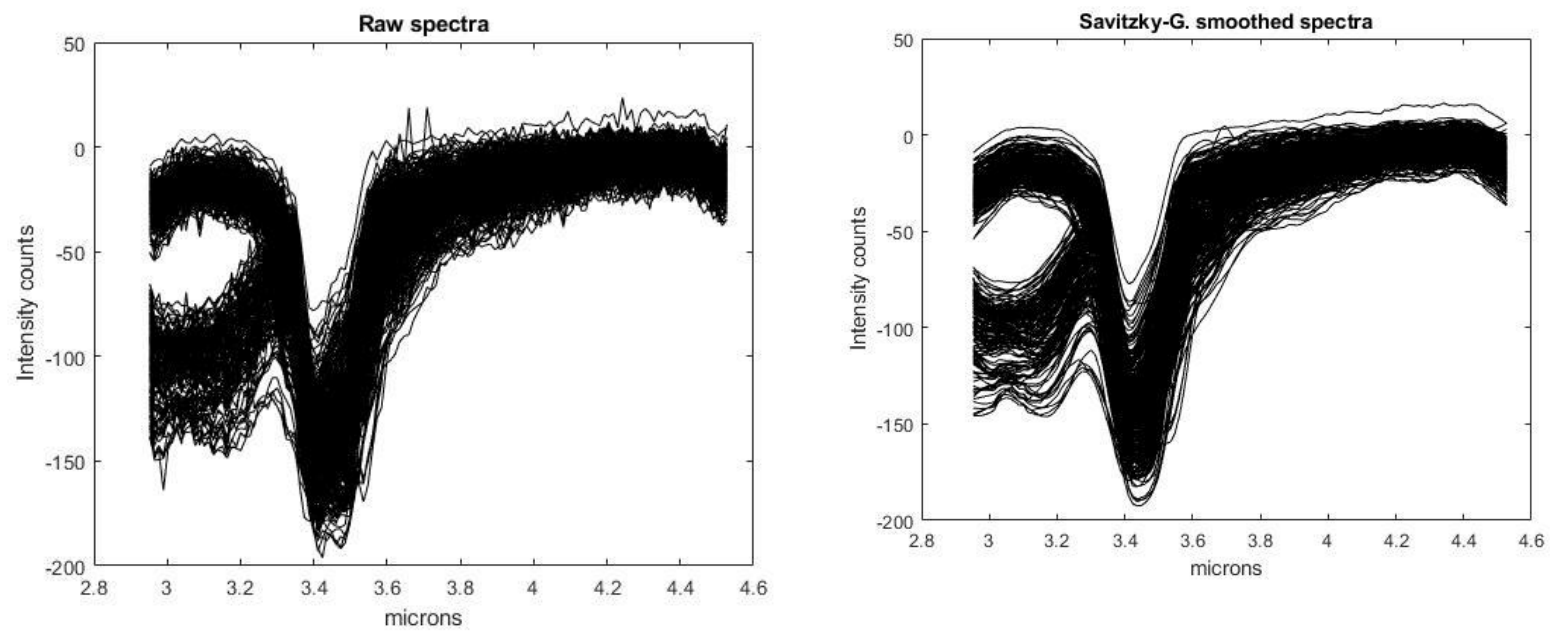

Figure 34. (Left) Raw middle infrared spectra from the validation set without any pre-processing. (Right) Pre-processed smoothed spectra using Savitzky-Golay algorithm.

\subsubsection{The Baseline Correction}

The main aim of the baseline correction is correcting or eliminating the drift in time in the spectra related to the device temperature. Baseline correction was conducted on the smoothed spectra by means of a dedicated MATLAB function. In this routine the baseline is defined as the straight line between the initial and final values of the spectra, computed based on two windows with 25 wavelengths. The base-line corrected spectra correspond to the smooth values minus the straight line. Figure 35 below shows examples of smoothed and base-line corrected spectra. 


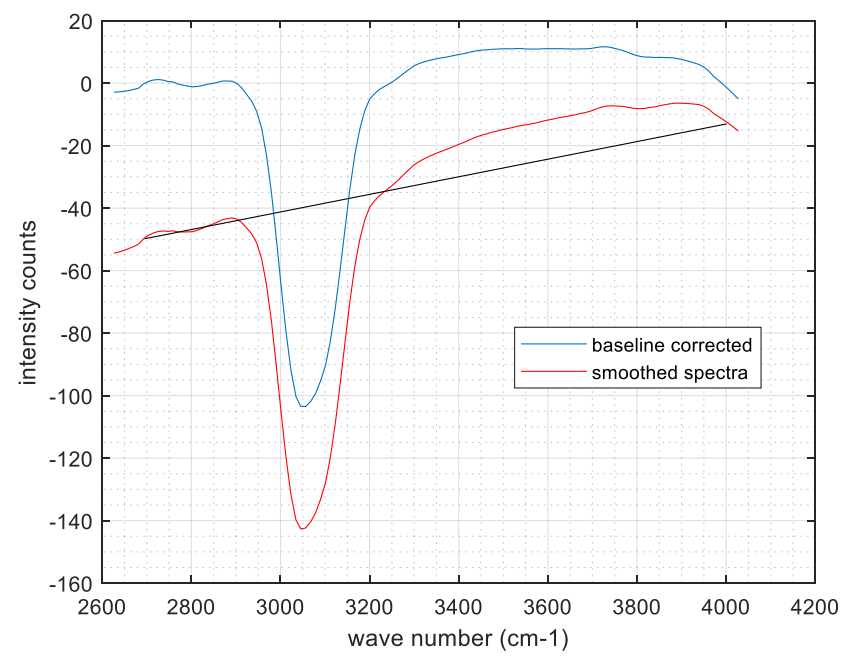

Figure 35. Comparison of the smoothed spectra versus the smoothed and baseline corrected spectra, with the highest and lowest parts of the curves taken to zero. This method is useful to eliminate the drift caused by the temperature in the sensor.

\subsection{Chemometric methods}

Whilst pre-processing methods were common to both experiments, the chemometric methods for data analysis were different for the experiment 1 , in which a Principal Component analysis (PCA) followed by a Multivariate Analysis of Variance (MANOVA) was applied, and the experiment 2, in which a Partial Least Squares regression (PLS) was used to quantify, and afterwards the same PCA and MANOVA was performed on the mixtures to segregate among chemicals (type of alcohol) blended with the gasoline. The PLS analysis was applied on the experiment 2, where quantitative determination was required, because this is one of the most useful and widely applied algorithm to quantitatively determine composition of blends.

\subsubsection{Experiment 1}

In this experiment, the first step consisted on a Principal Component Analysis. Afterwards, MANOVA was carried out by addressing the ability to distinguish between the additives and adulterants based on the PCA extracted from the MID IR spectra.

\subsubsection{Principal Components Analysis}

Principal Component Analysis was conducted on the pre-processed spectral data. It is useful to select a reduced set of PCs according to their relative weight for the non- 
supervised analysis. Since the PCA subspace was defined by the calibration set, the maximum number of PCs could not be more than 75 , retaining the information contained in 128 wavelengths. Once the PC variables are defined, any new set of spectra (in the case of study, the validation set formed by 420 spectra) may be projected on this subspace.

\subsubsection{Discriminant Analysis (MANOVA)}

One-way multivariate analysis of variance was applied to the PC scores obtained from the calibration set, using a categorical variable labelled according to the description of the materials and methods provided in the first section: gasoline, additives and adulterants. Canonical variables are a linear combination of the PCs that are created in this analysis, and they retain the maximum ability for segregation between individuals grouped in each category. Since MANOVA is preferably computed over a reduced amount of independent variables, in the case of MIR spectra, it is convenient to apply PCA in advance. MANOVA works by means of the diagonalization of Wilks's lambda matrix (in-between group variance compared to within-group or intra-group variance). The contribution of the original wavelengths to the canonical variables can be computed as $X$ (centered spectra)*L (loading matrix) *EV (eigenvectors matrix).

\subsubsection{Classification procedure}

After screening the quality of segregation done by MANOVA, a classification procedure was implemented by computing the Euclidean distance of each sample in the validation set (420 spectra) from the centroid of the categories in the canonical space created from the PCs of the calibration set (75 spectra). This procedure is then available for any new anonymous sample under routine analysis.

\subsubsection{Experiment 2}

Two kinds of supervised analysis were made in order to quantitatively and qualitatively determine the performance of the MID IR spectrometer applied to fuel-alcohol blends.

Firstly a Partial Least Square (PLS) regression analysis was applied for quantitatively addressing the overall concentration of blending in each sample, using a train set (253 sp) and a test set (134 sp), with ten folds cross validation, with the blend ratio in percentage as the predicted variable. 
Secondly, MANOVA was used to evaluate the segregation among chemicals, and the blend ratio; 181 spectra were used for the calibration set, and 97 spectra were used for the validation set (blend concentration below or equal $30 \%$ ).

\subsubsection{Quantitative PLS}

PLS was developed in 1975 for application in econometrics. It is based on the stepwise computation of a number of latent variables (L) that maximize the covariance of the independent variables $(X)$ with regard to the dependent variable $(Y)$ with the constrain of the latent variables being orthogonal one another. In our case, $X$ contains the spectra and $Y$ the concentration of alcohols in the blends. The latent variables are then used under multiple linear regression with regard to the dependent variable $(Y)$.

PLS regression is used in combination with a cross validation algorithm that estimates the optimal number of latent variables by dividing the train set in folds and leaving one out for internal validation of the model in order to prevent over-fitting.

\subsubsection{MANOVA analysis for each percentage and chemical simultaneously}

MANOVA is an extension of the univariate analysis of variance (ANOVA) that linearly combines multiple continuous variables into the so called canonical variables in order to maximize the separation between groups or categories, in our cases the additive used for blending: methanol, ethanol, and n-butanol. MANOVA estimates the dimension of the space containing the group means with the largest possible dimension being one less the number of categories, two in this study.

In order to decrease the dimensionality of the input space used by MANOVA, Principal Components Analysis is performed in advance as to retain $99.9 \%$ percentage of initial variance. Therefore, two consecutive projection vectors are used: from the spectra to the principal components, and from the principal components to the canonical variables. 


\section{Chapter 5}

\section{Results}

\subsection{Preliminary results from setting up the device and method}

The start of the LPF TAGRALIA research team collaboration with NIT began in 2012 at the request of the company, who was interested in expanding the range of applications of their PbSe detectors to other applications different than the military ones, for which the company's products were oriented. They had recently found a PhD thesis from the research group (Ruiz García, Barreiro Elorza and Robla Villalba 2008) in which there was a first approach to detection and differentiation of ethanol and ethylene by a MID IR sensor combined with an LVF. Both chemicals have traditionally been difficult to detect and segregate using conventional detectors such as chemical sensors based on resistive transducers.

The $\mathrm{CO}_{2}$ was another interesting gas investigated by the LPF research team through different research works using infrared technology. The main advantage of IR spectroscopy was the possibility of simultaneously detect different gaseous chemicals such as $\mathrm{CO}_{2}$, ethanol and ethylene.

The next application given to the PbSe sensors manufactured by NIT was the detection of organic volatile compounds such as the 1,3-pentadiene, which was a result of food spoilage by yeasts, together with the $\mathrm{CO}_{2}$ generated during the fermentation process. This development was carried out in a framework involving the company NIT and the LPF research group together with the Yeast research group from the Complutense University of 
Madrid. This application was published as a research paper inside the thesis work of its main author (Rivas, et al. 2015)and the patent developed is included in the Annex III of this document. Because of this publication, the apparatus and method were not eligible to be patented. Nevertheless the patent document became released (see it in Annex II, iError! No se encuentra el origen de la referencia.).

In this context it comes up the idea that inspired this thesis: the application of the NIT PbSe uncooled sensors to the Agroengineering field by means of the identification and quantification of additives and adulterants in fuels (See Annex I: Research paper published in Q1 journal (Fuel Processing technology)).

\subsection{Apparatus and method development for fuel analysis}

The results obtained from the experimental design gave back the optimal parameters for a reproducible and repetitive measurements batch.

\subsubsection{Fixing the light intensity and focusing the optical lens to obtain a stable signal}

As mentioned above, the NIT devices had been previously applied only for military purposes so focusing the light source was not necessary. But when it came to set it up or spectroscopic purposes this was the first step to obtain a reproducible and stable signal. The noise and the drift affecting the signal were the main obstacles to get this reproducibility, thus a preliminary calibration was needed as first step. The results obtained from focusing the light and obtaining reproducible signals with the two devices (the one used at the LPF laboratory and the one used at the NIT factory).

\section{Adjusting the signal at the LPF laboratory (using lens)}

The results of this process gave back the optimal signal by using optical lens to focus the light on the detector. The amount of light that reached the detector was high enough but not saturated, the noise was minimized and reproducible spectra were obtained using this configuration. 


\section{Adjusting the signal at the NIT factory (without lens)}

After adjusting the amount of light that reached the detector in order to minimize the signal to noise ratio and this way, getting a better resolution in the spectral measurements, the optics was removed. Figure 36 below displays the curve containing the optimal amount of radiation coming to the detector. The shape of the spectra corresponding to the light from the source should be "mountain shaped", as showed in Figure 36 below where the peak corresponds to the emission of the Silicon carbide filament of the lamp.

In a parallel way, the dynamics of the sensor were fixed too, setting the integration and the reset times to a fixed value of $20.0 \mu \mathrm{s}$.

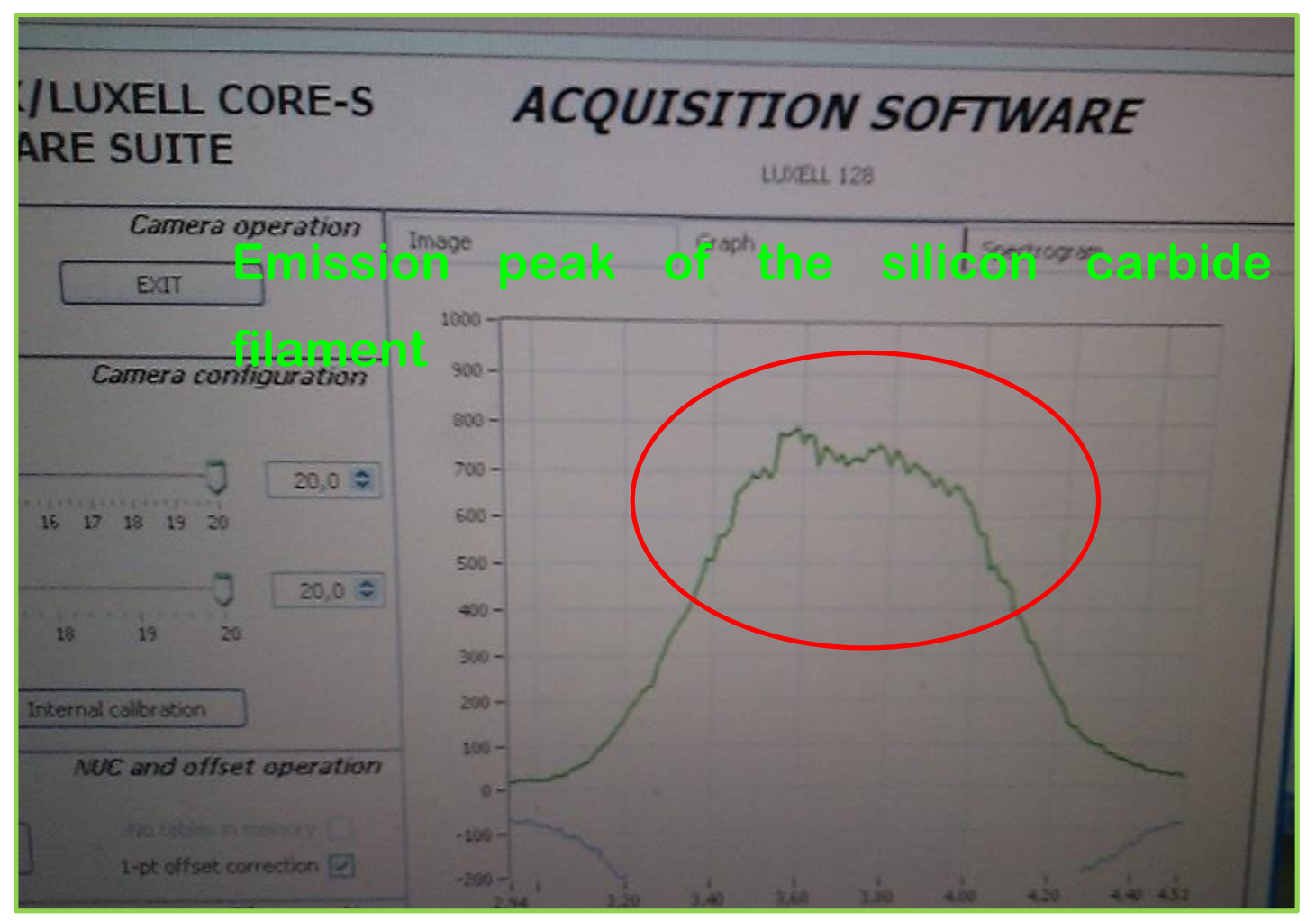

Figure 36. Shape of the spectra corresponding to the radiation from the infrared source, after being focused and optical lens removed in the acquisition sofware

\subsubsection{First spectra acquisition and data storage}

Before being able to directly read the files acquired by the camera through MATLAB, the pre processing and data analysis of spectra were done by directly exporting the acquired spectra to EXCEL files from the acquisition software (See Annex II about development of software Reading .dat files with optics and Reading the files without optics). 
No backgrounds were being subtracted from the spectra recorded and the data stored were an average of the 360 frames per second acquired by the 128 detectors. This means, an average of 360 frames per second was stored in each cell of the matrix formed by the 128 detectors and the wavelengths or channels that each of them captured in steps of 0.024 microns as showed in Figure 37 below:

\section{$1.5 \mu \mathrm{m} \quad 5 \mu \mathrm{m}$}
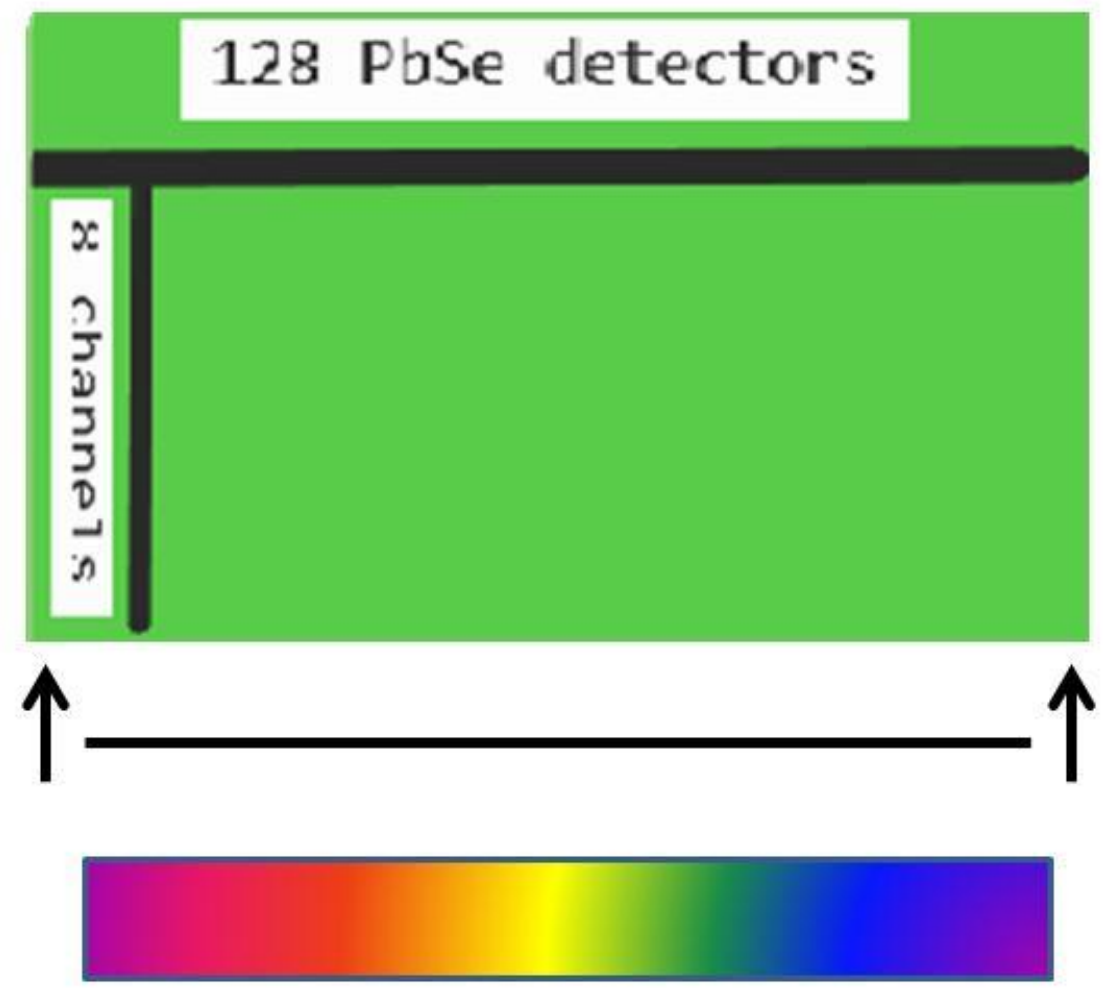

$2.5 \mu \mathrm{m}$

$4.5 \mu \mathrm{m}$

Figure 37. PbSe MID IR detector scheme in terms of wavelengths

Afterwards, the background was subtracted by taking the empty sapphire windows as a blank.

As mentioned above, in a first approach, the spectral data were stored as EXCEL files (.xlsx format). These first recorded spectra from liquid substances (aqueous potassium sorbate and glucose in concentrations ranging from 0.001 to $0.5 \mathrm{~g} / \mathrm{L}$ (See Figure 38 top); and patron compound 1,3-pentadiene in aqueous solution in concentrations ranging from 1 to 100 
g/L. Three repetitions and three replicates of each sample were recorded from each solution, reaching a total of 27 spectra for each concentration value. Figure 38 below shows some of the acquired spectral curves visualized in EXCEL datasheets.
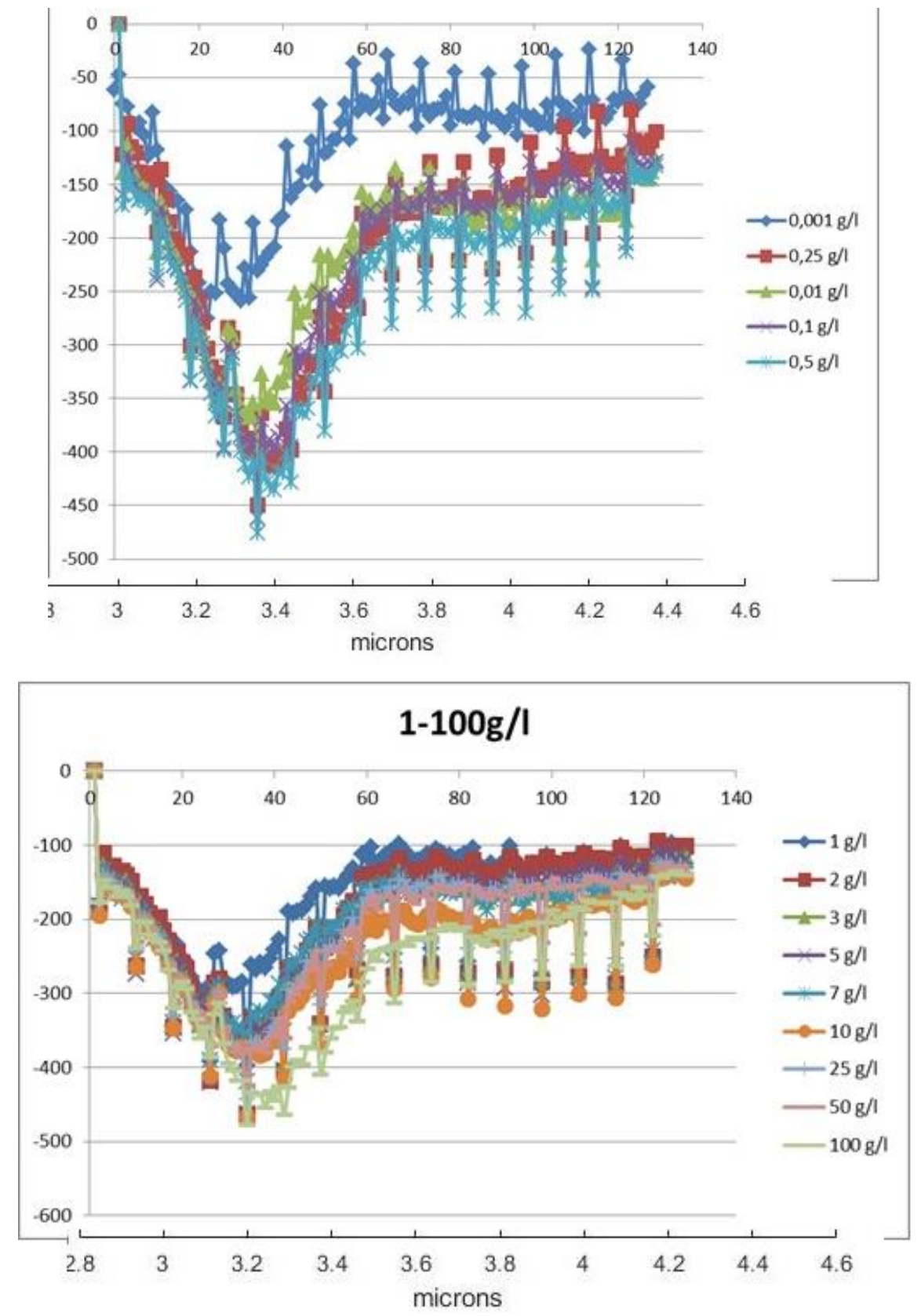

Figure 38. Spectra pre processing by Excel of an analyte in solution at different concentrations

As it can be observed, the absorption intensity of the peaks increased with an increasing value of the solute concentration. 


\subsubsection{Triggering the spectra recording to homogenize the data}

When performing the first experiments on liquid chemical substances the spectra were acquired and recorded during few seconds, time enough to obtain a stable signal and exporting it to EXCEL. This method resulted useful to process data from liquid chemicals but at the time of measuring gases or volatiles in headspace, or great amounts of spectra, it stopped being practical as the diffusion of the gas inside the measuring cell was depending on the acquisition time exclusively, so a dynamics of the measurements became necessary in order to process the data and apply the multivariate methods.

The Table 17 below shows the liquid substances measured in the first experiments, whose first derived spectra are displayed in the Figure 39 below:

Table 17. Liquid substances used for the preliminary experiments to set up the device and the method

\begin{tabular}{|ll|}
\hline \multicolumn{1}{|c|}{ TYPE OF LIQUID SUBSTANCE } & \multicolumn{1}{c|}{ TREATMENT } \\
\hline Olive oil & Different varieties (pure) \\
\hline Aqueous Glucose & Different concentrations from 0.001 to \\
& $100 \mathrm{~g} / \mathrm{L}$ \\
\hline Aqueous 1,3-pentadiene (patron) & Different concentrations from 0.25 to \\
& $10 \mathrm{ppm}$ \\
\hline Ethanol in water solution & 25,50 and $100 \%$ (v/v) \\
\hline Aqueous Potassium sorbate & Different concentrations from 0.001 to \\
& $10 \mathrm{~g} / \mathrm{L}$ \\
\hline
\end{tabular}

The Figure 39 below shows the processed spectra of liquid substances by means of a first derivative: 


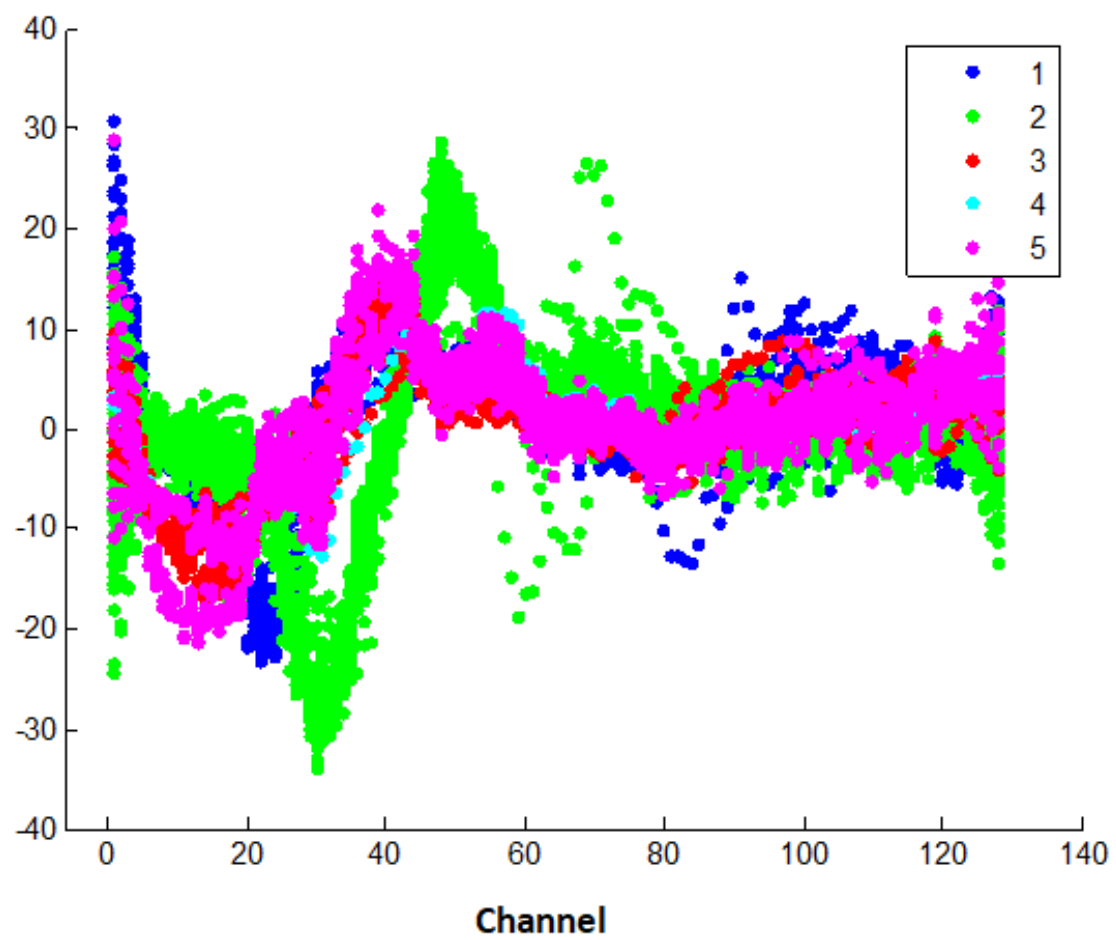

Figure 39. First derivative of the spectra from liquid substances. Numerals refer to each type of compound, being 1 the potassium sorbate, 2 the olive oil, 3 the glucose, 4 the ethanol and 5 the 1,3-pentadiene

As it can be inferred from this figure above, the spectra of the glucose and ethanol are overlapping. This proves the chemical sense of the measurements, as these two chemicals have a similar bound structure (Glucose is a polyalcohol) and both of them own vibrations corresponding to the $\mathrm{C}-\mathrm{H}$ and $\mathrm{C}-\mathrm{OH}$ bonds stretching (Bazan and Bryce 2016). By these preliminary experiments, the capacity of the sensor to segregate among chemical species which are present in foods was assessed. The results pointed out the need of Chemometric tools to distinguish these compounds when analyzing foods and other substrates.

The 1,3-pentadiene patron compound was volatilized to perform experiments of measuring this gas in a headspace. The aim of these experiments was testing the ability of the sensor to detect this organic volatile compound that is produced by yeasts during packed foods spoilage (Rivas, et al. 2015). Nevertheless, when working with gases or volatile headspaces, there existed confusion about the presence or concentration of the analyte due to the time of appearance of the absorption peak. Consequently, the measurements had to be taken while triggering the optimal time to see the neat spectrum. The importance of this variable 
is reflected in the Figure 40 below where the first derivative of the same experiment performed at different times (t1, t2 and $\mathrm{t} 3$ ) indicates the variation of the absorption spectrum first derivative $a^{\prime}$ the three different times.

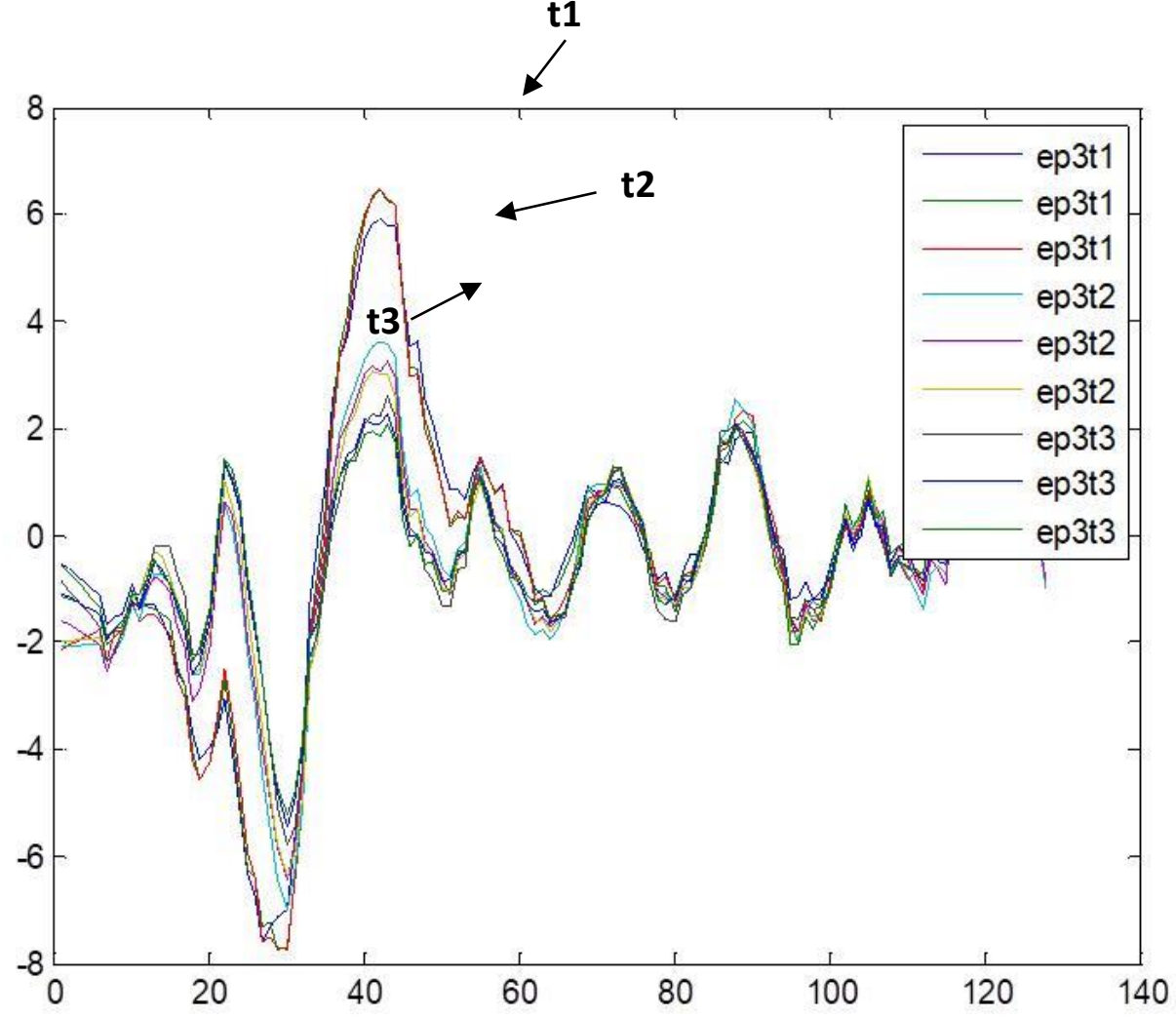

Figure 40. First derivative of the spectra acquired during a experiment (named as "ep3" in the legend) at different times of exposure (t1, $t 2$ and $t 3)$. As it can be observed, the variation on the concentration of the gas is higher during the first instants.

As the first derivative measures changes in the spectrum, a more pronounced slope in them means a bigger change (increase) in concentration of the target analyte (1,3-pentadiene) in the gas flow cell. When performing the Principal Components Analysis over these results, it was demonstrated that the first derivative of the spectra in these headspace measurements gathered the most information about the analyte concentration in the headspace. The Figure 41 below displays the loadings for PC1, which captures more than 90 $\%$ of the variance contained in the data set. 


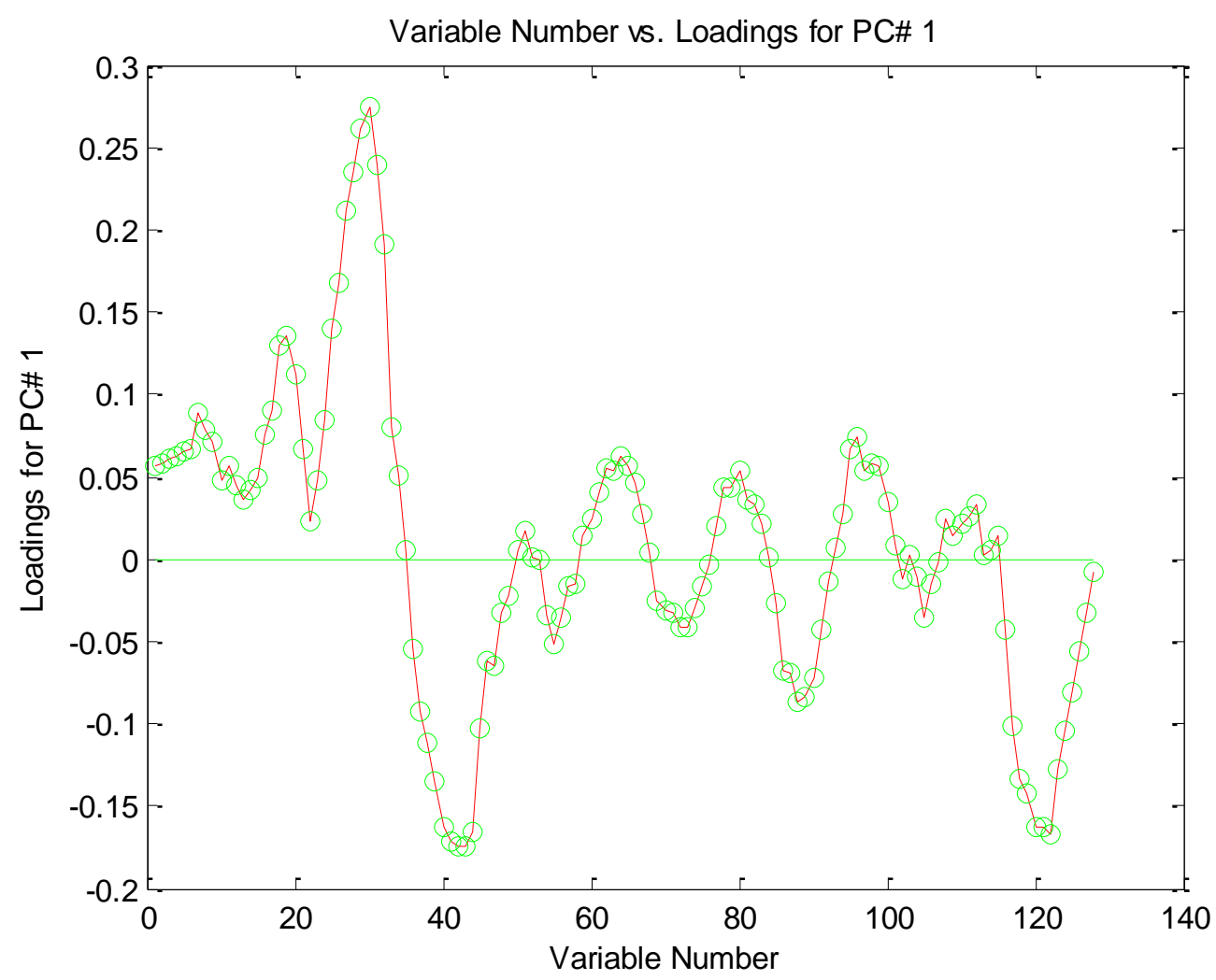

Figure 41. Loadings for the PC1 obtained from the PCA applied over the experiments performed on headspace volatile compounds

\subsubsection{Development of a MATLAB script for automatic reading of the acquisition files}

Once the measuring time was fixed and triggered for the experiments performed in headspace volatile compounds, it was not useful extracting just the average spectra from each of the 128 detectors, because in this case, the single frame or instant when the absorption peak appeared was the most important variable, and also the temporal evolution of the gas diffusion through the sample cell.

For this purpose, a MATLAB script was developed. This open source code was able to first read the file from its original format, calculating the number of frames of the whole file, eliminating the header of the file, measuring the number of frames of the data acquired and transforming them into time values (milliseconds). Both the number of frames as the time points became stored in different arrays. At the same time, and once stored these 
mentioned variables, the algorithm took the first seconds of the acquisition recording to subtract the background, taking the empty sample cell as a blank (See code in Annexes).

One example of the spectra plot using this code is shown in the Figure 42 below, where the abbreviation "ep3" corresponds to experiment 3 (the third repetition of the same experiment) and $\mathrm{t} 1, \mathrm{t} 2$ and $\mathrm{t} 3$ means the three times of recording along the duration of the experiment.
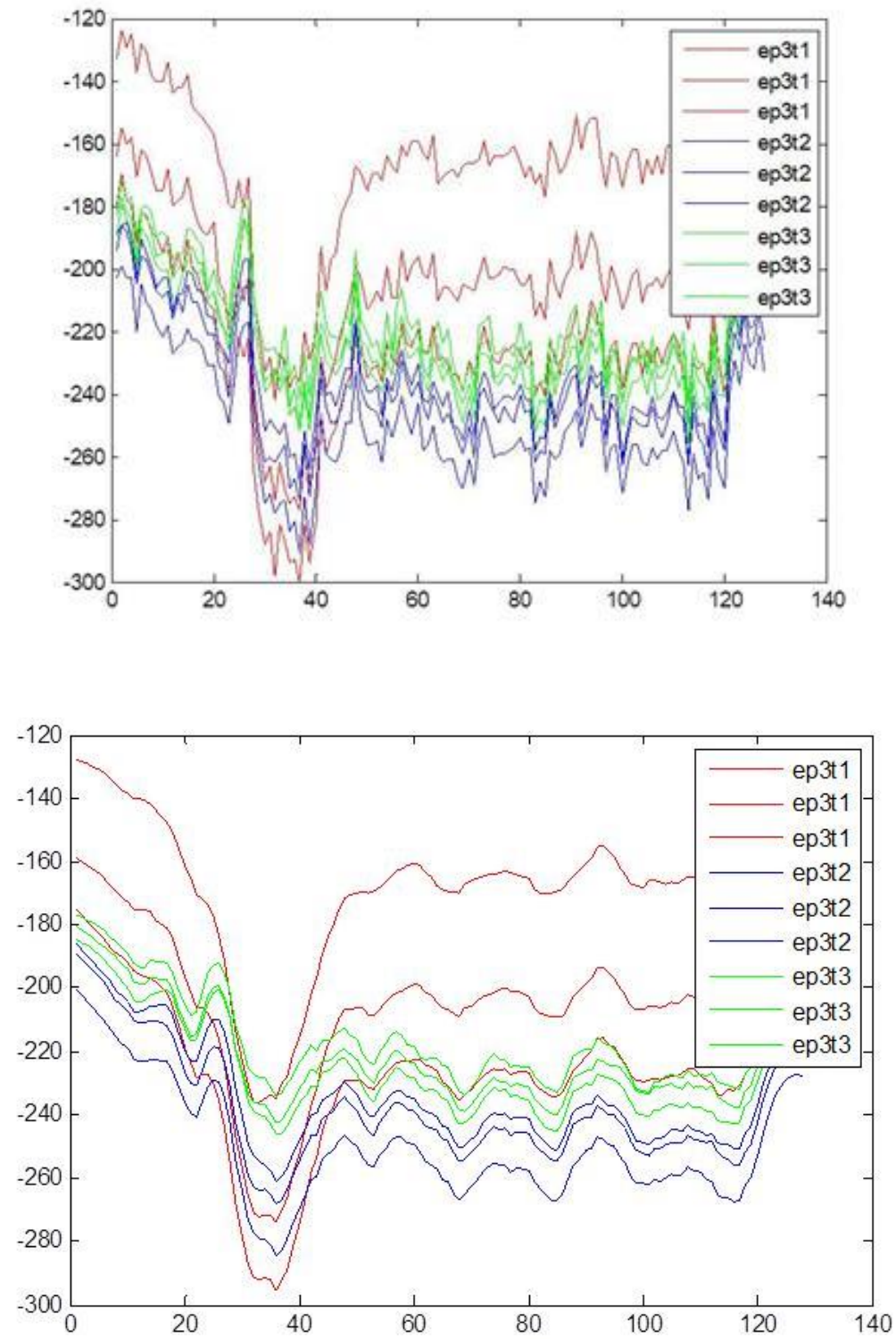

Figure 42. Raw (top) and smoothed spectra (bottom) obtained directly through the designed script 


\subsection{Establishing an experimental set up for gas measurements (volatile compounds in headspace)}

As mentioned in section 4.1.2 (Establishment of a fixed experimental set up) two different approaches were obtained for liquid and gas measurements respectively. While Liquid measurements were performed just dropping the sample between the two sapphire windows and recording during a fixed time, gas measurements required the use of a specifically designed recipient. The protocol for gas measurements is described in Figure 43 below:

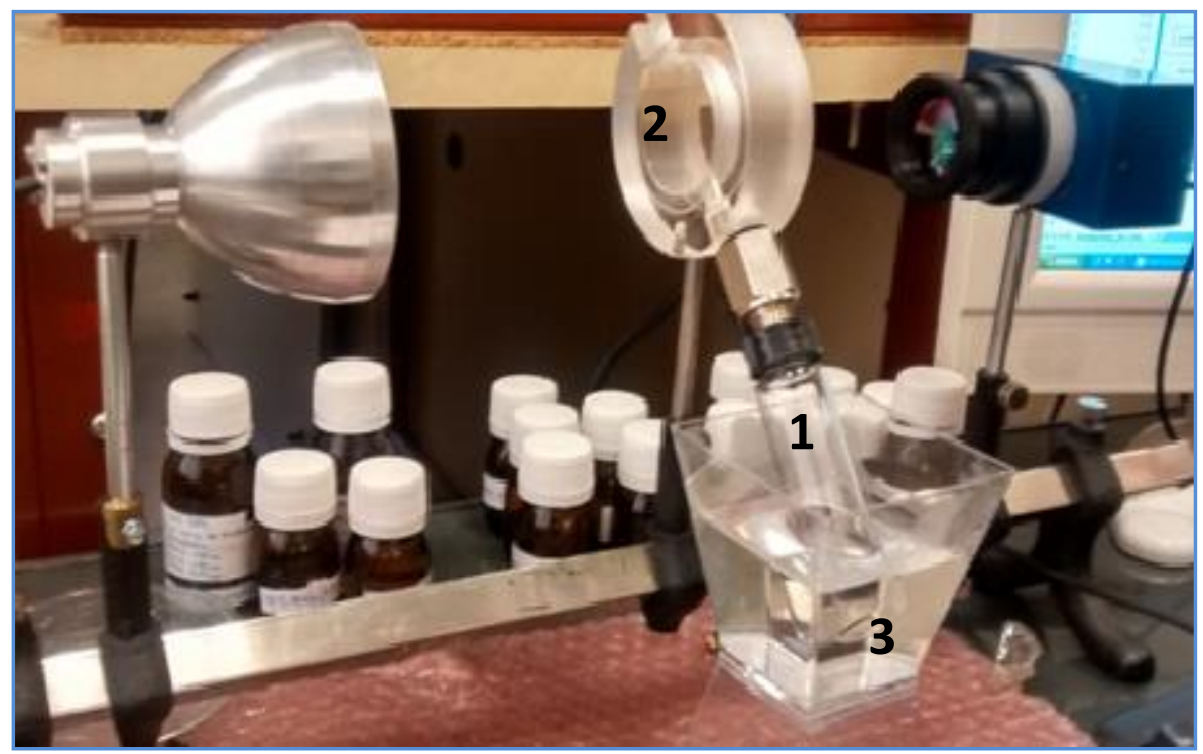

Figure 43. Experimental set up designed for volatile compounds in headspace

The recipient for sample (1) consisted on a bottle with a sealed cap connected to a valve and a tap. When opening the tap, the volatile compounds in the recipient's headspace were released to the sample cell (2) which consisted in a ring made of methacrylate, whose optical path length was $1 \mathrm{~cm}$. The volatile compounds entered the sample cell throughout diffusion mechanism. Volatilization was enhanced by heating the sample with boiling water (3).

\subsubsection{Acquisition from headspace in gasoline and alcohols}

Using the experimental set up described above some testing on volatile chemicals was performed. 
The first application in study was oriented to pure gasoline volatile compounds, which were released by the pure fuel in storage conditions (at room temperature and atmospheric pressure).

Gasoline is generally a refined product of petroleum consisting of a mixture of hydrocarbons, additives, and blending agents. The composition of gasoline varies widely, depending on the crude oils used, the refinery processes available, the overall balance of product demand, and the product specifications. But the typical composition of gasoline is based on hydrocarbons (\% volume) as follows: $4-8 \%$ alkanes; $2-5 \%$ alkenes; $25-40 \%$ isoalkanes; $3-7 \%$ cycloalkanes; I-4\% cycloalkenes; and $20-50 \%$ total aromatics $(0.5-2.5 \%$ benzene) (Ahmed and Goteng 2015).

The most volatile compounds evaporate at storage conditions (room temperature and atmospheric pressure) and the main aim of this acquisition was testing if the PbSe MID IR sensor was able to monitor these volatile emissions. The spectral results obtained are shown in Figure 44 below. The spectra belonging to the gasoline were not processed as there was no database to identify chemicals on them. They correspond to 3 replicates and 3 repetitions of the same gasoline sample. 


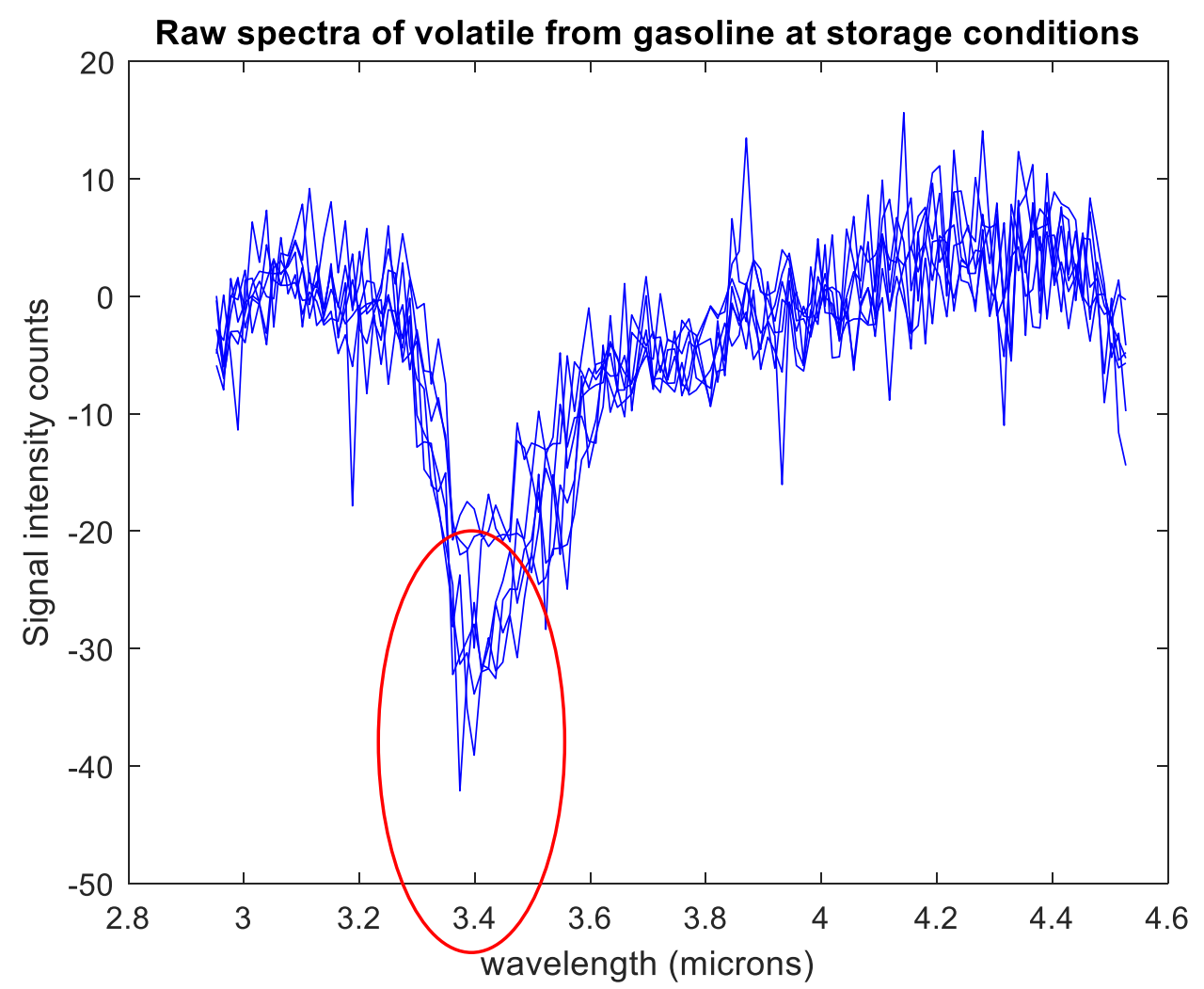

Figure 44. Raw spectra of volatile from pure commercial gasoline at different storage conditions

The next step in order to test the device for mixtures monitoring was assessing the ability of the device to detect volatile alcohols, concretely ethanol and methanol. For this purpose, the sample had to be volatilized as shown in the Figure 43 due to the boiling point of ethanol and methanol is higher than room temperature (Knorr and Stange 2015) as gathered in Table 18 below. This was not necessary at the gasoline measurements because of the much lower boiling point of gasoline than alcohols.

Table 18. Short-chain alcohols (ethanol and methanol) boiling points compared to pure gasoline

\begin{tabular}{|cc|}
\hline Alcohol & Boiling point (ㅇ) \\
\hline Methanol & 65 \\
\hline Ethanol & 78 \\
\hline Gasoline & 39 \\
\hline
\end{tabular}


The spectra recorded from volatilized alcohols are displayed in the Figure 45 beneath that displays the scattering of the raw spectra from volatilized alcohols recorded along a time interval without pre treatment whilst the Figure 46 shows the spectra of 3 replicates and 3 repetitions of volatilized ethanol and methanol (the same ones used for the experiment 2, see 4.3.2), smoothed and normalized. As it can be observed in the spectra of methanol differ considerably from the ethanol ones even in gas phase, as the hydrogen bonds of methanol are broken much more easily than ethanol, due to its high volatility (Knorr and Stange 2015).

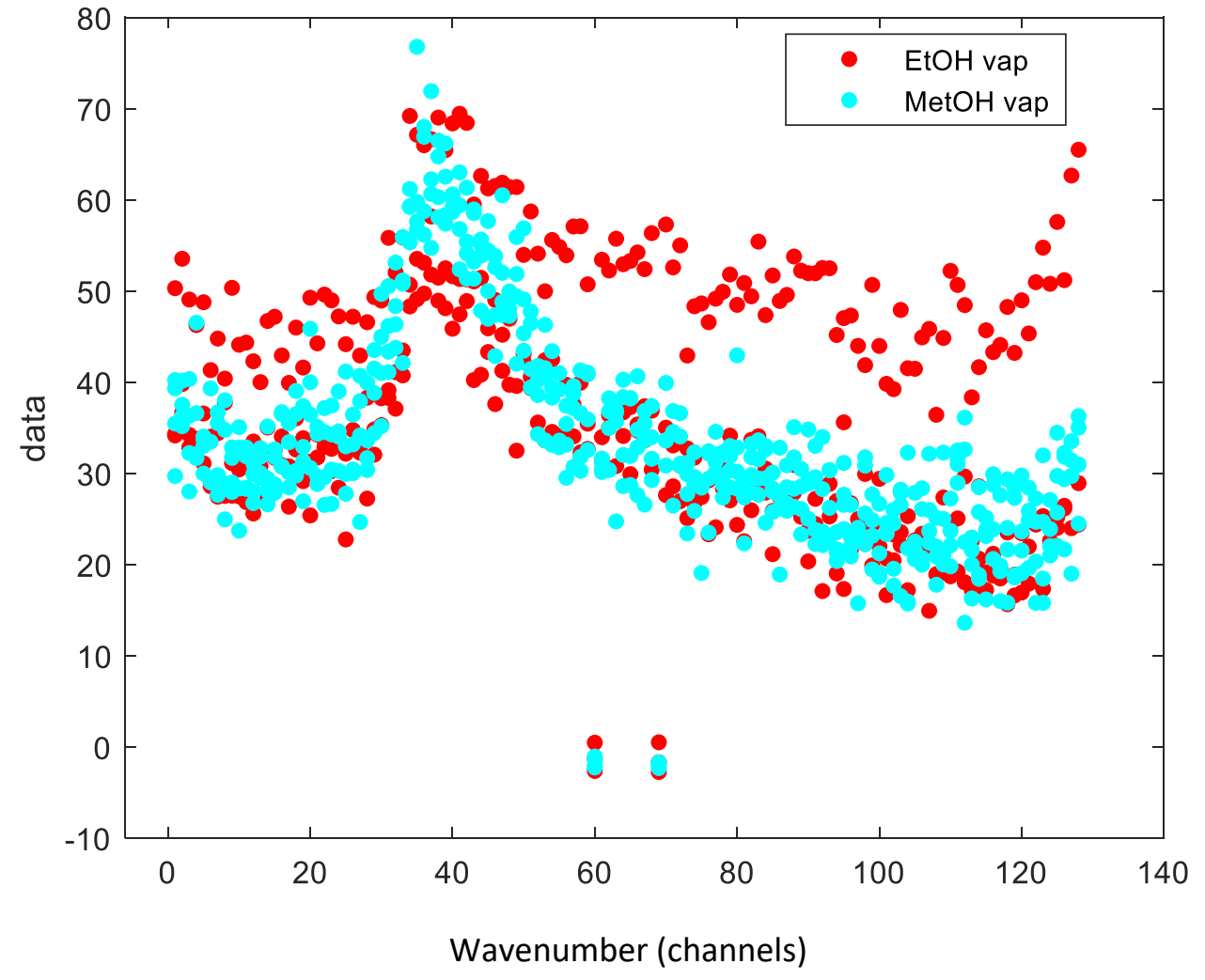

Figure 45. Raw spectra scattering of pure volatilized methanol and ethanol. The temperature of volatilization was above 60 ㄷ 


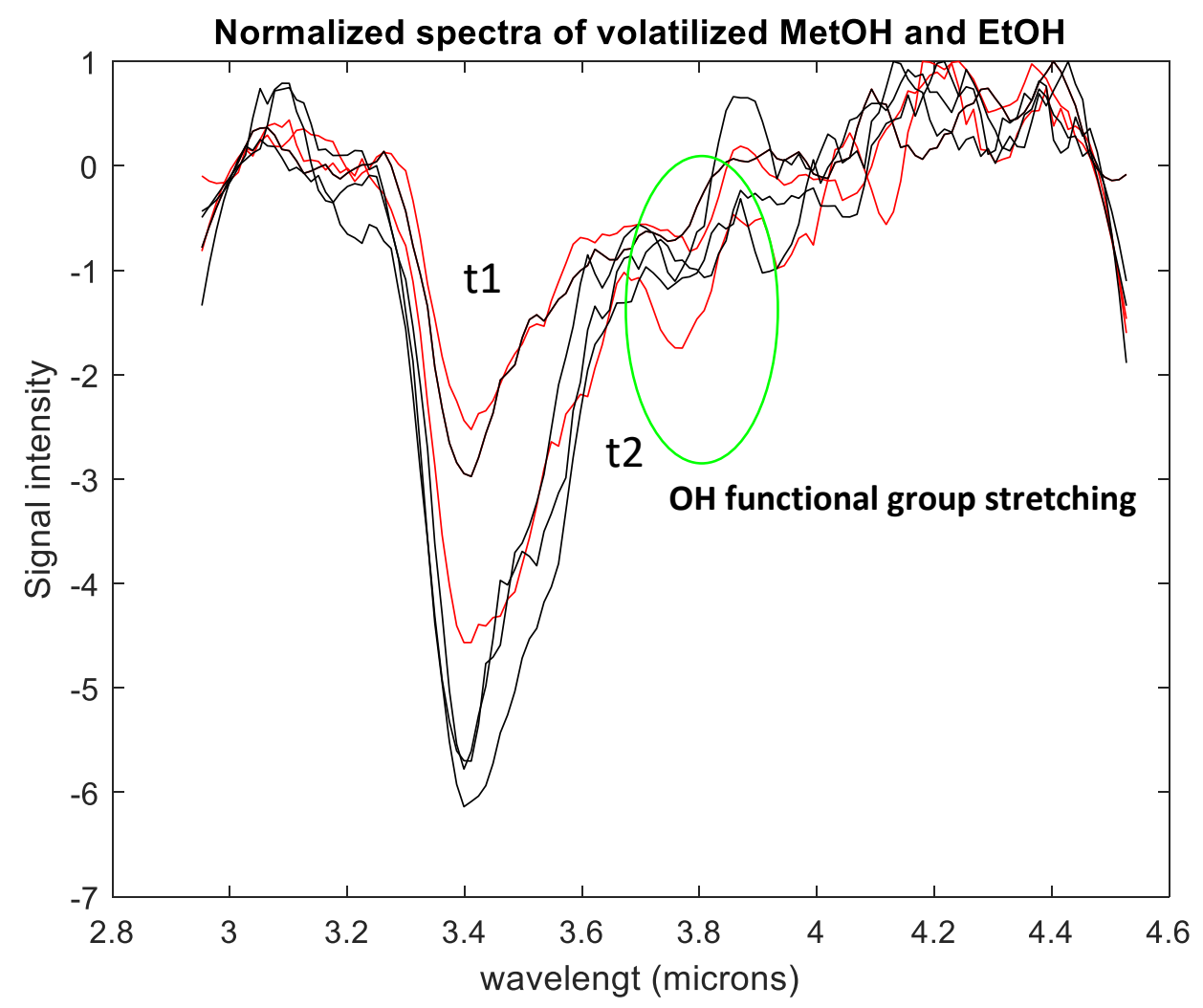

Figure 46. Smoothed and normalized spectra of volatilized pure alcohols (MetOH and EtOH) at the beggining and the end of the acquisition ( $\mathrm{t} 1$ and $\mathrm{t} 2$ respectively)

As it can be observed, the hydroxyl functional group $(\mathrm{OH})$ stretching disappeared progressively along time, because of the volatilization of these alcohols. This fact weakens the hydrogen bond between their molecules through this functional group, diminishing the importance of this interaction (Knorr and Stange 2015).

\subsection{The bandwidth calculation and its utility}

In order to get a better knowledge of the PbSe detector resolution, a new calculation was performed, using the spectra obtained from preliminary measurements of volatile 1,3pentadiene patron compound in a headspace (these spectra are displayed in the Figure 47 below), and the gaseous metabolites released by yeasts cultures in a headspace too (Rivas, et al. 2015). This approach consisted on finding out the bandwidth of the absorption peaks on the gaseous compounds spectra. The aim of this calculation was an attempt to estimate the concentration of a chemical in a headspace in a diffusion-controlled medium. 
Bandwidth is defined as the difference between the upper and lower cutoff frequencies or wavelengths in a spectral signal. A key characteristic of bandwidth is that any band of a given width can carry the same amount of information, and this information is what was correlated with the concentration of the volatile compound in the headspace (Sundararajan 2009).

The MATLAB function developed by Barreiro et al. from LPF was based on taking the first derivative of the absorption signal and extracting these upper and lower cutoff wavelengths by means of a mathematical algorithm.

The results are showed in the Figure 47 and Figure 48 below, where the bandwidth is marked in red for each spectrum obtained.

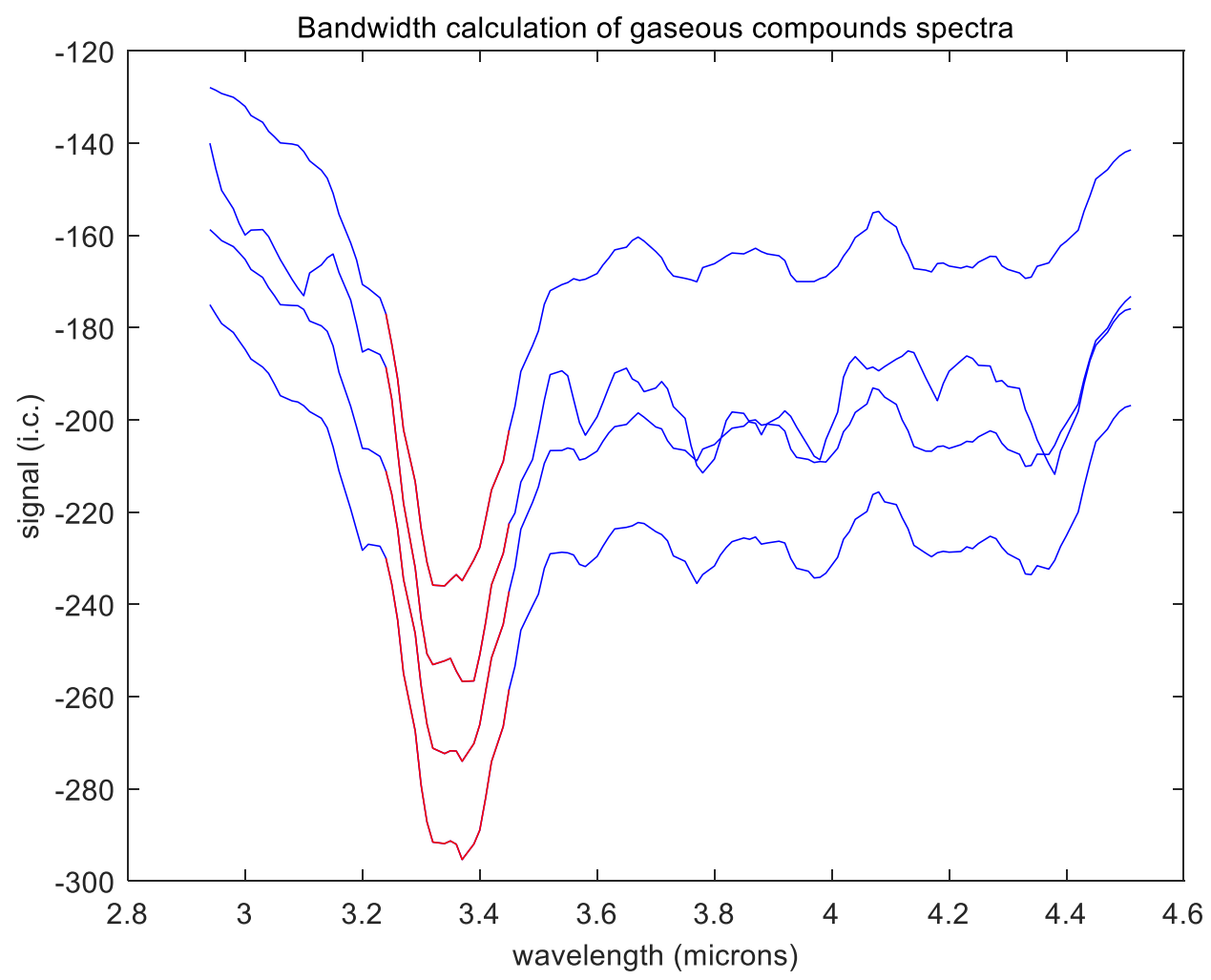

Figure 47. Bandwidth calculation on the raw spectra of a gaseous patron compound $(1,3-$ pentadiene) 


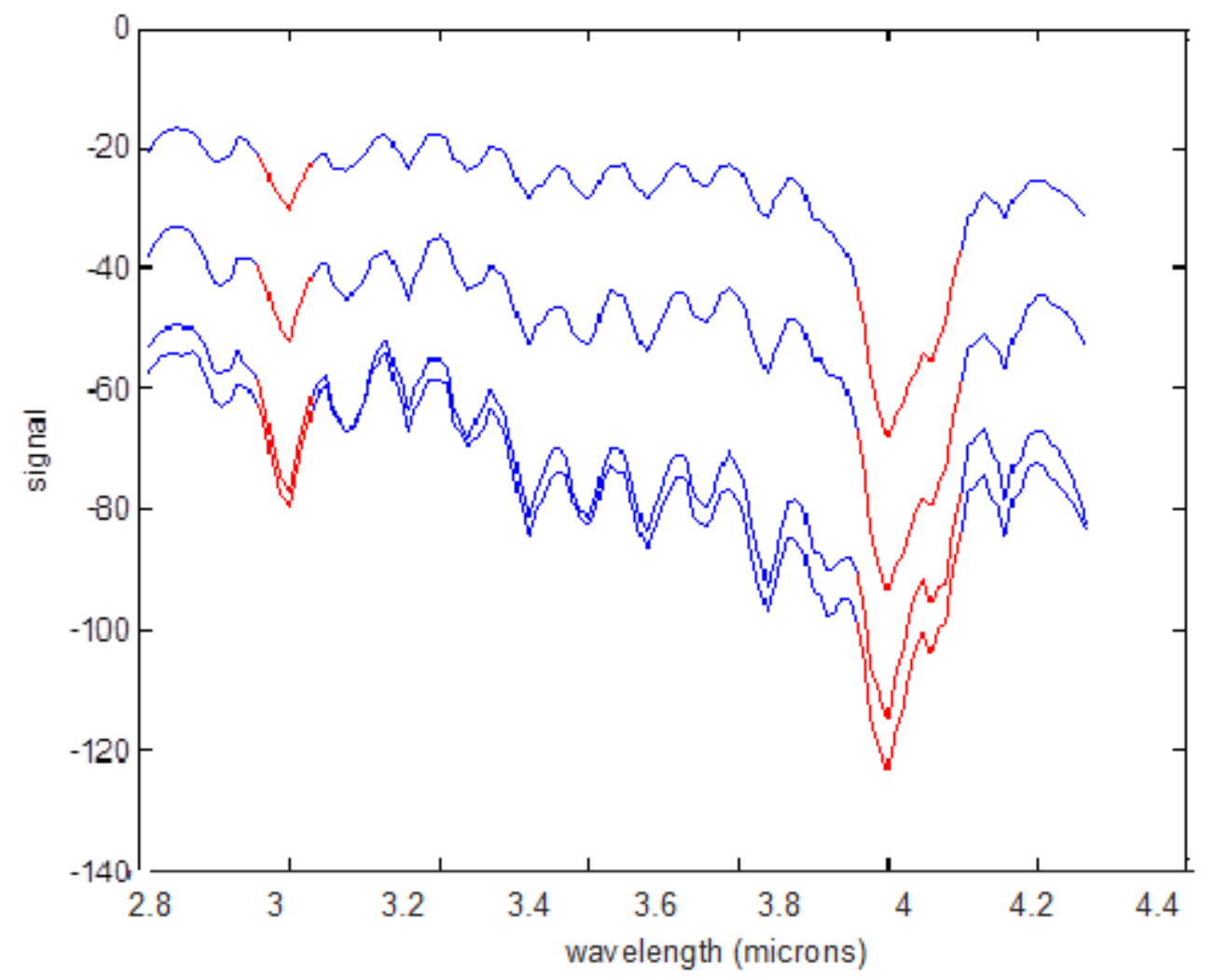

Figure 48. Bandwidth calculation of two absorption peaks in a set of measured spectra from headspace of yeasts cultures. The smaller ones correspond to the gas 1,3pentadiene whilst the bigger ones are typical absorption peaks of $\mathrm{CO} 2$ at channel 100 (which corresponds to 4.2 microns).

The bandwidth value obtained from the experimental measurements was 0.19 microns, whilst the resolution of the PbSe detector was of 0.2 microns. Thus, the conclusion obtained from this calculation was that the sensibility and resolution of the device was suitable to detect these volatile chemicals in a headspace at low concentrations.

\subsection{Establishing a fixed layout and protocol for new liquid measurement at the NIT laboratory}

The results obtained from experiments 1 and 2 are based on the experimental layout fixed in the NIT factory after a laboratory batch of measurements. In this layout, the source of light, the sample cell and the detector were screwed to the ground at fixed distances in order to optimize the acquisition time, the subtracting of background and the signal 
intensity in order to process the data through a specific script designed and calculated to extract the pure liquid spectra (See Annexes).

\subsection{Experiment 1: Identification of pure fuel, adulterants and additives in gasoline}

Even though fuels are the new focus of this $\mathrm{PhD}$ thesis, previous experiments were carried out with edible oils and the results are gathered in the Annexes (see the Section 4 from Annex I).

\subsubsection{Preliminary Analysis}

The Figure 49 below shows the average baseline-corrected spectra for all types of gasoline (winter and summer), diesel oils (adulterant type 2), additives (ethanol, n-propanol, nbutanol and $\mathrm{n}$-hexanol), and adulterant type 1 (methanol). The average was done using the 75 spectral curves that formed the calibration dataset.
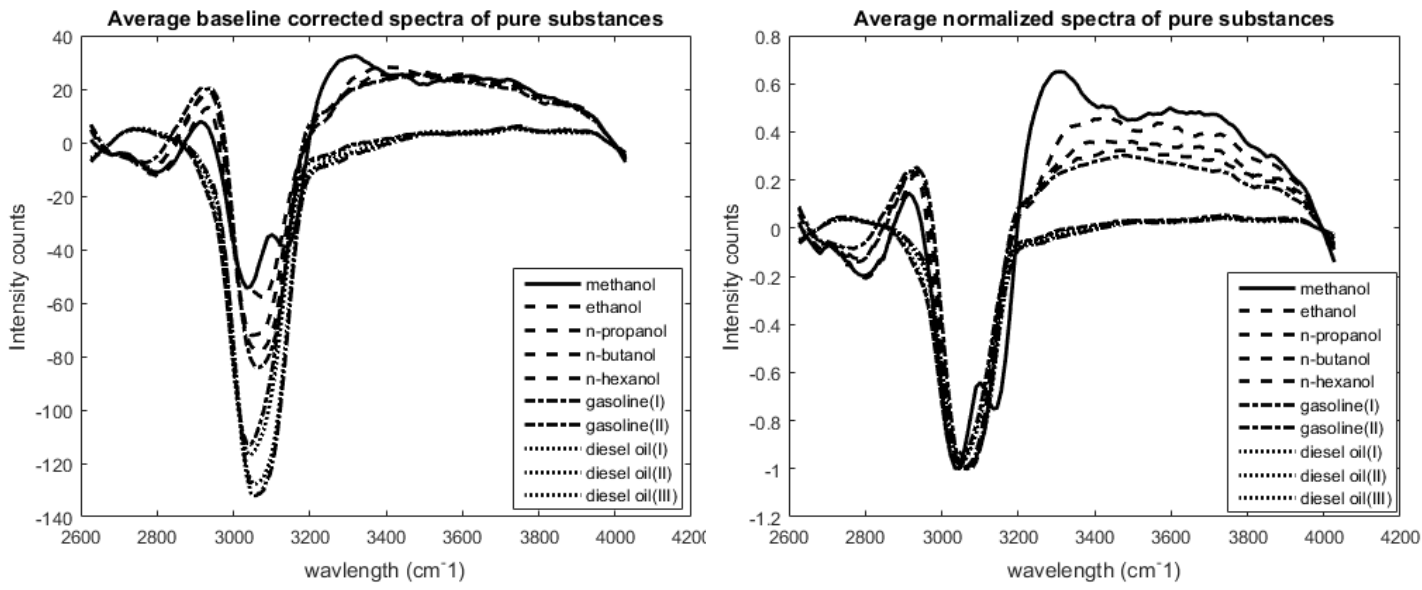

Figure 49.Spectral curves pre processing: (Left) Average blc-corrected-spectra from each sort of pure substance. (Right) Average normalized spectra from each of the pure substances.

As it can be observed, the saturated hydrocarbon $\mathrm{CH}$ stretching absorption all occurs around $3000 \mathrm{~cm}^{-1}$ (Coates 2000).

It is noticeable the second absorption peak corresponding to the hydroxyl group $(-\mathrm{OH})$ in the alcohols and more notoriously in methanol at $3145 \mathrm{~cm}^{-1}$. In ethanol, this absorption peak is slightly overlapped by an additional methyl group in the hydrocarbon chain, and its absorption wavelength is $3079 \mathrm{~cm}^{-1}$. From propanol to hexanol, the chain length is increasing and so the absorption peak corresponding to the hydroxyl groups becomes 
completely overlapped. The absorption peaks corresponding to the $\mathrm{OH}$ from methanol and ethanol respectively do not correspond to the theoretical absorption wavelength expected according to the Table 19. This fact is due to the absorption wavelength of hydroxyl results affected in a significant way by the Hydrogen bond interactions, which weakens the strength of the $\mathrm{O}-\mathrm{H}$ bond and then its absorption frequency will be much lower than the theoretically expected. Not only the $\mathrm{O}-\mathrm{H}$ bond, but also the $\mathrm{C}-\mathrm{H}$ bond of the alkane hydrocarbon chains of alcohols becomes affected by these intermolecular interactions, as it can be seen in the absorption frequency of $3035 \mathrm{~cm}^{-1}$ in methanol and ethanol hydrocarbon chains respectively; $3057 \mathrm{~cm}^{-1}$ in propanol and 3068 in hexanol $\mathrm{cm}^{-1}$ (Fornaro and Burini 2015).

Regarding to the gasoline and the diesel oils, the absorption peak of hydrocarbon bounds in aromatics corresponds to $3068 \mathrm{~cm}^{-1}$ in the winter gasoline, and $3046 \mathrm{~cm}^{-1}$ in both summer gasolines. The absorption peak for alkanes in diesel oils was at $3057 \mathrm{~cm}^{-1}$ (slightly shifted with respect to the theoretical value). The differentiation between gasoline and diesel oils was based mainly in the presence of olefins in gasoline, and naphtenes (cyclic alkanes) in diesel oils. The olefins absorption peak is closer to the $\mathrm{C}-\mathrm{H}$ bond in aromatics range (30003100, see Table 19), whilst the naphtenes have their absorption wavelength in the range of alkanes or paraffins.

The theoretical absorption peaks expected for each type of bond that is present in fuels and alcohols are indicated in Table 19 (Segneanu, et al. 2012). In all five average spectra, the main absorption band was found to be around $3000 \mathrm{~cm}^{-1}$, with slight changes in spectra shape, also referred as spectral fingerprint.

By means of this average of the spectra, it was feasible a preliminary differentiation between all the pure chemicals used in the experiment.

These hydrocarbons are present on the two kinds of gasoline (winter and summer), diesel oil (adulterant type 2), ethanol (additive) and methanol (adulterant type 1), in the mid infrared range used for this study $\left(2222.22-3333.33 \mathrm{~cm}^{-1}\right)$. 
Table 19.Theoretical absorption wavelengths for hydrocarbons and alcohol bonds

\begin{tabular}{|cc|}
\hline Wavelength/wavenumber $\left(\mathrm{cm}^{-1}\right)$ & Chemical functional group stretching \\
\hline $2850-3000$ & Alkanes (paraffins) (C-H) \\
\hline $3000-3100$ & C-H bond in Aromatics \\
\hline $3080-3140$ & Alkenes (olefins) (C=H) \\
\hline $3300-3600$ & Alcohol (-OH) \\
\hline
\end{tabular}

Figure 50 plots the complete set of 495 raw spectra (alcohol on the right side, and gasoline and diesel oil on the left side) corresponding to the calibration (75 spectra) and validation (420 spectra) sets. A large vertical dispersion is found, blurring the clarity of the averaged spectra and pointing to the need for chemometric techniques for the individual assignment of samples. It is also noticeable the clear difference between the shape of diesel and alcohol spectra, being the alcohols much broader and showing a sort of absorption valley in the left side of the main absorption peak. It can be observed that alcohols absorb more infrared radiation than diesel oils and gasoline, which may be caused by the molecular interactions between the hydroxyl groups $(-\mathrm{OH})$, which are more powerful electronically.
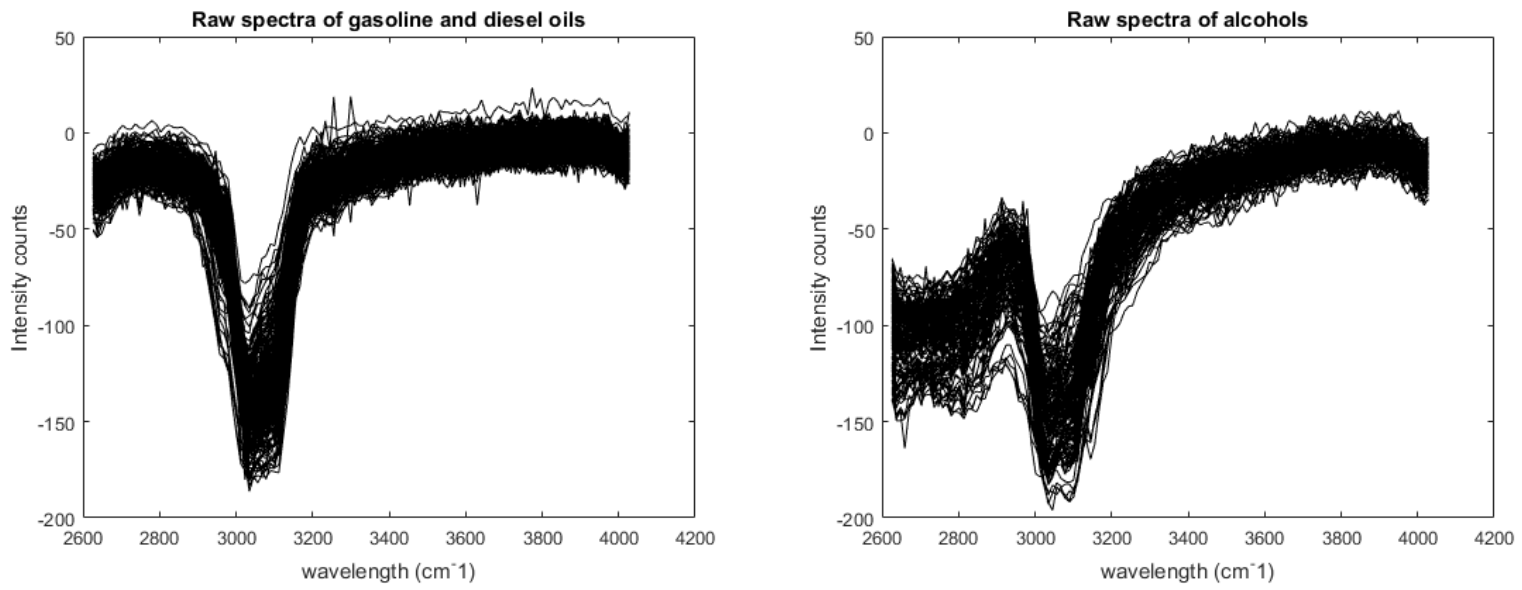

Figure 50. (Left) raw spectra of fuels (gasoline and diesel). Raw spectra of alcohols (Right). 


\subsubsection{Principal Component Analysis}

The percentage of variance retained by the first five principal components, accounts for more than $99.9 \%$ of normalized spectra. ANOVA analysis was performed on such principal components with regard to the type of substance: diesel, gasoline, adulterant and additive. PC2 and PC3 have higher relevance significance levels than PC1. This may be due to the fact that PC1 usually gathers information related to the signal intensity, which should not be very different among samples from the same substance; while PC2 and PC3 contain information about other spectral features that may be more relevant for reducing the scale of the information.

The Table 20 below shows the Fisher-test statistical values obtained from the ANOVA analysis of the first 5 PCs, and the figures 25 to 29 display the segregation between classes provided by each Principal component, considering 1 as the additives, 2 as the methanol adulterant, 3 as the diesel oil and 4 as the gasoline.

Table 20.Percentage of variance retained by the first five principal components and F-test values obtained from the ANOVA analysis performed on the scores of each principal component.

\begin{tabular}{|ccc|}
\hline Number of PC & \% of variance retained & F value (p) \\
\hline $\mathbf{1}$ & 95,35 & 53.49 \\
\hline $\mathbf{2}$ & 4,17 & 63.05 \\
\hline $\mathbf{3}$ & 0,21 & 26.89 \\
\hline $\mathbf{4}$ & 0,10 & 7.00 \\
\hline $\mathbf{5}$ & 0,067 & 16.48 \\
\hline Total variance percentage & 99,90 & \\
\hline
\end{tabular}

Table 20 displays the loadings or wavelength weights for PC 1, PC 2, PC 3 and PC 5 which provide the highest segregation of the individual spectra into fuel, additive and adulterant (1 and 2). The most relevant wavelengths are identified by the maximum absolute values in the loading plot: $3046 \mathrm{~cm}^{-1}$ (PC1); 2991, 3046 and $3145 \mathrm{~cm}^{-1}$ (PC5); $3068 \mathrm{~cm}^{-1}$ (PC2) and 2957, $3079 \mathrm{~cm}^{-1}, 3145 \mathrm{~cm}^{-1}$ (PC3). 


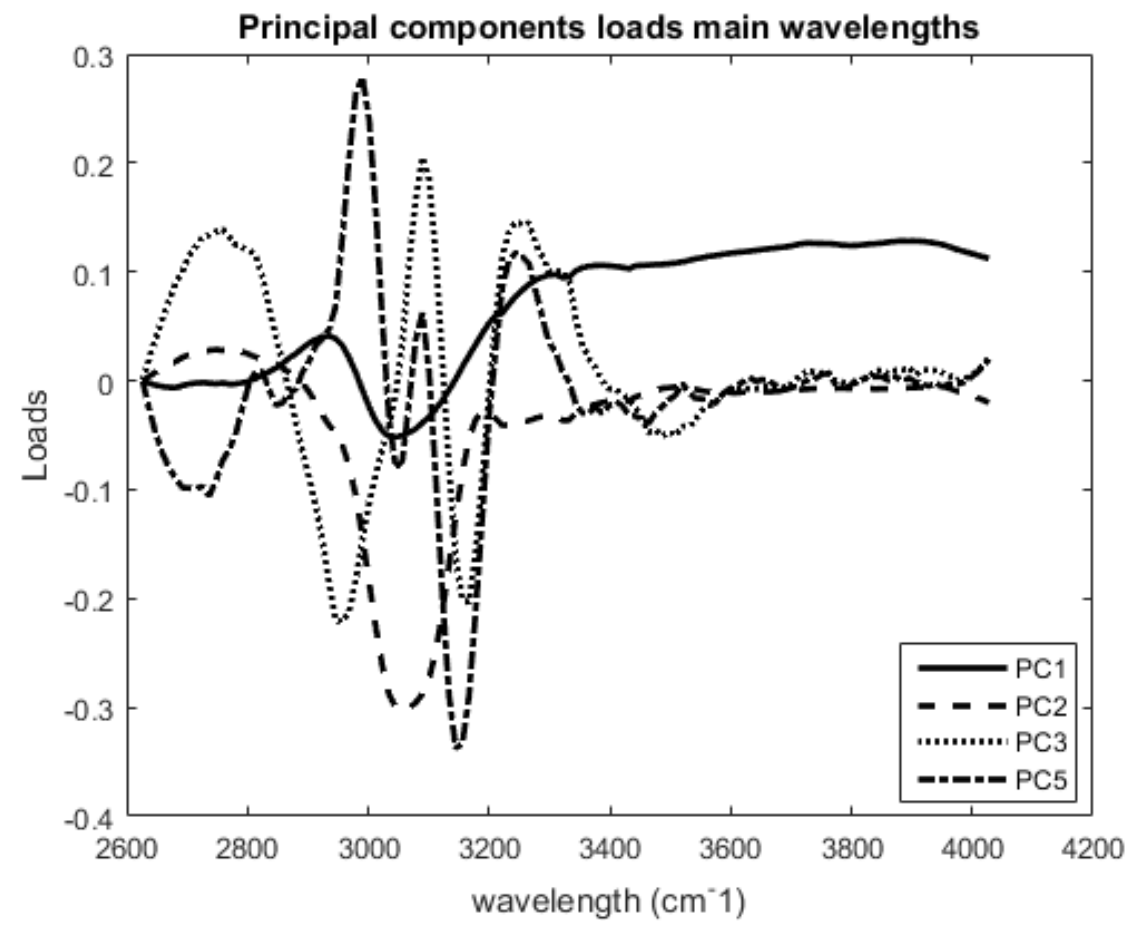

Figure 51. Loadings from principal components 1, 2, 3 and 5 of the calibration dataset.

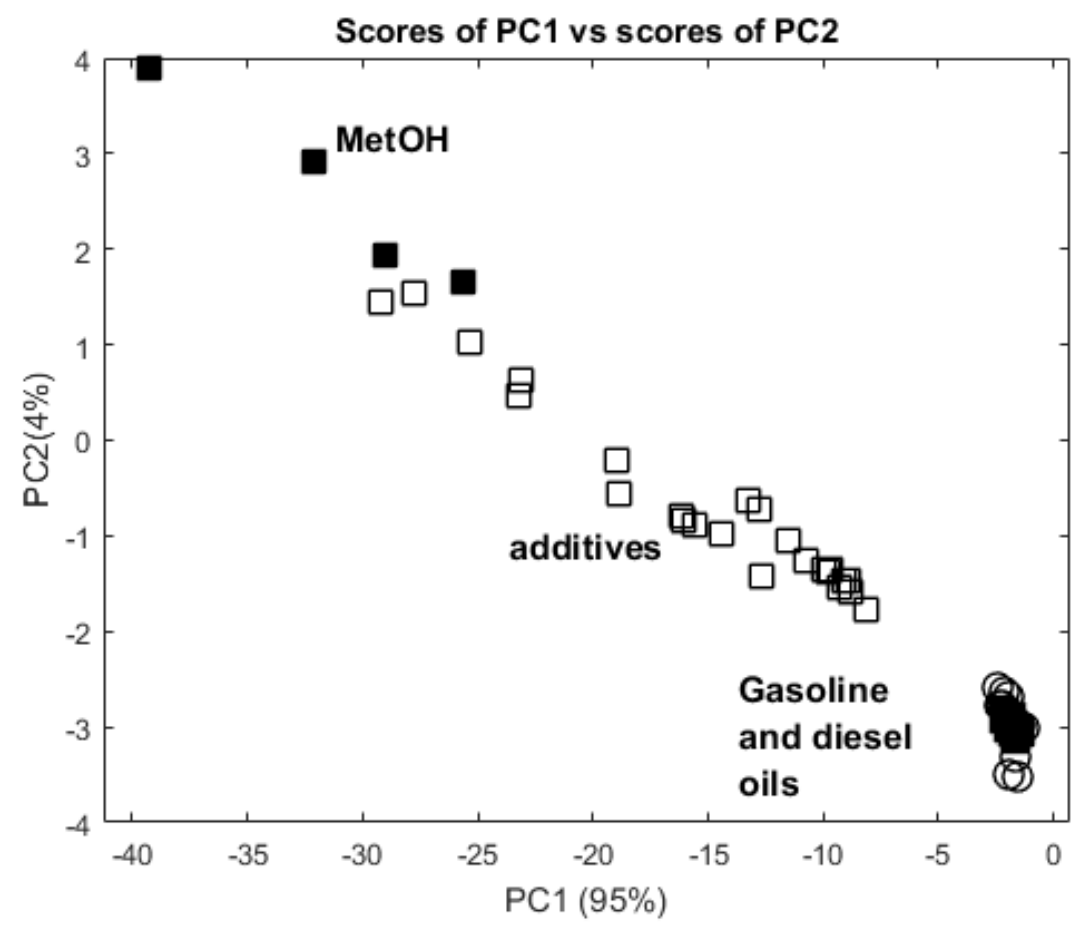

Figure 52. Graphical 2D scattering of the scores of PC1 versus the scores of PC2 of the same calibration dataset. 

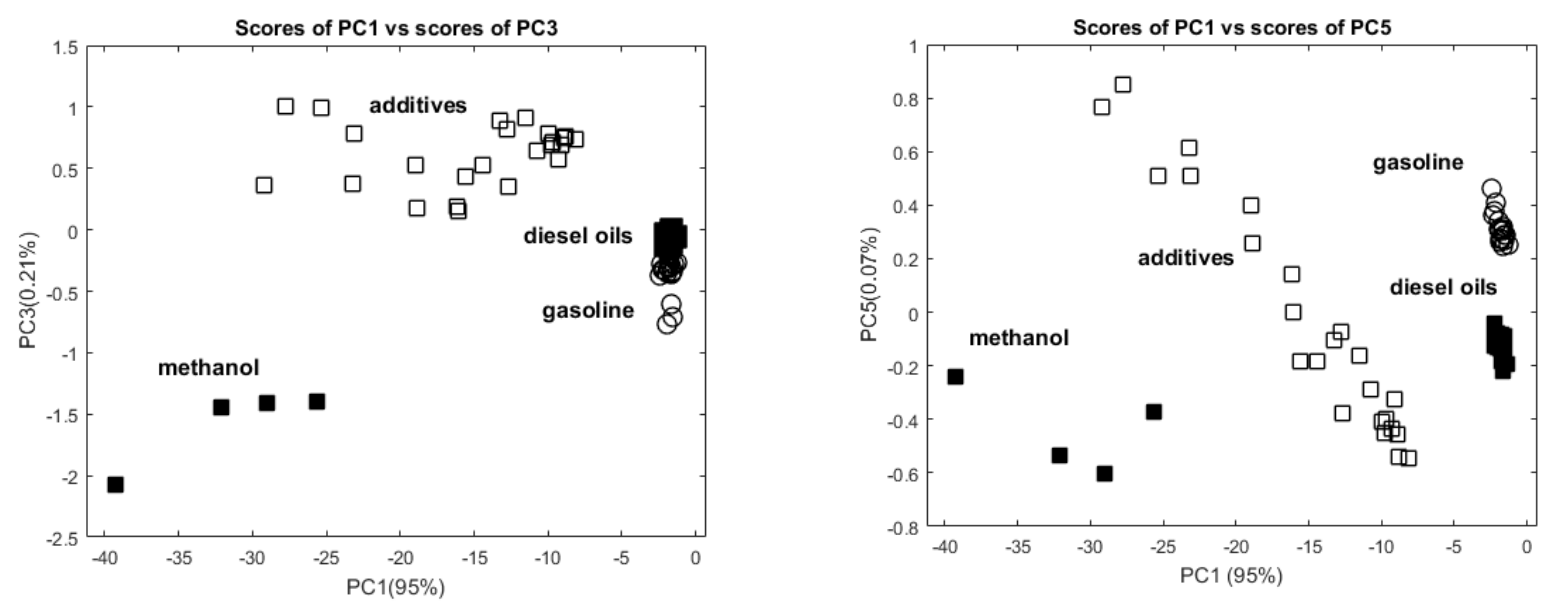

Figure 53. (Left and right) Graphical scattering of the scores of PC1 versus the scores of PC3 and PC5 respectively.

Although the highest percentage of the variance is retained by $P C 1$ and $P C 2$, the slight percentage retained by the PC5 $(0.07 \%)$ could result in a significant value as regards key spectral information. The scores of principal components 1 versus 2, 1 versus 3; and 1 versus 5 for fuels, additives and adulterants were represented in each Cartesian plane in the figures above. The following remarks should be made:

- PC1 (x-axis) allows distinguishing methanol from fuels, while not allowing such a clear separation between fuels, methanol and the rest of alcohols. Moreover, there is little specific spectral information contained in PC 1 , since there are no sharp bands in the load plot (Fig. 16, top left).

- PC2 (y-axis) versus PC1 (x-axis), makes a linear function of signal intensity with the hydrocarbon chain length of substances

- PC3 (y-axis) is able to difference between gasoline and diesel oils and also methanol from the rest of alcohols (additives).

- PC5 (y-axis) is capable of differentiating between gasoline and diesel oils.

In order to improve the segregation between alcohols, additives (ethanol, propanol, butanol or hexanol) and adulterants (methanol), a Multivariate Analysis of Variance was performed. 


\subsubsection{Multivariate Analysis of Variance (MANOVA)}

MANOVA differs from ANOVA in that it combines the segregation ability of several different inputs (which are the scores from PCs in this case). The analysis is performed on the basis of PC 1-5 (99.9\% of original spectral variance). Figure 54 shows the canonical scores for the calibration and validation data sets, showing neat segregation of the pure substances in three main clusters: alcohols, diesel oils and gasoline. Methanol appeared to be clearly differentiated from the rest of the alcohols, due to its particular spectral curve, with the hydroxyl absorption peak more pronounced than in the others. The validation data are the result of projecting anonymous spectra onto the PC space and then onto the canonical space by multiplying the spectral matrix by the eigenvectors obtained from MANOVA, and thus confirming the repeatability and reproducibility of the analysis.

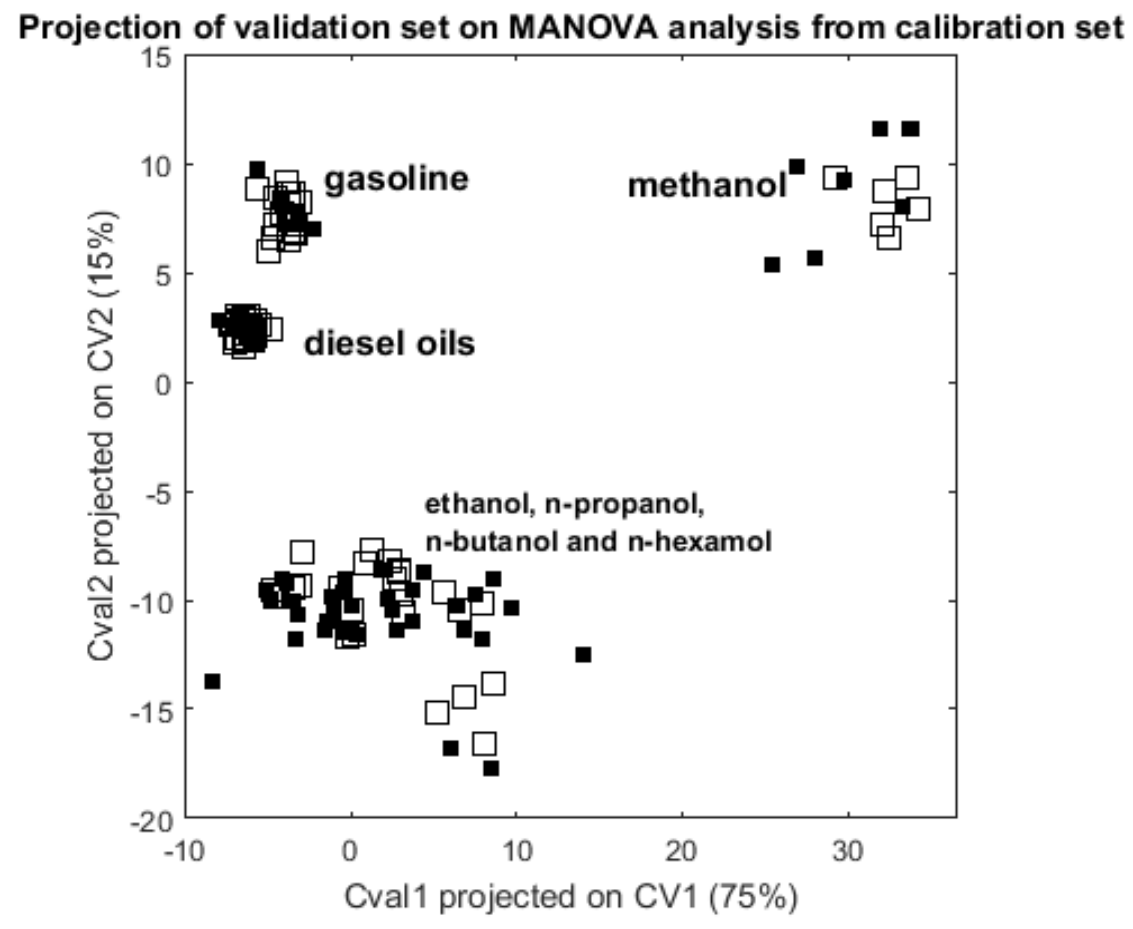

Figure 54.Projection of the validation set canonical variables (Cval1 and Cval2) on the calibration set canonical variables (CV1 and CV2, retaining the 75 and 15\% of the segregation power respectively)

Filled squares represent data from calibration set and empty squares represent data from validation set. 


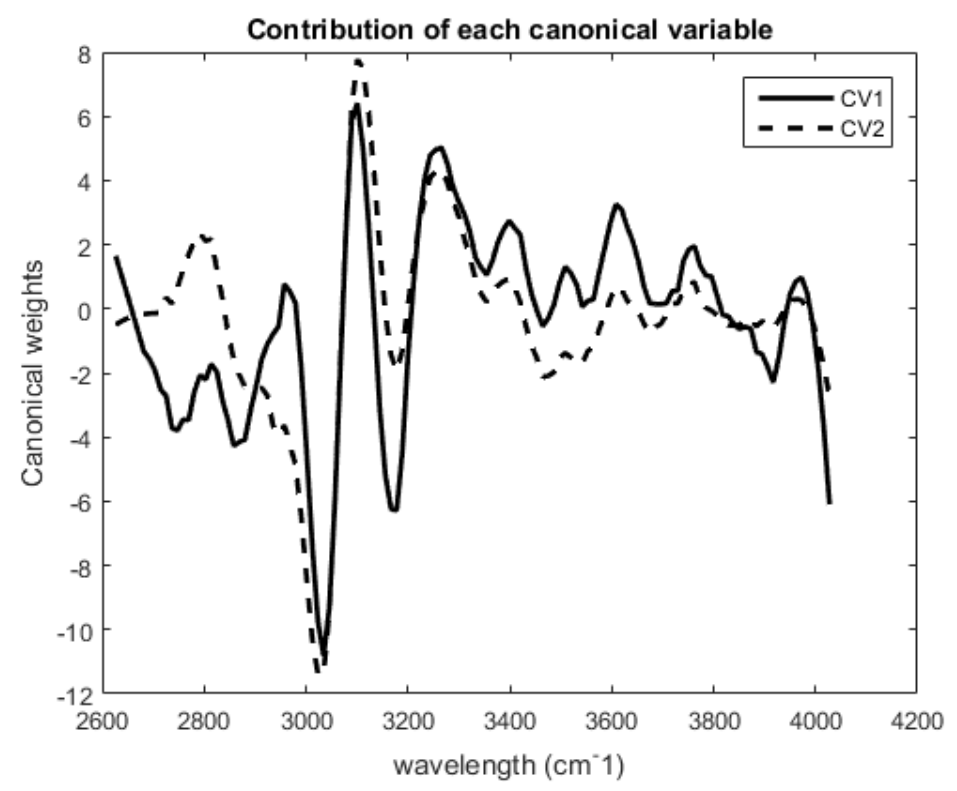

Figure 55. Weights of the contributions of wavelengths from the canonical variables.

The canonical variable 1 focuses on three wavelengths of 3035 and $3101 \mathrm{~cm}^{-1}$ (3.3-3.2 microns) regarding to the $\mathrm{C}-\mathrm{H}$ bond in aromatics (major constituents of gasoline) and the canonical 2 focuses on 3035 and $3145 \mathrm{~cm}^{-1}$. Both of them focus also in $3145 \mathrm{~cm}^{-1}(3.1$ microns), which correspond to the vibration of the hydrogen bond in the alcohols.

Table 21 below shows the segregation power provided by each canonical variable, as derived from the eigenvalues of MANOVA. As it can be observed, CV 1 and CV 2 retain 67.5 and $20.10 \%$ of the segregating power; the rest of the canonical variables retain the $12 \%$ of the segregation power approximately. According to MANOVA the dimension of the segregation space is set to 2 and therefore a segregation plane is considered.

Table 21. Eigenvalues and segregation power of each canonical variable obtained from MANOVA applied on the calibration set

\begin{tabular}{|ccc|}
\hline Canonical variable & Eigenvalue & Segregation power \\
\hline 1 & 205.18 & 67,50 \\
\hline 2 & 86.25 & 20,10 \\
\hline 3 & 58.76 & 11,32 \\
\hline 4 & 1.10 & 0,70 \\
\hline 5 & 0.99 & 0,40 \\
\hline
\end{tabular}




\subsubsection{Characteristic values}

Table 22 below provides the average canonical values CV1 and CV2 for each sample in either the calibration or the validation set showing significant congruence (among similar samples) and robustness (repeatability over time, 9 days in the validation set besides calibration) in the procedure. Additives and adulterants show positive average for CV1: around 30 for methanol (adulterant), and between 0.9 and 3.8 for the rest of alcohols (additives), while gasoline and diesel present average negative values for this canonical variable (around -4 and -6 respectively). In the case of CV2, only additives show negative values (around -9). The centroids for each category are included in Table 23.

On the other hand, MANOVA uses the highest wavelengths values (such as $3167 \mathrm{~cm}^{-1}$ ) to segregate between alcohols, as these compounds have the higher absorption frequencies (see Table 19), and the lowest ones to segregate between diesel oils and gasoline, because according to the composition of gasoline, who is richer in alkenes and aromatics than diesel, it should have higher frequency values than diesel oils.

Table 22.Characteristic values from MANOVA. The Average values of each canonical variable from the calibration and validation set are displayed.

\begin{tabular}{|cccccc|}
\hline & \multicolumn{3}{c}{ Canonical 1 } & \multicolumn{3}{c|}{ Canonical 2 } \\
\hline \multirow{2}{*}{$\begin{array}{c}\text { Potential } \\
\text { adulterant (1) }\end{array}$} & Methanol & 32.31 & 29.48 & 8.19 & 8.42 \\
\hline \multirow{2}{*}{$\begin{array}{c}\text { Potential } \\
\text { adulterant (2) }\end{array}$} & Diesel (1) & -6.29 & -6.36 & 2.35 & 2.15 \\
\cline { 2 - 6 } & Diesel (2) & -6.27 & -5.96 & 2.72 & 2.74 \\
\cline { 2 - 6 } & Diesel (3) & -6.32 & -6.20 & 2.22 & 2.27 \\
\hline \multirow{2}{*}{$\begin{array}{c}\text { Potential } \\
\text { additive }\end{array}$} & Propanol & 3.25 & 2.38 & -8.98 & -9.13 \\
\cline { 2 - 6 } & Butanol & 0.89 & 0.46 & -10.05 & -10.18 \\
\cline { 2 - 6 } & Hexanol & 3.24 & 3.80 & -9.24 & -9.70 \\
\hline \multirow{2}{*}{ Fuel } & Gasoline(1) & -3.98 & -4.04 & 8.28 & 8.13 \\
\cline { 2 - 6 } & Gasoline(2) & -4.08 & -4.11 & 6.78 & 6.99 \\
\hline
\end{tabular}


Table 23.Centroids

\begin{tabular}{|ccccc|}
\hline & & Canonical 1 & \multicolumn{2}{c|}{ Canonical 2 } \\
\hline & Calibration & Validation & Calibration & Validation \\
\hline Adulterant 1 Methanol & 32.31 & 29.48 & 8.19 & 8.42 \\
\hline Adulterant Diesel & -6.29 & -6.17 & 2.43 & 2.39 \\
\hline Additive Rest of acohols & 2.46 & 2.21 & -9.42 & -9.67 \\
\hline Fuel Gasoline & -4.03 & -4.08 & 7.53 & 7.56 \\
\hline
\end{tabular}

A classification algorithm was developed for calculating the distance between each individual in the canonical plane with regard to the centroids for each category in the calibration set: gasoline, additive (ethanol, propanol, butanol or hexanol), adulterant 1 (methanol) and adulterant 2 (diesel oil). Table 24 compares the observed and predicted classes for both the calibration and validation sets with $100 \%$ consistency.

Table 24.Confusion matrix comparing the observed and predicted classes for both the calibration and validation sets.

\begin{tabular}{|ccccc|}
\hline \multirow{2}{*}{$\begin{array}{c}\text { Predicted } \\
\text { Validation (calibration) }\end{array}$} & \\
& Gasoline & Additive & Adulterant 1 & Adulterant 2 \\
\hline Gasoline & $110(18)$ & 0 & 0 & 0 \\
\hline Additive & 0 & $120(24)$ & 0 & 0 \\
\hline Methanol (Ad1) & 0 & 0 & $28(6)$ & 0 \\
\hline Oil adulterant (Ad2) & 0 & 0 & 0 & $162(27)$ \\
\hline
\end{tabular}




\subsection{Experiment 2: Characterization of alcohol and gasoline blends}

Results in this experiment have been structured in three steps: the visualization of spectra, quantification of additive in the blends, identification of the type of additive in the blend, and the visualization of the wavelengths involved in blend quantification and identification.

\subsubsection{Visualization of spectra}

Figure 56 (left) shows four average MID IR raw spectra corresponding to pure gasoline and alcohols (methanol, ethanol, and butanol) in the training set. The right side of Figure 53 also shows the corresponding four average spectra with baseline line correction using the same method than in the experiment 1.
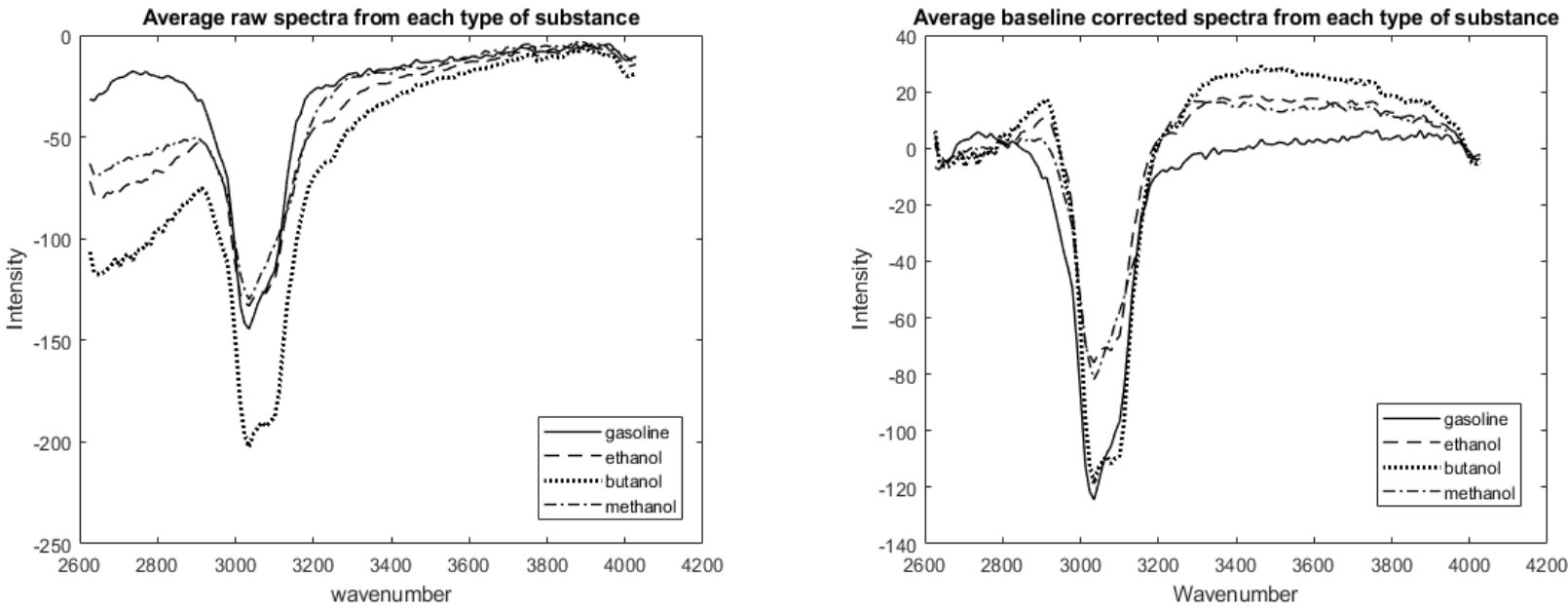

Figure 56. (Left) Mean raw spectra obtained from all the samples belonging to the pure substances from the train set. (Right) Pre-processed spectral curves from all the samples of the train set (baseline corrected).

\subsubsection{Quantitative prediction of overall blend concentration}

Figure 58 below shows the accumulated percentage of variance in overall blend concentration for increasing number of latent variables as derived from cross-validated PLS: $65 \%$ for one latent variable, and $95 \%$ for five.

The root mean square error of calibration (RMSEC) of the prediction and the root mean square error of the cross validation (RMSECV) obtained with ten-fold criterion are plotted against the number of latent variables (Figure 57) in order to select the optimal number for PLS regression. While RMSEC always tends to decrease for increasing number of latent variables, the RMSECV reaches a minimum at the optimal number which resulted to be 5 in 
this study. RMSEC and RMSECV were $7.43 \%$ and $8.42 \%$ respectively for this model indicating that the device would be useful to detect overall blends in which the additive or adulterant is above $10 \%$ in volume concentration. Below this threshold, there exists a risk of obtaining wrong or imprecise results. Table 25 characterizes the final selected model.

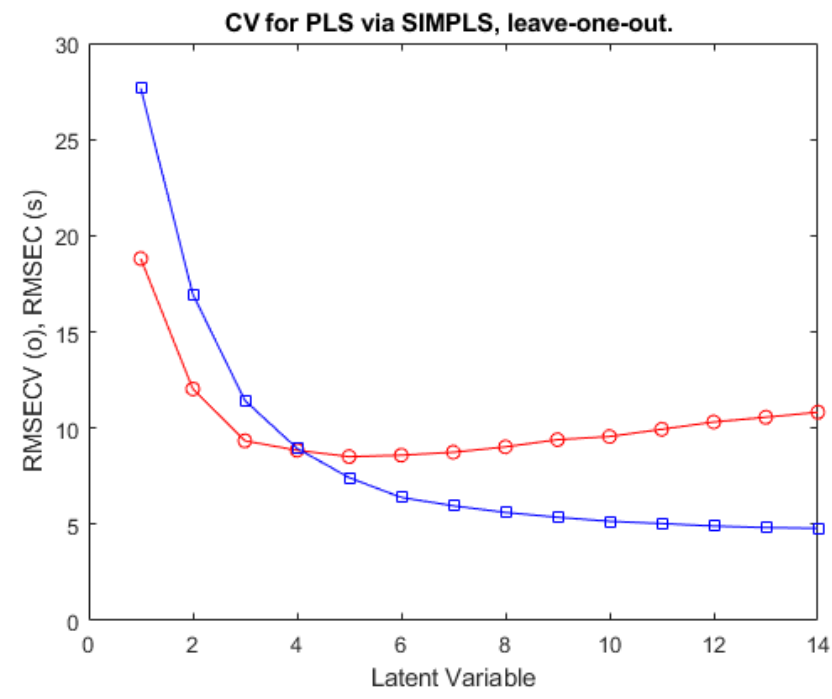

Figure 57.Root mean square error of Calibration and Cross Validation curves and indicating that the optimal number of Latent Variables is in the span between 4 and 5 in order to minimize these two errors.

As it can be observed, the quantitative model is able to predict $95 \%$ from this variance explained in $\mathrm{Y}$.

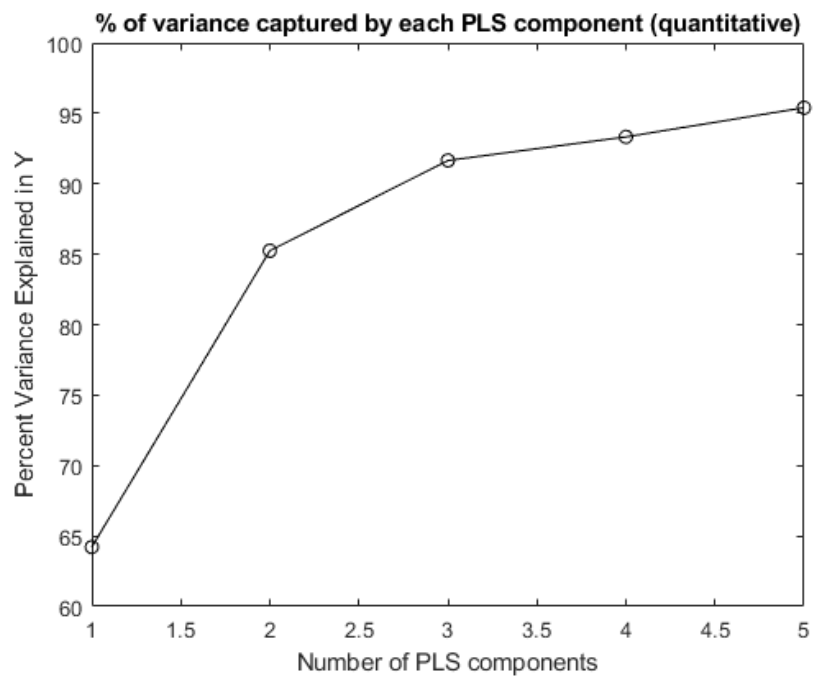

Figure 58. Plot of the percentage of variance explained in the dependent variable $Y$ captured by each PLS component or latent variable at the quantitative analysis. 
Table 25. Root mean square errors of calibration and validation in the quantitative prediction analysis by Partial Least Squares in the train and test sets and the applied spectral pre processing, that is baseline correction in this case.

\section{QUANTITATIVE PREDICTION ANALYSIS}

\begin{tabular}{|llllll|}
\hline $\mathbf{R}^{2}$ Train & $\mathbf{R}^{2}$ Test & RMSEC & RMSECV & Lv & Sp preprocessing \\
\hline $\mathbf{0 . 9 5 4 2}$ & 0.9442 & 7.43 & 8.52 & 5 & Baseline correction \\
\hline
\end{tabular}

As it can be observed in the table above, the goodness of the fitting in the train and in the test set is highly accurate (above 0.90), which indicates the robustness of the prediction model for quantitative analysis. By the other hand, the root mean square errors of calibration and validation are below 10 percent. This means that the method is able to predict concentrations from 10 percent and on.

\subsubsection{Supervised analysis of the blends by MANOVA}

Ten Principal components have been computed as a mean of dimension reduction from the initial 128 wavelengths. Table 26 shows the percentage of variance retained by the first ten principal components which accounts for $99.2 \%$ of total variance.

Table 26. Percentage of variance retained by each of the ten principal components used for the discriminant analysis in this experiment.

\begin{tabular}{|llllllllll|}
\hline PC1 & PC2 & PC3 & PC4 & PC5 & PC6 & PC7 & PC8 & PC9 & PC10 \\
\hline 92.37 & 2.78 & 2.70 & 0.76 & 0.15 & 0.11 & 0.10 & 0.06 & 0.05 & 0.04 \\
\hline
\end{tabular}

The scores from PCA are feed into MANOVA as source data. The first two canonical variables (Figure 59) generated with the MANOVA analysis, provide a strong radial trend (angle) that identifies the blending additive: methanol, ethanol or butanol, while the radial distance of each sample indicates the blend concentration of every particular measurement. Figure 60 provides increasing degraded color for increasing concentration of the additive in each sample, while bold black lines in this same figure, refer to the centroid of identical blend concentration (10, 20 and $30 \%)$. The maximum distance of each group centroid to the triangle center presented in tThe numerical values measured of the distance from each centroid to the center of the triangle are given in the Table 27 displays the overlapping calibration and validation sets radial distances and angles respectively, in a way to complement the results obtained numerically in the Table 25 above. 
Table 27 provides a quantitative measure of the segregation among alcohol percentages which is complementary to the quantitative PLS prediction. The correlation coefficient between the eleven radial distances in the calibration set and the blend concentrations reaches an $\mathrm{R}^{2}$ of 0.95 , that is, an explained variance of $90.7 \%, 94 \%$ in the validation set, reinforcing the results of the PLS model.

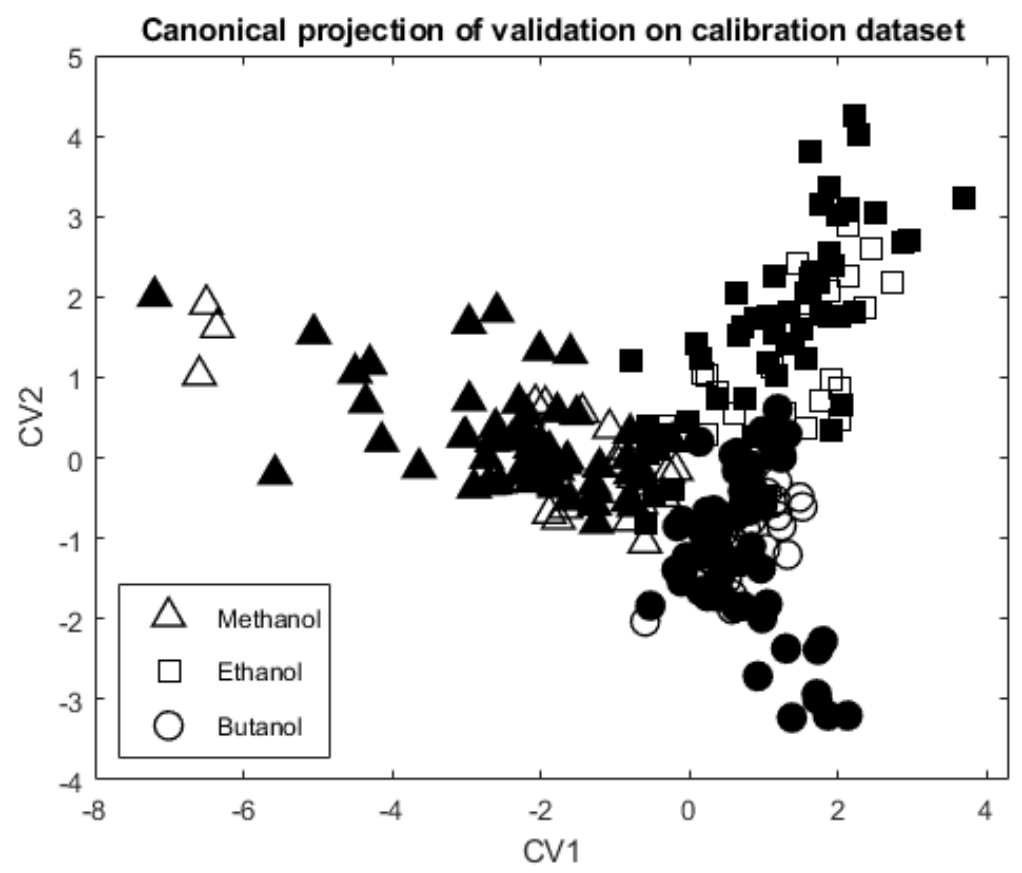

Figure 59. Projection of the validation set on the MANOVA plane

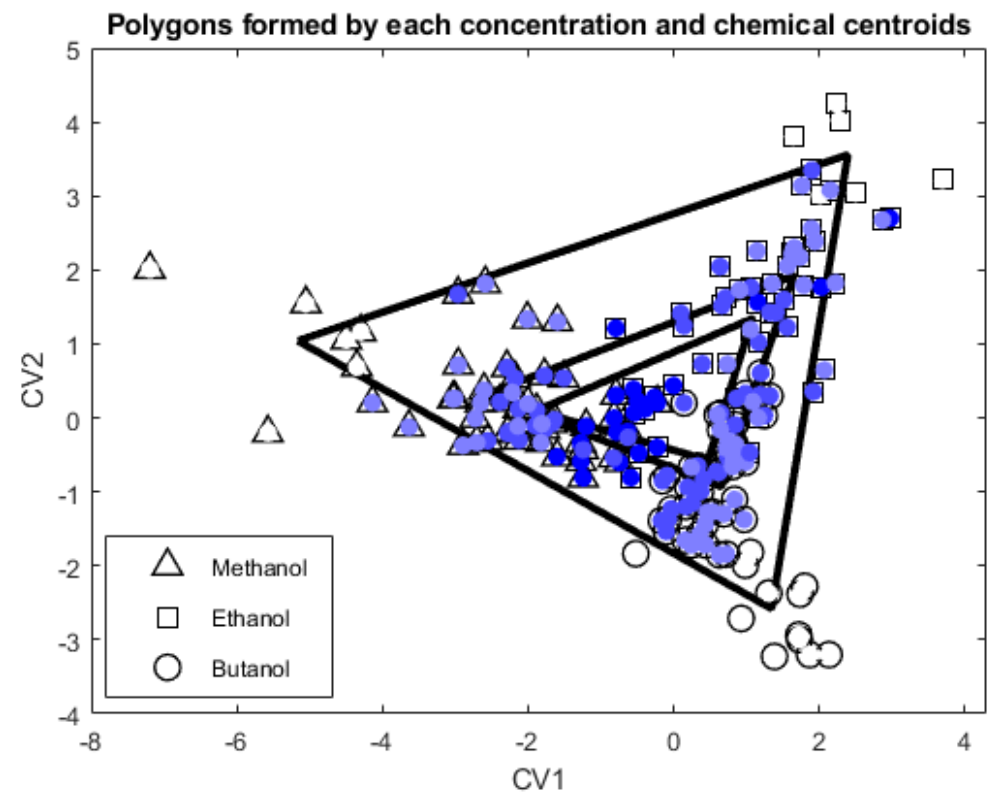

Figure 60.Centroids of latent variables in MANOVA. 
A triangle is clearly described by this figure, whose angles determine the type of substance and the degraded color represents an increasing concentration.

The figures above show that a triangle is clearly described by this figure, where the type of alcohol blended with the gasoline is positioned by the angles (in the figure, methanol blends are encoded by the triangles, ethanol blends by the squares and butanol blends are displayed as circles) and the position of each point in each branch of the triangle indicates the percentage contained in the blend from 0 to $30 \%$. These branches are defined by the lines that match each vertex. Decreasing intensity of the dots in Figure 60 means more percentage of the adulterant or additive in study.

The numerical values measured of the distance from each centroid to the center of the triangle are given in the Table 27 displays the overlapping calibration and validation sets radial distances and angles respectively, in a way to complement the results obtained numerically in the Table 25 above.

Table 27.Distances from each concentration in percentage group centroid to the center of the triangle formed by plotting canonical variables 1 and 2 .

\begin{tabular}{|ccccccc|}
\hline & \multicolumn{2}{l}{$\begin{array}{l}\text { CALIBRATION SET } \\
\text { RADIAL DISTANCES }\end{array}$} & & \multicolumn{2}{l|}{$\begin{array}{l}\text { VALIDATION SET } \\
\text { RADIAL DISTANCES }\end{array}$} \\
\hline $\begin{array}{c}\text { CONCENTRATION } \\
(\%)\end{array}$ & METHANOL & ETHANOL & BUTANOL & METHANOL & ETHANOL & BUTANOL \\
\hline 10 & 0.95 & 0.60 & 0.74 & 0.81 & 0.57 & 1.16 \\
\hline 20 & 1.90 & 1.72 & 1.14 & 0.95 & 1.50 & 1.47 \\
\hline 30 & 2.61 & 2.53 & 2.91 & 1.84 & 2.80 & 3.00 \\
\hline 40 & 5.30 & 4.30 & - & 5.73 & 4.10 & - \\
\hline $\begin{array}{c}\text { ANGLE } \\
\text { (DEGREES) }\end{array}$ & 173 & 57.1 & 304 & 177.4 & 55.05 & 306.3 \\
\hline
\end{tabular}

The $40 \%(\mathrm{v} / \mathrm{v})$ concentrations of butanol do not appear as they were not used in the data acquisition.

The radial distances or the so called branches above are represented in the Figure 61 below, where the circles symbolize the calibration dataset and the crosses correspond to the overlapped validation dataset distances. 


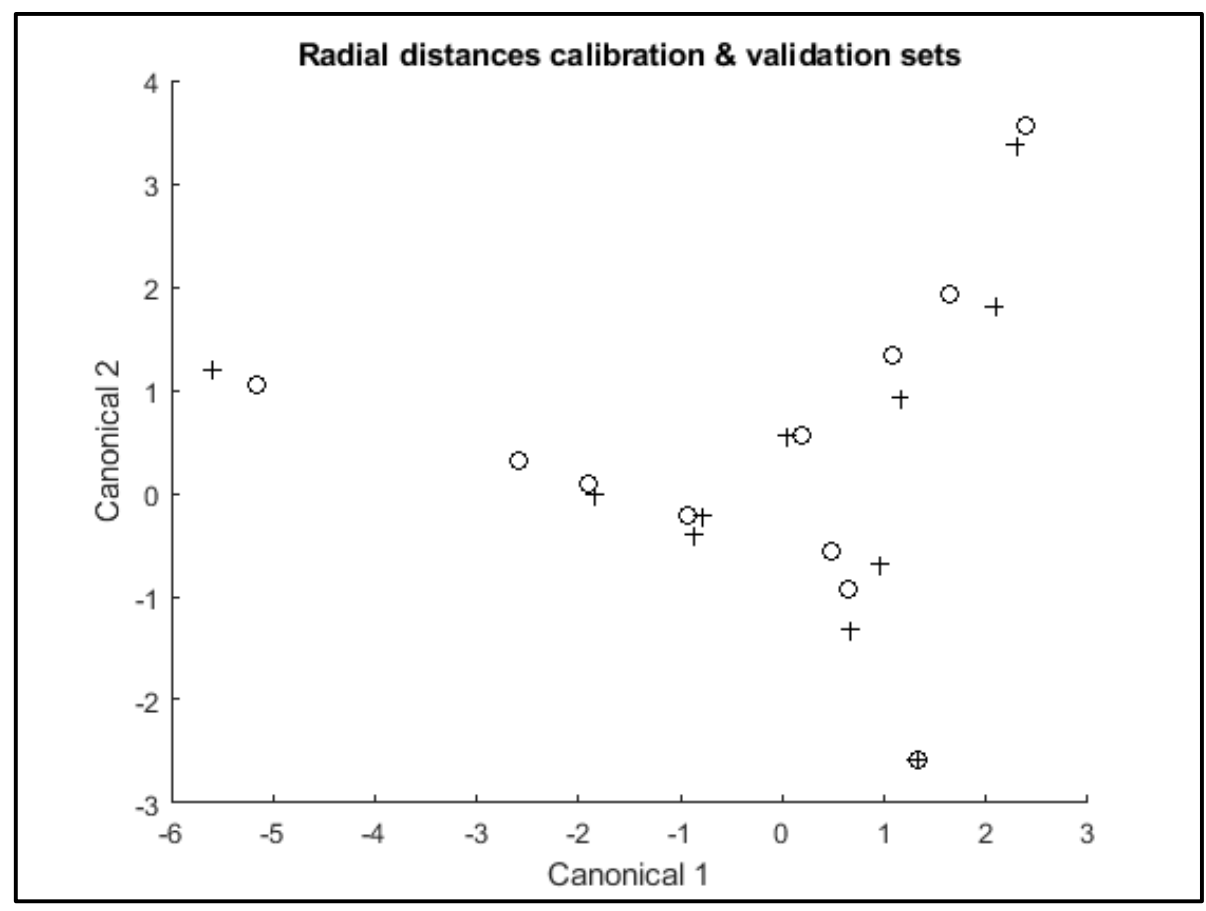

Figure 61. Radial distances and average angles from each alcohol blend cluster centroid to the origin according to MANOVA canonical variables.

The calibration and validation sets superposition graphically demonstrates the robustness of this analytical method to determine simultaneously the concentration and the type of substance in the blends.

\subsubsection{Wavelength contribution to quantitative and qualitative models}

Figure 62 provides the weight contributions of each wavelength in the computation of the PLS model (left) while the Figure 63 refers to MANOVA.

Figure 63 provides the main contributing wavelengths which were 2836, 2980 and $3167 \mathrm{~cm}^{-}$

${ }^{1}$ for the quantitative model (blend concentration); regarding to en $\mathrm{C}-\mathrm{H}$ bond in alkanes (main constituents of gasoline) and the hydrogen bonds from hydroxyl group.

For the qualitative model (additive identification), the wavelength of $3145 \mathrm{~cm}^{-1}$ provides the most relevant contribution for $\mathrm{C} 1$ which corresponds to the vibrational stretching the hydrogen bonding in alcohols and $3046 \mathrm{~cm}^{-1}$ which is related to the $\mathrm{C}-\mathrm{H}$ bond in aromatics (other important constituent of the gasoline). The major contribution to $\mathrm{C} 2$ comes from $2991 \mathrm{~cm}^{-1}$ which is around the vibrational stretching frequency of $\mathrm{C}-\mathrm{H}$ bond in alkanes and also $3145 \mathrm{~cm}^{-1}$ from the hydrogen bonding in alcohols. 


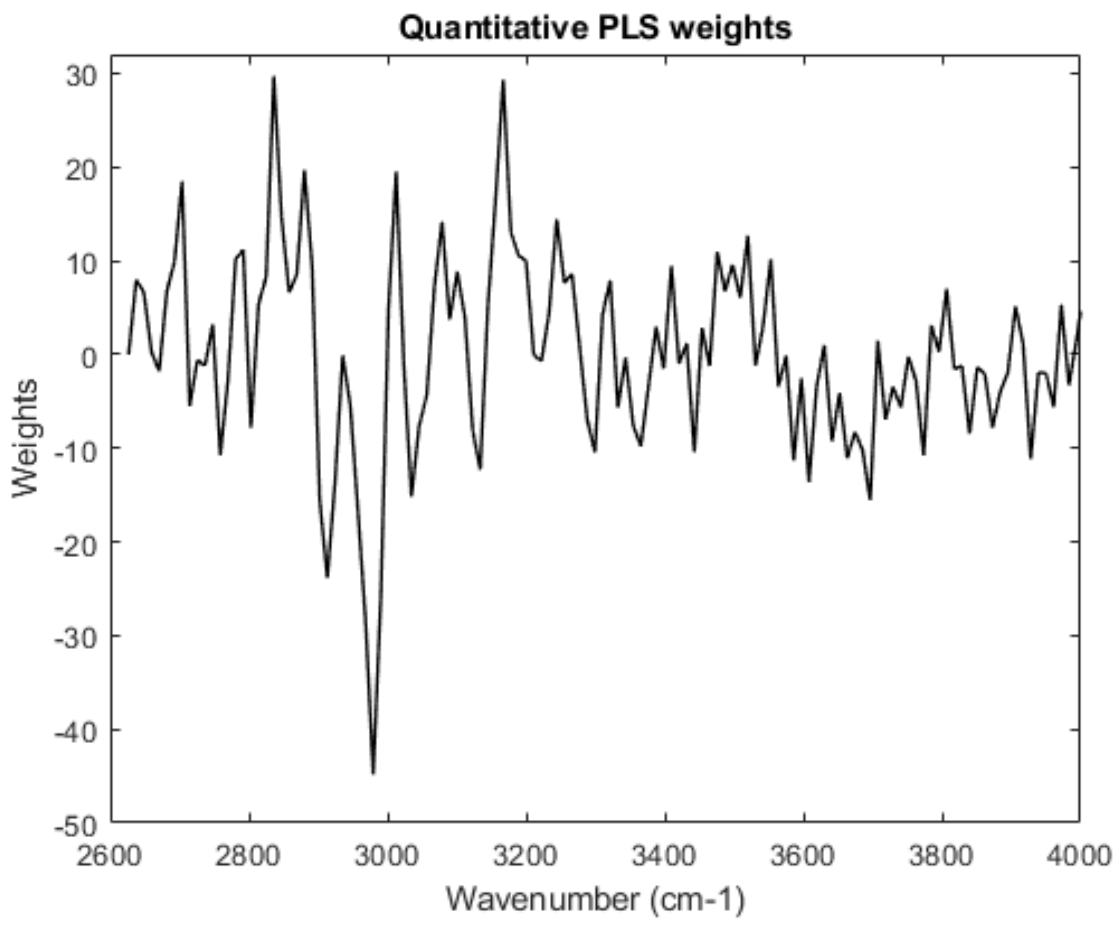

Figure 62.Contribution of the wavelengths to the quantitative PLS model

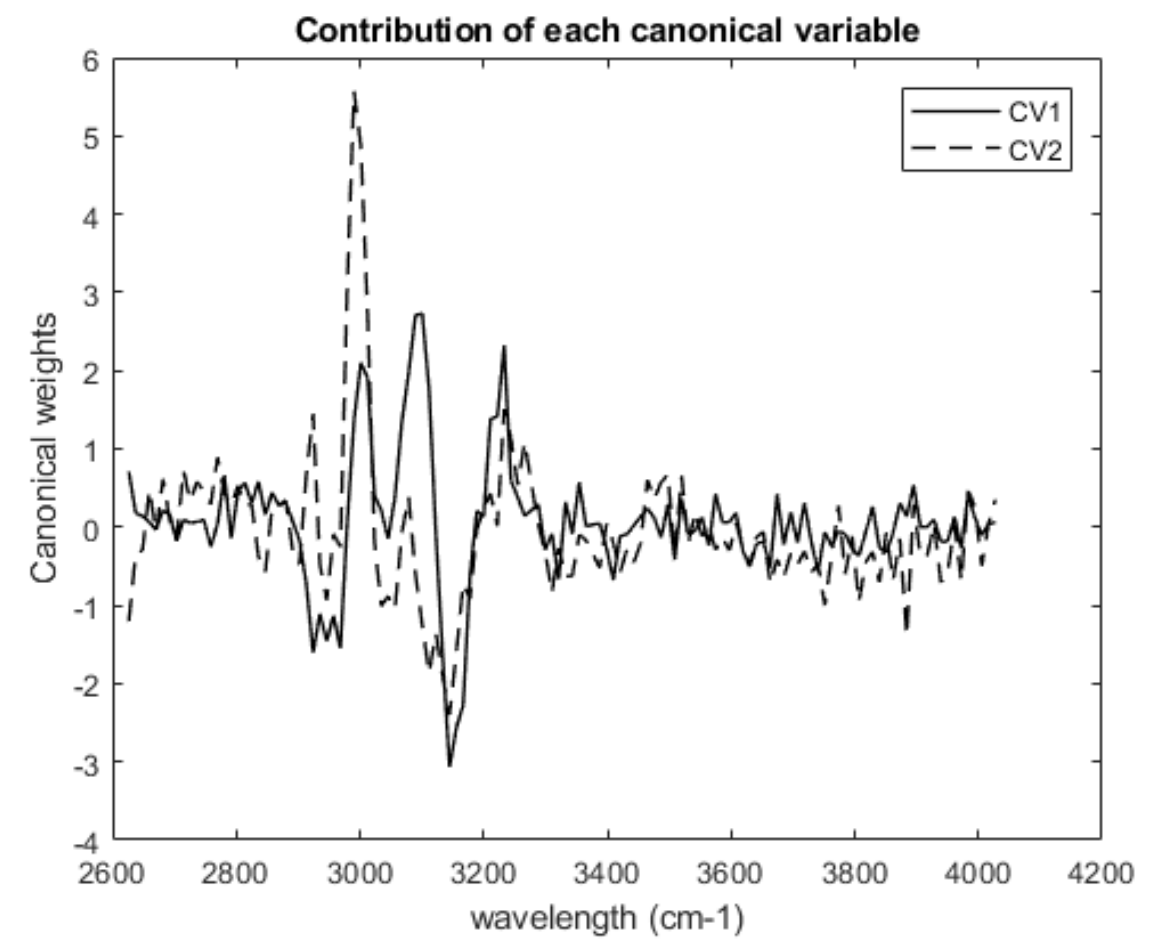

Figure 63.Weights of each wavelength from canonical variables CV1 and CV2. 


\subsection{The use of FTIR for determination of acetone and ethanol}

With regards to study and develop a method to detect volatile chemicals not inside a headspace but in a dynamic gas flux, also kwon as "plumes"; the experiment carried out at the Texas A\&M University Engineering Experimental Station was designed by using an air mass flow regulator to inject different ratios of the acetone and ethanol (Panreac ${ }^{\circ}$, USA) which were volatilized by being dragged in the air flux.

The measured percentages of each chemical are shown in the Table 28 below. As it can be observed, the ratio of acetone goes increasing as it is more volatile than ethanol (boiling point of $56 \stackrel{\circ}{\circ}$ ) so it became necessary an increasing injection ratio in the device along time. Each ratio was measured three times to assure the repeatability of the measurements.

Table 28. Percentages ratio of acetone and ethanol injected to the FTIR device through dynamic mass flow

\begin{tabular}{|c|c|c|}
\hline & Acetone (\% v/v) & Ethanol $(\% \mathrm{v} / \mathrm{v})$ \\
\hline \multirow{9}{*}{ 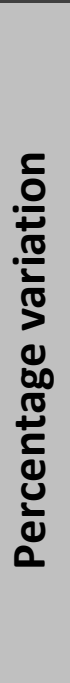 } & 0 & 100 \\
\hline & 5 & 95 \\
\hline & 10 & 90 \\
\hline & 15 & 85 \\
\hline & 25 & 75 \\
\hline & 75 & 25 \\
\hline & 85 & 15 \\
\hline & 95 & 5 \\
\hline & 100 & 0 \\
\hline
\end{tabular}

The spectral results obtained from these measurements are displayed in Figure 64 below: 


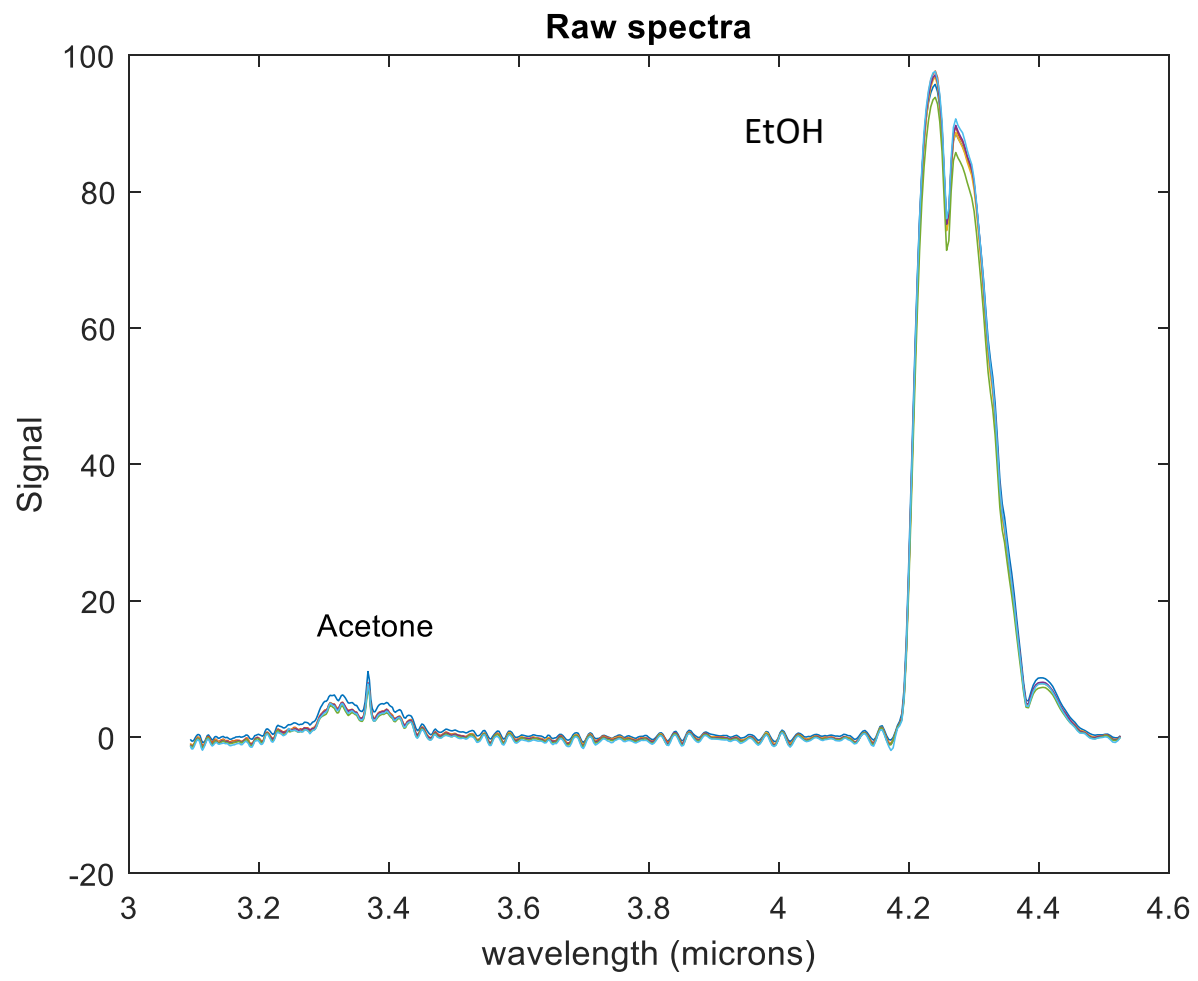

Figure 64. Spectra collected from de dynamic measurements of acetone and ethanol using an FTIR

As it can be observed in the Figure 64, after collecting 32 and 64 scans to improve the resolution, the results concluded that even though the FTIR owns a higher resolution than the PbSe dispersive device, there were fluctuations in the measurement of the same ratio. This fact made the spectra unstable to analyze the data with the prospective application of this device in the detection and quantification of volatile compounds at parts per million (ppm) levels. This fact leads to the conclusion that volatile plumes cannot be measured in a robust and reproducible way, so it was decided to differ it as a future challenge. 


\section{Chapter 6}

\section{Discussion}

The results obtained from the experiments 1 and 2 described above lead to an advance in the current state of the prior art (Section 2.1. and 2.2.) from a technical and scientific point of view. The technical advance consists mainly on the affordability and compactness of the apparatus, which is susceptible of being implemented in any production chain or process. From a scientific point of view the step forward regards to the easy acquisition method and a new way to investigate the composition of chemical substances such as fuels and their blends (but extendable to other type of chemical products based on organic molecules) more simple and rapid than the existing ones. The most relevant aspects from this dissertation are disclosed in the following points.

\subsection{The use of the MID IR spectral range for measuring chemicals in fuels. Comparison with the previous state of the art}

The application of the MID IR spectroscopy in the fuel quality control is not a novel matter. Qualitative and quantitative analysis have been performed before by other authors in previous works on a huge variety of determinations either in pure fuel or in its blends with alcohols or other additives. 
These many authors have well published or patented inventions improving the experimental set up or applying the technique to different analysis of fuel blends or pure gasoline or diesel. Nevertheless, none of the inventions or publications described in the State of Prior Art (Sections 2.1. and 2.2.) uses such a simple method in terms of instrumentation and experimental set-up

The FTIR and RAMAN techniques used by other authors in previous publications (Corsetti and Kiefer 2016, Corsetti, Zehentbauer, et al. 2015) were expensive and complex laboratory equipment, working in the spectral range of $4000-500 \mathrm{~cm}^{-1}$ (2.5-20 microns) both of them. This means an advantage regarding the measurable wavelengths, but even so authors had to apply chemometric methods to determine the ethanol content in the mixture that was prepared using a surrogate of gasoline instead of pure commercial gasoline.

From the point of view of the chemometric analysis, the results obtained by previous authors had to be pre and post processed using the same or similar methods to the ones used in this thesis. Despite of having obtained much narrower and noisy spectra from the acquisition stage, the classical supervised and non supervised algorithms such as PCA, PLS and MANOVA gave good results. And these results were more realistic as they were achieved from commercial gasoline samples instead of surrogates.

Other authors (Adenilton 2012) employed NIR and MIR spectroscopies associated to pattern recognition models to detect possible adulteration in hydrated ethyl alcohol fuel (HEAF). These authors also used an FTIR spectrometer to carry out the analysis in the wavelength range of 7449-3769 cm-1 (1.34-2.65 microns) in the NIR and another FTIR working in the MID IR range of 3477-698 cm-1 (2.87-14.3 microns). They were able to see the $\mathrm{C}-\mathrm{H}$ stretching in the NIR region at 4600-4000 cm-1 (2.2-2.5 microns), and the first O-H overtone of water and ethanol at $6870 \mathrm{~cm}-1$ (1.4 microns) from the NIR. In the MID IR region they could observe the peaks around $1180-840 \mathrm{~cm}-1$ (8.5-11.9 microns) corresponding to $\mathrm{C}-\mathrm{O}, \mathrm{C}-\mathrm{C}-\mathrm{O}$ stretching modes of alcohols and the $\mathrm{C}-\mathrm{H}$ stretching and absorption peak of water at $2900 \mathrm{~cm}-1$ (3.5 microns) and $3450 \mathrm{~cm}-1$ (2.9 microns) respectively. As it can be inferred from the above, the method developed by these authors is complex from the instrumentation point of view and not suitable for a possible on field or in situ analysis. The novelty provided by the work carried out for this PhD to this kind of publications in which various devices are combined to detect several species 
simultaneously, consists on the easiness of acquiring the relevant information using a unique device much simpler and compact than an FTIR. In this work the NIR range between 1 and 2 microns becomes unnecessary as water does not need to be detected in the mixture. Hence, it was demonstrated that the spectral range used here (2.5-4.5 microns) is more than enough to characterize organic substances and their mixtures.

As it can be observed in the Section 2.2. disclosed above, the major part of the state of the art regarding to the use of MID IR spectroscopy applied to fuel quality control has been based in the use of FTIR spectrometers along decades (Adenilton 2012), (Corsetti, McGloin and Kiefer 2015) (Corsetti and Kiefer 2016) (Niemeyer and Hagen 2016). Lower prominence has been given to the non-dispersive instruments for this application. This thesis provides an advance to the state of the art in terms of the application of dispersive devices to the field of fuel characterization.

On the other hand, the MID IR photon detectors have been traditionally relegated to a single-element detector or relative small linear arrays (Vergara, Torquemada and Montojo 2007), whilst this thesis used a sensor based on an array formed by $128 \mathrm{PbSe}$ detectors, which improves the covered wavelength span and as a consequence, the variety of molecular bonds vibrations. The linear variable filter (LVF) coupled to this sensor increased the level of responsivity compared to other detectors and allowed to select the wavelengths of the absorption spectra in a compact and affordable way that made possible the discrimination of chemicals using the multivariate analysis as a robust supporting tool to improve the accuracy of the method.

Regarding to the patented devices of infrared applied to fuel quality control, the first invention disclosed in previous Section 2.1., (Clarke 1993) it consisted on an in situ MID IR device to characterize the hydrocarbons in a fuel using the wavelength range from 4000 to $500 \mathrm{~cm}-1$. Whilst this invention needed to use various narrowband filters (one filter per each hydrocarbon to detect), the device used in this research provided information of all the species simultaneously without the need of changing the linear filter, as the LVF provided all the necessary wavelengths for the detection and quantification.

Maggard et al, (Maggard 1994) used the NIR to characterize the PIANO profiling (i.e. Paraffin, Isoparaffin, Aromatic, Naphtenes and Olefins) octane rate and percent of other various hydrocarbons by means of a optimal key wavelengths selection that made possible 
the identification and differentiation of these chemicals among them. But their method only consisted in a mathematical procedure for wavelength selection without providing any device to it. In our case, we did a wavelength selection in the MID IR but it was automatically performed by the algorithm which quantified and discriminated among the chemicals of interest.

More recently Zelepouga et al., (Zelepouga 2016) patented a method and apparatus for real-time measurement of fuel gas composition and heating values, consisting on a NIR to measure concentrations of hydrocarbons and carbon dioxide, a MID IR sensor for measuring concentrations of carbon monoxide and a non-optical semiconductor based sensor for measuring hydrogen. This sensor measured the concentration of Hydrogen gas by changing its polarity and sending this signal to the electrical transducer to be processed. Again, instead of combining three different sensors, the contribution provided here is the possibility of measuring hydrocarbons, carbon dioxide $\left(4.27\right.$ microns or $\left.2342 \mathrm{~cm}^{-1}\right)$ and carbon monoxide (4.55-4.65 microns/2193-2198 $\left.\mathrm{cm}^{-1}\right)$ in the same spectrum, giving a more compact device than the one described in this patent.

These all contributions done in small advances to each of the previous research papers or inventions patented have improved the state of the art by providing a more compact, economically affordable and at the same time versatile and useful device and method to determine properties in a fuel that are important from an environmental and mechanical point of view.

\subsection{The most relevant aspects regarding to the results}

From the two experiments performed within this PhD thesis, the first one regarding to pure substances and the second one to mixtures, the determination of alcohol content in a gasoline mixture and the type of alcohol simultaneously gave the most promising results regarding to the practical industrial application in the fuel quality control field. On the other hand, the results obtained from the experiment 1 allowed the clear and robust differentiation of pure substances whose molecular structure shows a big similarity with the molecular structure of the most of the chemicals used for industrial purposes. This fact makes it useful as a potential prospective tool in laboratory analysis for pharmaceutical, food and fuel environments. 
Sections 5.1 and 5.2. reveal the infrared spectra of pure substances and how it influenced their differentiation by the sensor employed.

The experiment 1 method and its results exposed above was the first step to find out the ability of this sensor to differentiate among substances of different chemical nature, i.e. the oily compounds such as diesels, whose main molecular bounds are alkanes hydrocarbons (C simple bound to $\mathrm{H}$ ); the gasolines, whose main bonds are the corresponding to aromatics (these are the ones derived from benzene, i.e. double and single bond $\mathrm{C}-\mathrm{C}$ and $\mathrm{C}=\mathrm{C}$ combined alternatively in a ring shaped molecule basis) and the linear-chained alcohols, whose chemical structure is an hydrocarbon chain (single $\mathrm{C}-\mathrm{H}$ bound) bounded to an hydroxyl group $(\mathrm{O}-\mathrm{H})$ which absorbs radiation at a different wavelength and on the other hand it also absorbs more radiation due to the higher electronic density provided by the oxygen atom, that is much bigger in size than the hydrogen and presents 2 free electron pairs (not taking part in any bound) (Graybeal and Hurst 2018) This is the reason why the shape of the alcohols spectra was observed to be different to the rest, as it showed another additional absorption peak at a different wavelength next to the 3.4 microns $\left(2940 \mathrm{~cm}^{-1}\right)$ typical of alkanes. As the hydrocarbon chain of alcohols was increasing (from methanol, 1C to $\mathrm{n}$-hexanol, $6 \mathrm{C}$ ) this second absorption peak of $\mathrm{O}-\mathrm{H}$ group was getting overlapped by the $\mathrm{C}-\mathrm{H}$ absorption peak, causing a progressive broadening of the spectra in the alcohols cluster.

It is remarkable that the methanol (1C) gave back a notoriously different spectral shape from the rest of substances, even from his closest one: the ethanol (2C). This fact was unexpected because of the chemical similarity of both alcohols. But as the methanol is toxic, cheaper and a perfect candidate to be an adulterant in commercial blends, these results potentially gave a chance of profit our device to detect adulterations in fuel industry.

These all facts favored a clear and robust discrimination among oily, aromatic and alcoholic substances, and the results obtained from applying the MANOVA analysis on these spectra were encouraging to give a next step in the fuel quality control provided by this method. 


\subsubsection{The infrared spectra of mixtures and how it influenced the simultaneous quantification and identification of gasoline and alcohol blends from a chemical point of view}

The experiment 2 disclosed afterwards was the next step to test the ability of this sensor and method to quantify the ethanol, methanol and butanol concentration in volume percentage $(\% \mathrm{v} / \mathrm{v})$ in a gasoline-alcohol blend. The sense of this research pathway was because of the progressive insertion of ethanol and more recently butanol (this one in form of its different isomers as n-butanol, iso-butanol, etc.) in the gasoline formulation, for the reasons disclosed in the introduction of this thesis dissertation.

The accuracy of the sensor and method was demonstrated to be high, in terms of qualitative and quantitative analysis the results showed a $100 \%$ classification success and less than a $10 \%$ of prediction error respectively considering that the gasoline and alcohol blends were prepared in a non-certified laboratory with no standardized volumetric materials; and also the low resolution of the sensor used for the analysis. The root means square error was not more than 8.5 percent and the goodness of the fitting obtained was of 0.954 and 0.944 in the train and test sets respectively.

Chemist dictates the basis of the results obtained. Always the molecular structure of the substances influences the vibrations and stretching modes, and so on the shape and intensity of the spectra. In this case, the intensity was not as important as the shape. One could expect that the higher is the amount of alcohol in the mixture, the more absorption intensity of the spectra (because of what was explained in the previous section about the bigger absorption of the hydroxyl group). But nevertheless, the method used at this stage was focused on the progressive shape changes in the spectral curves as the alcohol concentration in the blend was increased from 10 to $30 \%$. Due to the basis of the sensor, it is sensitive to changes in the spectral curves within different concentrations. Nevertheless it is not so accurate when it comes to the intensity changes, as it has a considerable level of drift during the measurements. This progressive change was enough for the PLS algorithm developed in the Texas A\&M University (Huang and Gutiérrez-Osuna 2016)to build a robust prediction model using only 5 latent variables and with an acceptable accuracy especially for mixtures of 20 and 30 percent of alcohol.

But this ability of quantification was not really useful if it was not possible to know the type of alcohol contained in the blend so the lack of a way to identify it took us to apply a 
MANOVA analysis on the same datasets, using the training and test sets for the PLS as calibration and validation sets for MANOVA respectively, which gave back a regular triangle. This triangle was the key tool to discriminate and quantify simultaneously. The vertexes of the triangle were each one of the three alcohols and the measure of the radial distances were the amount in their respective blends.

So the vertexes and the distance measures were finally the tool that was obtained from this experiment 2. They may have the potential applicability of being implemented in the interface screen of the software addressed to the measuring sensor.

\subsection{Discussion on spectra pre-processing and data analysis}

From the point of view of Chemometrics, several facts are remarkable. The first one is comparing our results to other authors from previous works who combined the FTIR or the RAMAN spectra (which provides more amount of clearer chemical information as its resolution is much higher). These authors used prediction models such as the PLS algorithm, or methods like the PCA to discriminate among different species. In our case, and having less resolution than a RAMAN or FTIR, these same methods resulted useful and suitable for the quantification and the discrimination of chemical substances.

The second point to remark is that none of the authors reviewed in this thesis used the MANOVA analysis to discriminate among chemicals and doing a wavelength selection. Even when the PCA was also used, as the MANOVA analysis were performed on the scores obtained from this analysis. This MANOVA analysis provided highly clear and robust results, that allowed the differentiation and segregation among the substances to analyze.

The third and last item regards to the spectra pre processing methods. When it may be expected that the spectral curves obtained from our PbSe detector (and subsequently more noisy, drifty and blurry) would need much more pre processing than the RAMAN and FTIR spectra, the results demonstrated the usefulness of our algorithm just composed by a smoothing and a baseline correction. No first or second derivatives of the spectra were necessary.

However, other mathematical methods such as the Lambert Beer approach, which stablishes a linear correlation of absorption data and the concentration of the chemical substance in the spectrum, (Clarke 1993), (Lord 2002), (Chen and Asher 2006) and linearly 
or higher order polynomials correlating the spectrum fitting baselined over the absorption band of the analyte measured would not be reliable when applied on our spectral data, due to the drift of the spectrometer.

\subsection{The infrared spectral range used by the PbSe sensor and what to expect about it}

According to previous works, (Corsetti, Zehentbauer, et al. 2015) further characteristics of ethanol can be found in the fingerprint region of the spectrum. As these authors used an interferometric spectrometer in the MID IR (FTIR) working in the range span of 4000-500 $\mathrm{cm}^{-1}$, they were able to see this fingerprint region.

The sensor used for this thesis works in the infrared spectrum region that goes from 2.5 and 4.9 microns $\left(4000-2200 \mathrm{~cm}^{-1}\right)$, with a maximum of absorption in 3.7 microns. The main difference with an interferometric sensor like an FTIR is that it does not use the finqerprint, but only the stretching and bending regions. This fact prior reduces its accuracy, but regardless of $i t$, this thesis work aims the goal of offsetting the "inaccuracy issue" by means of the chemometric tools, and that is what provided an added value to an instrumentation that is simple and economically affordable.

The Figure 65 below shows the infrared spectra obtained from a FTIR, displaying both the stretching and bending, and the fingerprint regions. It can be observed that the fingerprint region starts from approximately $1400 \mathrm{~cm}^{-1}$ and it extends to $500 \mathrm{~cm}^{-1}$. The functional group region runs from $4000 \mathrm{~cm}^{-1}$ to $1550 \mathrm{~cm}^{-1(8)}$.

\footnotetext{
${ }^{8}$ www.chem.ucla.edu
} 


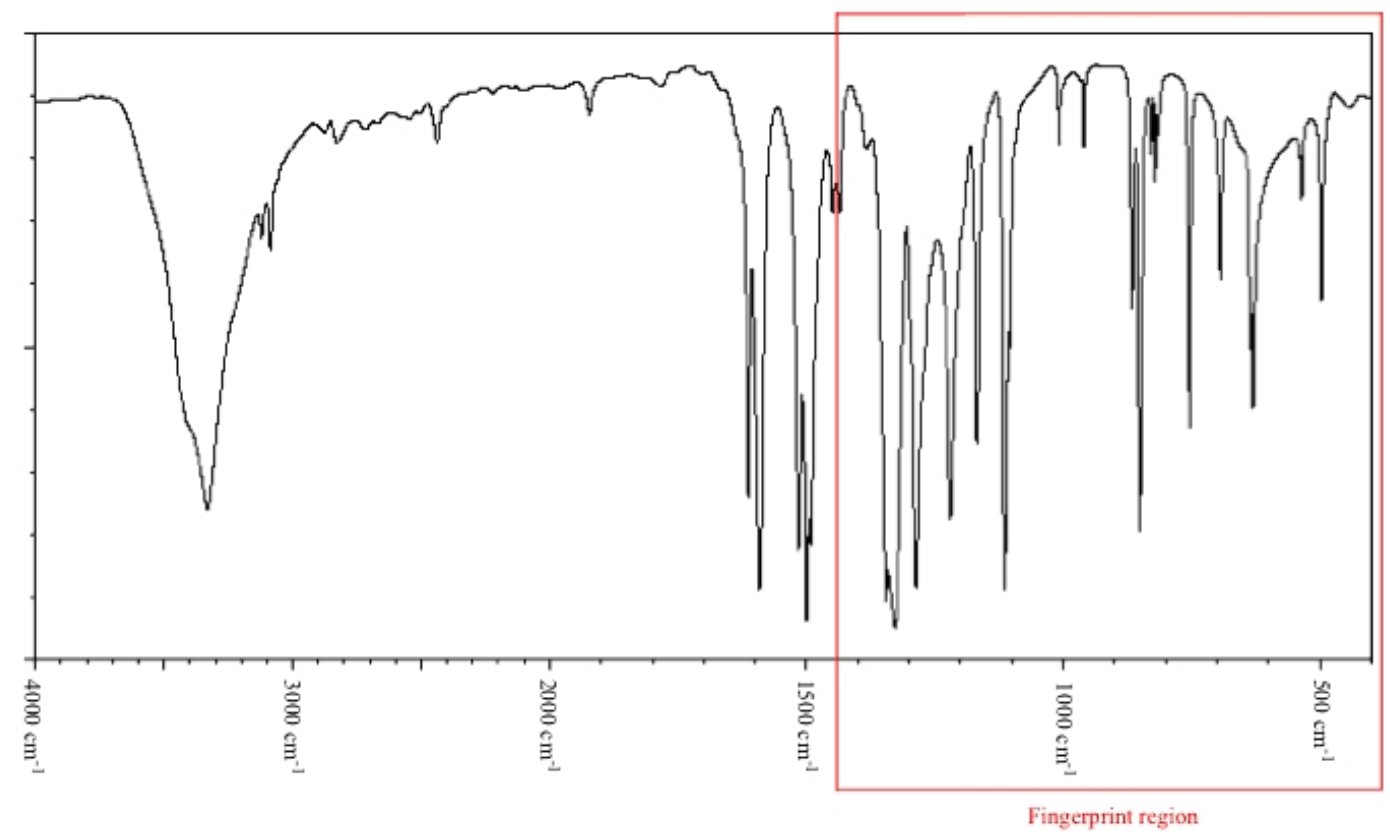

Figure 65.Generic Middle infrared spectrum.

Due to this limitation of wavelength range, only one a single broad absorption peak was observed in our spectra, except in the methanol and ethanol mixtures that have the highest concentrations (the 20 and 30 percent ones), where two peaks can be found: the first one around $2940 \mathrm{~cm}^{-1}$ (around 3.4 microns), corresponding to the $\mathrm{C}-\mathrm{H}$ bounds and the second one around $2800 \mathrm{~cm}^{-1}$ (around 3.6 microns), which corresponds to the hydroxyl (O-H) vibrations.

But in the end, keeping in mind all the issues and solutions discussed above, and after an exhaustive review of the literature from the last decades, it has to be concluded that we are faced with a different kind of concept in what refers to infrared spectroscopy. Once it was made a comparison of the advantages and drawbacks of each type of sensor published or patented, the device used in this thesis work is able to achieve the same purposes or applications than the most of the equipment from other authors do, with less costs and execution time, in a simpler way and an easier interpretation of results within everyone's grasp.

In addition, this device offers the possibility of being implemented in diverse points of the process such as the oil refinery, the pipeline for the distribution of fuel or even in the gas stations, due to its simpler instrumentation and its ruggedness. The study developed for 
this PhD has opened this possibility of application, which was the main aim of the thesis. And it has been accomplished.

\subsection{Possible prospective applications of the developed device in field}

Another contribution provided by this thesis with regards to previous authors consists on the prospective applicability of the studied device in field. For this purpose, there is still large amount of research and development to be done starting from these preliminary results obtained.

The work carried out here and the main goals achieved are oriented to the attainment of a compact, rugged and affordable spectrometer that measures chemical compounds which vibrate in the Infrared spectral region, and is based on a fast response and uncooled sensor, which is able to give back a rapid in situ measurement and whose resolution has become clearly improved by means of the Chemometric techniques provided in this research work.

The final developed product would become implemented in field, such as a gas station or a fuel distribution point. Its main tools for determining the fuel quality in terms of the qualitative and quantitative analysis should be the vertexes of the triangle described by the plot of canonicals 1 and 2 from the MANOVA analysis. This chemometric method would become deployed in the software, taking a few seconds to be performed. The user interface of this software should display the point of the triangle determined by the calibration dataset in which the acquired test sample of fuel is located. The equipment should be calibrated every season of sampling using an elevate number of gasoline samples up to 75 or 80 individuals.

This point would indicate the nearest vertex from the triangle, and this way, the type of alcohol blended with the gasoline should be known.

In a parallel way, the user interface would display the distance of this point corresponding to the test sample from the centre of the triangle. This distance would be correlated with the concentration value, given in total volume percentage.

A graphical approach is given in the Figure 66 below: 


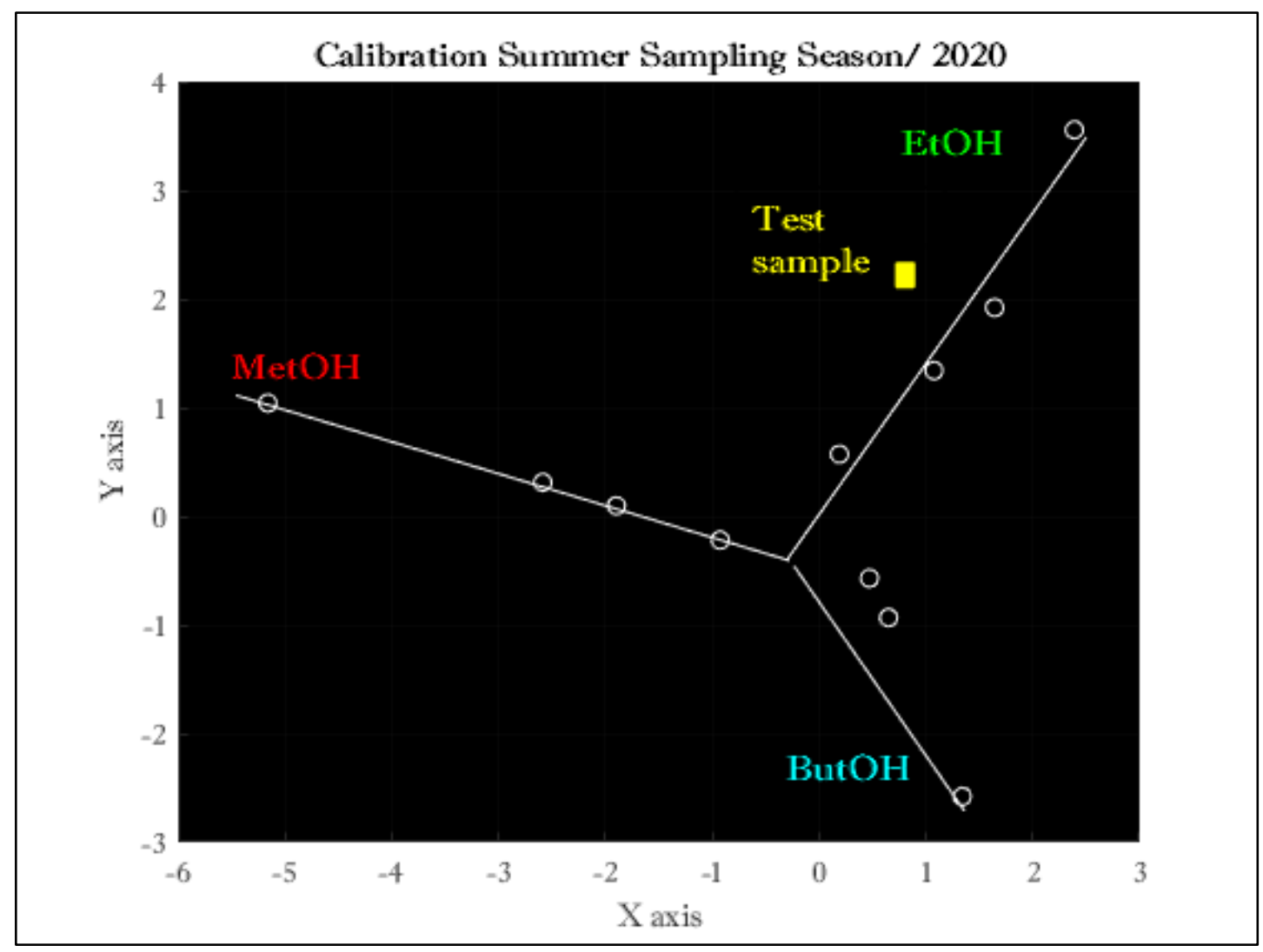

Figure 66.User interface approach of the proposal for a future prospected device

And a numerical approach is demonstrated using an example for the quantification of ethanol content in a test sample of gasoline the below:

Table 29.Example given as an approach to the prospective future application of the results obtained in quantitative terms.

Training and Calibration for Summer Sampling Season/ 2020- Et0H content

\begin{tabular}{|c|c|c|c|c|}
\hline $\begin{array}{c}\text { Goodnes of } \\
\text { prediction }\end{array}$ & $\begin{array}{c}\text { Error of Calibration } \\
(\%)\end{array}$ & $\begin{array}{c}\text { Concentration } \\
(\% \mathrm{v} / \mathrm{v})\end{array}$ & $\begin{array}{c}\text { Radial distance } \\
\text { to the center in } \\
\text { calibration }\end{array}$ & $\begin{array}{c}\text { Radial } \\
\text { distance in } \\
\text { the test }\end{array}$ \\
\hline 0.992 & 8.54 & 10.43 & 1.75 & 1.78 \\
\hline
\end{tabular}





\section{Chapter 7}

\section{Conclusions}

The main aim of this thesis was proposing a MID IR detector that posed a clear prospect for an industrial application. And the results provided a fast, simple and reliable method for the in situ differentiation of pure chemical substances that are potential adulterants or additives in fuels such as gasoline. The procedure was validated as regards the repeatability of the methods (tests conducted on several different dates). The main goals achieved are listed below:

\subsection{The identification of the key absorption wavelengths for each chemical compound}

This is one of the most important steps. In this thesis, the identified absorption bands match the chemical information obtained from the bibliography. Thus, the proposed MID IR device gathers at least five absorption bands corresponding to the main functional groups, i.e. the methyl, methylene and hydroxyl groups that are typical of organic molecules. This device has a clear ability for classification based on the presence of functional groups such as hydroxyl. Moreover, the shorter the hydrocarbon chain, the higher the influence of the hydroxyl, as may be seen in the case of methanol. 


\subsection{The discriminant analysis performed on the spectra according to the key wavelengths: A tool to differentiate between chemical substances}

Principal Component Analysis focuses on the most significant wavelengths, i.e. the most intense wavelengths in the spectra $\left(3145,3046\right.$ and $3068 \mathrm{~cm}^{-1} / 3.18,3.30$, and 3.26 microns respectively) to group the spectra variables in a space with reduced dimensions. On the other hand, MANOVA chooses the most discriminating wavelengths (those that are most different to the rest) regardless of their intensity.

\subsection{The issue of high volatile compounds such as methanol and gasoline: A prospect of future improving}

Highly volatile substances revealed greater dispersion in measurements, as may be seen in Cartesian diagrams, particularly methanol. This calls for a device capable of ensuring an uniform measurement procedure, by fixing the sample volume between the wafers, or using a specific sample holder for volatile substances, as an issue to be explored in subsequent studies.

\subsection{The algorithm for quantitatively determine concentrations: An useful tool to implement in fuel industry}

A quantitative cross validated PLS model is proposed for the estimation of overall alcohol concentration in gasoline using low cost non-destructive MID IR spectroscopy, attaining $95 \%$ of explained variance and root mean square errors below $8.5 \%$. The wavelengths used for the PLS model make use of alkane hydrocarbons vibration bond $\left(2980 \mathrm{~cm}^{-1} / 3.35\right.$ microns) with regard to internal blank reference in the spectra (3167 and $2836 \mathrm{~cm}^{-1} / 3.15$ 3.53 microns).

\subsection{A qualitative approach by MANOVA to reinforce and validate the quantitative results obtained by PLS}

A qualitative approach for additive identification has also been performed through MANOVA defining two canonical variables that enable the isolation of the type of alcohol used for blending as related to the radial angle in the canonical plane. The wavelengths that contribute to the segregation incorporate the vibration bond of aromatics (which are typical of gasoline) to the PLS selected alkane band. 
A secondary output of the qualitative approach is an estimation of the overall concentration of alcohols in the blend derived from the radial distance in the canonical plane, which reinforces the PLS prediction.

\subsection{Main goals achieved}

This thesis provides an improvement in fuel quality control by incorporating the estimation of additive concentration in gasoline blends using MID IR, compared to our initial work were only pure samples were identified with this technology.

The combination of quantitative-qualitative MID IR models constitutes a robust mean for blend characterization and quantification that may be used as screening method by more advanced and standardized chemical tests in order to reduce time and laboratory reagents needs.

Based on a simple and cheap experimental design and two fast and accurate algorithms, a reliable analysis of the most relevant alcohol-gasoline blends may be performed. This results in a promising industrial application in a moment when the sustainability and environmentally friendly fuels are issues of a big concern all over the world. 


\section{Chapter 8}

\section{Proposal for future research}

Based on the conclusions obtained from this thesis dissertation, the next steps to take may be proposed and disclosed below:

- $\quad$ Expand the spectrum of applications to the detection of edible oil adulterations.

- Develop a head space sampling device that solves the problems of quick volatilization of gasoline and alcohols, which causes an error in the results obtained from measurements.

- Design and build an online device for the evaluation of liquid fuels at different stages along the distribution chain.

- $\quad$ Establish a calibration transfer between FTIR and MID IR models aimed at the characterization of fuels and their mixtures

- Analyze the critical control points of fuels throughout the process of production, refining and commercial distribution.

- Adapt the above-mentioned sampling designs to industrial environments 


\section{Chapter 9}

\section{References}

Abu-Zaid, M., O. Badran, and J. Yamin. "Effect of Methanol Addition on the Performance of Spark Ignition Engines." Energ. Fuel (18), 2004: 312.

Abu-Zaid, Omar Badran, and Yamin. "Effect of Methanol Addition on the Performance of Spark Ignition Engines Energ." Fuel (18), 2004: 312.

Adenilton, Camilo. "Detection of adulteration in hydrated ethyl alcohol (HEAF) fuel using infrared spectroscopy and supervised pattern recognition methods." Talanta (93), 2012: 129-134.

Ahmed, Ahfaz, and Gokop Goteng. "A computational methodology for formulating gasoline surrogate fuels with accurate physical and chemical kinetic properties." Fuel (143), 2015: 290-300.

Alasadi, Suad, and Wesam S. Baya. "Reiew of Data Preprocessing Techniques in Data Mining." Journal of Engineering and Applied Sciences 12 (16), 2017: 4102-4107.

Aparicio, Harwood and. Handbook of olive oil: Analysis and properties. 2013.

Balat, M. "Production of bioethanol from lignocellulosic materials via the biochemical pathway : A review." Energy Conversion and Management (52), 2011: 858-875.

Bazan, Guillermo, and Martin R. Bryce. "Themed issue on small molecules and monodisperse oligomers for organic electronics." Royal Society of Chemistry, 2016: 3675-3676.

Chemical, The Dow. "Product Safety Assessment (PSA): n-Butanol." 2009.

Chen, Yu Min, and William Asher. Massachussets, US Patent US20060192122A1. 2006.

Clarke, Richard. Massachussets, United States Patent US005225679A. 1993.

Coates, John. "Interpretation of Infrared spectra, a practical approach." Newton, USA, 2000.

Correia, Domingos. "Portable near infrared spectroscopy applied to fuel quality control." Talanta (176), 2018: 26-33.

Corsetti, Stella, and Johanes Kiefer. "Comparison of Raman and IR spectroscopy for quantitative analysis of gasoline / ethanol blends." Fuel (166), 2016: 488-494. 
Corsetti, Stella, David McGloin, and Johannes Kiefer. "Characterization of gasoline/ethanol blends by infrared and excess infrared spectroscopy." Fuel (141), 2015: 136-142.

Corsetti, Stella, Florian M Zehentbauer, David McGloin, and Johannes Kiefer. "Characterization of gasoline/ethanol blends by infrared and excess infrared spectroscopy." Fuel (141), 2015: 136-142.

Davis S.C., Diegel S.W. , Oakridge, T.N. Center for Transportation Analysis, Transportation Energy Data Book: Edition 25. Oak Ridge National Laboratory, 2006.

Demirbas. "Biofuels securing the planet's future energy needs." Energy Conversion and Management (50), 2009: 2239-2249.

Demirbas. "Octane rating of gasoline and Octane booster additives." Petroleum Science and Technology (33), 2015: 1190-1197.

Dengfeng, R., T. Hong, X. Yimin, H. Yuge, and L. Qiang. "Apparatus for measuring spectral emissivity of solid materials at elevated temperatures." International Journal of Thermophysics, 2016: 37-51.

Dudley, Bob. British Petroleum. 2015.

Dupuy, Brahem, and Amat Kister. "Near-infrared spectroscopy analysis of heavy fuel oils using a new diffusing support." Appl. Spectrosc.(69), 2015: 1137-1143.

Eyidogau, Muharrem, Ahmet Necati Ozsezen, Mustafa Canacki, and Ali Turcan. "Impact of alcohol-gasoline fuel blends on the performance and combustion characteristics of an SI engine." Fuel (89), 2010: 2713-2720.

Fernandes, H.L., M. Ivo, C. Pasquini, and J. J. R. Rohwedder. "Simultaneous determination of methanol and ethanol in gasoline using NIR spectroscopy: Effect of gasoline composition." Talanta (75), 2008: 804-810.

Figueiredo Monique K.-K., Costa-Felix Rodrigo P.B., Maggi Luis E., Alvarenga André V.,Romeiro G.A. «Biofuel ethanol adulteration detection using an ultrasonic measurement method.» Fuel (91), 2012: 209-212.

Fornaro, Teresa, and Diletta Burini. "Hydrogen-Bonding Effects on Infrared Spectra from Anharmonic Computations: Uracil-Water Complexes and Uracil Dimers." J. Phys. Chem (119), 2015: 4224-4236.

Gallagher PW, Shapouri H, Price J, Schamel G, Brubaker H. "Some Long-run Effects of Growing Markets and Renewable Fuel Standards on Additives Markets and the US Ethanol Industry.» Journal of Policy Modeling (25), 2003 : 585-608.

Gilbert. Encyclopedia of Spectroscopy and Spectrometry (Third Edition). El Sevier, 2017.

Gopinath. "Investigation of n-butanol as fuel in a four-cylinder MPFI SI engine." Energy (125), 2017.

Graboski. An Analysis of Alternatives for Unleaded Petrol Additives for South Africa. 2009.

Graybeal, Jack D, and George S Hurst. Spectroscopy. Encyclopedia Britannica, 2018.

Hansen, Zhang, Lyne, Peter. "Ethanol-diesel fuel blends - A review." Bioresource Technology (96), 2005: 277-285. 
Huang, Jin, and Ricardo Gutiérrez-Osuna. "Active wavelength selection for mixture identification with tunable mid-infrared detectors." Anal Chim Acta.(937), 2016: 1120.

Jamrozik. "The effect of the alcohol content in the fuel mixture on the performance and emissions of a direct injection diesel engine fueled with diesel- methanol and diesel-ethanol blends." Energy Conversion and Management, 2017: 461-476.

José Piñeiro-Ave, Manuel Blanco-Velasco. "Target detection for low cost uncooled MWIR cameras based on empirical mode decomposition.» Infrared Physics \& Technology, 2014: 222-231.

K., Brekke. «Butanol-An Energy Alternative?» Ethanol Today, 2007.

Khijwania, V.S. Tiwari, Fang-Yu Yueh, J.P. Singh. Sensors and Actuators B (125). 2007. 563.

Knorr, Anne, and Peter Stange. "Spectroscopic Evidence for Clusters of Like-Charged Ions in Ionic Liquids Stabilized by Cooperative Hydrogen Bonding." Chem Phys Chem, 2015: 458-462.

Lemos, S. G., E. L. Romário, and José E. Abreu. "Ethanol fuel adulteration with methanol assessed by cyclic voltammetry and multivariate calibration." Fuel (156), 2015: 2025.

Linares-Herrero, Vergara G., Gutiérrez-Álvarez R., Fernández-Montojo C., Gómez L.J., Villamayor V., Baldasano-Ramírez A. and Montojo M.T. «Variable filter array spectrometer of VPD PbSe.» Proceedings of SPIE, 2012.

Lord, Baum. California, United States Patent US6455851B1. 2002.

Luo, Yi, Rui, Wan, Xie, Xiaojian, Zhu, Yang. "Study on the nugget growth in single-phase AC resistance spot welding based on the calculation of dynamic resistance. ." Materials Processing Technology (229), 2016: 492-500.

Maggard, Steven. United States Patent 5349189. 1994.

Maio, L., Liberini, M., Campanella, D., Astarita, A., Esposito, S., Boccardi, S., Meola, C. 2017. "Infrared thermography for monitoring heat generation in a linear friction welding process of Ti6Al4V alloy.» Infrared Physics \& Technology (81), 2017: 325-338.

Maldonado, María, Raúl Gutiérrez, Pilar Barreiro, and Germán Vergara. "Spot welding process monitoring using MWIR online thermography." IX Congreso de Estudiantes Universitarios de Ciencia, Tecnología e Ingeniería Agronómica 2017. 2017.

Martins, J.C., J.I. Da Silva Filho, and M.T.T. Pacheco. "Determinação da concentração de etanol na gasolina comum através da técnica de espectroscopia Raman." Unisanta Sci. Technol., 2016: 200-209.

Masaki Hirota, Yoshimi Ohta. "Low-cost thermo-electric infrared FPAs and their automotive applications.» Proceedings of SPIE- The Inteernational Society for Optical Engineering 6940, 2008.

Nadim, F., P. Zack, George E. Hoag, and S. Liu. "United States experience with gasoline additives." 2001.

Nadim, Zack, and George Hoag. "United States experience with gasoline additives." 2001. 
Niemeyer, Daly, and Cannella Hagen. "Predicting fuel research octane number using Fourier-transform infrared absorption spectra of neat hydrocarbons." Fuel (183), 2016: 359-365.

Oliveri, Pablo, Cristina Malegori, Remo Simonett, and Monica Casale. "The impact of signal pre-processing on the final interpretation of analytical outcomes - A tutorial." Analytica Chimica Acta (1058), 2019: 9-17.

Pasadakis, Sourligas, and Foteinopoulos. "Prediction of the distillation profile and cold properties of diesel fuels using mid-IR spectroscopy and neural networks." Fuel (85), 2006: 1131-1137.

Peeran, Mehboob. ChemVista.org. 2005. http://www.chemvista.org/ramanIR1.html.

Peirs, A., N. Scheerlinck, K. Touchant, and B. Nicolaï. "Comparison of Fourier Transform and Dispersive Near-Infrared Reflectance Spectroscopy for apple quality measurements." Biosystems Engineering (81) 3, 2002: 305-311.

Qingzhong Li, Nannan Wang, Qun ZHou, Suqin Sun, Zhiwu Yu. «Infrared Excess Spectroscopy." Applied spectroscopy (62) 2, 2008: 166-170.

R., Clarke. Massachusets, United States Patente Methods and apparatus for determining hydrocarbon fuel properties. 1993.

R.E., Reynolds. " The current fuel ethanol industry transportation, marketing, distribution, and technical considerations. Bremen, IN: Downstream.» s.f.

Rivas, Eva María, Belén Diezma, Pilar Barreiro, Isabel de Silóniz, and María Maldonado. "Detection of Biological CO 2 and 1,3-Pentadiene Using Non-refrigerated Low-Cost MWIR Detectors." Food Analytical Methods (9), 2015: 1-10.

Romário, E. L., José E. Abreu, and M. Paz. "Ethanol fuel adulteration with methanol assessed by cyclic voltammetry and multivariate calibration." Fuel (156), 2015: 2025.

Ruiz García, Luis, Pilar Barreiro Elorza, and Jose Ignacio Robla Villalba. "Development of monitoring applications for refrigerated perishable goods transportation." 2008.

Santos, Valle. "Economia e Energia, ano IV, no. 19." 2000.

Savitzsky, and Golay. "Smoothing and differentiation of data by simplified least squares procedures." Anal. Chem.(36), 1964: 1627-1639.

Schafer, R.W. "Lecture notes about Savitzky-Golay smoothing." IEE SIGNAL PROCESSING MAGAZINE, 2011: 111-117.

Segneanu, Adina E., Ioan Dabici, A. Gozescu, P. Sfirloaga, and Z. Szabadai. Organic compounds FT-IR spectroscopy. 2012.

Sheehan J., Camobreco V., Duffield J., Graboski M., Shapouri H. Golden, C.O. « An Overview of Biodiesel and Petroleum Diesel Life Cycles.» National Renewable Energy Laboratory, 1998.

Sierra, C., M. C. Torquemada, and G. Vergara. "Multicolour PbSe sensors for analytical applications." Sensors and Actuators B-Chemical (90), 2014: 464-471.

Smil, Vaclav. Energy Transitions: Global and National Perspectives. ISBN: 144085324X. 2017. 
Soares, Rocha, and Teixeira. "Contributions of flow analysis for quality control of automotive fuels: a review." Analytical Letters (46), 2013: 1621-1639.

Sundararajan, D. A practical approach to signals and systems. John Wiley and Sons, 2009.

Szulczyk, Kenneth R. "Which is a better transportation fuel - butanol or ethanol?" International Journal of Energy and Environment, 2010: 501-512.

Tasumi M., Shimanouchi T. Watanabe A. "Infrared spectra of normal higher alcohols .» Spectrochimica Acta (20), 1964: 629-666.

Thomas Charles Wilkes, Leigh Russell Stanger. "The development of a Low-Cost, Near Infrared, High Temperature Thermal Imaging System and its application to the retrieval of accurate lava lake temperatures at Masaya Volcano, Nicaragua.» Remote Sensing 10 (3), 2018.

U.S. Energy Information Administration. Today in energy. 2015.

Ugena, L., S. Moncayo, S. Manzoor, D. Rosales, and J. O. Cáceres. "Identification and Discrimination of Brands of Fuels by Gas Chromatography and Neural Networks Algorithm in Forensic Research." Journal of analytical methods in Chemistry, 2018: 1-7.

Ulberth, Buchgraber. "Authenticity of fat and oils." European Journal of Lipid Science and Technology, 2000.

US, Environmental Protection Agency of. "Inventory of Greenhouse Gas Emissions and Sinks." Washington D.C., 2008, $1990-2006$.

Van Bommel, W. Encyclopedia of Color Science and Technology. New York: Springer, 2012.

Vergara, Germán, Gloria Pérez, and María Teresa Montojo. "Monolithic integration of spectrally selective uncooled lead selenide detectors for low cost applications." Applied Physics Letters 83 (14), 2003: 2751-2753.

Vergara, Germán, Mari Carmen Torquemada, and María Teresa Montojo. "Polycristalline lead selenide: The resurgence of an old infrared detector." Opto-Electronics Review (15) 2, 2007: 110-117.

Vergara, Germán, Rodrigo Linares, Raúl Gutiérrez, and M Teresa Montojo. "Monitoring of industrial welding processes using high-speed uncooled MWIR imaging sensors." 2014 conference paper Thermosense: Thermal Infrared Applications XXXVI. 2014.

Vergara, Germán, Rodrigo Linares, Raúl Gutiérrez, and María Teresa Montojo. "Monitoring of industrial welding processes using high-speed uncooled MWIR imaging sensors." 2014 conference paper Thermosense: Thermal Infrared Applications XXXVI. 2014.

Vergara, Linares, Gutiérrez, Montojo. «Monitoring of industrial welding processes using high-speed uncooled MWIR imaging sensors.» 2014 conference paper Thermosense: Thermal Infrared Applications XXXVI. 2014.

Villena Gonzales, W., and A. Mobasher. "The progress of Glucose monitoring- A review of invasive to minimally and non invasive techniques, devices and sensors." Sensors (19), 2019: 800.

Wellch, William, and Roy Bledsoe. United States Patent 6140647. 2000.

Wu M., Wang M., Liu J., and Huo H. "Life-Cycle Assessment of Corn-Based Butanol as a Potential Transportation Fuel.» Argonne National Laboratory, 2007. 
www.mabanaft.com. s.f. https://www.mabanaft.com/en/home.html.

Ye, Qing, Qinfeng Xu, Yongai Yu, Ronghui Qu, and Zujie. Fang. "Rapid and quantitative detection of ethanol proportion in ethanol-gasoline mixtures by Raman spectroscopy." Optics Communications (282), 2009: 3785-3788.

Zelepouga, Serguei. United States Patent US9291610B2. 2016.

Zhang, Yuan, and Coronado. "Predicting the dynamic and kinematic viscosities of biodiesel - diesel blends using mid- and near-infrared spectroscopy." Applied Energy (98), 2012: 122-127. 


\section{Annexes}




\section{Annex I: Conferences}

In this annex I, the contributions done to national and international conferences through the works carried out in conjunction with the manufacturing company New Infrared Technologies are attached as an important part of this thesis development.

\section{International Conference of Agricultural Engineering (CIGR) Aarhus, Denmark. June 2016.}

\section{PROSPECTIVE OF THE USE OF MID IR FOR FOOD-TO-FUEL CHARACTERIZATION}

\subsection{Abstract}

A new MID IR spectrometry device is used based on linear array of 128 elements of vapor phase deposit (VPD) PbSe coupled to a linear variable filter (LVF) working in the spectral range between 2.5 and 4.6 microns. This compact device, with no moving parts, is based on a rugged and affordable detector and is suitable to be used in applications with liquid and gas samples which demand high sensitivity, good spectral discrimination, reliability and compactness and where an alternative to the traditional scanning instrument is desired.

In this work a wide set of edible oils, diesel, biodiesel and pyrolysis oil samples, together with gasoline and alcohols, are used to assess the feasibility of the MID IR technique in either liquid or gas samples. GC/MS is also used as a reference advanced analytical platform.

Three replicates and three repetitions of each sample have been tested with the MID IR equipment (135 spectra with 128 wavelengths). The first step has consisted of the reduction of dimension for the identification of relevant differences according to the chemical species (oil, alcohol) and type (chain length and complexity of the oil mixture). 
Furthermore, MANOVA analysis is accomplished to address the discrimination ability based on the MID IR spectra on liquid samples.

The volatilization process of industrial oils has also been faced, recording at 400 frames per second the MID IR spectra in a confined chamber (20 minutes of acquisition time, 480.000 spectra per sample). This information is confronted with regard to GS/MS spectra (0-600 $\mathrm{mz}$ ) obtained using two different solvents (hexane and chloroform). Some final remarks on the application and interest of this particular technology in the petrochemical and engine industry are given, together with further development steps.

\subsection{Introduction}

Adulteration of automobile fuels i.e. gasoline and diesel is a clandestine and profit oriented operation that leads to increased tailpipe emissions and the consequent illness effects on public health and environment; in addition to damages in the engine. As an example, one of the most usual adulteration in renewable bio fuels such as hydrous ethanol is replacing ethanol by methanol, which is much cheaper but also much more toxic (Figueiredo Monique K.-K. 2012). No variations are observed with regards to density or other physical properties of fuels once adulterated. Usually, density remains within the prescribed value. So, for example density test is not a good indicator of diesel adulteration.

Usually, time and reagents consuming techniques are used such as Inductively Couple Plasma Optical Emission Spectrometry (ICP-OES), High Temperature Gas Chromatography (HTGC) and High-Performance Liquid Chromatography (HPLC) at the certificating laboratories of analysis. In contrast, infrared spectroscopy techniques are quick, nondestructive and highly accurate and require little or no pre-treatment of samples.

Similarly, the adulteration of food products such as edible oils involves the replacement of high cost ingredients with lower grade and cheaper substitutes. Due to its sensory quality and nutritional benefits extra-virgin olive oil is often adulterated with less expensive oils. Actually, blend edible oils can be prepared only for suitable products, but when the resulting blend deviates from the mixture proportions given on the label, or if the blend is traded as genuine, it means the oil is adulterated (Ulberth 2000)). The edible oils widely employed in virgin olive oil adulteration can be lower quality olive oil (refined or pomace olive oil) or other vegetable or seed oils such as corn, peanut, cottonseed, sunflower, soybean and poppy seed oils (Aparicio 2013). There exist numerous methodologies to 
detect and quantify vegetable or seed oils in olive oil. Techniques involving application of chromatographic methods are commonly applied. There is an increasing demand for the development of new rapid and sensitive methods instead of traditional time-consuming and expensive analysis techniques.

Application of spectroscopy which includes IR techniques combined with chemometric methods is a relatively new approach to determine authenticity of olive oil.

Over the past twenty years the use of the infrared region of the spectrum has grown precipitously for a wide variety of the analytical procedures. Its great development during the last years is tightly linked to the big advances reached in related fields such as chemometrics, computing power and, over all, instrumentation.

MID IR spectroscopy (from 3 to 5 microns) shows a large potential in the current IR devices market, due to its multiple applications (gas detection, chemical analysis, industrial monitoring, combustion and flame characterization, food packaging, etc) and its outstanding performance (good sensitivity, NDT method, velocity of response, among others), broadening this technique to very diverse fields of application, such as industrial monitoring and control, agriculture, medicine and environmental monitoring. The need for simple solutions for analytical measurements has prompted the development of better and more affordable uncooled MID IR detectors, electronics and optics (Linares-Herrero 2012).In the MID IR spectral region several molecular vibration bands exist, such as $\mathrm{CH}$, $\mathrm{CH} 2, \mathrm{CH} 3, \mathrm{CN}$, and NCS stretching, that are related to organic compounds such as oils and biofuels.

New Infrared Technologies (Boadilla del Monte, Madrid) is a spin-off company that manufactures MID IR a variety of instruments based on their own detector patents based on vapor phase deposited (VPD) PbSe on Silicon matrix. At current stage MID IR detectors are coupled to a linear variable filter (LVF) that works in the spectral range between 3 and 4.6 $\mu \mathrm{m}$. LVF have been often used in the Near Infrared range (NIR), but the use of a LVF in the Middle Infrared is the novelty presented by this device; Figure 1 shows the linear array covered with the LVF (left) and the camera formed by the detector assembled to its $44.8 \mathrm{x}$ $80 \mathrm{~mm}$ size metal housing and the optics (right) as proprietary design of NIT Technologies. 
This paper presents an approximation of the used of MID IR spectrometer for the characterization of edible oils and alcohols and its prospective of use in the assessment of quality of olive oil and bioethanol. And derive adulterations.

\subsection{Materials and methods}

\subsubsection{Samples}

Three replicates of 8 edible commercial oils ( 24 samples) and 5 alcohols ( 15 samples) were tested with the compact MID IR spectrometer, acquiring three repetitions per samples (117). The set of edible oils consisted of 7commercial samples from different origins: sunflower, corn, soy, sesame and virgin olive oil (1 extra high quality AOVE and 2 low cost olive oil, LOO). All the samples were acquired from local supermarkets. The alcohols: methanol, ethanol, propanol, $\mathrm{n}$-butanol and $\mathrm{n}$-hexanol were bought as laboratory reagents of analysis grade from Panreac ${ }^{\circledR}$ (Barcelona, Spain).

The experimental device consisted on the sensor LUXELL FPA described in the introduction part. Its LVF goes from 2.5 to 4.95 microns, and is connected by an USB 2.0 to a software package NIT SOFTWARE SUITE (Acquisition and visualization SW).

\subsubsection{MID IR equipment}

A novel MID IR spectrometer is used consisting of a low-cost uncooled MID IR readout module with USB output system, based in microcontroller ARM M3 CORTEX architecture for linear LUXELL FPA (64, 128 and 256 px). In this study, a 128 pixels type was used. The module includes a LUXELL FPA and its band of detection goes from 1 to 5 microns without the LVF. Its peak wavelength of detection is 3.7 microns. The integration time goes from 4 to $20 \mu$ s (selectable by the user). The acquisition rate is up to 300 frames per second (http://www.niteurope.com/luxell-fpa/). This spectrometer, with no moving parts, can be considered a rugged, compact and affordable device

In this spectrometer, the narrow wavelength range (3-4.6 microns) and the $60 \mathrm{~nm}$ spectral resolution imposed by the LVF suppose a limitation regarding the spectrometer performance. This is the reason why it becomes necessary to use Chemometrics as a complementary tool to analyze chemical species.

The electro-magnetic radiation source of the spectroscopy device is an infrared lamp made of a $\mathrm{SiC}$ mounted within a parabolic reflector. The acquisition was performed in frequency 
mode. The sample was placed in between the IR light path inside two sapphire wafers; spectra of empty sapphire wafers were recorded during a few seconds and used as blank reference.

\subsubsection{Measurements}

The samples (oils and alcohols) were prepared using a Pasteur pipette, by spotting a single drop over one of the sapphire wafers, used as sample holder, and enclosing it, with the other wafer, like a "sandwich". Special care was taken for uniformly sample spreading through the whole surface of the sapphire.

\subsubsection{Data analysis}

For the mathematical analysis, MATLAB ${ }^{\circledR}$ was used together with the software package NIT SOFTWARE SUITE ${ }^{\circledR}$. The first step consisted on the reduction of dimension for the identification of relevant differences according to the chemical species (oil and alcohol) and type (chain length and complexity of the oil mixture) by means of a Principal Component Analysis. Furthermore, MANOVA analysis has been accomplished by addressing the discrimination ability based on the MID IR spectra on liquid samples.

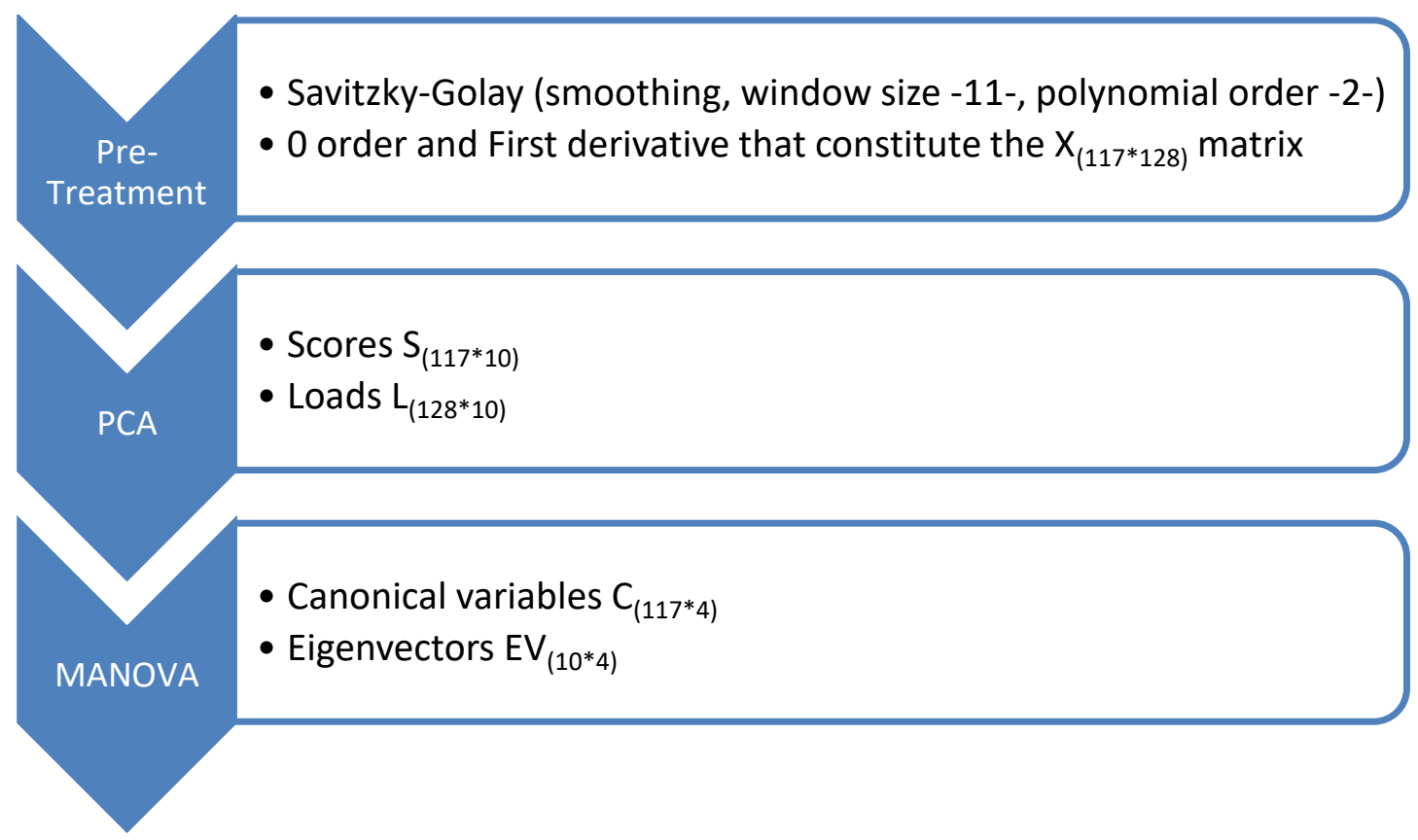

Figure 67.Graphical scheme of the steps followed in the mathematical analysis carried out.

The first main step is the pre-treatment of the row spectra, by means of a Savitzky-Golay smoothing algorithm. The parameters used for this treatment were a window size of 11 and 
the curves were fitted to an order 2 polynomial; followed by the first derivative of the spectra.

The second step was the Principal Component Analysis in order to reduce the variable space dimensions, from which a scores matrix of $\mathrm{n}$ individuals $\mathrm{x} m$ wavelengths was obtained; and a loads matrix with $\boldsymbol{m}$ individuals $\times \boldsymbol{n P C}$ principal components.

And by the last the MANOVA analysis was performed, obtaining the canonical variables matrix ( $\boldsymbol{n}$ individuals $\mathrm{x} \boldsymbol{n C}$ canonical variables) and the eigenvectors matrix ( $\boldsymbol{n} \boldsymbol{P C}$ principal components $\times \boldsymbol{n C}$ canonical variables).

\subsubsection{Principal Component Analysis}

Principal component is a multivariate technique that allows dimensionality decrease without information reduction by means of diagonalization of data variance. Thus several linear combinations of spectral variables are generated with decreasing information weight, while providing non-linear relationship among them. The new variables also called Principal Components retain the spectral variance though they may or may not refer to the information that is required to segregate populations. In cases where the main variance in the data corresponds to the differences in search, this procedure will be sufficient to easily identify the species of interest.

\subsubsection{MANOVA analysis}

Discriminant analysis is used when two or more groups or clusters or populations are known a priori and one or more new observations are classified into one of the known populations based on the measured characteristics. One-way multivariate analysis of variance (MANOVA) is used to determine whether there are any differences between independent groups on more than one continuous dependent variable by mean of the diagonalization of the between-groups sum of squares and cross-products matrix compared to the within-groups sum of squares and cross-products matrix. In this procedure a linear combination of variables is created that retain the segregation ability instead of data variance. MANOVA is compute preferably in a reasonable amount of independent variables, and thus in the case of NIR it is convenient to apply PCA in advance. The contribution of the original wavelengths to the canonical variables, can be computed as $\boldsymbol{X}$ (row data matrix)* ${ }^{*}$ (loads matrix) ${ }^{*} E V$ (eigenvectors matrix). 


\subsection{Results and discussion}

Results obtained from the PCA and MANOVA are described in this paragraph.

\subsubsection{Principal Component Analysis}

PC1, PC2 and PC3 respectively account for $75 \%, 18 \%$, and $7 \%$ of spectral variance. In all three planes (PC1-PC2, PC1-PC3, and PC2-PC3) an overall separation of oils and alcohols can be found (data not shown), however some of the oil samples (sunflower and sesame) appear mixed with alcohols, that is to say no $100 \%$ segregation is attained by nonsupervised procedures.

\subsubsection{MANOVA analysis}

Figure 68 (up) presents the results of MANOVA for the segregation of alcohols and oils. Only the first canonical variable is required for segregation since there are only two categories (100 \% of Wilks-lambda retained). Oils present negative canonical values in variable 1 , while alcohols show positive ones. Compared to PCA, both groups appear very distant with no overlapping of individuals. This is in accordance with this procedure being a supervised analysis compared to the unsupervised nature of PCA. In addition to the nature of the substances (oil or alcohol), a vertical distribution of data is found in both groups, which points to the existence of further sources of variation that are not a priori identified.

For global MANOVA, 10 of the 117 PCs (minimum between spectra number -117- and wavelength-128- ) have been used corresponding to $99.9951 \%$ of spectral variance. Figure 68 (down) presents the eigenvectors (weight of each PC in the definition of the canonical variable). The absolute value of the eigenvector increases for increasing number of PC as expected, since the amount of information retained by the large PC numbers is very low. 

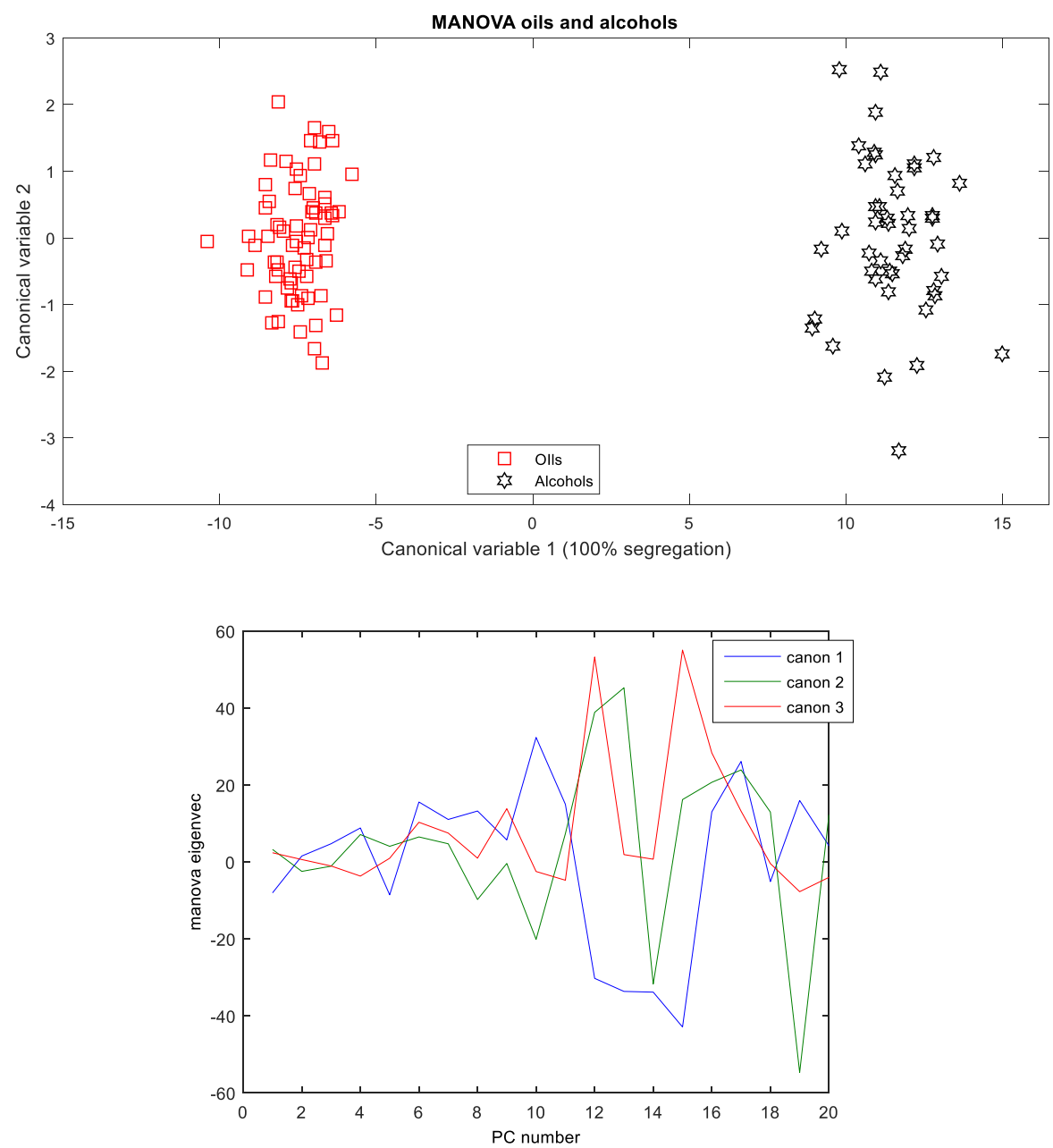

Figure 68.Scattering representation of the 1-way-MANOVA analysis performed on the whole data set (up), and Weight of each principal component contribution to their MANOVA eigenvectors regarding the information given by the canonical variables.

The second step in the analysis is the segregation among oils: AOVE (high quality olive oil from very different varietal origin), LCOO (low cost olive oil), others vegetable oils (sunflower, corn, soybean, and sesame). To this end a new MANOVA is performed on the PC scores based on the previous identification. A main feature from this plot is that both AOVE (first canonical variable $>0$ ) can be easily segregated from the rest $(\mathrm{C} 1<0)$. Moreover, the position of the two LCOO samples suggests adulteration by other vegetable oils that are proximal in the canonical plane (sunflower, and soybean respectively). This fact is confirmed when representing the second and forth canonical variables, since it is feasible to segregate among two large groups: A (sunflower, corn, LCOO1, AOVE2 ) and B (AOVE1, LCOO2, soybean, sesame). 

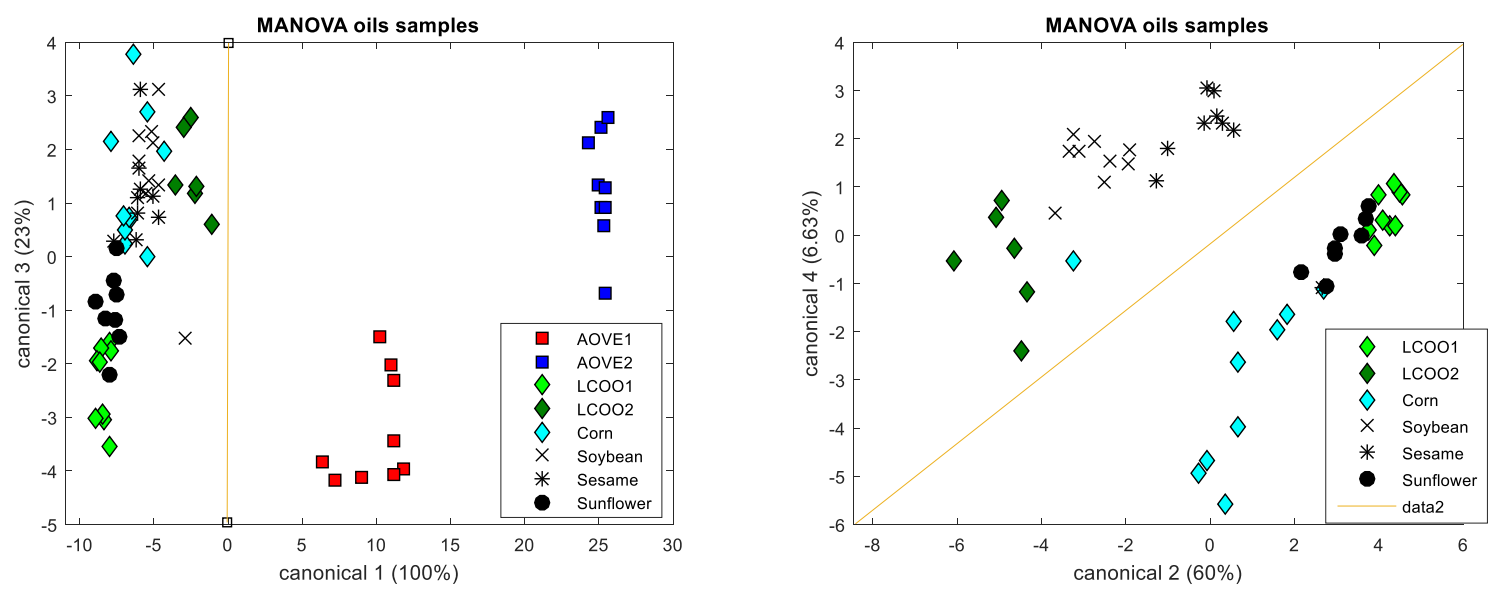

Figure 69.Graphical scattering representation of the 1-way-MANOVA analysis made to the oils data set, using the canonical variables $\mathrm{C} 1, \mathrm{C2}, \mathrm{C} 3$ and $\mathrm{C4}$. The legend displays the different types of oils classified in the analysis.

Figure 69 shows the results of MANOVA carried out on alcohols: methanol, ethanol, propanol, $n$-butanol and $n$-hexanol. As a main feature, it results feasible to segregate among short chain (methanol, ethanol) and the longer chained alcohols (propanol, nbutanol and n-hexanol). In order to segregate between the intermediate classes (propanol, n-butanol and $\mathrm{n}$-hexanol), the plane represented by canonical variables 1 and 3 provides the required segregation power.
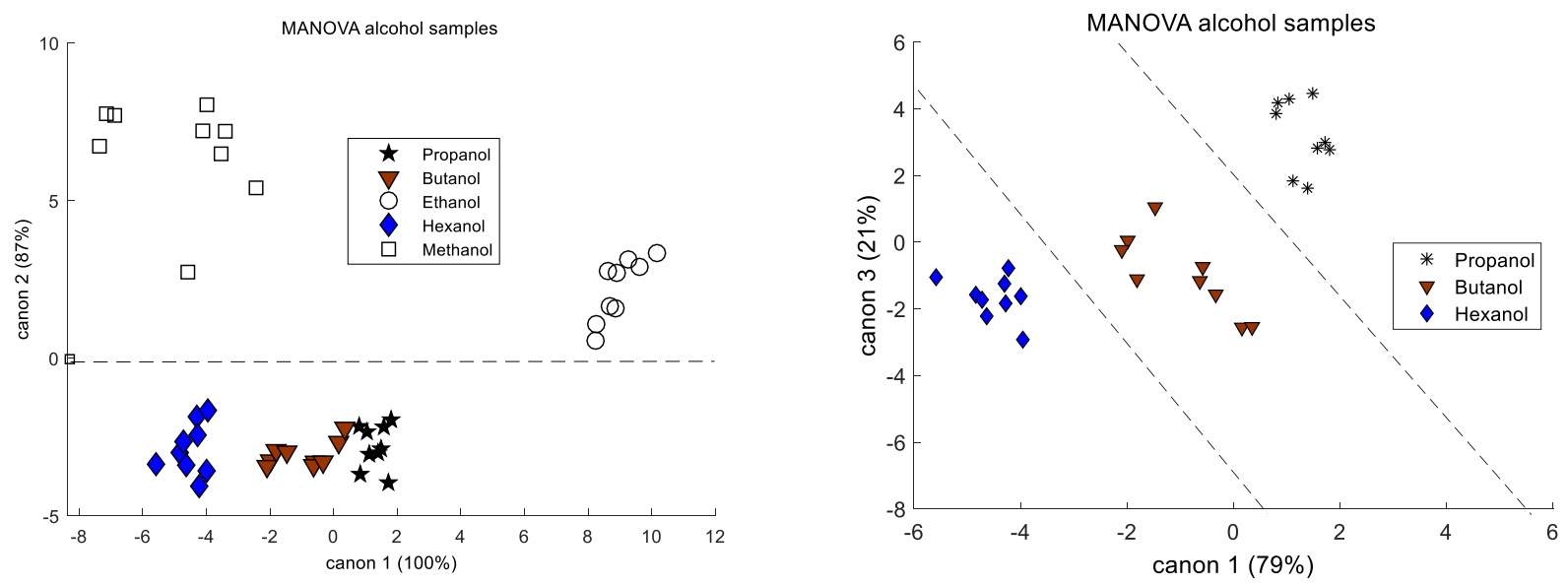

Figure 70.Graphical scattering of the 1-way-MANOVA analysis made to the alcohols data set using the canonical variables: C1 agaist C2 and C1 against C3.

The legend shows the alcohol names. Left: The separation given by canonical 1 against canonical 2 clearly differentiates the methanol and ethanol from the rest of the alcohols. This fact is quite positive since it could be useful to detect adulterations in which ethanol is replaced by methanol. Nevertheless, the separation made by canonical 1 against 3 (right) clearly separates the rest of alcohols. 
Figure 71 summarizes the hierarchical segregation procedure, and Table 30 includes the discriminant functions.

The Table 30 below summarizes the canonical values for each type of chemical or oil analyzed in the mathematical process.

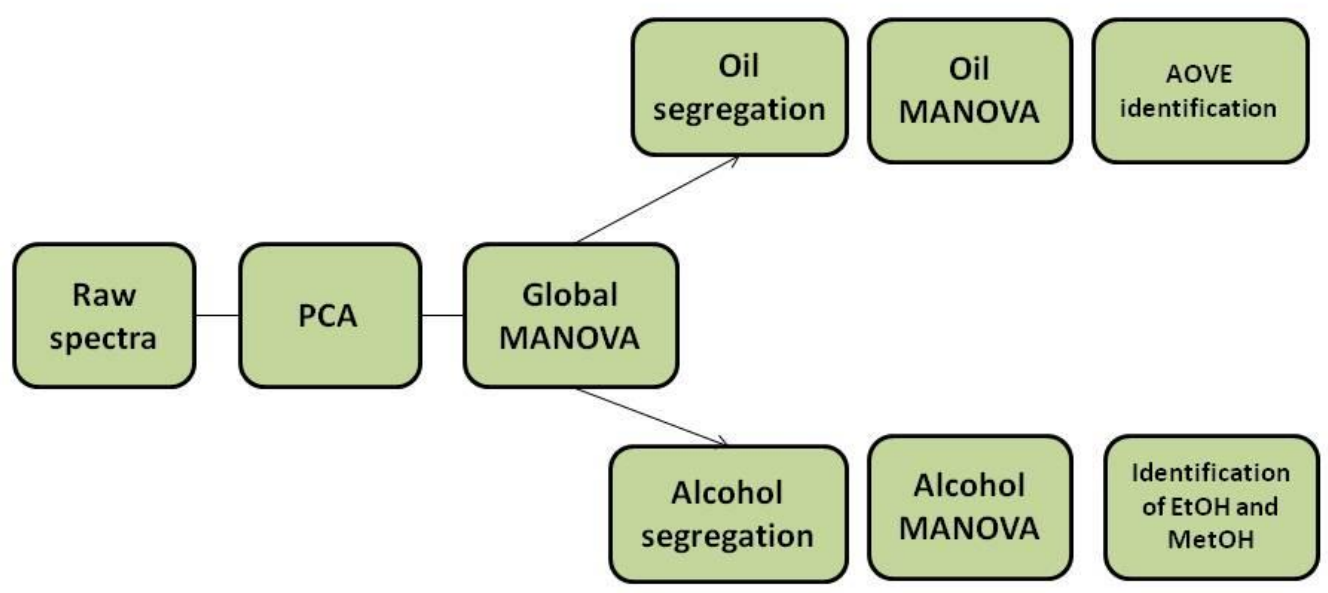

Figure 71. Mathematical hierarchical segregation procedure carried out from the row spectra to the end classification which predicts potential sources of adulteration between oils, and distinguishes between different chain lengths of alcohols 
Table 30.Summary of segregation functions used in the MANOVA analysis at each stage of the mathematical procedure. Canonical variables are represented by $\mathrm{C1}, \mathrm{C2}, \mathrm{C3}$ and $\mathrm{C4}$.

\begin{tabular}{|c|c|c|}
\hline $\begin{array}{l}\text { MATHEMATICAL } \\
\text { ANALYSIS }\end{array}$ & $\begin{array}{l}\text { DISCRIMINANT } \\
\text { FUNCTION }\end{array}$ & GIVEN INFORMATION \\
\hline \multirow{2}{*}{ Global MANOVA } & $C_{1}>0$ & \\
\hline & $\mathrm{C}_{1}<0$ & Oil \\
\hline \multirow{4}{*}{ Oil MANOVA } & $\mathrm{C}_{1}>2$ & AOVE \\
\hline & $\mathrm{C}_{1}<2$ & Rest of the vegetable oils \\
\hline & $C_{4}>0.7 * C_{2}-6$ & $\begin{array}{l}\text { Probable adulteration with (sunflower } \\
\text { or corn) }\end{array}$ \\
\hline & $\mathrm{C}_{4<} 0.7 * \mathrm{C}_{2}-6$ & $\begin{array}{l}\text { Probable adulteration with soybean or } \\
\text { sesame }\end{array}$ \\
\hline \multirow{5}{*}{ Alcohol MANOVA } & $C_{2}>0$ & $\begin{array}{c}\text { Short chain alcohol (ethanol and } \\
\text { methanol) }\end{array}$ \\
\hline & $\mathrm{C}_{2}<0$ & $\begin{array}{l}\text { Long chain alcohol (Propanol, n-butanol } \\
\text { and n-hexanol) }\end{array}$ \\
\hline & $C_{3}<-1.71 * C_{1}-4.5$ & n-hexanol \\
\hline & $\begin{array}{c}-1.71 * C_{1}-4.5<C_{3}<- \\
1.71 * C_{1}-6\end{array}$ & n-butanol \\
\hline & $C_{3}>-1.71 * C_{1}-6$ & Propanol \\
\hline
\end{tabular}




\subsection{Conclusions}

This paper shows the ability of a compact and low cost MID IR uncooled spectrometer to segregate between oils and alcohols, as well as among several kinds of oil species, and alcohol chain length. The advantage given by this device is its compactness and easy set up, versus other laboratory analytical techniques based on chemical separations such as mass spectrometry or chromatography, which usually result in more accurate results, at the expense of reagent requirements, acquisition time, and chemical pre treatment and destruction of the samples.

Proposed low cost MID IR uncooled spectrometer is poor in spectral resolution as compared to other spectrometric devices, and so this technique must be strongly supported by new chemometrics tools.

This paper is the first step in a deep collaboration between university and a technology based SME for the application of MID IR in the agrofood industry that will take place in an upcoming period of four years. This type of action is viewed as a strategic challenge by the Spanish Ministry of Economy. 


\section{IX Congresso Ibérico de Agroengenharia. Bragança, Portugal. September, 2017}

\section{EDIBLE OILS MEASURING USING LOW COST MID IR}

\subsection{Abstract}

A low cost, uncooled and rugged middle infrared camera was used for measuring edible oils spectra and so on studying its potential for quality control in edible oils industry.

The samples used were different edible oil brands belonging to different origins but mainly classified in:

-Extra Virgin Olive Oils

-Non-extra virgin olive oils

The aim of this work is testing the feasibility of this device to the segregation of high and low quality oils.

Also, a set up device and experimental procedure was developed, first at the factory department and after wards the device was moved to the University laboratory. Additionally, the results obtained with and without optics coupled to the sensor were compared.

Some changes were observed in the results by changing some parameters such as integration time, and also, through the experimental analytical procedure.

During the factory measuring stage, a much higher signal level was obtained (the order of 400 intensity counts) and a notorious decrease of the signal was observed when the device was installed at the UPM laboratory (in the order of 100 intensity counts with an integration time of 20.48 and approximately 250 intensity counts with an integration time of 21.12 us.

Also, during the factory stage, the measuring was carried out using an unknown sample amount. This fact became changed when the laboratory at UPM stage, by means of several trials that were made using different weights (20-30 mg of sample, $70-80 \mathrm{mg}$ of sample and 
around $50 \mathrm{mg}$ sample. The $70-80 \mathrm{mg}$ samples were not taken into account for this study, because of the lacks of oil through the wafers. In other words, this means that the quantity is too much to the wafer.

The 20-30 mg samples were also discarded because this amount did not cover the entire surface of the wafer.

Those facts made the $50 \mathrm{mg}$ samples the optimal for the analysis. This change in the experimental procedure made the method more capable of distinguish, which could be checked out in a decrease of non-classified individuals (around the 10\%).

The raw spectra were submitted to different pre treatments and after they were applied a PCA and MANOVA analysis. The results show the reproducibility and repeativity of the method in the new experimental set up at UPM.

The next question is if a calibration transfer should be made from the results obtained at UPM to the results obtained in the NIT experimental set up.

\subsection{Materials and methods}

\subsubsection{Samples}

Eight oils from different brands were used for this experiment. The eight oils were tested during the first stage at the factory department. In the second stage at the UPM, only six samples were used, having been removed the ones belonging to the cocoa (too different from the rest and so on distorted the MANOVA analysis) and sunflower (too similar to sunflower+palm oil).

The Table 31 below shows a screening of the type of edible oils used for the analysis and their origin. 
Table 31. Samples numbers and type of edible oils and their procedence

\begin{tabular}{cc}
\hline Número de muestra & Origen \\
\hline 1 & Aceite de oliva virgen extra (1) (baja calidad) \\
\hline 2 & Soja \\
\hline 3 & Preparado graso para fritura (girasol + palma) \\
\hline 5 & Maíz \\
\hline 6 & Girasol \\
\hline 7 & Aceite de oliva virgen extra (2) (alta calidad) \\
\hline 8 & Aceite de oliva virgen extra (3) (alta calidad) \\
\hline
\end{tabular}

\subsubsection{Device}

A middle infrared camera with a frame rate of acquisition of $2000 \mathrm{fps}$ was used. The wavelength range used was from 2.95 to 4.5 microns.

The sample was placed between two sapphire wafers and the source and the detector following the set up described in the Figure 72 below:
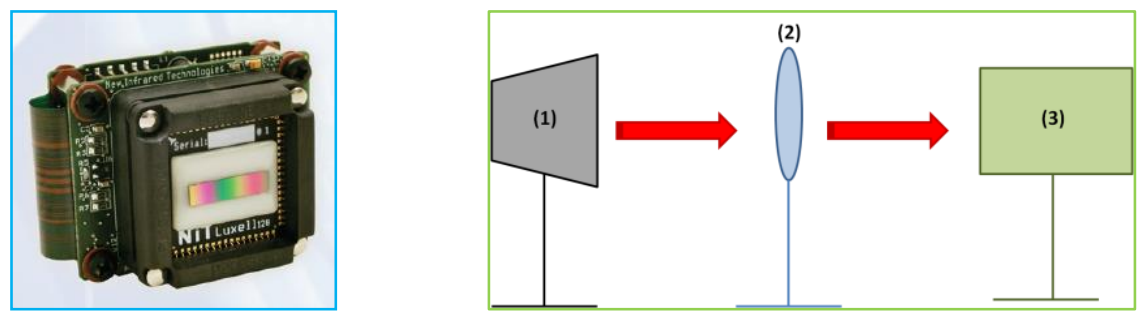

Figure 72.(Left) Picture of the sensor used to the experiment, consisting in an array of 128 detectors. (right) Experimental set up of the measure device: (1) infrared source with a parabolic reflector (Hawkeye technologies, Inc.) (2) sapphire wafers containing the sample, (3) middle infrared detector (New Infrared Technologies, S.L.).

The Table 32 shows the main spectral wavelengths of interest selected for the analysis 
Table 32. Spectral wavelengths of interest given in microns

\begin{tabular}{ccc}
\hline $\begin{array}{c}\text { Longitud de onda de absorción } \\
\text { (micras) }\end{array}$ & Grupo funcional & $\begin{array}{c}\text { Fórmula } \\
\text { molecular }\end{array}$ \\
\hline 3.411 & Metileno & $=\mathrm{CH}_{2}$ \\
\hline 3.424 & Metilos presentes en aldehídos & $-\mathrm{CH}_{3}$ \\
\hline 3.436 & Grupo hidroxilo en alcoholes & $-\mathrm{OH}$ \\
\hline 3.461 & Metileno presente en alcohol & $=\mathrm{CH}_{2}$ \\
\hline 3.486 & $\begin{array}{c}\text { Metilos presentes en cadenas } \\
\text { hidrocarbonadas }\end{array}$ & $-\mathrm{CH}_{3}$ \\
\hline
\end{tabular}

\subsubsection{Measuring procedure}

Two different measuring procedures were carried out, one of them at the NIT department and the second one at the UPM. The main conditions featuring these procedures are described in the Table 33 below:

Table 33.Main parameters of the measuring procedures carried out at each department.

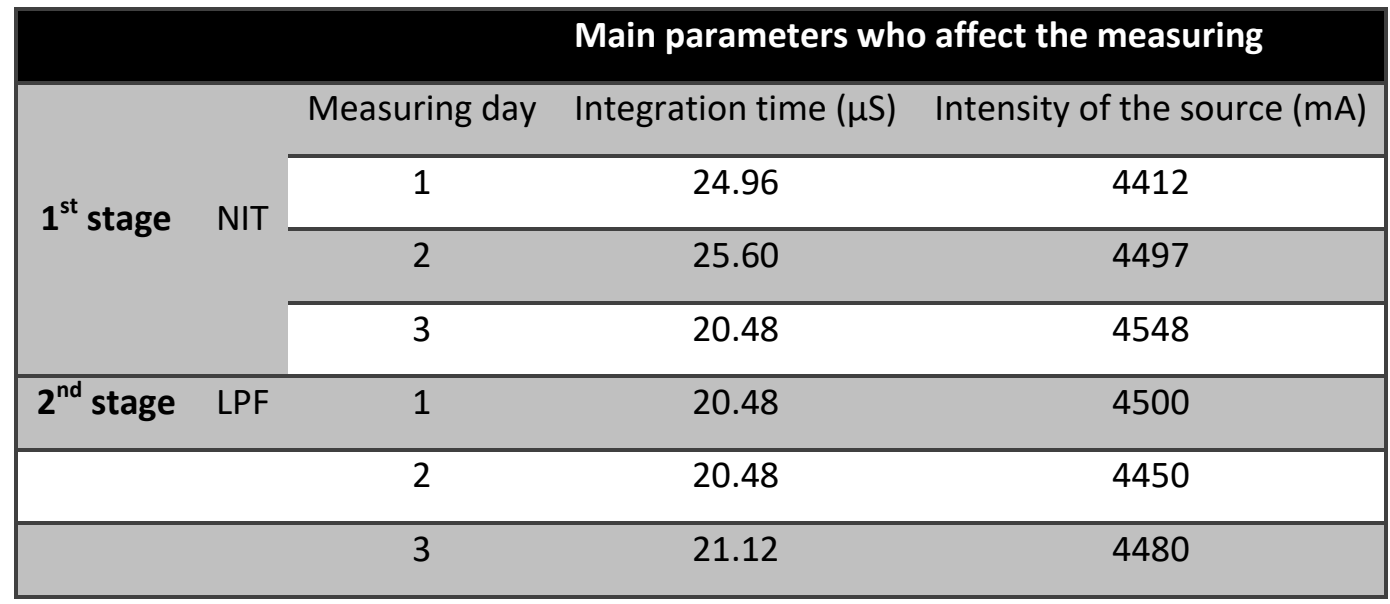

Another important tip regarding the measuring procedure is the amount of sample put between the two sapphire wafers, which directly affects the optical path length and so on the intensity of the signal obtained. During the first stage, an unknown amount of sample was used. Sometimes it was too much for the capacity of the windows, so the oil squeezed out through the wafers. Too much dispersion was observed in the measurements, so on, in the second stage, a more accurate method was tried in order to control the amount of sample put between the wafers. It consisted in weighting different amounts of oil and find 
out the optimal weight to put between the wafers. Three different ranges of weight were used for this purpose, which are shown in the Table 34 below:

Table 34.Weight ranges tested in the new analytical procedure.

\begin{tabular}{|cc|}
\hline Range & Weights (mg) \\
\hline $\mathbf{1}$ & $20-30$ \\
\hline $\mathbf{2}$ & $50-70$ \\
\hline $\mathbf{3}$ & $80-100$ \\
\hline
\end{tabular}

\subsubsection{Spectra acquisition}

The spectra were recorder during 11 seconds, using the first empty 5 seconds as a blank in order to subtract the background to the image.

\subsubsection{Spectra pre-treatment}

The spectral curves obtained were subjected to a pre treatment consisting on a SNV and afterwards a baseline correction (Barreiro et al, 2016) and a normalization of the spectra between 0 and 1 intensity values.

\subsubsection{Principal Component Analysis}

A principal component analysis was applied to the 128 variables corresponding to the acquired 128 wavelengths, in order to reduce the dimensions to 10 without loss of information.

\subsubsection{MANOVA analysis}

The MANOVA analysis was applied to the scores obtained at the first stage, by makig the PCA to the pre-trated spectra. 


\subsection{Results}
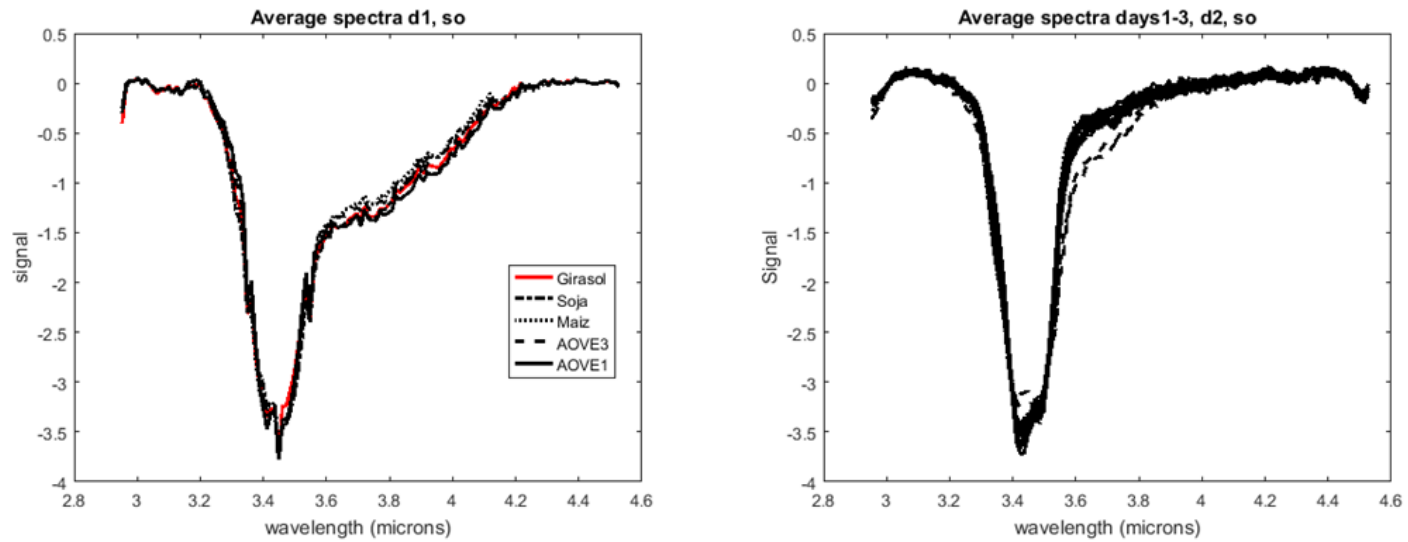

Figure 73. Spectra acquisition during 6 seconds, taking 3 replicates and 3 repetitions per sample.

\subsubsection{Data analysis}

The Figure 74 below schematizes the mathematical procedure carried out for the chemometric analysis of the spectra acquired in order to discriminate between edible oils.

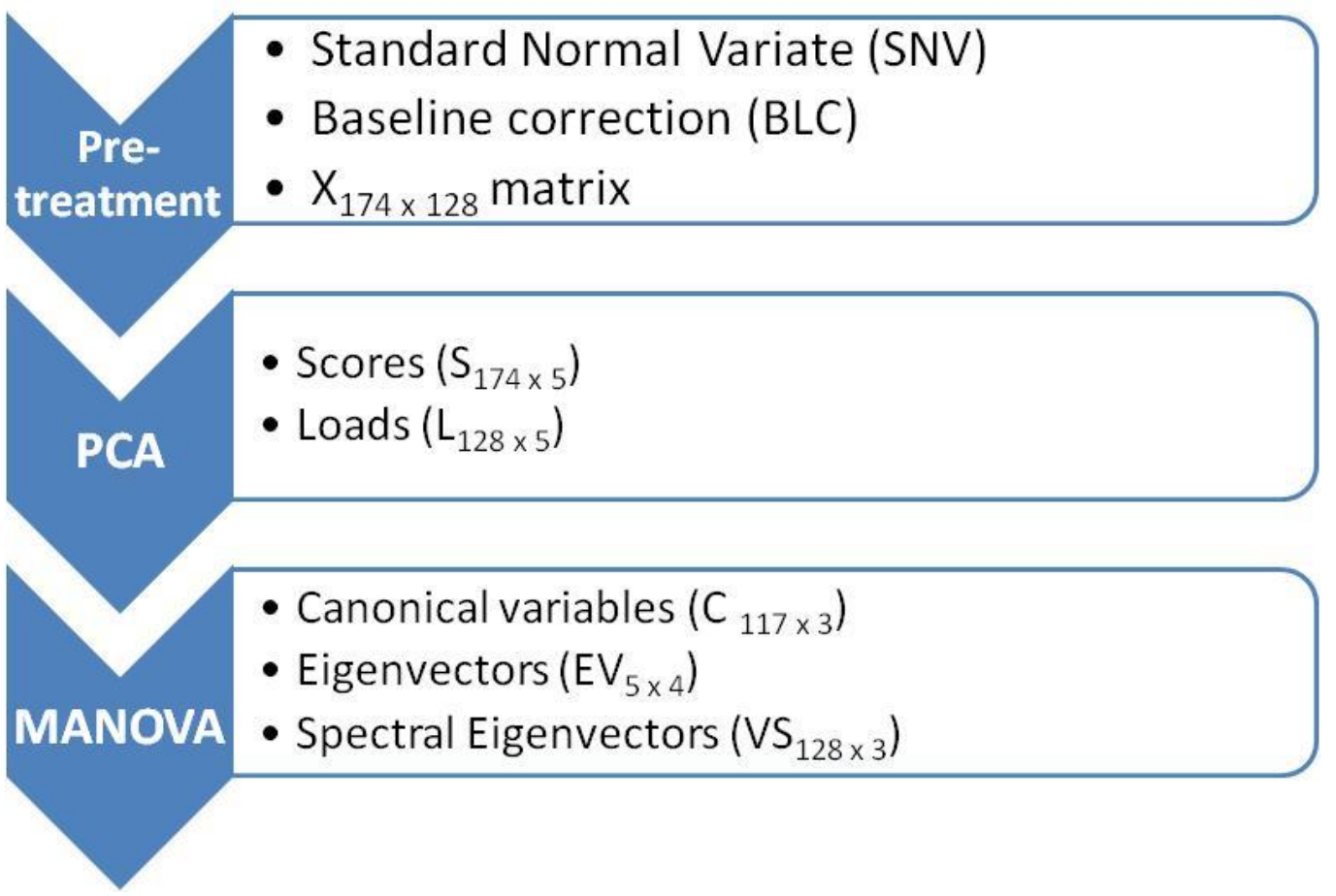

Figure 74. Mathematical procedure carried out to perform the data analysis, starting by the spectral curves pre-treatment, followed by the PCA and the MANOVA analysis to discriminate between samples. 
The results obtained from the multivariate PCA and MANOVA analysis are displayed on the below:
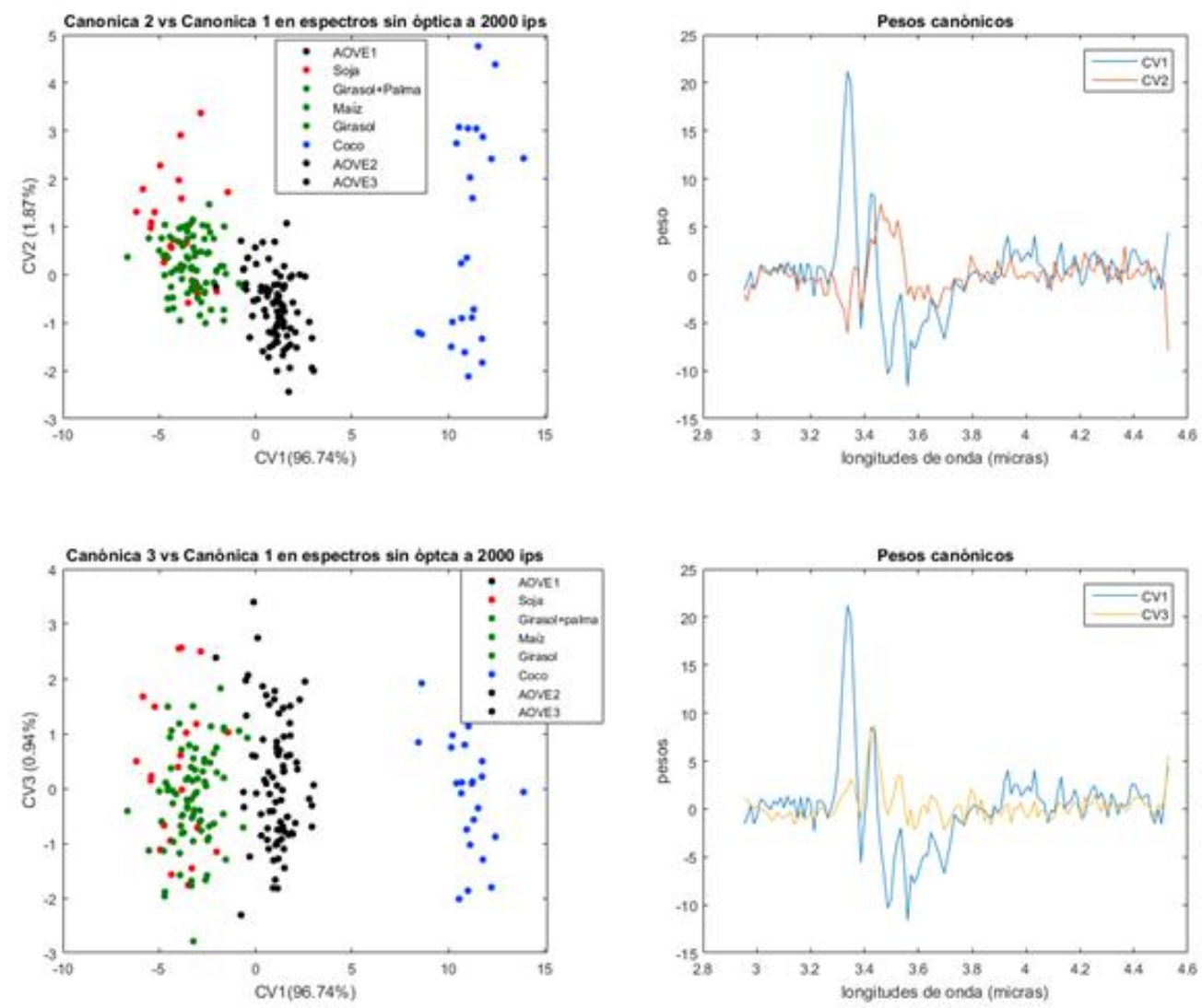

Figure 75. Cartesian diagram plot of the main clusters segregated by the MANOVA analysis performed on the oil samples (top and bottom left). Contribution of CV1 and CV3 in terms of wavelenght weights to the analysis (Top and bottom right)

A projection of the canonical variables obtained from the MANOVA analysis applied to the data set without optics on the MANOVA analysis on the data set with optics was done, as shown in the Figure 76 below. 


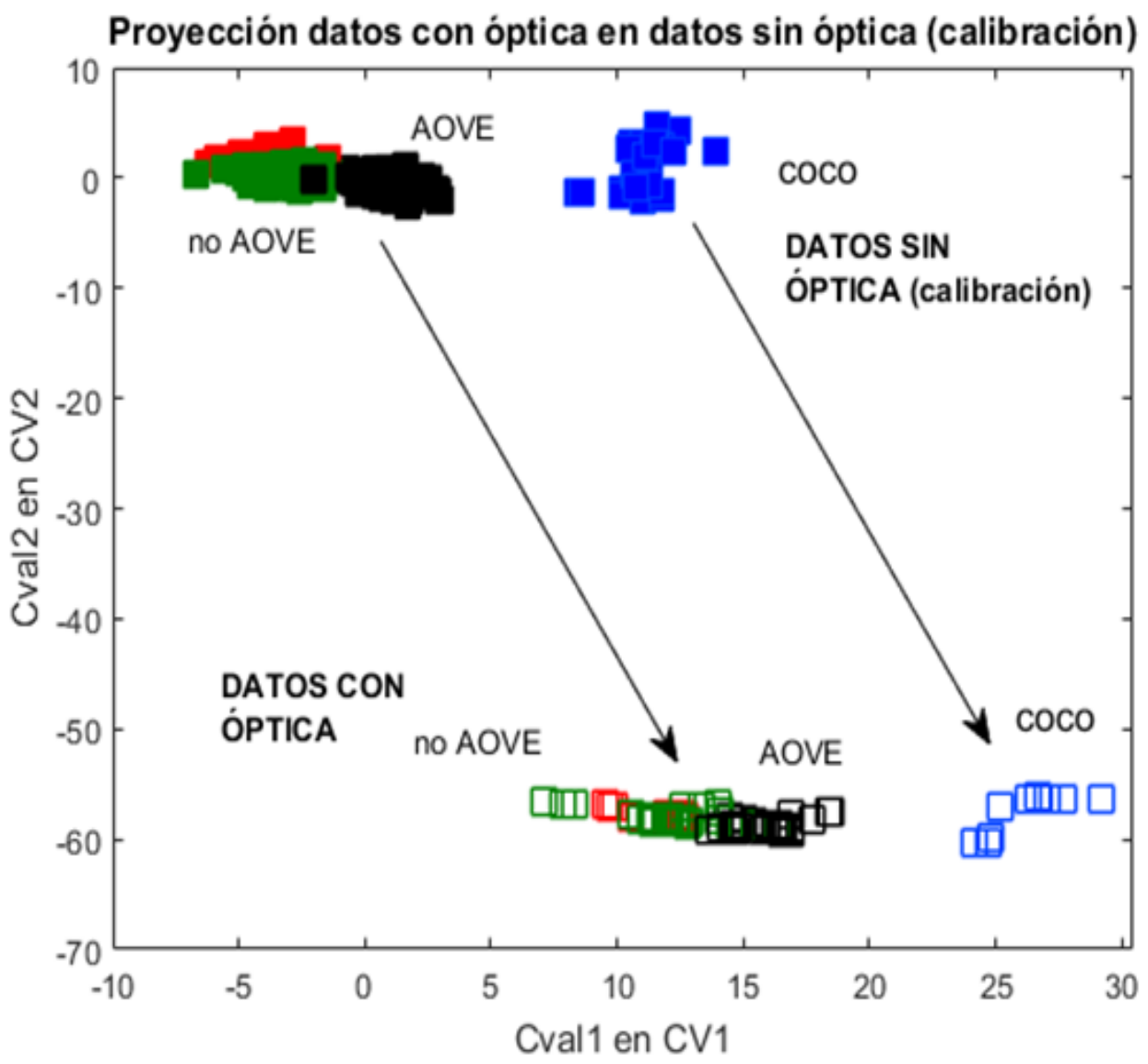

Figure 76. Projection of the MANOVA space obtained from the results with optics on the MANOVA space obtained from the results without optics.

And finally, a comparison between the segregation power of the canonical variables obtained by the MANOVA analysis from the device 1 ( 360 frames per second) and the ones obtained from the device 2 (2000 frames per second) was done, and the results are shown in the Table 35 below.

Table 35. Comparison between the segregation power of the canonical variables obtained from the MANOVA analysis performed in both devices 1 and 2

\begin{tabular}{|c|c|}
\hline Dispositivo 1 & Dispositivo 2 \\
(360 imágenes por segundo) & $\begin{array}{c}\text { (2000 imágenes por } \\
\text { segundo) }\end{array}$ \\
\hline 49,00 & 96,75 \\
\hline 30,42 & 1,875 \\
\hline 12,25 & 0,942 \\
\hline
\end{tabular}


As it can be observed, the first canonical variable gains significantly in segregation power when using the device 2 for measuring, whilst canonical 2 and 3 decreases their segregation power very notoriously.

\subsection{Conclusions}

A non-destructive and in-situ analysis device is proposed for the quality control of edible oils in the agri-food industry.

The Chemometric analysis methods are fundamental tools for this purpose.

The device with a rate acquisition of $2000 \mathrm{fps}$ plus optics has been the one in giving the best results.

It is necessary establishing a delimited method of measurement and an appropriate calibration transfer system.

A future proposal of research is analyzing the headspace on frying processes for the detection of adulterations and non desirable mixtures. 


\section{Annex II: Dissemination}

This annex shows the research paper that was published in a Q1 journal during this thesis and other ways of results dissemination in shape of prizes and/or awards and patents.

\section{Research paper published in Q1 journal (Fuel Processing technology}

\section{MID-INFRARED UNCOOLED SENSOR FOR THE IDENTIFICATION OF PURE FUEL, ADDITIVES AND ADULTERANTS IN GASOLINE}

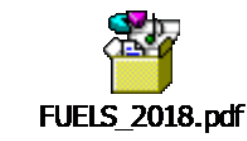

\section{Annex III: Software development}

This annex contains the open source MATLAB ${ }^{\circledR}$ code (.mat files) that was developed by NIT and the LPF TAGRALIA to read the files acquired by the PbSe sensor in both devices (the first one in the LPF Laboratory using optical lens and the second one in the NIT factory without optical lens).

\section{Reading .dat files with optics}

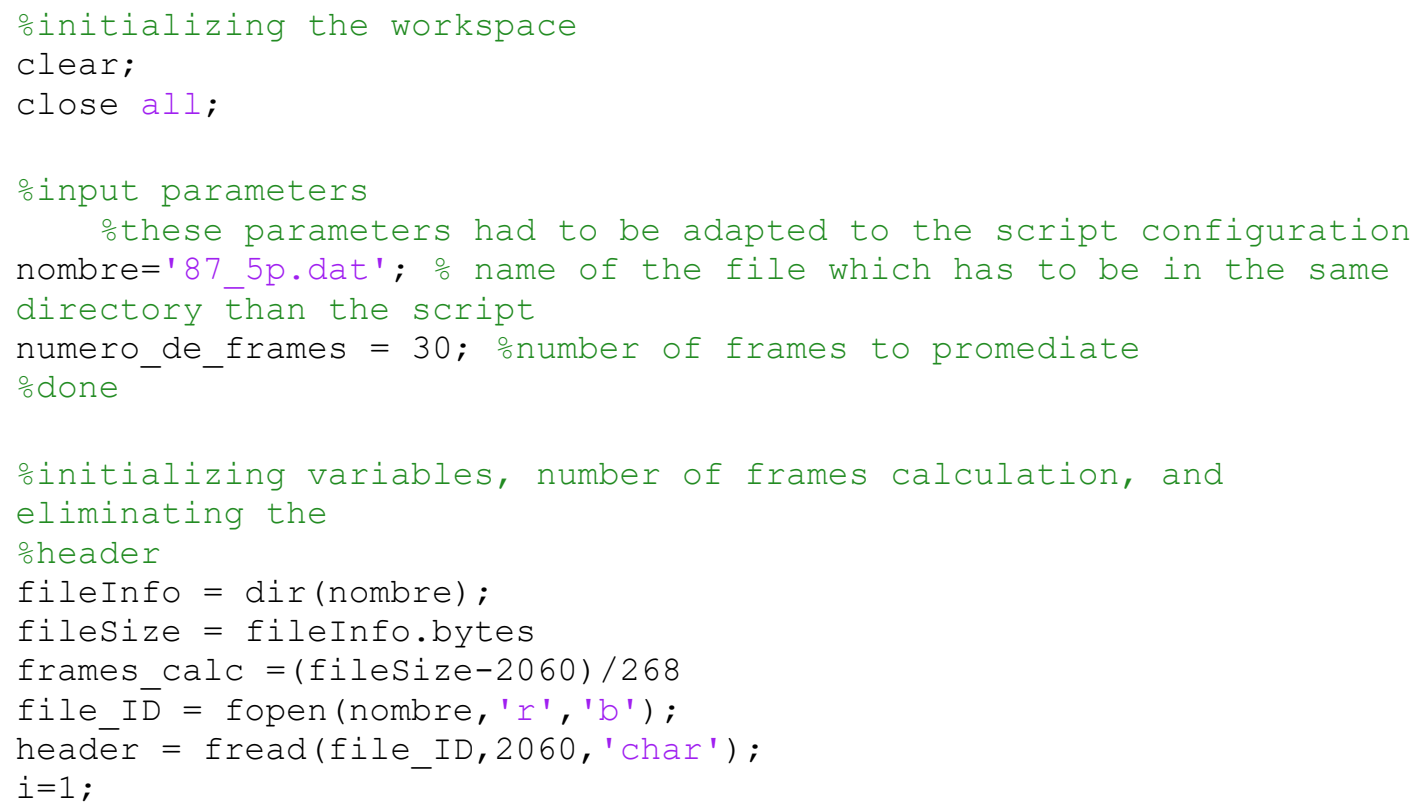




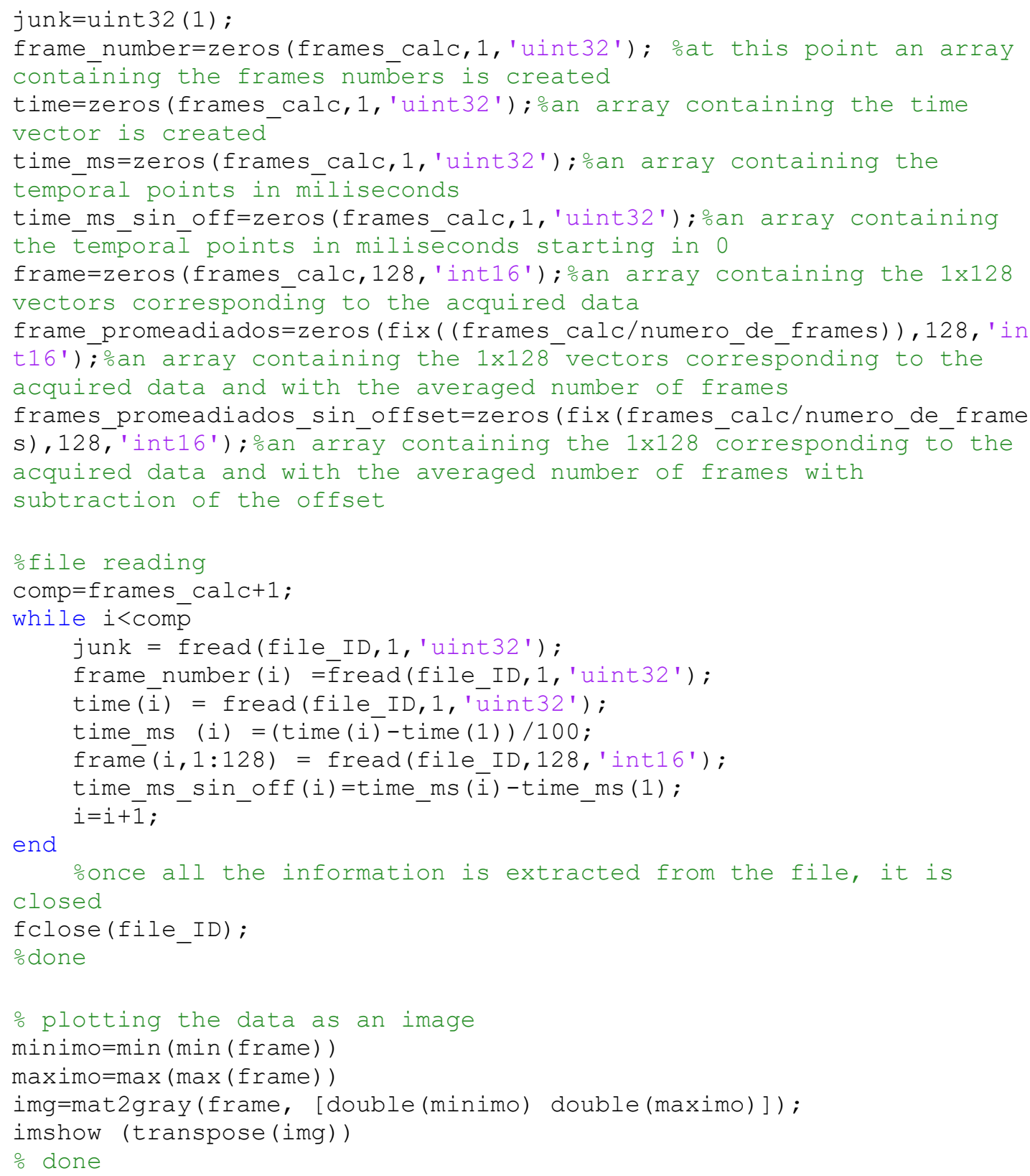

\section{Reading the files without optics}

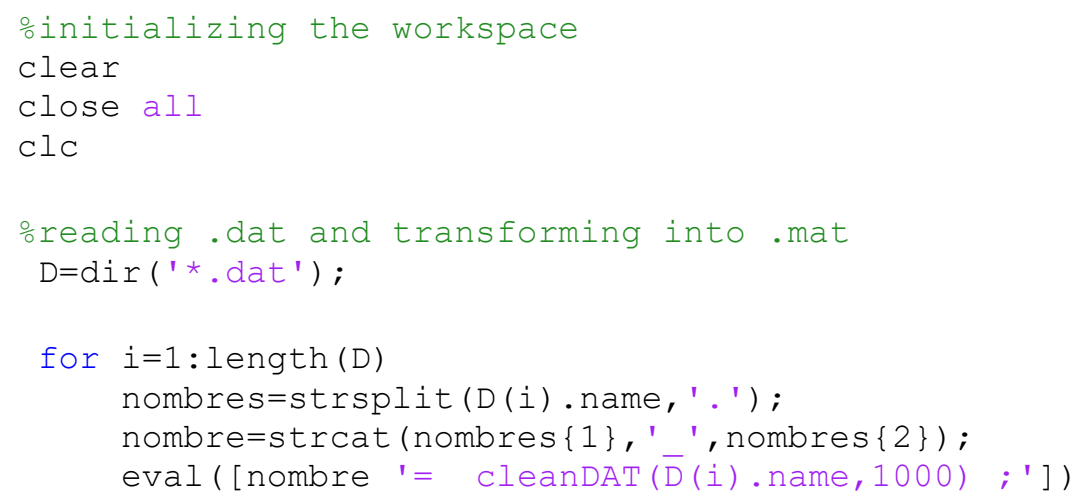




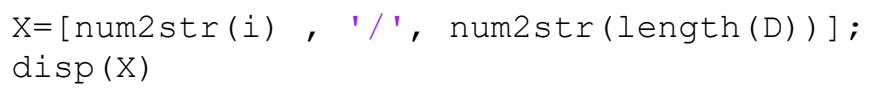

